\author{
UNIVERSIDADE DE SÃO PAULO \\ FFCLRP - DEPARTAMENTO DE BIOLOGIA \\ PROGRAMA DE PÓS-GRADUAÇÃO EM ENTOMOLOGIA
}

\title{
Análise filogenética de alguns gêneros de vespas sociais Neotropicais (Hymenoptera, Vespidae, Epiponini).
}

Sergio Ricardo Andena

Tese apresentada à Faculdade de Filosofia, Ciências e Letras de Ribeirão Preto da USP, como parte das exigências para a obtenção do título de Doutor em Ciências, Área: Entomologia

Ribeirão Preto - SP

2007 
UNIVERSIDADE DE SÃO PAULO

FFCLRP - DEPARTAMENTO DE BIOLOGIA

PROGRAMA DE PÓS-GRADUAÇÃO EM ENTOMOLOGIA

\title{
Análise filogenética de alguns gêneros de vespas sociais Neotropicais (Hymenoptera, Vespidae, Epiponini).
}

\author{
Sergio Ricardo Andena \\ Orientador: Prof. Dr. Fernando Barbosa Noll
}

Tese apresentada à Faculdade de Filosofia, Ciências e Letras de Ribeirão Preto da USP, como parte das exigências para a obtenção do título de Doutor em Ciências, Área: Entomologia

Ribeirão Preto - SP

2007 


\section{AGRADECIMENTOS}

À Universidade de São Paulo, Faculdade de Filosofia, Ciências e Letras de Ribeirão Preto e ao Programa de Pós-Graduação em Entomologia, pela oportunidade concedida e pelas facilidades oferecidas.

À Fundação de Amparo à Pesquisa do Estado de São Paulo (FAPESP) pelo auxílio financeiro.

Ao Conselho Nacional de Desenvolvimento Científico e Tecnológico (CNPq) pela bolsa concedida.

Ao “Collection Study Grant” (Amerincan Museum of Natural History - New York) pelo auxílio financeiro, que proporcionou minha visita a esta instituição.

Ao Prof. Dr. Fernando Barbosa Noll, pela orientação nesta tese, pela amizade, pelas oportunidades oferecidas e, principalmente, por ter confiado no meu trabalho.

Ao Prof. Dr. Ronaldo Zucchi, por toda a ajuda, disponibilidade, amizade, sugestões, e pelo exemplo de profissional e pesquisador de vespas no Brasil.

Ao Dr. Sidnei Mateus, por sempre estar disposto a ajudar, pelas sugestões, e pelo inestimável companherismo e ensinamentos durante o trabalho de campo na Amazônia.

Ao Dr. James M. Carpenter que gentilmente me recebeu no American Museum of Natural History, pela amizade, e por sempre estar disponível no que fosse necessário.

Ao Prof. Dr. Kurt M. Pickett (University of Vermont) por ter me recebido no American Museum of Natural History, pela amizade, disponibilidade, e por toda a orientação em análises moleculares.

Ao Dr. Ward Weeler (American Museum of Natural History) por ter disponibilizado o "Institute for Comparative Genomics” durante minha visita a esta instituição.

Ao Dr. Gavin Broad (Natural History Museum - London) pelos empréstimos concedidos.

Ao Prof. Dr. Carlos Roberto Brandão (Muzeu de Zoologia da Universidade de São Paulo) pelos empréstimos, e pelas facilidades oferecidas nessa instituição.

Ao Prof. Dr. Orlando Tobias Silveira (Museu Paraense Emilio Goeldi) pelos empréstimos concedidos.

Ao Prof. Dr. Carlos Sarmiento (Instituto de Investigación de Recursos Biológicos Alexander Von Humboldt - Colômbia), pelos empréstimos concedidos.

Ao Prof. Dr. Gabriel Mello (Universidade Federal do Paraná), pela disponibilidade em me receber nessa instituição e pelos empréstimos concedidos. 
Ao Prof. Dr. Marcio Oliveira e ao Prof. Dr. Augusto Henriques, pelas facilidades concedidas durante minha visita a coleção do INPA (Instituto Nacional de Pesquisas da Amazônia).

À Profa. Dra. Luci Rolandi Bego, que me orientou no mestrado e sempre me apoiou durante o desenvolvimento desta tese.

Ao Prof. Dr. Dalton de Sousa Amorin, pela disponibilidade e ajuda oferecida.

À Prof. Dra. Vera Cristina Silva (UNESP - Assis) que me orientou durante minha graduação e me introduziu na sistemática filogenética.

Ao Dr.Guilherme Ribeiro por todo o auxílio na utilização de softwares, sugestões e amizade durante minha tese.

À secretária da pós-graduação em entomologia Renata Andrade Cavallari, por todas as facilidades oferecidas.

A todas as pessoas da comunidade de Presidente Figueiredo-AM que contribuiram durante nosso trabalho de campo.

Ao Marcel Hermes (Universidade Federal do Paraná), por disponibilizar a coleção de Vespidae durante minha visita a essa instituição.

Ao Craig Starger, meu “roommate”em Nova York, pelo apoio e amizade durante todo o período que convivemos.

À minha família, especialmente minha mãe, meu irmão e meu padrasto, pelo apoio, amor incondicional, e por compreender minha constante ausência.

À Lilian Mostasso, por todo amor, companherismo, e amizade. Pela disponibilidade em me ouvir e me consolar nos momentos difíceis, por compreender minha ausência, e por nunca deixar que a distância interferisse em nossa relacionamento.

Aos colegas de laboratório Ana Carolina, Solange, Christiano, Mario, Rita, Gustavo, Fábio, Ivelize, Eunice, Gisele, Juliana, Janaina, Evandson, Denise, Maria Juliana, Túlio, Rafael, Lucas, que tornaram a convivência e amizade uma grande alegria diária.

A todos que direta ou indiretamente contribuiram para o desenvolvimento dessa tese. 
Lutei pelo justo, pelo bom, e pelo melhor do mundo.

Olga Benario Prestes

Dedico esta tese à minha mãe, Maria Rita Meu maior exemplo. 


\section{RESUMO}

Vespidae (Hymenoptera) é uma família monofilética, de ampla distribuição, representada por seis subfamílias existentes (Carpenter 1993): Euparagiinae + $($ Masarinae $+($ Eumeninae $+($ Stenogastrinae $+($ Polistinae + Vespinae $))))$. A subfamília Polistinae apresenta grande diversidade, especialmente na região Neotropical e inclui quatro tribos: Polistini, Mischocyttarini, Ropalidiini, e Epiponini. Os Epiponini representam a mais tribo diversa nos neotrópicos, correspondendo a 19 gêneros (Carpenter, 2004), todos com representantes no Brasil, sendo que um gênero e 103 espécies são endêmicos. Apresentam variada arquitetura de ninho, fundação por enxameio e poliginia (múltiplas rainhas funcionais) (Richards \& Richards, 1951). Atualmente existem três filogenias para os Vespidae, as quais apresentam pequena variação entre si (Carpenter, 1991, basicamente com dados morfológicos; Wenzel, 1993, com dados de arquitetura de ninho; e uma análise combinada dos caracteres citados anteriormente, mais dados de estágios imaturos, proposta por Wenzel \& Carpenter, 1994), além de uma filogenia apenas para os Epiponini (Noll, 2000, utilizando a matriz de Wenzel \& Carpenter (1994) e dados de diferenciação de castas). Todas as filogenias, embora altamente concordantes, foram todas ao nível genérico.

Este trabalho teve como objetivo testar o monofiletismo de de alguns gêneros Epiponini: Angiopolybia, Pseudopolybia, Chartergellus, Synoeca, e Charterginus. A filogenia das espécies foi produzida, bem como as chaves de identificação foram reformuladas, quando possível.

Dados de morfologia de fêmeas, genitália de macho e arquitetura de ninho foram empregados neste trabalho. Todos os cinco gêneros estudados provaram ser monofiléticos e em todos os gêneros somente um único cladograma foi encontrado, 
sendo: Angiopolybia com 20 passos, índice de consistência 0,90 e índice de retenção de 0,88, tendo a seguinte relação entre as espécies: $((A$. pallens $+A$. zischkai $)+(A$. obidensis + A. paraensis)); Pseudopolybia com 56 passos, índice de consistência 0,64, índice de retenção 0,70, e relação entre as espécies: $(P$. langi $+(P$. difficilis $(P$. vespiceps $+P$. compressa))); Chartergellus com 60 passos, índice de consistência 0,71, índice de retenção de 0,73 , e relação entre as espécies: (C. afoveatus $+C$. punctatior $)+$ $(($ C. amazonicus + C. communis $)+($ C. atectus + (C. zonatus $+($ C. nigerrimus + C. sanctus)))))); Synoeca com 65 passos, índice de consistência 0,84, índice de retenção de 0,82, e relação entre as espécies: $(S$. chalibea + $(S$. virginea $+(S$. septentrionalis $+(S$. surinama + S. cyanea)))); e Charterginus com 54 passos, índice de consistência 0,75, índice de retenção de 0,81 , e relação entre as espécies: $(C$. xanthura $+C$. fulvus $)+(C$. weyrauchi $+($ C. nevermanni $+($ C. carinatus + C. zavattarii $))))$. 


\section{ABSTRACT}

Vespidae (Hymenoptera) is a widely distributed, monophyletic family, with six subfamilies (Carpenter 1993): Euparagiinae + (Masarinae + (Eumeninae + $($ Stenogastrinae $+($ Polistinae + Vespinae)))). The Polistinae shows great diversity, mainly in the Neotropical region, including four tribes: Polistini, Mischocyttarini, Ropalidiini and Epiponini. Including 19 genera, the Epiponini is the most diverse tribe (Carpenter, 2004), These, one genus and 103 of the species are endemic to Brazil. Epiponines show a great variety of nests, swarming-founding and polygyny (several queens) (Richards \& Richards, 1951). Presently, three phylogenies were proposed in the Vespidae, even though a few differences are found (Carpenter, 1991, basically morphological data; Wenzel, 1993, nest architecture; and a combined analysis using the data previously cited plus data on immature stages, proposed by Wenzel \& Carpenter, 1994). Also, there is a phylogeny for the Epiponini (Noll, 2000, using the matrix of Wenzel \& Carpenter (1994) plus caste differentiation data). All phylogenies, though highly corroborating, were only based at the generic level perspective.

This work aimed at checking the hypothesis of monophyly of some genera of Epiponini, that is: Angiopolybia, Pseudopolybia, Chartergellus, Synoeca, and Charterginus. Species phylogenies were produced and as well the species identification keys were revised, when it was possible.

This work was based on morphological data of females, male's genitalia and nest architecture. All the five genera studied here proved to be monophyletic, and in all genera only a single tree was found as follows: Angiopolybia with 20 steps, consistence index (CI) of 0.90 and retention index (RI) of 0.88 , with the following ingroup topology: ((A. pallens + A. zischkai) + (A. obidensis + A. paraensis)); Pseudopolybia 
with 56 steps, CI of 0.64 , and RI of 0.70 and the following ingroup topology: (P. langi $+(P$. difficilis (P. vespiceps $+P$. compressa) $))$; Chartergellus with 60 steps, CI 0.71 and RI 0.73 and the following ingroup topology: $(C$. afoveatus $+C$. punctatior $)+((C$. amazonicus + C. communis $)+($ C. atectus $+($ C. zonatus $+($ C. nigerrimus $+C$. sanctus)))))); Synoeca with 65 steps, CI of 0.84, RI of 0.82, and the following ingroup topology: $(S$. chalibea $+(S$. virginea $+(S$. septentrionalis $+(S$. surinama $+S$. cyanea)))); and Charterginus with 54 steps, CI of 0.75, RI of 0.81, and the following ingroup topology: (C. xanthura + C. fulvus $)+($ C. weyrauchi $+($ C. nevermanni $+(C$. carinatus + C. zavattarii)))). 


\section{ÍNDICE}

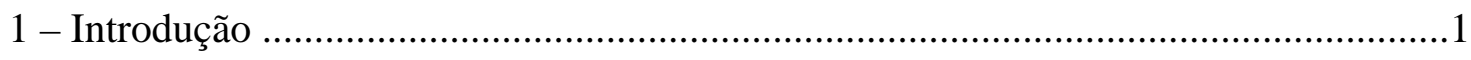

1.1 - Relações filogenéticas dos gêneros estudados ....................................................5

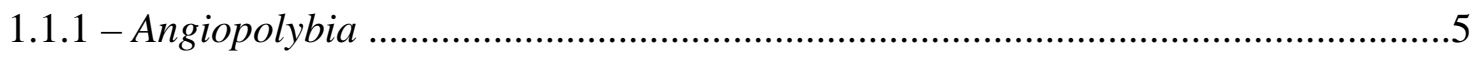

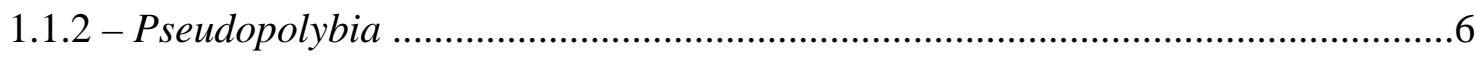

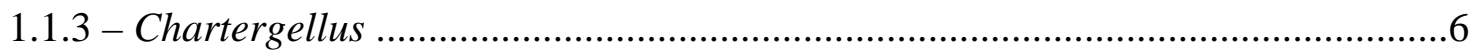

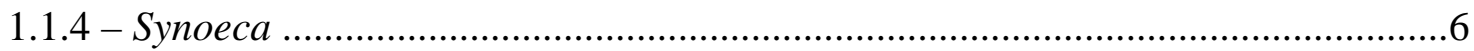

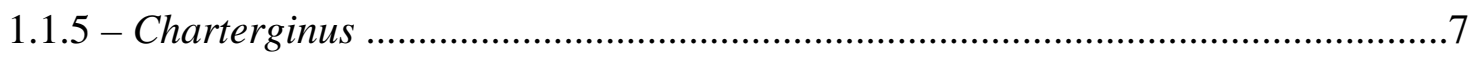

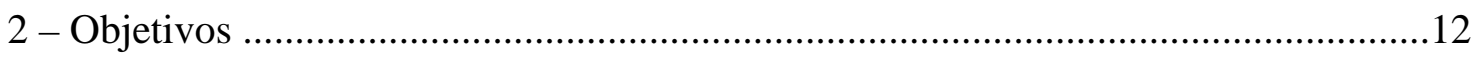

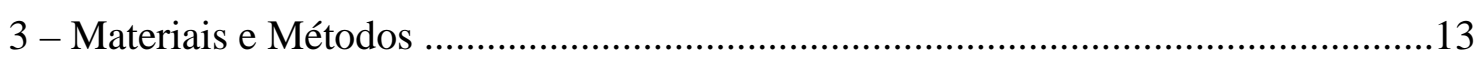

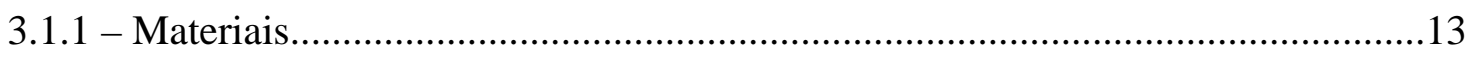

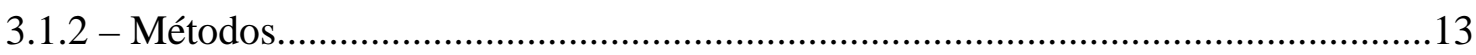

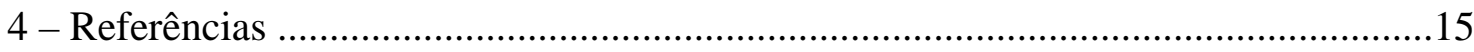

Capítulo 1 - Análise Filogenética do Gênero Angiopolybia Araujo, 1946 (Hymenoptera,

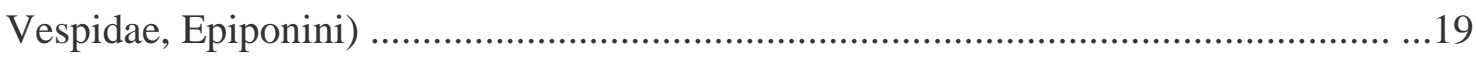

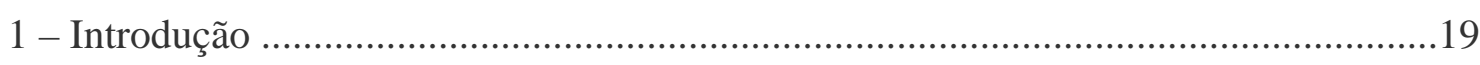

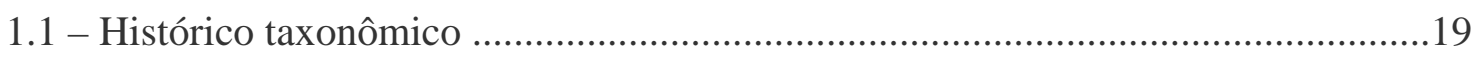

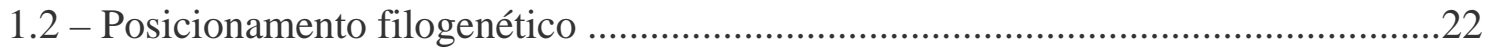

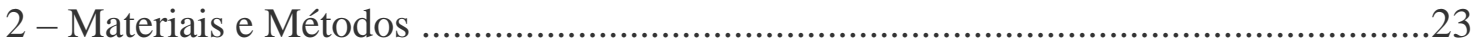

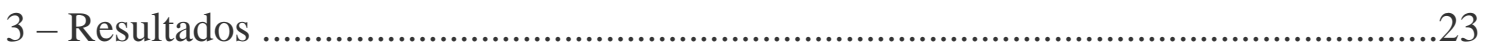

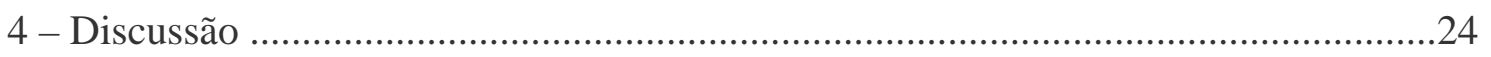

5 - Chave de identificação para as espécies de Angiopolybia .......................................26

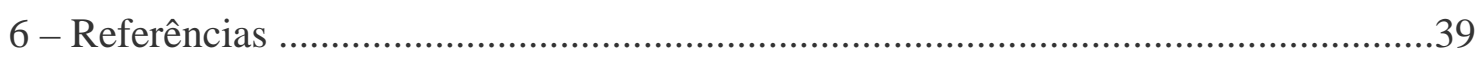

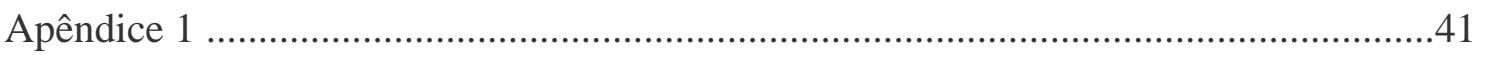

Capítulo 2 - Análise Filogenética do Gênero Pseudopolybia de Saussure, 1863, com a Descrição da Genitália do Macho de Pseudopolybia vespiceps (Hymenoptera:

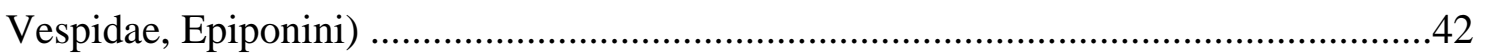

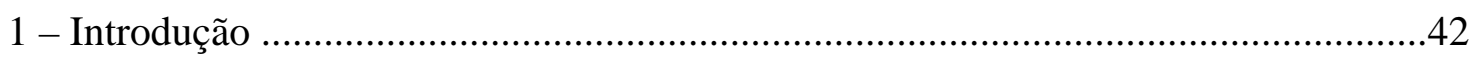

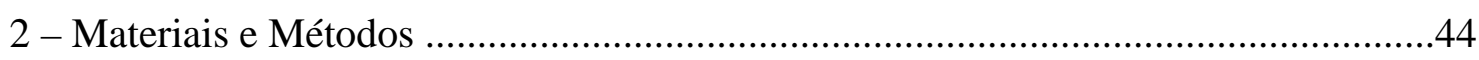

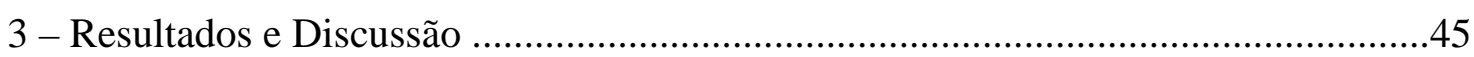


4 - Chave de identificação para as espécies de Pseudopolybia ......................................50

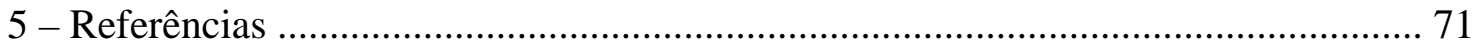

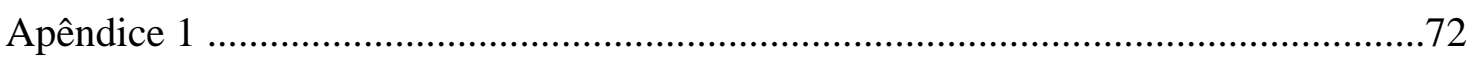

Capítulo 3 - Análise Filogenética do Gênero Chartergellus Bequaert, 1938 (Hymenoptera, Vespidae, Epiponini) ……..............................................................73

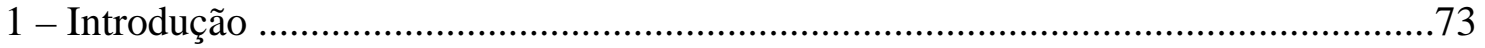

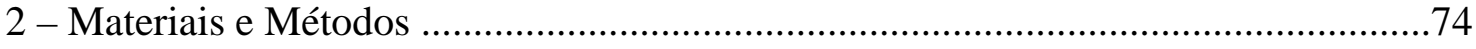

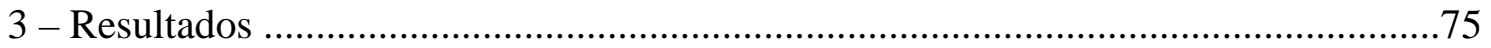

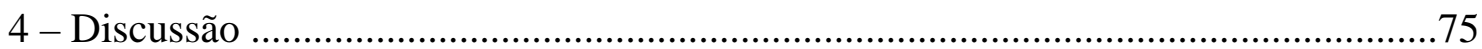

5 - Chave de identificação para as espécies de Chartergellus ..................................... 79

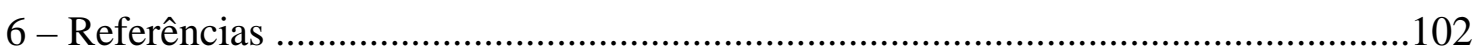

Apêndice 1 .............................................................................................................. 103

Capítulo 4 - Análise Filogenética do Gênero Synoeca De Saussure, 1852 (Hymenoptera,

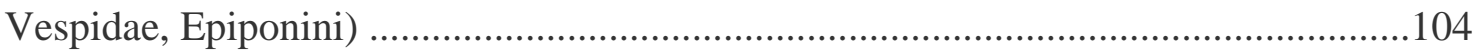

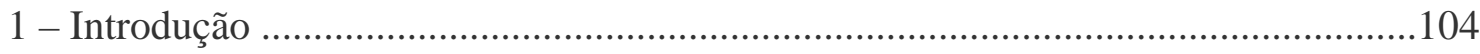

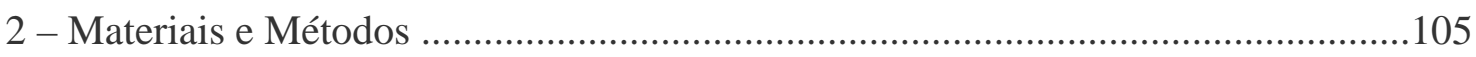

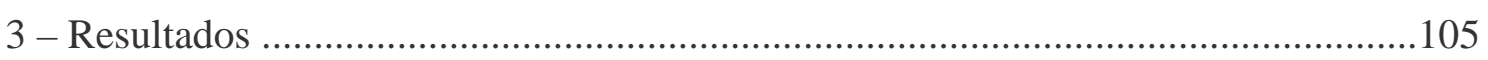

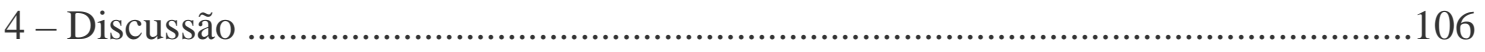

5 - Chave de identificação para as espécies de Synoeca ..............................................110

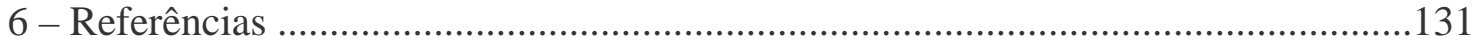

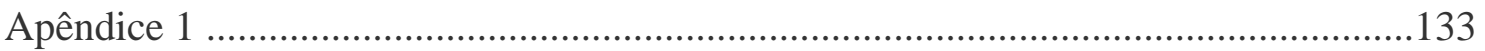

Capítulo 5 - Análise Filogenética do Gênero Charterginus Fox 1898 (Hymenoptera,

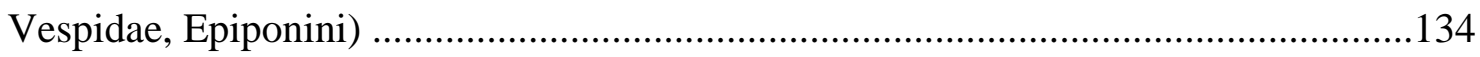

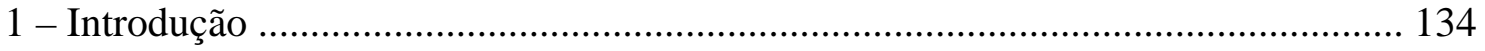

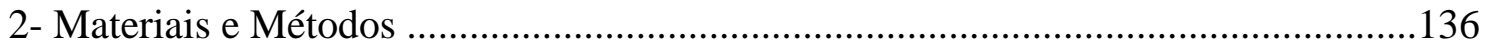

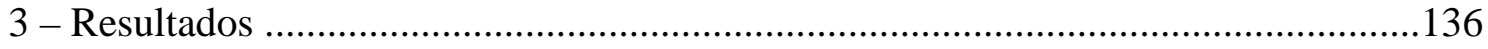

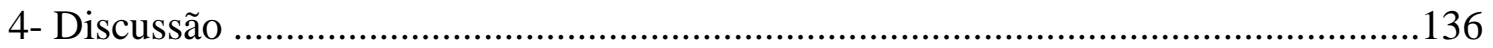

5 - Chave de identificação para as espécies de Charterginus ......................................140

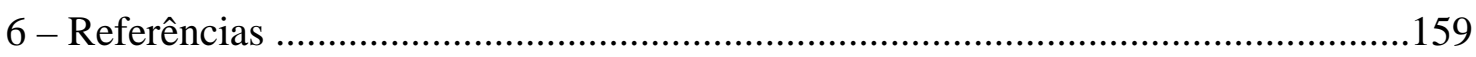

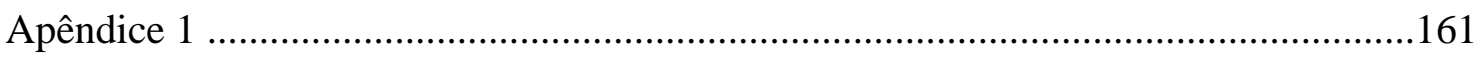




\section{INTRODUÇÃO}




\section{1 - INTRODUÇÃO}

Vespidae (Hymenoptera) é uma família monofilética, que apresenta como autapomorfias: célula discal alongada (pelo menos igual à célula submediana), espinhos no parâmero e oviposição dentro de uma célula vazia (Carpenter, 1982). Na maioria das vezes, apresenta vespas de tamanho médio a grande, e são encontradas principalmente nas regiões temperadas e tropicais, sendo que, no primeiro caso, apresentam ciclos de vida claramente definidos devido à sazonalidade. Tais padrões de sazonalidade não se verificam em espécies tropicais devido à ausência de fatores limitantes para o desenvolvimento da colônia (Jeanne, 1991).

Analises cladísticas (Fig. 1) indicam o monofiletismo das seis subfamílias existentes (Carpenter 1993): Euparagiinae + (Masarinae + (Eumeninae + (Stenogastrinae + $($ Polistinae + Vespinae)))). Nos Euparagiinae, Masarinae, Eumeninae, as espécies são tipicamente solitárias. Nos Stenogastrinae, há fundação solitária e são encontradas apenas associações entre fêmeas, de modo que a eussocialidade restringe-se a Vespinae + Polistinae (Carpenter, 1993).

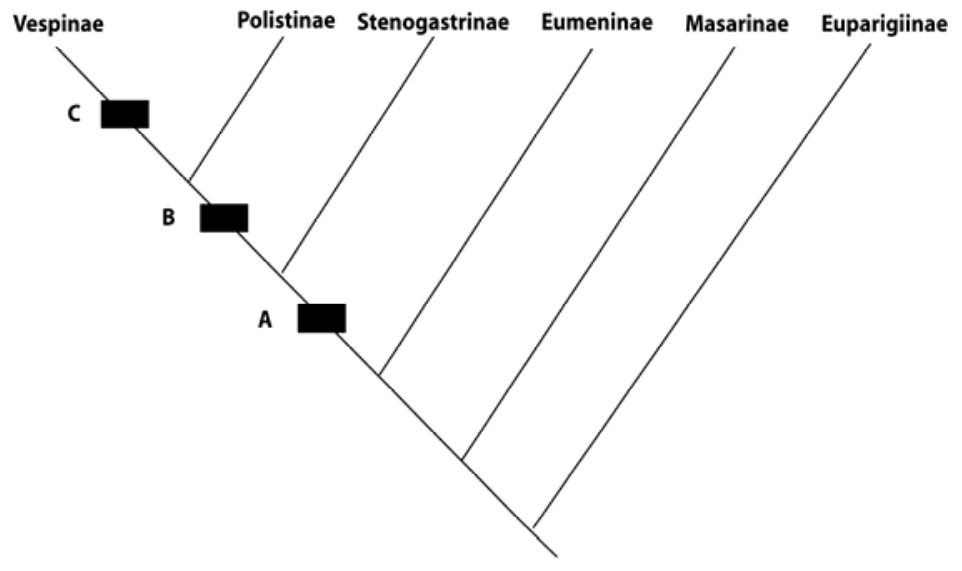

Figura 1 - Filogenia de Vespidae (Carpenter, 1993): (A) origem da eussocialidade facultativa ou temporária; (B) origem da eussocialidade permanente com monoginia de curto período; (C) origem da eussocialidade avançada (castas morfologicamente bem definidas). 
Os Vespidae formam uma parte comum e conspícua da fauna neotropical, especialmente as espécies eussociais. São encontrados em quase todos os ambientes, desde as florestas da América Central até Amazônia, Pantanal, Mata Atlântica, Cerrado, Caatinga, Campos Sulinos, etc. Constróem ninhos ou ocupam as cavidades, como tronco de árvores preexistentes, sendo, o ninho, geralmente, construído com fibras maceradas de plantas ou mesmo barro. Alguns ninhos podem apresentar estruturas grandes e complexas, podendo exceder milhões de indivíduos adultos (Zucchi et. al.,1995). Dentre os insetos sociais, a família Vespidae tem sido utilizada para estudos de modelos evolutivos por apresentarem uma ampla diversidade de níveis de socialidade, variando desde espécies solitárias até as altamente sociais (West-Eberhard, 1978, 1996; Wilson, 1985; Itô, 1986; Spradbery, 1991).

As vespas sociais formam dois grupos distintos, de acordo com a maneira de fundação de seus ninhos (Jeanne, 1984). No primeiro grupo, o ninho é iniciado por uma rainha inseminada, podendo unir-se à fundadora uma ou mais fêmeas inseminadas (fundação independente). O segundo grupo é formado por uma ou várias rainhas seguido de um grupo de operárias que irá iniciar uma colônia (fundação por enxame). Os enxames ocorrem em Vespinae (Provespa), Ropalidiini (Ropalidia e Polybioides) e nos outros 19 gêneros Neotropicais da tribo Epiponini (Carpenter, 2004). Tal fundação está associada a uma ampla complexidade em relação às diferenças entre as suas castas (Shima et al., 1998).

Os Polistinae inclui quatro tribos: Polistini (cosmopolita, exceto na Nova Zelândia), Mischocyttarini (Argentina até sudeste dos Estados Unidos e Columbia Britânica), Ropalidiini (Austrália, África Sub-Saharian, Península Arábica, Trópicos Orientais, China, Coréia, Japão, Irã, África Equatorial, Índia), e Epiponini (Argentina até sudeste dos Estados Unidos (Polybia e Brachygastra ocorrem no Texas e Arizona)). 
Os Polistinae apresentam grande diversidade, especialmente na região Neotropical, com 28 gêneros e aproximadamente 900 espécies descritas. No Brasil, ocorrem 23 gêneros e 301 espécies com representantes nas tribos Polistini (Polistes), Mischocyttarini (Mischocyttarus) e Epiponini (Carpenter, 1993).

Os Epiponini representam a mais diversa tribo, correspondendo a 19 gêneros (Carpenter, 2004), todos com representantes no Brasil, sendo que um gênero e 103 espécies são endêmicos. Apresentam variada arquitetura de ninho, fundação por enxameio e poliginia (múltiplas rainhas funcionais) (Richards \& Richards, 1951).

O enxameamento se caracteriza por uma ou mais rainhas, acompanhadas por operárias (fêmeas estéreis), deixarem um ninho estabelecido e fundarem uma nova colônia, sendo a rainha, desde o início, responsável apenas pela oviposição. As operárias selecionam o local para o novo ninho e o deslocamento até este local é indicado por meio de trilhas de feromônio (Naumann, 1975; Jeanne, 1981; West-Eberhard, 1982): operárias exploradoras movimentamse entre o velho e novo local de nidificação, esfregando uma glândula abdominal de odor sobre folhas proeminentes; em seguida, várias vespas voam seguindo a trilha de odor.

Os ninhos, geralmente, são construídos com materiais vegetais, os quais são triturados, misturados com água e, provavelmente, secreção salivar das glândulas mandibulares, resultando em um produto semelhante a papel (Wenzel, 1991, 1998), o qual varia consideravelmente em espessura, sendo grosseiro na maioria dos Epiponini e mais delicado em Polistini (Richards \& Richards, 1951; Richards, 1978). Os ninhos podem ser construídos na superfície inferior de folhas, em construções humanas (espécies de Polistes, Mischocyttarus e Leipomeles), diretamente sobre o tronco de árvores (Metapolybia e Synoeca), presos em ramos vegetais (Brachygastra, Polybia), ou escondidos em cavidades 
como, por exemplo, buracos em troncos de árvores (algumas espécies de Agelaia) (Carpenter \& Marques, 2001).

A arquitetura dos ninhos foi grandemente influenciada pela predação por formigas. Em Polistes e Mischocyttarus, uma substância repelente de formigas, secretada por uma glândula no sexto esternito do metassoma (glândula de Van der Vecht), é aplicada ao pedicelo do ninho (Jeanne, 1970; Post \& Jeanne, 1981; Espelie \& Hermann, 1990). A maioria das vespas enxameadoras constrói ninhos com envelope, o que poderia sugerir uma proteção contra formigas (Jeanne, 1975 apud Smith, et. al. 2001), seguida da perda de secreção repelente. Os únicos dois gêneros de Epiponini sem envelope no ninho (Apoica e a maioria das espécies de Agelaia) que mantém a glândula de Van der Vecht, mas sem eficiência repelente contra formigas (London \& Jeanne, 2000). Provavelmente, Apoica e Agelaia (ver discussão em capítulo de Angiopolybia) são gêneros intermediários, entre a ausência e a presença de envelope no ninho, que refletiu na morfologia e fisiologia do restante dos gêneros de Epiponini. Um ponto ainda não estudado é a associação de algumas espécies de Epiponini que constroem seus ninhos contiguamente às formigas, havendo uma cooperação de defesa.

A diferenciação de castas nos Epiponini é complexa (Richards \& Richards 1951, Richards, 1971, 1978: Jeanne 1996; Noll et. al., 1996; Mateus et. al., 1997; Noll \& Zucchi, 2000, 2002; Noll et al., 2004). As rainhas são maiores que as operárias porque o abdome é dilatado por causa da presença de oócitos e rainhas velhas de algumas espécies (Polybia, Metapolybia e Agelaia) apresentam coloração mais escura (Carpenter \& Marques, 2001). Entretanto, rainhas podem ser menores que operárias como é o caso de Apoica flavissima (Shima, et. al., 1994) e Polybia dimidiata (Shima et al., 1996), ou não haver diferenciação morfológica marcante em algumas espécies, ao contrário de outros grupos, é possível determinar tal diferenciação através da condição ovariana (inseminada ou não) (Noll, 2000). 
Existem três filogenias para os Vespidae (Carpenter, 1991 - Fig 2, basicamente com dados morfológicos; Wenzel, 1993 - Fig 3, com dados de arquitetura de ninho; e uma análise combinada dos caracteres citados anteriormente, mais dados de estágios imaturos, proposta por Wenzel \& Carpenter, 1994 - Fig 4), além de uma filogenia apenas para os Epiponini (Noll, 2000, utilizando a matriz de Wenzel \& Carpenter (1994) e dados de diferenciação de castas - Fig. 5). Apesar das mudanças de posicionamento de alguns gêneros nas filogenias citadas, utilizaremos como base para este trabalho a filogenia de Wenzel \& Carpenter (1994) por apresentar grande quantidade de caracteres e maior resolução dos táxons.

Embora a topologia entre os vários gêneros de Epiponini seja relativamente estável, não existe nenhum estudo filogenético ao nível específico. Este trabalho compreende o resultado das primeiras análises filogenéticas, ao nível específico, para os Epiponini. Apresentaremos abaixo um resumo das principais informações sobre os gêneros estudados.

\subsection{Relações filogenéticas dos gêneros estudados}

\subsubsection{Angiopolybia}

A relação entre os gêneros Agelaia e Angiopolybia é ambígua. Richards \& Richards (1951) e Richards (1978) incluíram Angiopolybia como um subgênero de Agelaia. Em Wenzel (1993 - Fig. 3) essa politomia permanece, agregando-se a ela Pseudopolybia e Parachartergus. Em Wenzel \& Carpenter (1994 - Fig 4), utilizando conjuntamente dados de morfologia e arquitetura de ninhos, essa politomina é resolvida, mantendo Agelaia + Angiopolybia. Tanto Agelaia quanto Angiopolybia tiveram um histórico taxonômico complexo (ver detalhes no capítulo 1 - Angiopolybia). De fato, muitas das espécies desses gêneros são muito semelhantes e compartilham várias características. Apesar de Araujo (1946) ter separado as espécies que construíam ninhos com envelope, criando o gênero 
Angiopolybia, ainda existia dúvida sobre o monofiletismo do gênero, principalmente após a descrição de espécies de Agelaia que constroem ninhos com envelope (ver Richards, 1978; Cooper, 2000, 2001).

\subsubsection{Pseudopolybia}

Pseudopolybia é um gênero que não sofreu mudanças no seu posicionamento, exceto em Wenzel (1993 - Fig 3). Em Carpenter (1991 - Fig 2)) e em Wenzel \& Carpenter (1994 Fig 4), Pseudopolybia é grupo irmão de Parachartergus + (Leipomeles (= Marimbonda) + (Chartergellus + Nectarinella)). Em Wenzel (1993), Pseudopolybia se posiciona em uma politomia com Agelaia, Angiopolybia, Parachartergus e o clado, também politômico, composto por Leipomeles (= Marimbonda), Nectarinella e Chartergellus. Os dados de arquitetura de ninho utilizados por Wenzel (1993), apesar de terem elucidados alguns clados, se mostraram pouco informativos para os gêneros mais basais de Epiponini.

\subsubsection{Chartergellus}

Chartergellus não sofreu mudança de posicionamento tanto em Carpenter (1991 - Fig. 2) quanto em Wenzel \& Carpenter (1994 - Fig. 4). Nesses trabalhos, o clado (Pseudopolybia $+($ Parachartergus + $($ Leipomeles + $($ Chartergellus + Nectarinella $))))$ é estável. Em Wenzel (1993 - Fig. 3) Chartergellus é politômico com Leipomeles e Nectarinella, e, como já citado anteriormente, os dados de arquitetura de ninhos não foram informativos para tal clado.

\subsubsection{Synoeca}

Synoeca sempre esteve posicionado em um clado compreendendo os gêneros Clypearia (= Occipitalia), e Asteloeca. Em Carpenter (1991 - Fig. 2), Synoeca é grupo-irmão dos três gêneros acima citados, estando eles organizados de forma politômica. Em Wenzel (1993 - Fig.3) Clypearia e Occipitalia, que até então não eram consideradas sinônimos, é grupo-irmão de Asteloeca + (Synoeca + Metapolybia $)$. A politomia entre Clypearia e 
Occipitalia dava indícios de que, ao menos quanto aos dados de ninhos, estes gêneros deveriam ser sinonimizados, por não apresentarem sinapomorfias que suportassem sua separação. Em Wenzel \& Carpenter (1994 - Fig. 4), Synoeca é novamente o gênero mais basal, sendo grupo-irmão de Clypearia (= Occipitalia $)+($ Metapolybia + Asteloeca $)$.

\subsubsection{Charterginus}

Charterginus, segundo Carpenter (1991 - Fig. 2), era o grupo irmão mais basal do clado que aqui denominamos componente Polybia, existindo uma politomia entre os gêneros que compreendem esse clado. Posteriormente, em Wenzel (1993 - Fig 3), o clado ao qual Synoeca estava incluído (ver acima) se torna grupo-irmão de Charterginus + (Synoecoides + Epipona $)+($ Brachygastra $+($ Protonectarina + Polybia $)))+$ Chartergus. Wenzel \& Carpenter (1994 - Fig. 4) mantém Charterginus como gênero mais basal, sendo grupo irmão de $($ Chartergus + Brachygastra $)+($ Protonectarina $+($ Polybia $+($ Synoecoides + Epipona $))))$. 


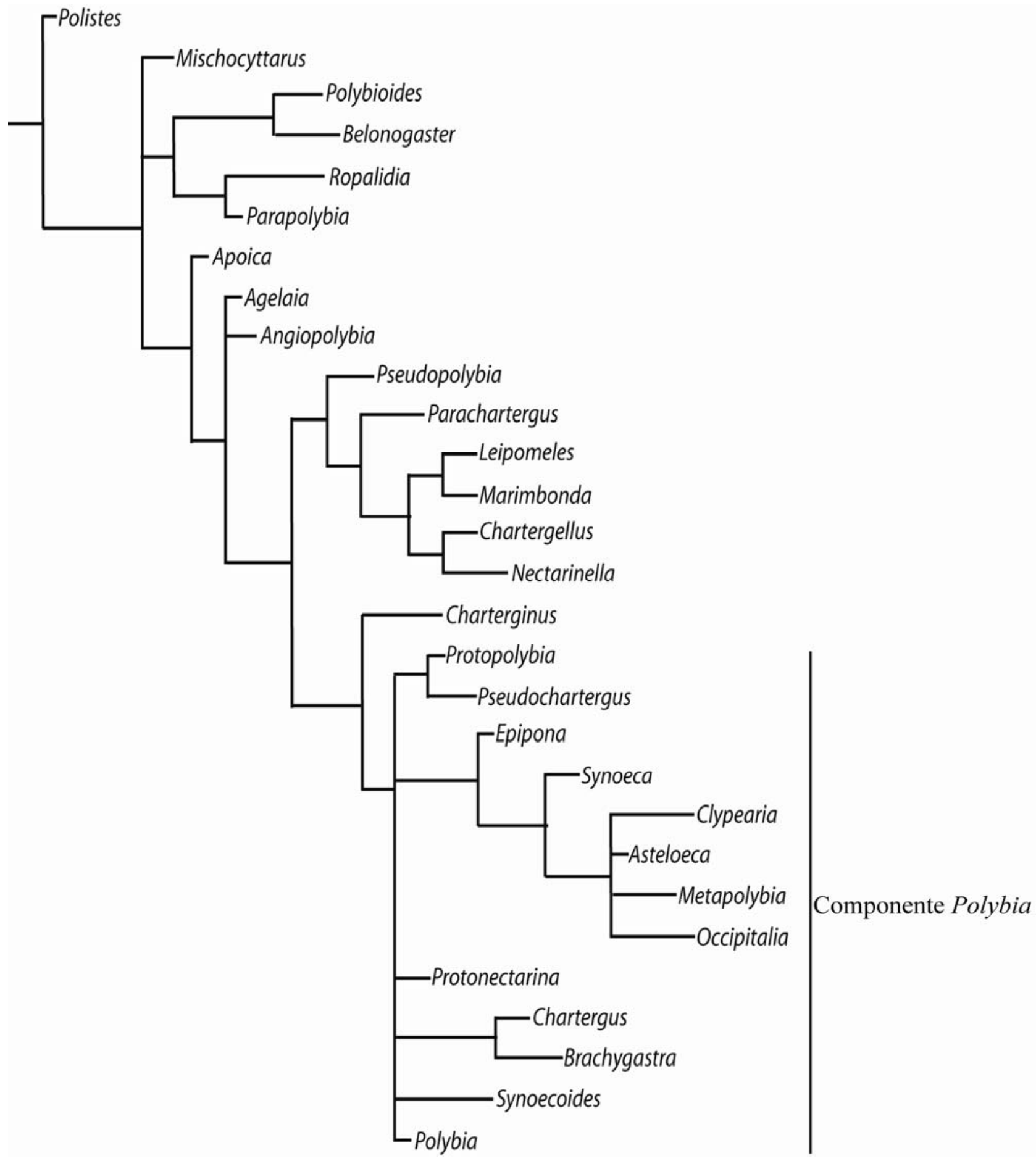

Figura 2 - Árvore de consenso da filogenia dos Polistinae proposta por Carpenter (1991). 


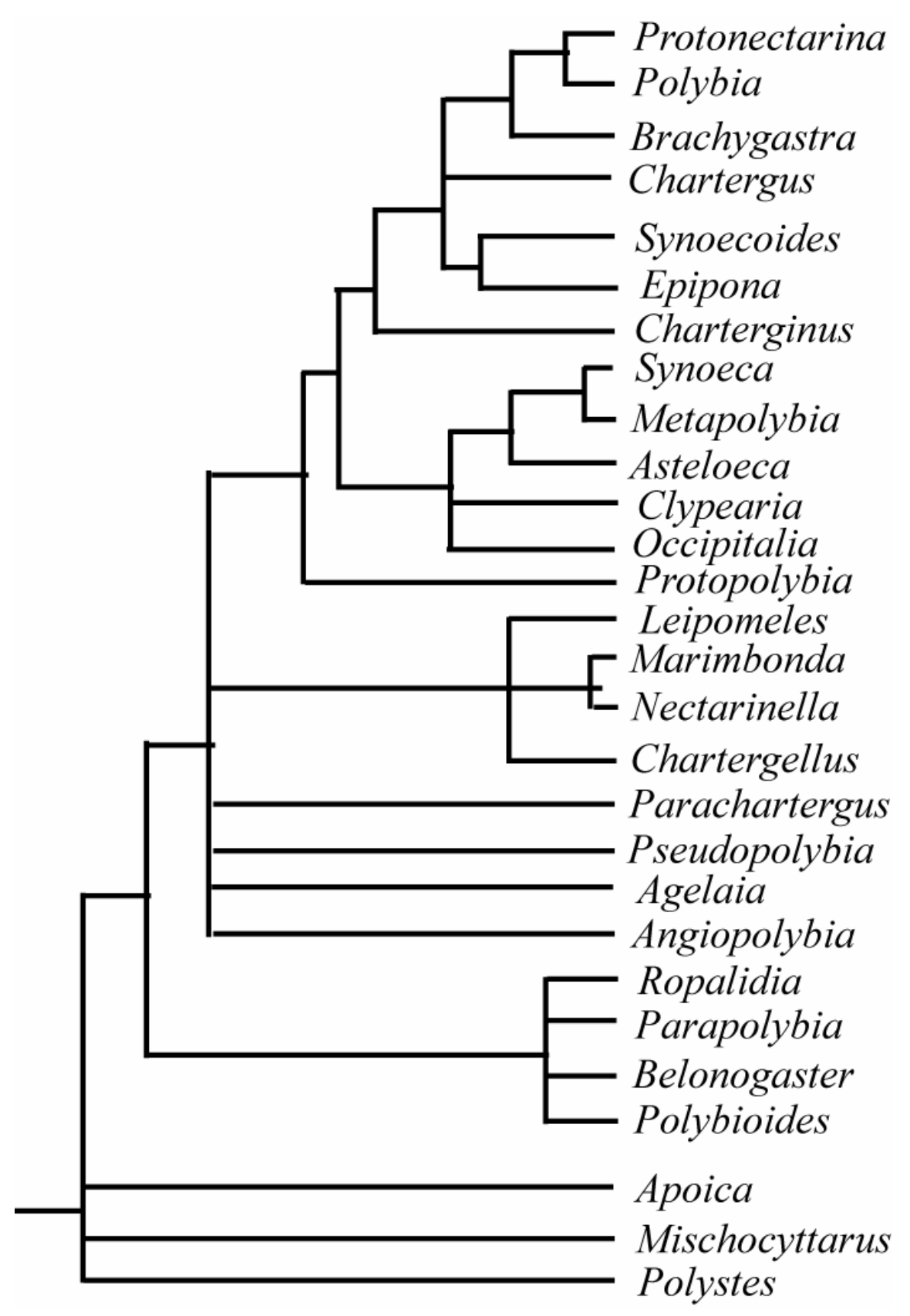

Figura 3 - Árvore de consenso da filogenia dos Polistinae proposta por Wenzel (1993). 


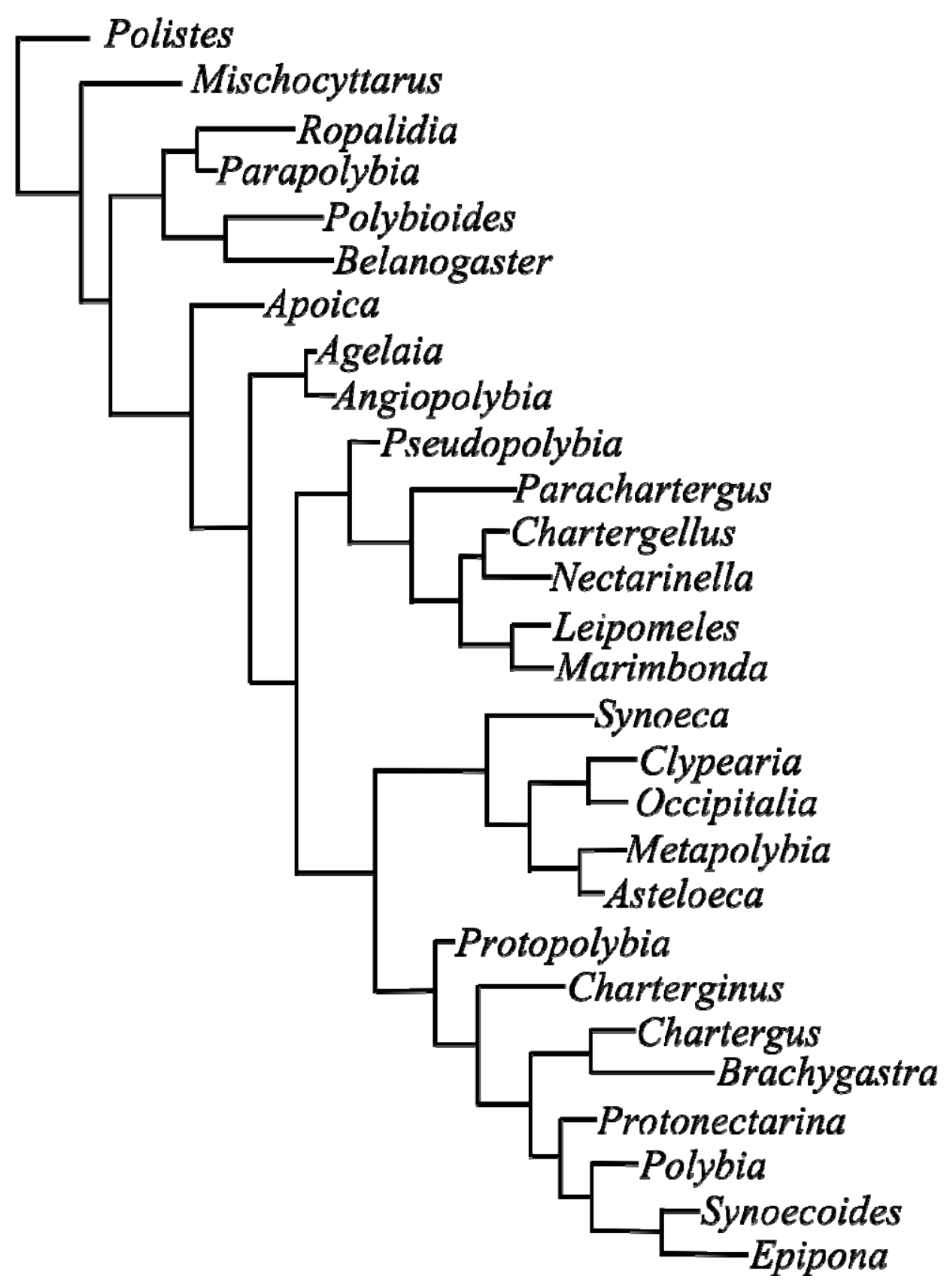

Figura 4 - Árvore de consenso da filogenia dos Polistinae proposta por Wenzel \& Carpenter (1994). 
Introdução

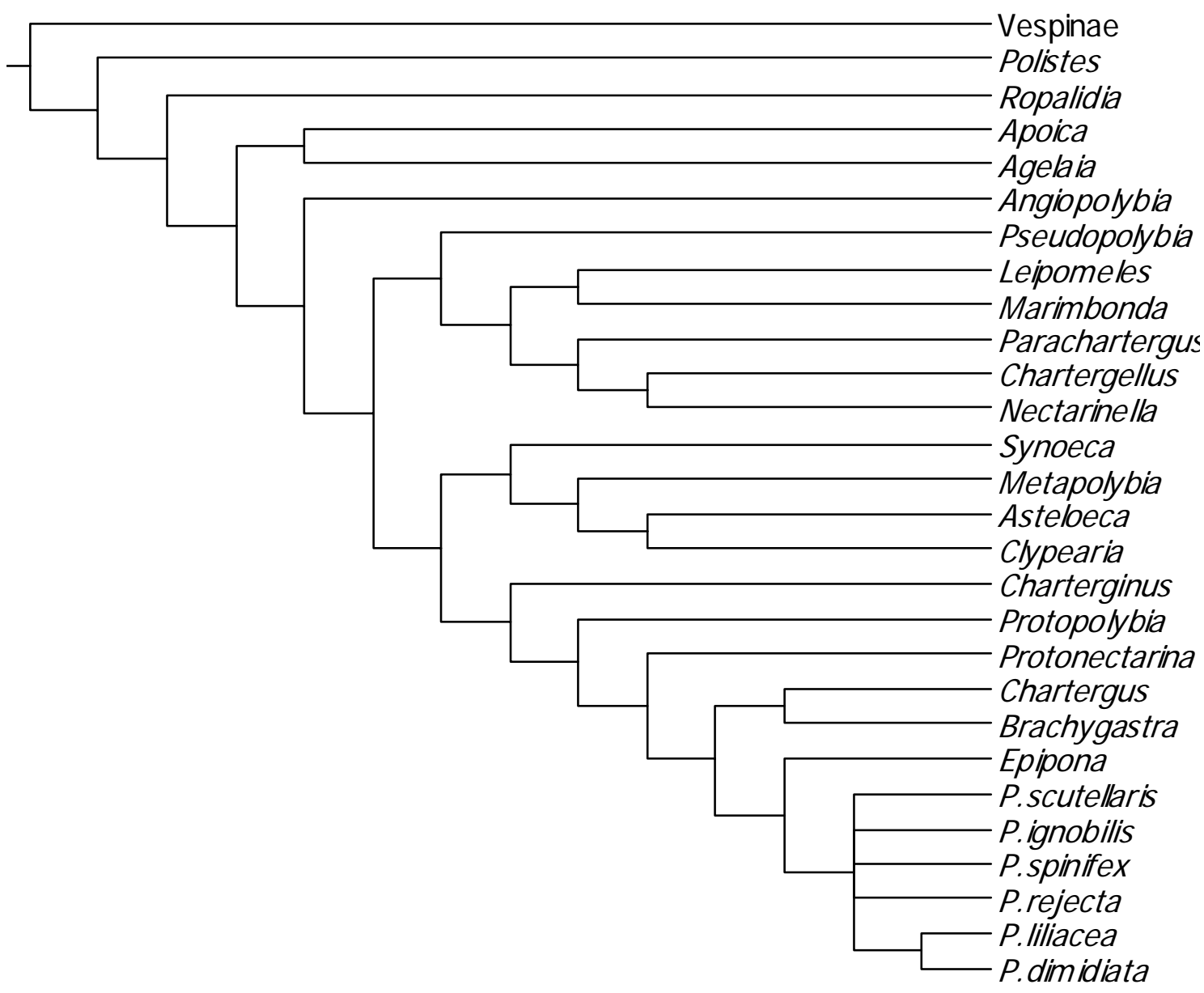

Figura 5 - Árvore de consenso da filogenia dos Epiponini proposta por Noll (2000). 


\section{2 - OBJETIVOS}

Este trabalho teve como objetivos testar o monofiletismo dos gêneros Angiopolybia, Pseudopolybia, Chartergellus, Synoeca, e Charterginus, bem como estabelecer uma relação filogenética entre as espécies desses gêneros. 
MATERIAIS E MÉTODOS 


\section{3 - MATERIAIS E MÉTODOS}

\subsection{1-Materiais}

Os espécimes utilizados neste estudo foram analisados na Faculdade de Filosofia, Ciências e Letras de Ribeirão Preto da Universidade de São Paulo e no “American Museum of Natural History” (New York, USA). Material adicional foi observado no Museu de Zoologia da Universidade de São Paulo (São Paulo, Brasil), Universidade Federal do Paraná (Curitiba, Brasil) e Instituto Nacional de Pesquisas da Amazônia (Manaus, Brasil). Coletas foram realizadas na região do município de Presidente Figueiredo-AM, e o material encontra-se na coleção da FFCLRP-USP.

Informações adicionais sobre empréstimos e localidade do material analisado serão descritas especificamente para cada gênero estudado nos seus respectivos capítulos.

\subsection{2-Métodos}

Para confecção das figuras e medidas utilizou-se um estereomicroscópio Leica MZ 7.5, com câmara fotográfica digital Leica DFC 280, câmara clara, e software de captura de imagem Leica IM 50.

Descrevemos aqui a metodologia empregada para análise das espécies dos cinco gêneros estudados, para que não houvesse repetição ao longo dos capítulos, no entanto são fornecidas informações adicionais específicas em cada capítulo.

Os caracteres obtidos na análise morfológica foram somados aos já existentes na literatura, combinados e analisados segundo a metodologia desenvolvida por Hennig (1966), sintetizada em Amorim (1997), Scotland \& Pennington (2000) e Schuh (2000). 
A metodologia de análise filogenética utilizada foi a da escola cladística, sob um enfoque de parcimônia "numérica". Os caracteres foram codificados como binários ou estados múltiplos.

A polaridade dos caracteres foi determinada através dos métodos propostos por Farris (1982), Nixon \& Carpenter (1993) e de Pinna (1994), no qual os táxons terminais do grupo "interno" são tratados conjuntamente com os táxons terminais dos grupos "externos" na análise de parcimônia.

O algoritmo de análise filogenética adotado foi o de parcimônia de Wagner, estrita ou simples, de tal forma que as reversões e convergências possuam o mesmo valor de transformação (Farris, 1983). Para a análise utilizamos o programa de parcimônia NONA versão 2.0 (Goloboff, 1999) usando como interface o programa WinClada versão Beta (Nixon, 1999). 


\section{REFERÊNCIAS}




\section{4 - REFERÊNCIAS}

Amorim, D.S. 1997. Elementos Básicos de Sistemática Filogenética. Ribeirão Preto-SP. Ed. Holos e Sociedade Basileira de Entomologia, 276p.

Araujo, R.L. 1946 Angiopolybia Nom. N., para o conceito revalidado de "Stelopolybia Ducke, 1914” (Hym. Vespidade. Polybiinae). Papeis Avulsos do Departamento de Zoologia, 7: 165-170.

Carpenter, J.M. 1982. The phylogenetic relationships and natural classification of the Vespoidea (Hymenoptera). Systematic Entomology, 7: 11-38.

Carpenter, J.M. 1991. Phylogenetic relationships and the origin of social behavior in the Vespidae. pp. 7-32, In: K.G. Ross and R.W. Matthews (eds), The social biology of wasps, Ithaca, New York, Cornell University Press.

Carpenter, J.M. 1993. Biogeographic patterns in the Vespidae (Hymenoptera): Two views of Africa and South America. pp. 139-155 In: P. Goldblatt (editor), Biological relationships between Africa and South America,. New Haven, CT: Yale University Press, ix + 630pp.

Carpenter, J.M. 2004. Synonymy of the Genus Marimbonda Richards, 1978, with Leipomeles Möbius, 1856 (Hymenoptera: Vespidae: Polistinae) and a New Key to the Genera of Paper Wasps of the New World. American Museum Novitates, 16: 16 pp.

Carpenter, J.M. \& Marques, O.M. 2001. Contribuição ao Estudo dos Vespídeos do Brasil (Insecta, Hymenoptera, Vespoidea, Vespidade). Série Publicações Digitais vol. 2. Universidade Federal da Bahia. 144 pp.

Cooper, R. 2000. Five new species of Agelaia Lepeletier (Hym., Vespidae, Polistinae) with a key to members of the genus, New Synonymy and notes. Entomologist's Monthly Magazine, 136: 177-198.

Cooper, R. 2001.Two new species of Agelaia Lepeletier (Hym., Vespidae, Polistinae). Entomologist's Monthly Magazine, 137: 233-236.

De Pinna, M.C.C. 1994. Ontogeny, rooting and polarity. Pages 157-172 In: R.W. Scotland, D.J. Siebert \& D.M. Williams (eds). Models of Phylogeny Reconstruction. Oxford Clarendon Press.

Espelie, K. E. \& Hermann, H. R. 1990. Surface lipids of the social wasp Polistes annularis (L.) and its nest and nest pedicel. Journal of Chemistry Ecology, 16: 1841-1852.

Farris, J.S. 1982. Outgroups and parsimony. Systematic Zoology, 31: 328-334. 
Farris, J.S. 1983. The logical basis of phylogenetic analysis. pp 7-36 In: N.I. Platnick \& V.A. Funk. (eds). Advances in Cladistics proceedings of the Second meeting of the Willi Hennig Society. New York .Columbia University Press.

Goloboff, P.A. 1999. NONA ver 2.0 for Windows 95/98/NT program and documentation. Fundación e Instituto Miguel Lillo, Tucuman.

Hennig, W. 1966. Phylogenetic Systematics. . Urbana .Univ. Illinois Press. 263 p.

Itô, Y. 1986. On the pleometrotic route of social evolution in the Vespidae. Monitore. Zoologico Italiano, 20: 241-262.

Jeanne, R. L. 1970. Chemical defense of brood by social wasp. Science, 168: 1465-1466.

Jeanne, R. L. 1981. Chemical communication during swarm emigration in the social wasp Polybia sericea (Olivier). Animal Behavior, 29: 102-113.

Jeanne, R.L. 1991. The swarm-founding Polistinae, pp 191-231. In: Ross K.G. and Matthews R.W. Edits. In: The social biology of wasps. Ithaca. Cornell University Press.

Jeanne, R.L. 1996.Non-allometric queen-worker dimorphism in Pseudopolybia difficilis (Hymenoptera: Vespidae). Journal of the Kansas Entomological Society, 69 (4): 370374.

Jeanne, R.L., \& Davidson D. W. 1984. Population regulation in social insects. Pp. 559-590. In: C. B. Huffaker \& R. L. Rabb (eds). Ecological Entomology. Wiley, New York.

London, K. B \& Jeanne, R. L. 2000. the interactions between mode of colony founding and nest architecture to ant defense in polistine wasps. Ethology, Ecology, Evolotion, 12: 1335

Mateus., S.; Noll, F.B. \& Zucchi, R. 1997. Morphological caste differences in neotropical swarm-founding polistinae wasps: Parachartergus smithii (Hymenoptera: Vespidae). Journal of the New York Entomological Society, 105(3-4): 129-139.

Naumann, M.G. 1975. Swarming behavior: evidence for communication in social wasps. Science, 189: 642-644.

Nixon, C.K. \& Carpenter, J.M. 1993. On outgroups. Cladistics, 9: 413-426.

Noll, F.B. 2000. Uma análise da evolução das castas nos Epiponini (Hymenoptera: Vespidae). Tese de Doutorado. Ribeirão Preto, FFCLRP-USO. 217 pp.

Noll F.B., Mateus S. \& Zucchi R. 1996. Morphological caste differences in Neotropical swarm-founding polistinae wasps. V- Protopolybia exigua exigua (Hymenoptera: Vespidae). Journal of New York Entomological Society, 104 (1):61-69. 
Noll, F. B. \& Zucchi, R. 2000. Increasing caste differences related to life cycle progression in some neotropical swarm-founding polygynic polistine wasps (Hymenoptera: Vespidae, Epiponini). Ethology Ecology \& Evolution, 12(1): 43- 65.

Noll F. B. \& Zucchi R. 2002. Castes and the influence of the colony cycle in swarm- founding polistine wasps (Hymenoptera: Vespidae; Epiponini). Insectes Sociaux. 49: 62-74

Noll, F.B., Wenzel, J. W \& Zucchi, R. 2004. Evolution of Caste in Neotropical SwarmFounding Wasps (Hymenoptera: Vespidae; Epiponini). American Museum Novitates, 3467: 1-24.

Post, D. C. \& Jeanne, R. L. 1981. Colony defense against ants by Polistes fuscatus (Hymenoptera, Vespidade) in Wisconsin. Journal of Kansas Entomological Society, 54: 599-615.

Richards O.W. 1971. The biology of the social wasps (Hymenoptera: Vespidae). Biology Rev. (Cambridge), 46: 483-528.

Richards O.W. 1978. The social wasps of the Americas excluding the Vespinae. London (British Museum Natural History): 580 pp.

Richards O.W. \& Richards M.J. 1951. Observations on the social wasps of South America (Hymenoptera, Vespidae). Transactions of the Royal Entomological Society of London. 102: $1-170$.

Scotland, R.E. \& Pennington, R.T. 2000. Homology and Systematics: coding characters for phylogenetic analyis. The Systematic Association Special Volume Series 58. London and New York. Taylor \& Francis. 217 p.

Schuh. R.T. 2000. Biological Systematics: principles and applications. New York.Cornell University Press.

Shima S.N., Noll, F.B., Zucchi, R. \& Yamane, S. 1998. Morphological caste differences in the Neotropical swarm-founding polistine Wasps IV. Pseudopolybia vespiceps, with preliminary considerations on the role of intermediate females in social organization of the Epiponini (Hymenoptera, Vespidae). Journal of Hymenoptera Research, 7: 280-295.

Shima S.N., Yamane S. \& Zucchi, R. 1996. Morphological caste differences in Some neotropical swarm-founding polistine wasps II- Polybia dimidiata (Hymenoptera, Vespidae). Japanese Journal of Entomological, 64(1): 131- 144.

Smith, A. R.; O`Donnell, S. \& Jeanne, R. L. 2001. Correlated evolution of colony defence and social structure: A comparative analysis in eusocial wasps Hymenoptera: Vespidae). Evolutionary Ecology Research, 3: 331-344.

Spradbery, J.P 1991.Evolution of queen number and queen control. pp. 191-231 In: The social biology of wasps (ed Ross and Matthews). Cornell University Press, Ithaca. 
Wenzel, J.W. 1991. Evolution of Nest Architeture. In The Social Biology of wasps, (ed. Ross and R.W. Matthews). Cornell University Press, Ithaca.

Wenzel, J.W. 1993. Application of the biogenetic law to behavioral ontogeny: a test using nest architecture in paper wasps. Journal of Evolutionary Biology, 6: 229-247.

Wenzel, J. W. 1998. A generic key to the nests of hornets, yellowjackets, and paper wasps worldwide (Vespidae: Vespinae, Polistinae). American Museum Novitates, 3224. 26 pp.

Wenzel, J.W. \& Carpenter, J. M. 1994. Comparing methods: adaptative traits and tests of adaptation. pp 79-101. In: P. Eggleton, \& R. Vane-Wright (eds.), Phylogenetics and Ecology. London. Academis Press.

West-Eberhard, M.J. 1978. Temporary queens in Metapolybia wasps: non- reproductive helpers without altruism? Science, 200: 441-443.

West-Eberhard, M.J. 1982. the nature and evolution of swarming in tropical social wasps (Vespidade, Polistinae, Polybiini). Pp 97-128 In: Jaisson, P. (ed.). Social Insects in the Tropics. Paris: Univ. Paris-Nord. vol 2.

West-Eberhard, M.J. 1996.Wasp societies as microcosms for the study of development and evolution. pp 290-317 In: Turillazzi, S. \& West-Eberhard, M.J. Natural History and evolution of paper wasps. Oxford. Oxford Univ. Press.

Wilson, E.O. 1985. The sociogenesis of insect colonies . Science, 228 (4704): 1479-1485.

Zucchi, R; Sakagami, S.F; Noll, F.B; Mechi, M.R; Baio, M.V; Mateus, S \& Shima, S.N. 1995. Agelaia vicina, a swarm-founding Polistinae with the largest colony size among wsps and bees (Hymenoptera, Vespidae). Journal of the New York Entomological Society, 103 (2): 129-137. 


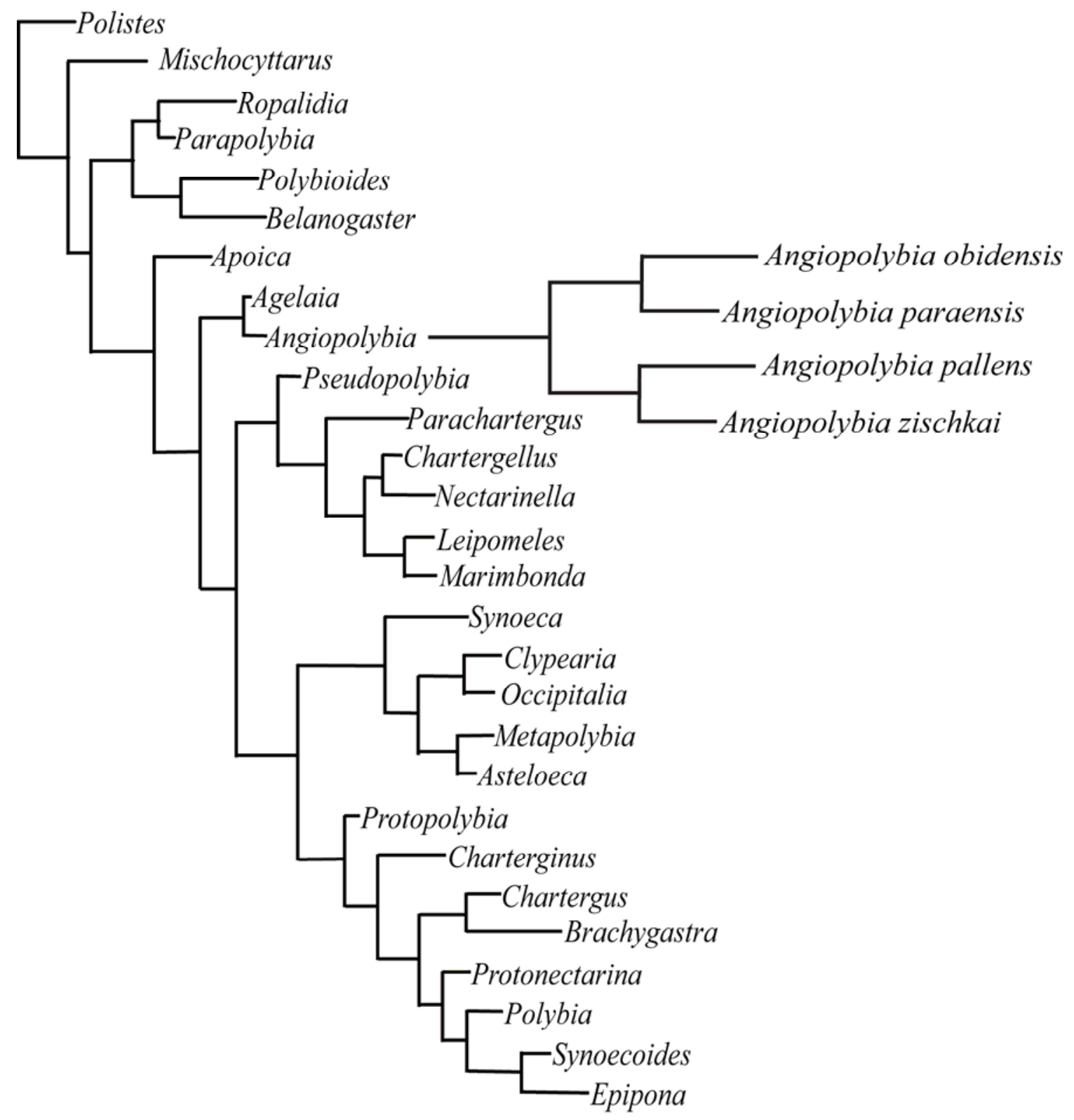

Capítulo 1 - Análise Filogenética do Gênero Angiopolybia Araujo, 1946 (Hymenoptera, Vespidae, Epiponini) 


\section{Capítulo 1 - Análise Filogenética do Gênero Angiopolybia Araujo, 1946}

\section{(Hymenoptera, Vespidae, Epiponini).}

\section{1- INTRODUÇÃO}

Angiopolybia é um gênero pequeno de vespas sociais neotropicais com apenas quatro espécies descritas: Angiopolybia pallens (Lepeletier, 1836), A. paraensis (Spinola, 1851), A. obidensis (Ducke, 1904) e A. zischkai Richards, 1978. Estas espécies são amplamente distribuídas, desde a Costa Rica até a Bolívia, e com grande abundância na região Amazônica. Os ninhos de Angiopolybia consistem de vários favos conectados geralmente a uma folha pelos pedicelos (Richards, 1978). Possuem um envelope característico, que é ovóide na região superior e geralmente termina em uma entrada tubular na região inferior (Wenzel, 1998, ver também Figs. 5 e 6). As colônias geralmente possuem algumas centenas de indivíduos (Richards, 1978) e a diferenciação de castas é baixa (Noll et al., 2004). A história taxonômica de Angiopolybia é complexa, e uma revisão é apresentada abaixo (ver 1.1).

\subsection{Histórico taxonômico}

Angiopolybia foi inicialmente descrito como Rhopalidia por Lepeletier (1836), com base em duas novas espécies: $R$. pallens e $R$. rufithorax. Guérin-Méneville (1838) adotou a nomenclatura de Lepeletier para um gênero que havia sido anteriormente descrito como Ropalidia (Guérin-Méneville, 1831). Esta troca de nomes era injustificada. O genêro Ropalidia do “velho mundo” de Guérin-Méneville 1831 e Rhopalidia do “novo mundo” de Lepeletier 1836 são grupos distintamente diferentes (veja abaixo). Rhopalidia não foi 
reconhecida por De Saussure em sua monografia (1853-58). As espécies descritas por Lepeletier foram tratadas como sinônimos: Rhopalidia pallens como sinônimo de Polybia pallipes (Olivier) e R. rufithorax de P. sericea (Olivier). De Saussure (1854) também descreveu uma nova espécie: Polybia infernalis. Du Buysson (1906: 342) considerou R. pallens como sinônimo de Apoica pallida var. pallens (Fabricius). Ducke (1910: 542) analisou uma espécie de $R$. pallens, evidentemente o tipo, e a reconheceu como coespecífica de $P$. infernalis. No entanto, ele seguiu o sinônimo de Du Buysson para $R$. pallens, e não a adotou como sinônimo sênior de $P$. infernalis.

Para complicar ainda mais a situação, Ducke (1910) também descreveu um novo gênero, Stelopolybia, para 13 espécies, incluindo Polybia infernalis de Saussure, mas não designando uma espécie tipo. Stelopolybia foi separada de Polybia por apresentar, como caracteres diagnósticos, fenda dorsal mesepisternal presente e ninhos gimnódomos (sem envelope). Lucas (1912: 210) designou S. angulata (Fabricius) como a espécie-tipo. Schulz (1912: 60) enquanto designava $R$. pallens como espécie tipo de Rhopalidia, notou que, baseado no tipo, $R$. pallens deveria ser tratada como sinônimo-sênior de $P$. infernalis, e, portanto, Rhopalidia era sinônimo sênior de Stelopolybia. Ducke (1913: 331) não aceitou a nova designação de Schulz, argumentando que o uso de Rhopalidia Guérin-Méneville se aplicava ao gênero Icaria de Saussure (Icaria de Saussure foi sinonimizada com Ropalidia Guérin-Méneville por Bequaert, 1918: 244). Ducke também citou o sinônimo de R. pallens de Du Buysson.

Os argumentos de Ducke eram incorretos, mas ele continuou a utilizar Stelopolybia, e então, em 1914, Ducke propôs o gênero Gymnopolybia para as espécies de Stelopolybia que constroem ninhos em cavidades e não possuem envelope, restringindo o uso de 
Stelopolybia às espécies que constroem ninhos aéreos e com envelope. Ducke não designou a espécie tipo para Gymnopolybia, mas incluiu 10 espécies, entre elas S. angulata. Gymnopolybia é, portanto, considerada sinônimo de Stelopolybia (sendo os dois gêneros agora tratados como sinônimos de Agelaia Lepeletier; ver Carpenter \& Day, 1988). Bequaert (1918: 245), enquanto reposicionava Icaria com Ropalidia Guérin-Méneville, notou que Rhopalidia era sinônimo de Gymnopolybia, como também evidenciado por Lucas (1912).

Esta confusão se manteve por um bom tempo. Richards (1943: 45) designou Polybia vulgaris Ducke, 1904 [= Agelaia fulvofasciata (DeGeer, 1773)] como espécie-tipo de Gymnopolybia, e Polybia infernalis de Saussure, 1854 [= Angiopolybia pallens (Lepeletier, 1836)] como espécie tipo de Stelopolybia, mas como citado acima, sua designação de tipo para Stelopolybia era precedida por aquela de Lucas (1912). Bequaert (1944: 292) notou o sinônimo de Gymnopolybia com Stelopolybia, mas não reconheceu o gênero para as espécies que constroem ninhos aéreos e com envelope, argumentando que a distinção entre os dois grupos foi puramente "biológica”, e os caracteres morfológicos que haviam sido propostos por Ducke (1914) e Richards (1943) eram inadequados para suportar a separação dos dois gêneros. Araujo (1946) propôs o gênero Angiopolybia como novo nome para Stelopolybia Ducke (1914). Araujo argumentou que a diferença de arquitetura de ninho era suficiente para o reconhecimento do mérito dos dois gêneros, e citou vários caracteres morfológicos que os diferenciavam. Richards (1973), no "International Commission on Zoological Nomenclature”, suprime Rhopalidia Lepeletier em favor de Angiopolybia, citando o problema de se citar Rhopalidia e Ropalidia como nomes 
genéricos em Polistinae. Opinião 1051 (International Commission on Zoological Nomenclature, 1976) da requisição de Richards.

\section{2- Posicionamento filogenético}

Na primeira análise cladística para os Polistinae (Carpenter, 1991), o monofiletismo de Angiopolybia era suportado pela lamela do escuto reduzida, mas seu posicionamento em relação aos outros gêneros não era completamente resolvido. Tanto em Carpenter (1991), baseado principalmente em caracteres morfológicos, quanto em Wenzel (1993), baseado em caracteres de arquitetura de ninho, Angiopolybia era parte politômica em relação a Agelaia. Wenzel e Carpenter (1994) apresentaram uma análise combinada para os Polistinae, usando caracteres de arquitetura de ninho e morfológicos. Nesta análise Angiopolybia é grupo irmão de Agelaia. Uma relação próxima à Agelaia poderia ser esperada dada à história taxonômica destes gêneros (ver acima). Estes gêneros possuem várias características morfológicas em comum e algumas espécies são muito similares. De qualquer modo, enquanto todas as espécies de Angiopolybia possuem ninhos aéreos e com envelope, algumas espécies de Agelaia também possuem ninhos com tais características (ex. A. areata Say, A. timida Cooper). Portanto, os dois gêneros não podem mais ser separados baseados apenas na arquitetura dos ninhos, como havia sido sugerido por Araujo (1946).

Neste trabalho apresentamos a primeira análise filogenética do gênero Angiopolybia baseada em caracteres morfológicos de fêmeas adultas, além de uma nova chave ilustrada para a identificação das espécies. 


\section{2- MATERIAIS E MÉTODOS}

Os materiais obtidos por empréstimos foram adquiridos das seguintes instituições: Museu de Zoologia da Universidade de São Paulo, São Paulo, Brasil, (MZSP); Museu Paraense Emilio Goeldi, Belém, Pará, Brasil (MPEG), e Instituto de Investigación de Recursos Biológicos Alexander Von Humboldt, Bogotá, Colômbia (IIRBAVH) (ver lista de localidades dos exemplares examinados no Apêndice 1).

Baseando-se na mais recente revisão (Richards, 1978), os caracteres diagnósticos para Angiopolybia são: espaço malar pequeno, carena pronotal dorsal evanescente ou ausente, esclerito mesepisternal dorsal amplo, escuto sem uma lamela adjunta a borda da tégula, escutelo sem uma linha impressa, e a área basalar metapleural achatada. Seis desses caracteres, mais outros nove (Tabela 1), foram plotados em uma matriz de dados para reconstrução filogenética (Tabela 2). As figuras 1-4 ilustram alguns desses caracteres. Alguns dos caracteres previamente citados que diferenciam Angiopolybia de Agelaia não foram incluídos, como o tamanho do espaço malar ou a largura da gena, uma vez que apresentam grande variação. O caráter com estados múltiplos foi tratado como não aditivo. Os caracteres foram polarizados por enraizamento baseado nos grupos-externos (Nixon \& Carpenter, 1993), no caso específico, Apoica e Agelaia .

\section{3- RESULTADOS}

A análise da matriz de caracteres resultou em um único cladograma com 20 passos, índice de consistência 0,90 e índice de retenção de 0,88 (Fig. 7). Angiopolybia é suportada 
como monofilético, tendo a relação entre as espécies: $(($ A. pallens + A. zischkai $)+(A$. obidensis + A. paraensis)).

\section{4- DISCUSSÃO}

As sinapomorfias que suportam o monofiletismo de Angiopolybia são: prestigma tão longo quanto largo (caráter 1, estado 1, Tabela 1), proepisterno com carena reduzida (caráter 10, estado 1), lamela escutal reduzida (caráter 11, estado 1), escutelo sem linha impressa (caráter 12, estado 1), fenda dorsal praticamente reta (caráter 13, estado 1) e área metapleural basalar achatada (caráter 14, estado 1). O monofiletismo do gênero é bem estabelecido. As quatro espécies possuem carena pronotal dorsal ausente lateralmente (caráter 7, estado 3), e, como salientado por Silveira \& Carpenter (1995), é agudamente prolongada na região central. Para A. pallens + A. zischkai é evanescente, mas, pelo fato de a carena estar ausente em Agelaia cajennensis, a otimização deste caráter é ambígua, e não se apresenta como uma sinapomorfia de Angiopolybia (Fig. 7).

Os clados A. pallens + A. zischkai e A. paraensis + A. obidensis já eram esperados. Richards (1978), sem uma perspectiva filogenética, citou similaridades para cada par, fazendo isso, também, em sua chave de identificação. Alguns dos caracteres, adicionados em sua chave, provaram ser sinapomorfias. Quatro caracteres suportam o clado $A$. paraensis + A. obidensis: ocelos acima da linha dos olhos (caráter 2, estado 1), olhos sem cerdas (caráter 4, estado 1), gena angulada na região inferior (caráter 5, estado 1), e segundo segmento metassomal tão longo quanto largo (caráter 15, estado 1). Nestas duas espécies o lobo lateral do clípeo não toca os olhos (caráter 3, estado 1), mas como Agelaia 
cajenennsis também apresenta este estado, a otimização para este caráter é ambígua. Uma sinapomorfia ambígua suporta o agrupamento de A. pallens + A. zischkai, a carena occipital evanescente na região inferior (caráter 6, estado 1; este caráter é ausente em A. pallens, mas não em A. zischkai como erroneamente citado por Richards). Ambas as espécies são similares por possuírem a carena pronotal dorsal reduzida a um mero traço (caráter 7, estado 2), mas como já citado, a otimização é ambígua por esta carena ser completamente ausente em Agelaia cajenennsis. Finalmente, a diferença diagnostica entre A. pallens e A. zischkai é a região anterior ventral pronunciada de A. pallens (caráter 8, estado 1), e entre A. paraensis e $A$. obidensis, é a margem anterior frontal amplamente lamelada em $A$. obidensis (caráter 9, estado 1). Ambas as características diagnósticas foram apresentadas na chave de Richards (1978).

Araujo (1946) argumentou que ninho com envelope já justificaria a separação de Angiopolybia e Agelaia. Como já citado, é óbvio que este caráter não justificaria os dois gêneros, uma vez que ninhos com envelope estãos presentes em algumas Agelaia. Mas os dados morfológicos deste trabalho apresentam seis sinapomorfias que suportam o gênero. Se mais espécies de Agelaia fossem incluídas, os caracteres que foram ambíguos poderiam dar um suporte adicional ao gênero e a interrelação entre suas espécies. No entanto, gruposexternos adicionais não afetariam a interpretação dos seis caracteres que suportam o gênero na presente análise, como Agelaia é invariante na condição plesiomórfica de caracteres como lamela escutal presente, escutelo com linha impressa, fenda dorsal obliqua, e área metapleural basalar pronunciada. Tendo definido o monofiletismo de Angiopolybia, podese questionar sobre o monofiletismo de Agelaia. Quais sinapomorfias suportariam o monofiletismo desse gênero? Nenhuma análise (Carpenter, 1991; Wenzel, 1993; Wenzel e 
Carpenter, 1994) teve sucesso em recuperar o monofiletismo de Agelaia e seguramente esta é uma área em aberto.

\section{5- CHAVE DE IDENTIFICAÇÃO PARA AS ESPÉCIES DE ANGIOPOLYBIA}

Na mais recente chave para o gênero feita por Richards (1978), alguns erros foram identificados e alguns caracteres eram ambíguos. Além disso, essa chave incluía várias variações morfológicas (denominadas “morphs” por Richards (1978) de A. paraensis, viz. ruficornis (Ducke) e obscurior (Bequaert), mas na verdade todas são sinônimos de $A$. paraensis. A chave aqui apresentada se baseia nos caracteres morfológicos utilizados na análise filogenética do gênero

1 Olhos com cerdas; gena pouco curvada na região inferior; espaço malar curto, clípeo com os lobos laterais tocando os olhos (Fig. 1A); ocelo acima da linha dos olhos (Fig. 1A); esclerito mesepisternal dorsal estreito (Fig. 2A); espécies pequenas, 10-13 mm

.

- Olhos sem cerdas; gena angulada na região inferior; espaço malar longo, clípeo com lobos laterais se estendendo abaixo do olhos mas não os tocando (Fig. 1B); ocelos abaixo da linha dos olhos (Fig. 1B); esclerito mesepisternal dorsal amplo (Fig. 2B);

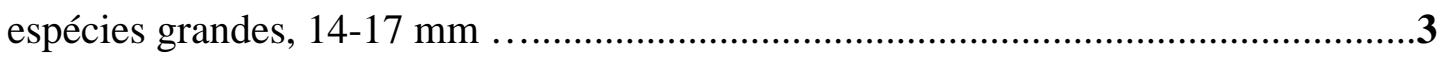

2 Região antero-inferior do pronoto, abaixo da fóvea pronotal, pouco ou não proeminente (Fig. 3A); carena occipital evanescente na região inferior; geralmente espécimes amarelados e enegrecidos zischkai Richards 
- Região antero-inferior do pronoto, abaixo da fóvea pronotal, proeminente (Fig. 3B); carena occipital ausente;espécimes amarelos claros, pálidas......... pallens (Lepeletier)

3 Pronoto com uma ampla lamela na margem da região frontal (Fig. 4A); amareladas, manchas pálidas ..................................................................... obidensis (Ducke)

- Pronoto com uma estreita lamela na margem da região frontal (Fig. 4B); amarelo escuro, manchas pálidas .......................................................... paraensis (Spinola) 
Tabela 1- Lista de caracteres para Angiopolybia

Caráter Estados

1. Prestigma: mais longo do que largo =0; tão longo quanto largo $=1$

2. Ocelos: acima da linha dos olhos $=0$ (Fig. 1A); em uma declividade, abaixo da linha dos olhos $=1$ (Fig. 1B)

3. Lobos laterais do clípeo: tocando os olhos = 0 (Fig. 1A); não tocando os olhos $=1$ (Fig. 1B)

4. Olhos: $\operatorname{com}$ cerdas $=0$ (Fig $1 \mathrm{~A})$; sem cerdas $=1$ (Fig. $1 \mathrm{~B})$

5. Gena: pouco curvada na região inferior $=0$; angulada na região inferior $=1$

6. Carena occipital: presente $=0$; evanescente na região inferior $=1$; ausente $=2$

7. Carena pronotal dorsal: estendendo-se lateralmente $=0$; mesal $=1$; traço $=2$; ausente $=3$

8. Região antero-inferior do pronoto, abaixo da fóvea pronotal: não proeminente =0; proeminente $=1$

9. Margem frontal do pronoto: com lamela estreita =0 (Fig. 4B); com lamela ampla = 1 (Fig. 4A)

10. Proepisterno: carinado lateralmente $=0$; carena reduzida $=1$

11. Lamela escutal: desenvolvida ao longo da tégula $=0$; reduzida $=1$

12. Escutelo: com linha impressa $=0$; sem linha impressa $=1$

13. Fenda mesepisternal dorsal: obliqua $=0$; praticamente reta $=1$

14. Área metapleural: proeminente $=0$; reta $=1$

15. Segundo segmento metassomal: mais longo do que largo = 0; tão longo quanto largo $=1$ 
Tabela 2 - Matriz de dados para Angiopolybia

\begin{tabular}{|c|c|c|c|c|c|c|c|c|c|c|c|c|c|c|c|}
\hline & 1 & 2 & 3 & 4 & 5 & 6 & 7 & 8 & 9 & 10 & 11 & 12 & 13 & 14 & 15 \\
\hline Apoica arborea & 0 & $\overline{0} 0$ & 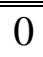 & 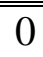 & 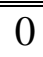 & 0 & 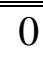 & 0 & 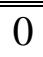 & 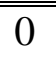 & 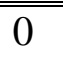 & 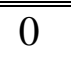 & 0 & 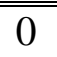 & 0 \\
\hline $\begin{array}{l}\text { Agelaia } \\
\text { cajennensis }\end{array}$ & 0 & 0 & 1 & 0 & 0 & 0 & 3 & 0 & 0 & 0 & 0 & 0 & 0 & 0 & 0 \\
\hline $\begin{array}{l}\text { Angiopolybia } \\
\text { pallens }\end{array}$ & 1 & 0 & 0 & 0 & 0 & 2 & 2 & 1 & 0 & 1 & 1 & 1 & 1 & 1 & 0 \\
\hline $\begin{array}{l}\text { Angiopolybia } \\
\text { zischkai }\end{array}$ & 1 & 0 & 0 & 0 & 0 & 1 & 2 & 0 & 0 & 1 & 1 & 1 & 1 & 1 & 0 \\
\hline $\begin{array}{l}\text { Angiopolybia } \\
\text { obidensis }\end{array}$ & 1 & 1 & 1 & 1 & 1 & 0 & 1 & 0 & 1 & 1 & 1 & 1 & 1 & 1 & 1 \\
\hline $\begin{array}{l}\text { Angiopolybia } \\
\text { paraensis }\end{array}$ & 1 & 1 & 1 & 1 & 1 & 0 & 1 & 0 & 0 & 1 & 1 & 1 & 1 & 1 & 1 \\
\hline
\end{tabular}



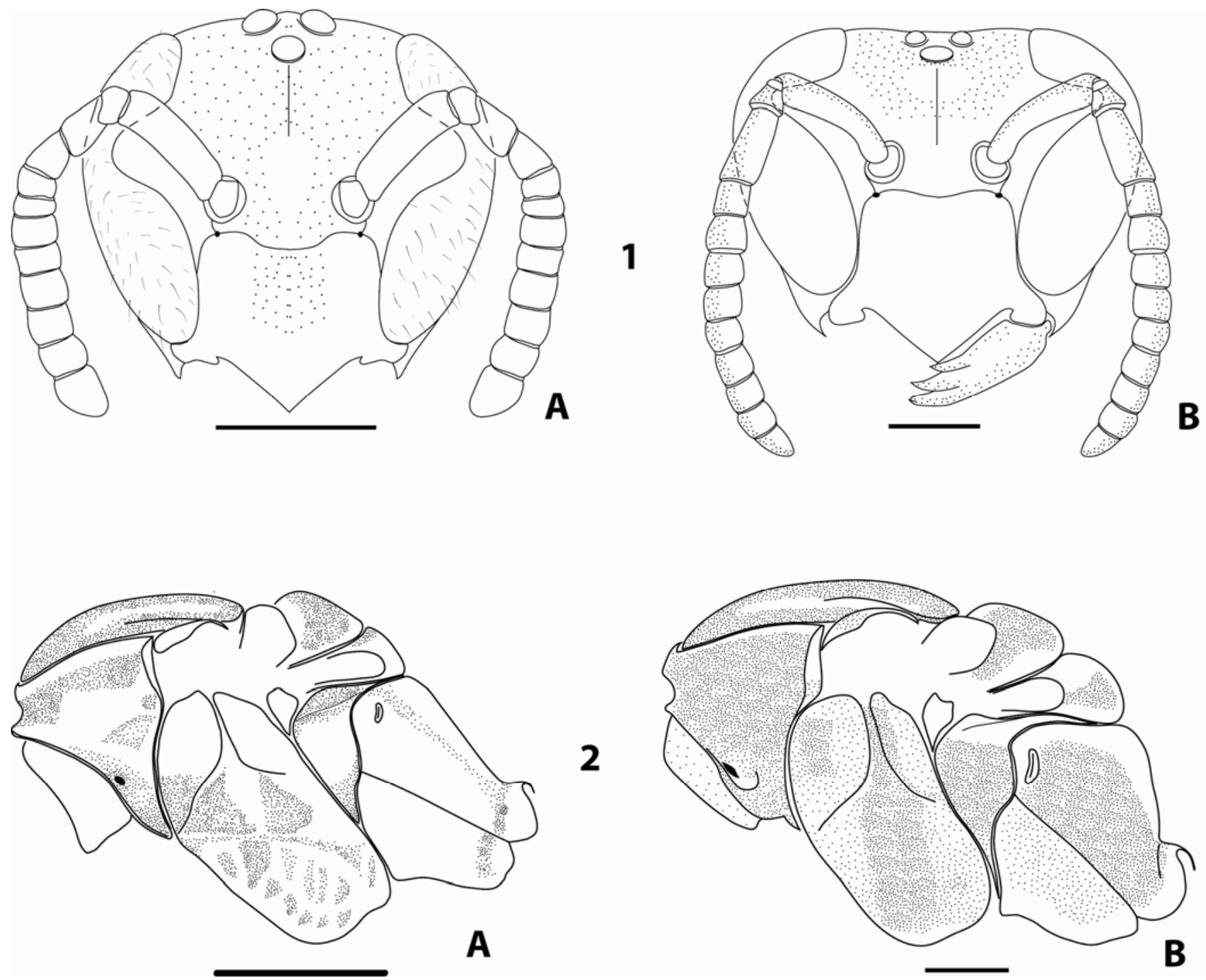

Figura 1 - Cabeça, visão frontal: $\mathbf{A}=$ Angiopolybia pallens. $\mathbf{B}=$ A. paraensis; Figura 2Metassoma, visão lateral: $\mathbf{A}=$ Angiopolybia pallens. $\mathbf{B}=$ A. obidensis. Escala $=1,0 \mathrm{~mm}$. 

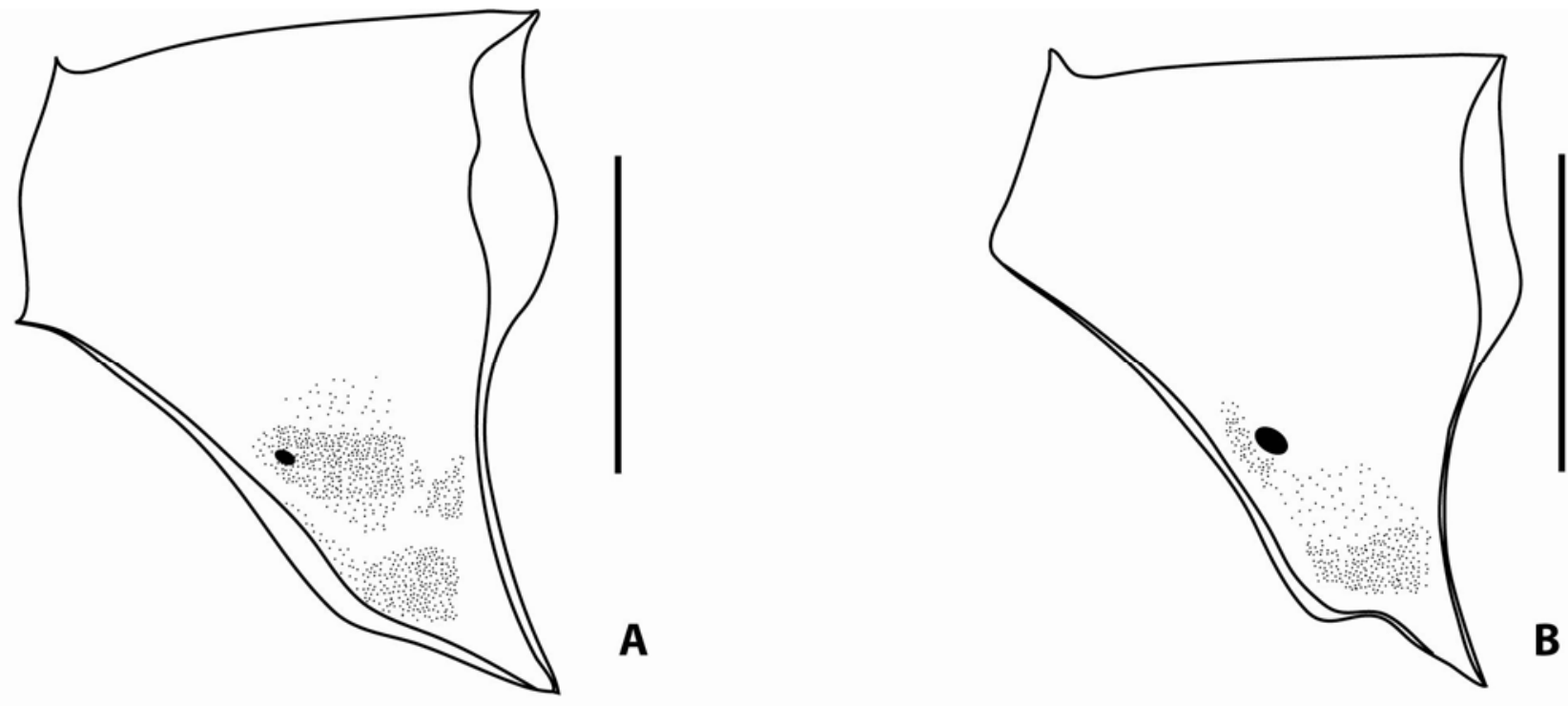

3

B
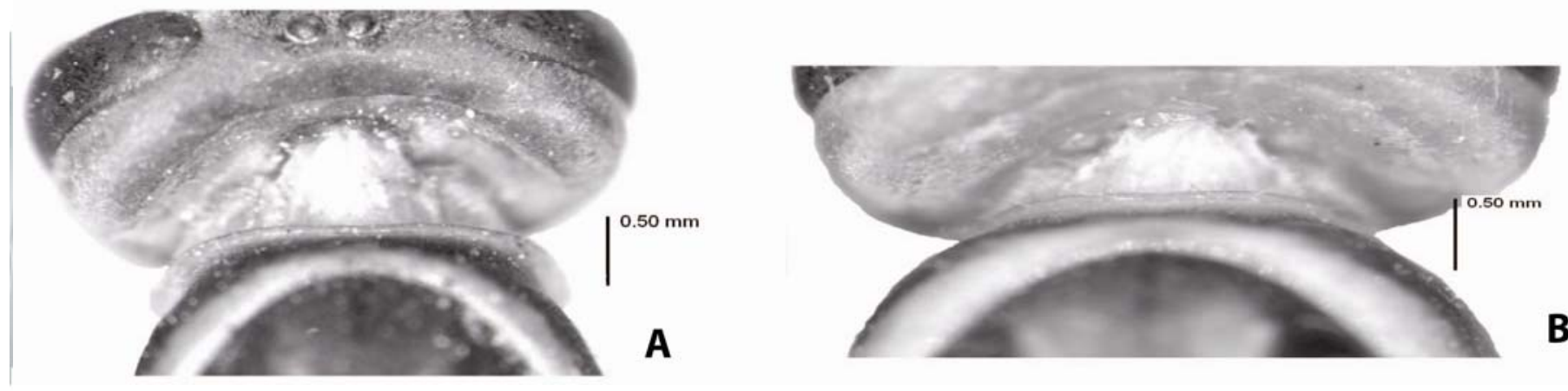

4

Figura 3 - Pronoto, visão lateral: A= Angiopolybia zischkai. $\mathbf{B}=$ A. pallens; Figura 4 Pronoto, visão dorsal: $\mathbf{A}=$ Angiopolybia obidensis. $\mathbf{B}=$ A. paraensis. Escala $=0,5 \mathrm{~mm}$. 

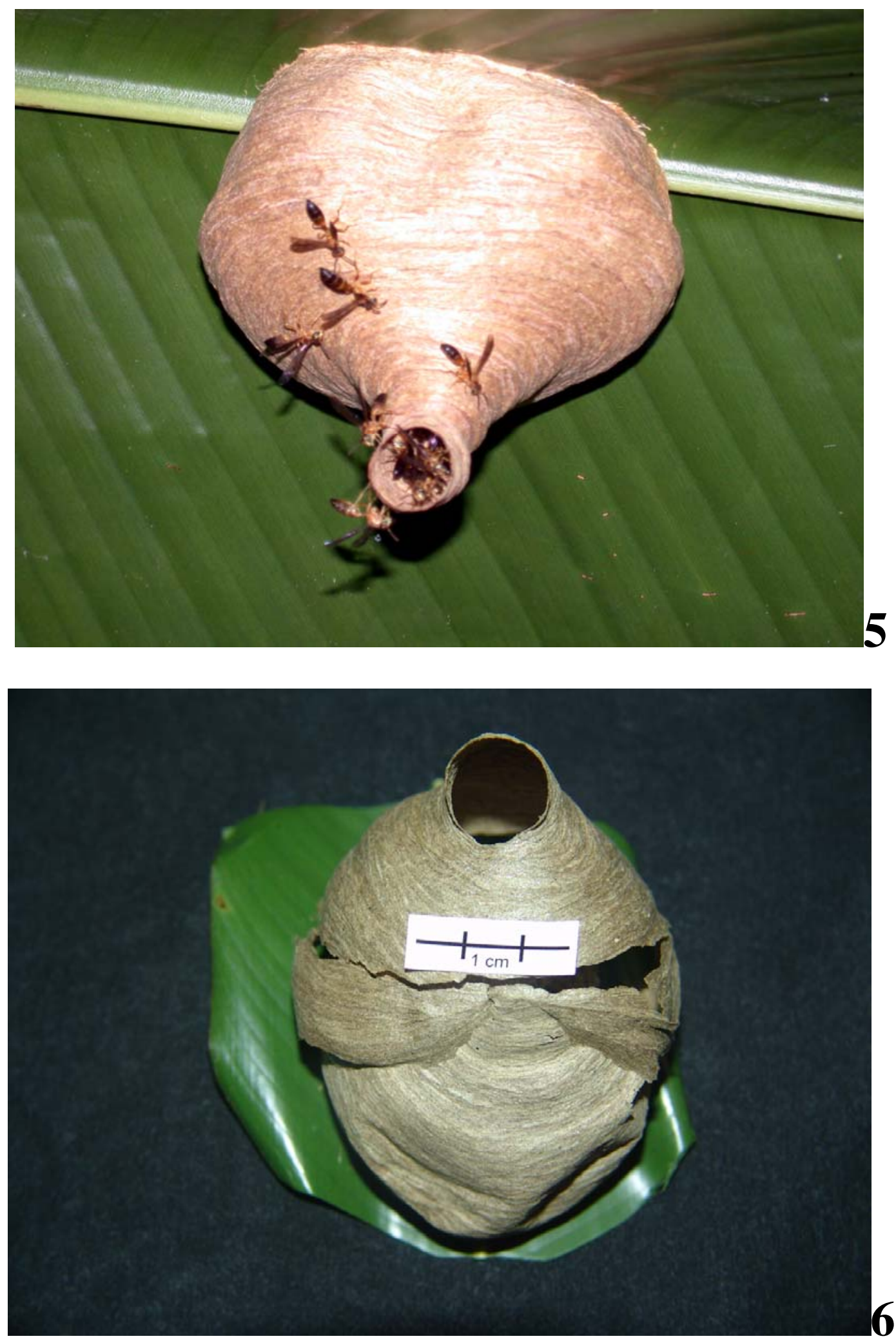

Figuras 5 e 6 - Ninho de Angiopolybia pallens, coletado em Presidente Figueiredo-AM, 2005. Fotos de Sidnei Mateus e Fernando B. Noll. 


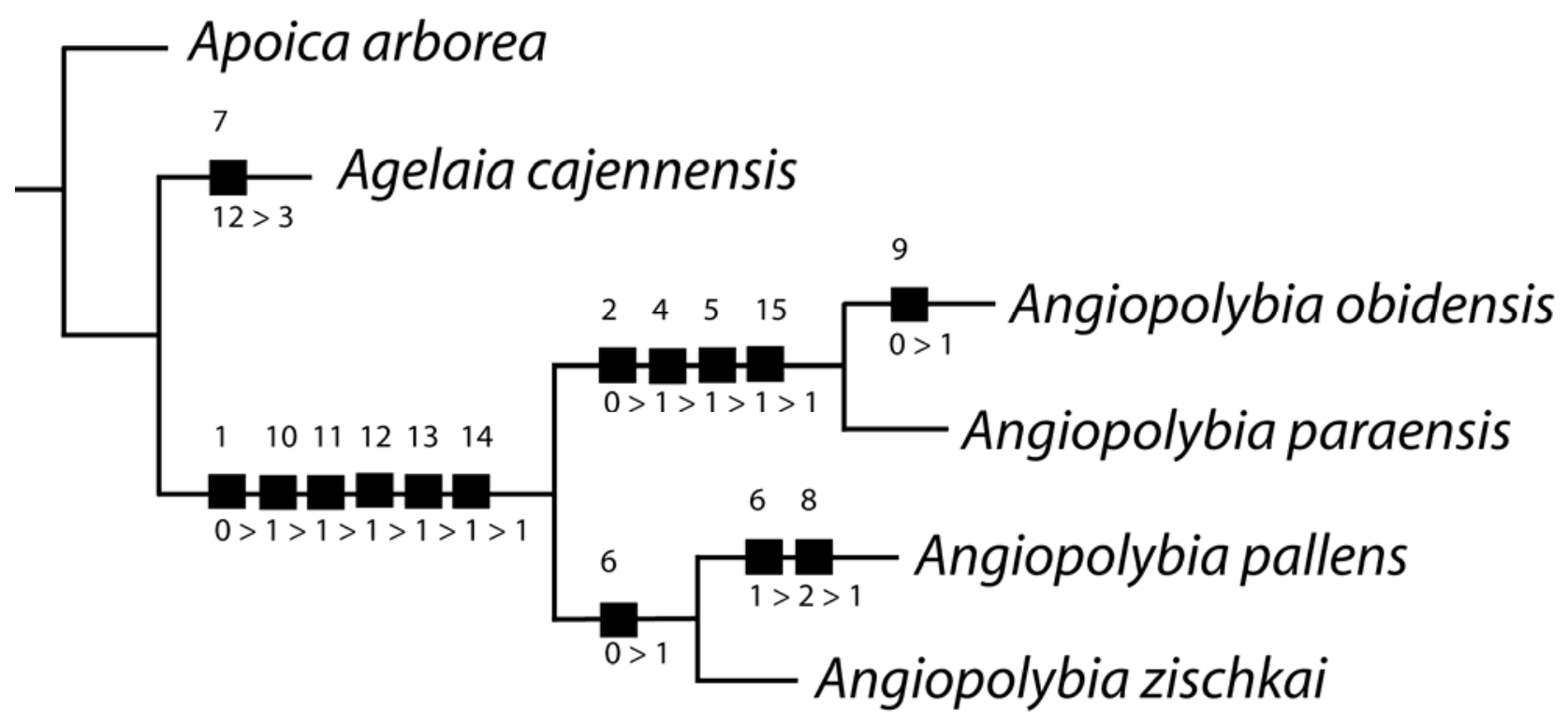

Figura 7 - Cladograma de Angiopolybia, com 20 passos, índice de consistência 0,90 e índice de retenção de 0,88; baseado na matriz de dados da Tabela 2. Somente caracteres não ambiguos estão plotados. O número de cada caráter está sobre os quadrados, enquanto que a transição de cada estado está abaixo, separado por “>.” 


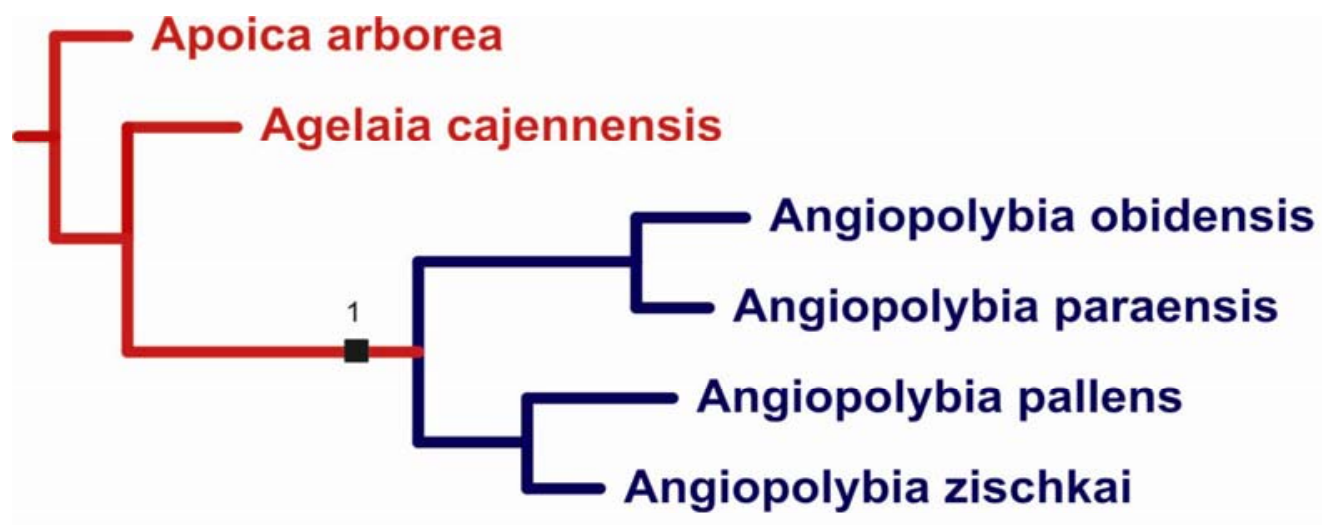

CHAR 1: Prestigma

$\mathrm{L}=1 \mathrm{Cl}=100 \mathrm{RI}=100$

$\square$ 0: longer than wide

1: about as long as wide

$\square$ Ambiguity
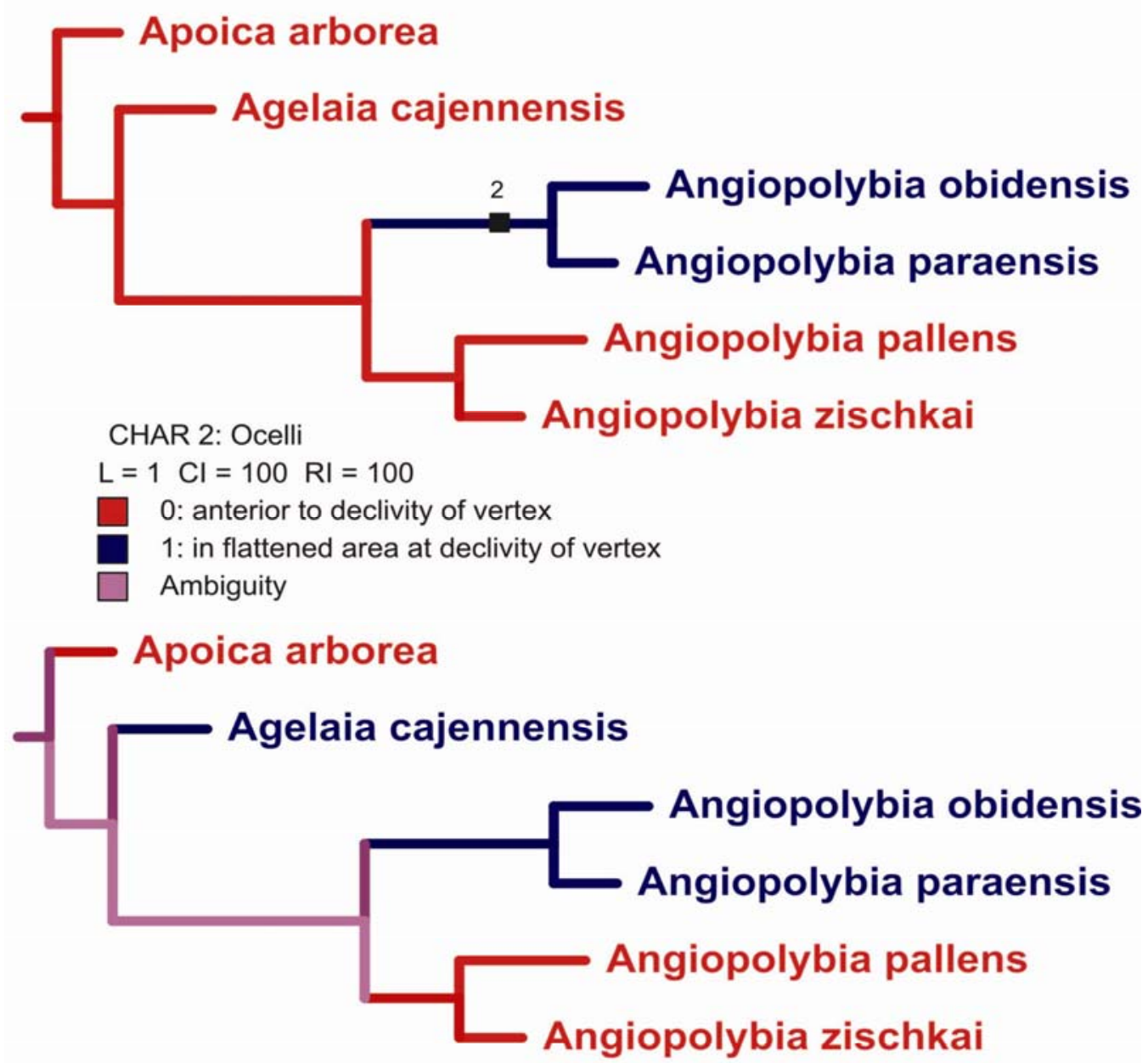

CHAR 3: Lateral clipeal lobes

$\mathrm{L}=2 \mathrm{Cl}=50 \mathrm{RI}=50$

$\square$ : touching the eyes

1: not touching the eyes

$\square$ Ambiguity

Figura 8 - Otimização dos caracteres 1, 2 e 3. 


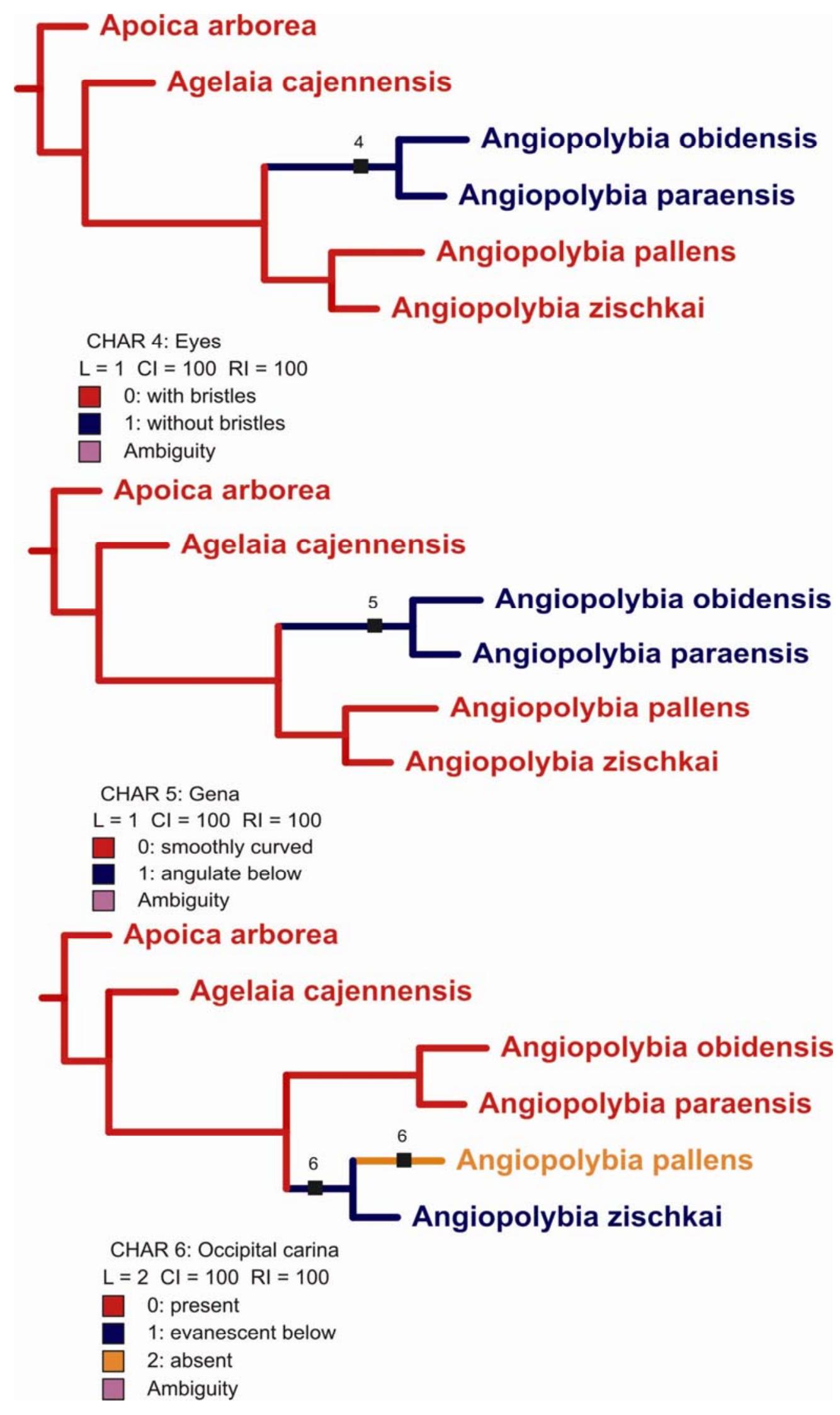

Figura 9 - Otimização dos caracteres 4, 5 e 6. 


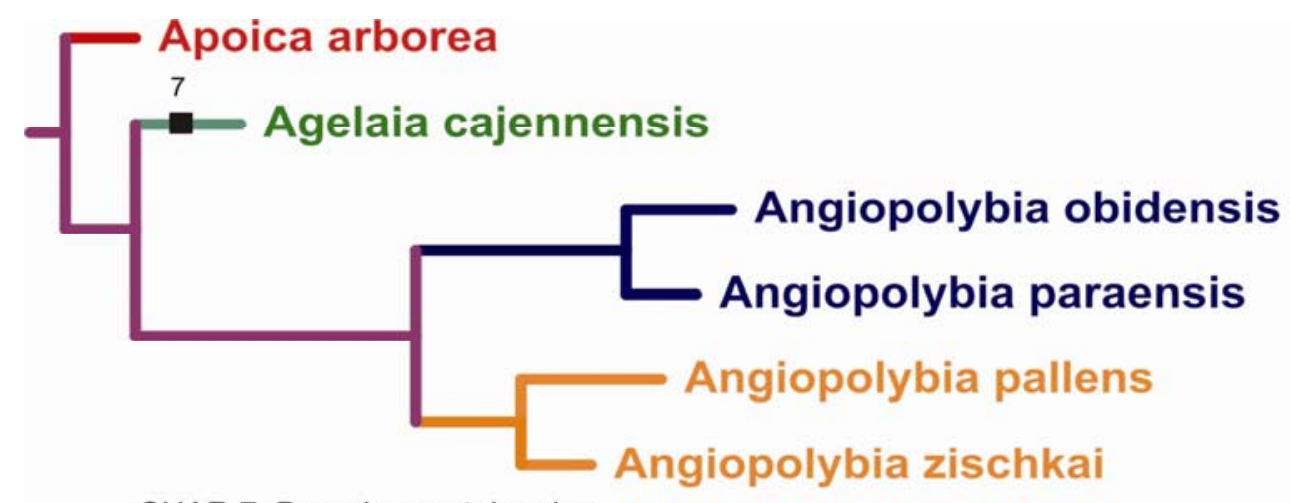

CHAR 7: Dorsal pronotal carina $\mathrm{L}=4 \mathrm{Cl}=75 \mathrm{RI}=50$

$\square$ 0: extending laterally

1: mesal

$\square$ 2: trace

$\square$ 3: absent

$\square$ Ambiguity

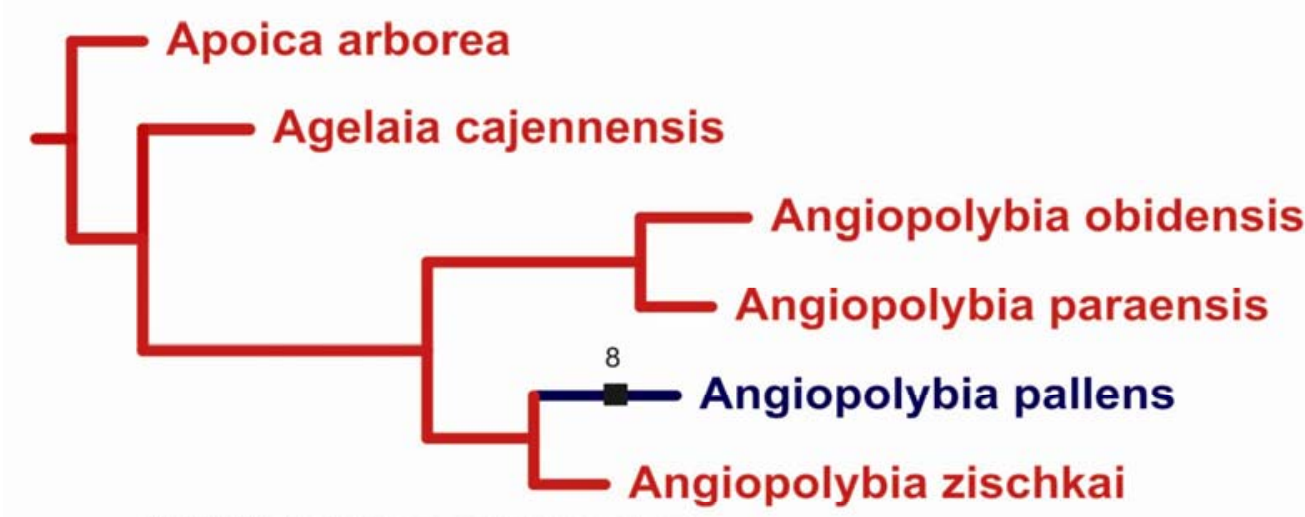

CHAR 8: Anterior corner of pronotum

$\mathrm{L}=1 \mathrm{UNINF}$

0: smooth

1: bulging

$\square$ Ambiguity

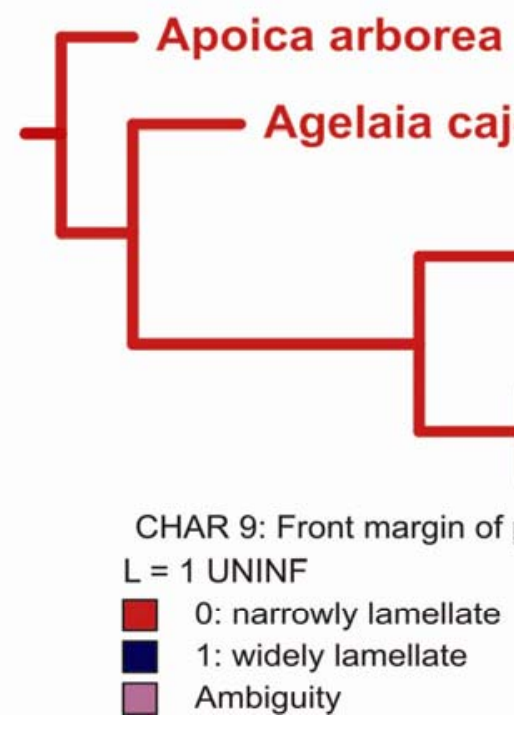

Figura 10 - Otimização dos caracteres 7, 8 e 9. 


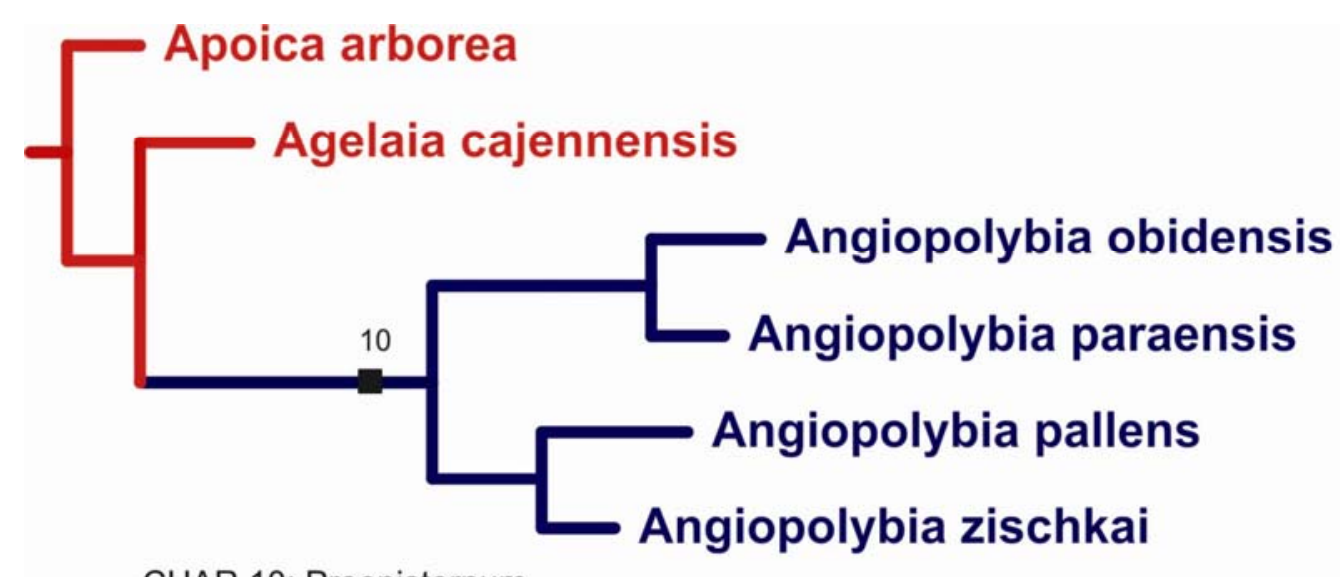

CHAR 10: Proepisternum

$\mathrm{L}=1 \mathrm{Cl}=100 \mathrm{RI}=100$

0 : carinate laterally

1: carina reduced

$\square$ Ambiguity

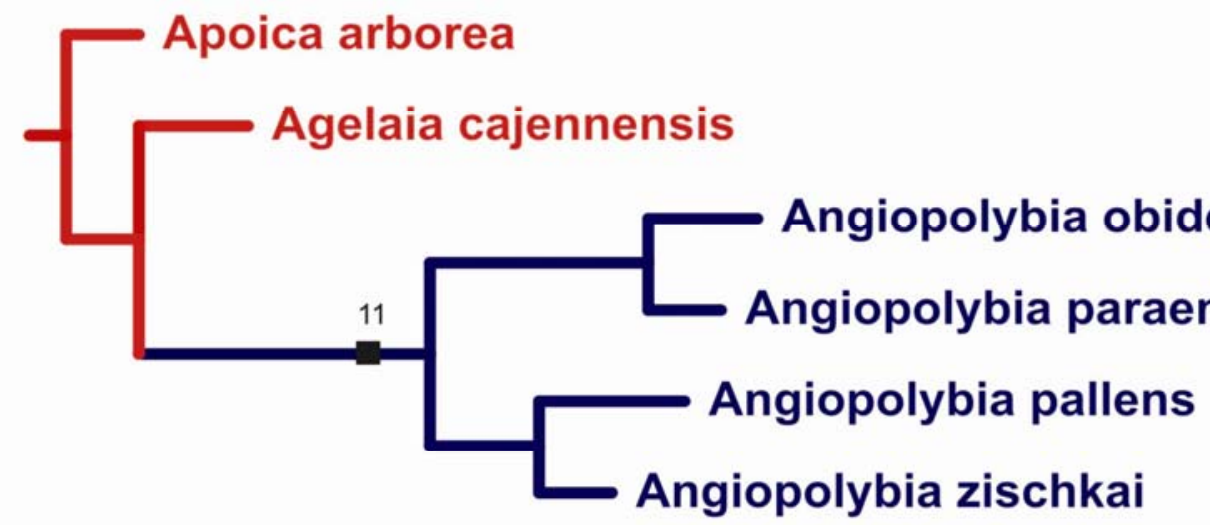

CHAR 11: Scutal lamella

$\mathrm{L}=1 \mathrm{Cl}=100 \mathrm{RI}=100$

$\square$ 0: developed adjoining tegula

1: reduced

Ambiguity

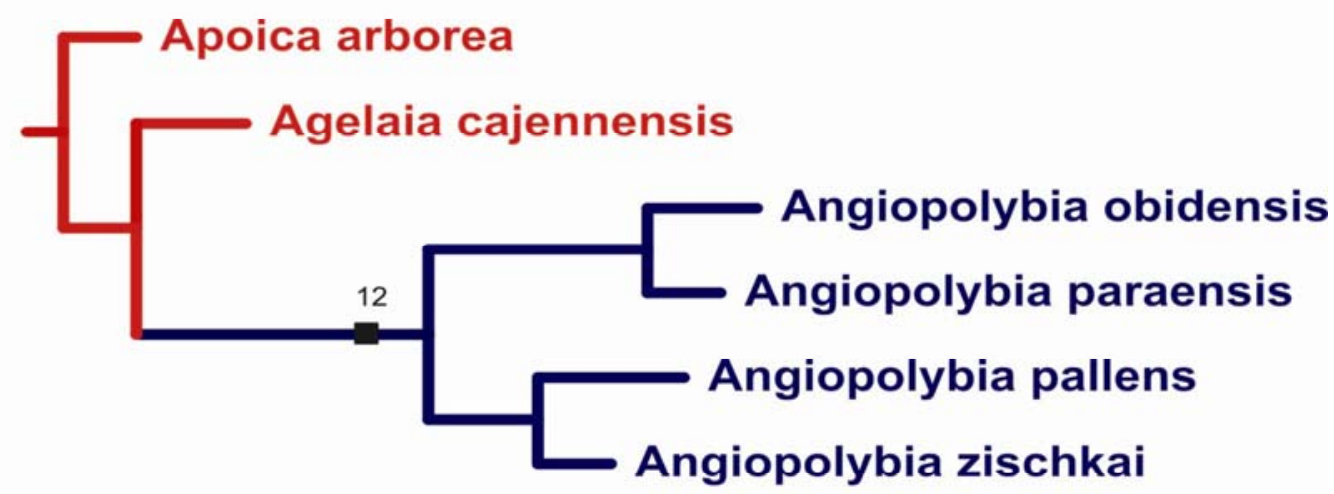

CHAR 12: Scutellum

$\mathrm{L}=1 \mathrm{Cl}=100 \mathrm{RI}=100$

0 : with impressed line

1: without impressed line

Ambiguity

Figura 11 - Otimização dos caracteres 10, 11 e 12. 


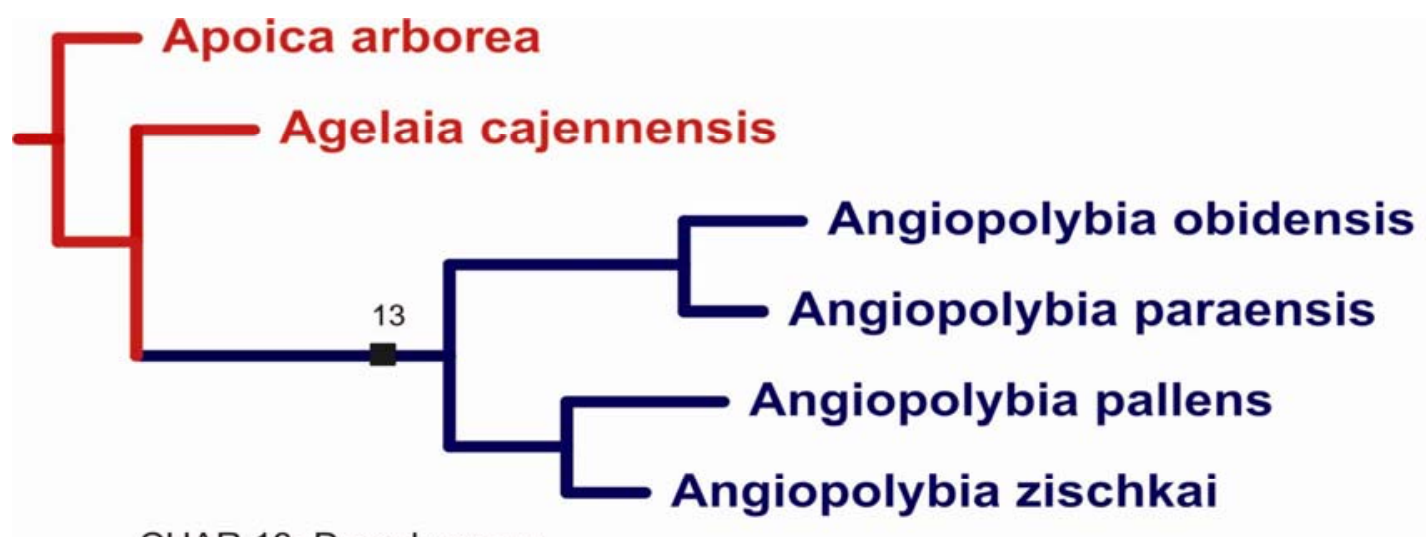

CHAR 13: Dorsal groove

$\mathrm{L}=1 \mathrm{Cl}=100 \mathrm{RI}=100$

$\square$ 0: oblique

1: practically straight

$\square$ Ambiguity

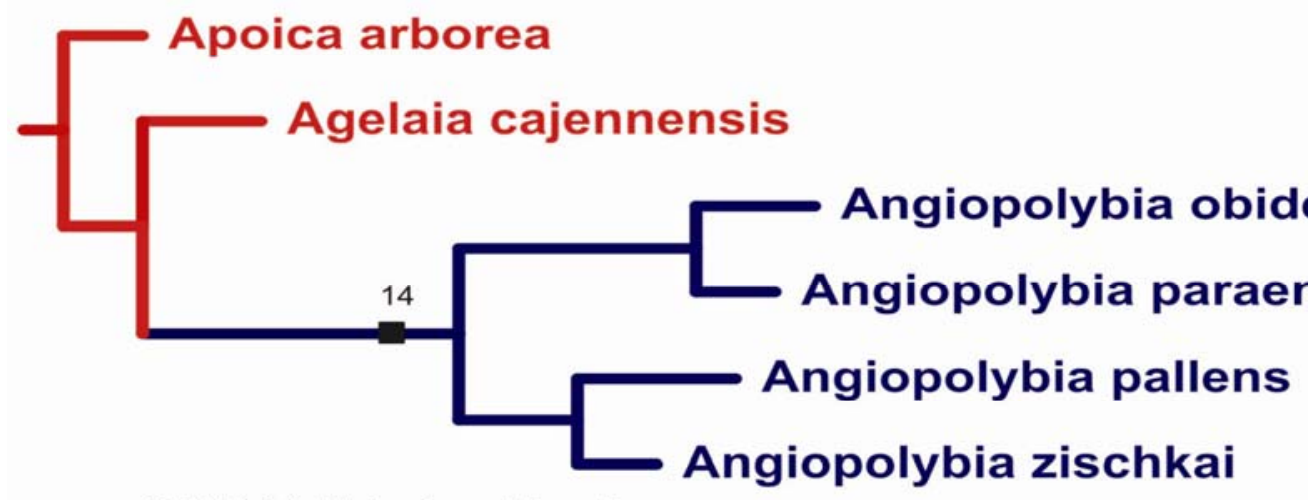

CHAR 14: Metapleural basalar area

$\mathrm{L}=1 \mathrm{Cl}=100 \mathrm{RI}=100$

$\square$ 0: raised, bulging

1: flat

Ambiguity

\section{Apoica arborea}

Agelaia cajennensis

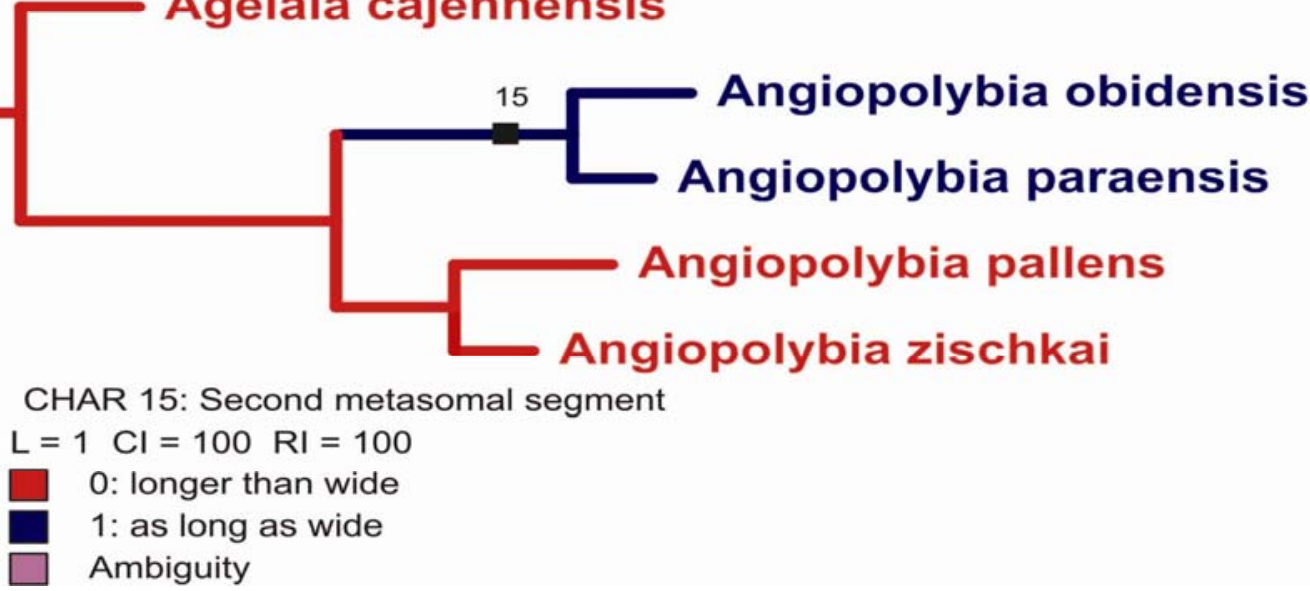

Figura 12 - Otimização dos caracteres 13, 14 e 15. 


\section{6 - REFERÊNCIAS}

Araujo, R.L. 1946. Angiopolybia Nom. N., para o conceito revalidado de "Steloplybia Ducke, 1914” (Hym. Vespidade. Polybiinae). Papeis Avulsos do Departamento de Zoologia, 7: 165-170.

Bequaert, J.C. 1918. A revision of the Vespidae of the Belgian Congo based on the collection of the American Museum Congo Expedition, with a list of Ethiopian diplopterous wasps. Bulletin of American Museum of Natural History, 39: 1-384.

Bequaert, J.C. 1944. The social Vespidae of the Guianas, particularly of British Guiana. Bulletin of the Museum of Compative Zoology, 94: 249-300.

Buysson, R. du. 1906. Monographie de Vespides appartenant aux genres Apoica et Synoeca. Annales de la Société Entomologique de France, 75: 333-362.

Carpenter, J.M. 1991. Phylogenetic relationships and the origin of social behavior in the Vespidae. In: K.G. Ross \& R.W. Matthews (eds), The social biology of wasps. Cornell University Press, Ithaca, New York,pp. 7-32.

Carpenter, J.M. \& Day, M.C. 1988. Nomenclatural notes on Polistinae (Hymenoptera: Vespidae). Proceedings of the Entomological Society of Washington, 90: 323-328.

Ducke, A. 1910. Révision des guêpes sociales polygames d'Amérique. Annales Historico-Naturalies Musei Nationalis Hungarici, 8: 449-544.

Ducke, A. 1913. Zur Synonymie einiger Hymenopteren. Deutsche Entomologische Zeitschrift, 330-333.

Ducke, A. 1914. Über Phylogenie und Klassification der sozialen Vespiden. Zoologische Jahrbuecher-Abteilung für Systematik, Ockologie und Geographic der Tiere, 36: 303-330.

Guérin-Meneville, F.E. 1831/1838. Crustacees, Arachnides et Insects. In : L. I. Duperrey, Voyage autour du monde sur la Coquille (1882-25). Zoologie 2 (2), div. 1. Paris, 319 pp., 22 col. pls. (1831: pls. 8 and 9, with figures of Hymenoptera; 1838: text of vol. 2, pt. 2).

International Commission on Zoological Nomenclature. 1976. Opinion 1051. Rhopalidia Lepeletier, 1836 (Insecta: Hymenoptera): Suppressed under the plenary powers. Bulletin of Zooogical. Nomenclature, 32: 240-241.

Lepeletier de St. Fargeau, A.L.M. 1836. Histoire Naturelle des Insectes. Hyménoptères, 1. Roret’s Suites à Buffon, Paris.

Lucas, R. 1912. Hymenoptera für 1910. Jahresbericht Archive Naturgesch, 77: 1-325.

Nixon, K.C. \& Carpenter, J.M. 1993. On outgroups. Cladistics, 9, 413-426. 
Noll, F.B., Wenzel, J. W \& Zucchi, R. 2004. Evolution of Caste in Neotropical SwarmFounding Wasps (Hymenoptera: Vespidae; Epiponini). American Museum Novitates, 24 pp.

Richards, O.W. 1943. A new species of Gymnopolybia Ducke (Hymen., Vespidae). Proceedings of the Royal Entomological Society of London, 12: 45-49.

Richards, O.W. 1973. Rhopalidia Lepeletier, 1836 (Hymenoptera: Vespidae): proposed suppression under the plenary powers. Z. N. (S) 2017. Bulletin of Zoological Nomenclature, 30: 49-50.

Richards O.W. 1978. The social wasps of the Americas excluding the Vespinae. London British Museum (Natural History), 580 pp.

Saussure, H.de. 1853-58. Monographie des Guêpes Sociales ou de la Tribu des Vespiens. Masson, Paris, and J. Cherbuliez, Genève. [1-96, 1853; 97-256, 1854].

Schulz, W.A. 1912. Aelteste und alte Hymenopteren skandinavischer Autoren. Berliner Entomologische Zeitschrift, 57: 52-102.

Silveira, O.T. \& Carpenter, J.M. 1995. A new species of Agelaia from Brasilian Amazonia (Hymenoptera: Vespidae; Polistinae). Journal of the New York Entomological Society, 103: 69-72.

Wenzel, J.W. 1993 Application of the biogenetic law to behavioral ontogeny: a test using nest architecture in paper wasps. Journal of Evolutionary Biology, 6: 229-247.

Wenzel, J.W. 1998. A generic key to the nests of hornets, yellowjackets, ande paper wasps worldwide (Vespidae: Vespinae, Polistinae). American Museum Novitates, 3224: 39 pp.

Wenzel, J.W. \& Carpenter, J. M. 1994. Comparing methods: adaptative traits and tests of adaptation In: P. Eggleton, \& R. Vane-Wright (eds.), Phylogenetics and Ecology. Academis Press, London, pp 79-101. 
Apêndice 1 - Localidades dos exemplares de Angiopolybia examinados

A. pallens- Brasil (Acre - Rio Branco. Amapá - Br 156 km14; Serra do Navio. Amazonas - Alvarães; Mamirauá; Marajó P. Pedras. Bahia - Parque Nacional Monte Pascoal. Pará - Acará, Ilha Cambu; Belém; Benevides; Caxinauã; Garofire; Itaituba, Parque Nacional da Amazônia; Ilha Jatuba; Jambuaçu; Melgaço; Ourém; Santarém; Serra Norte; Tapajós; Tucuruí, Rio Tocantins; Xingu; Vigia). Colômbia (Caquetá). Peru (Tingo Maria). San Ramon (Valle Chanchamayo). Trinidad (Porto de Espanha). Venezuela (localidade não especificada).

A. zischkai- Equador (Zumbi- Rio Zamora [incluindo o Holotipo] ${ }^{1}$ ). Panamá (Gamboa e Zumbi). Peru (Vale San Ramon).

A. paraensis- Brasil (Acre - Porto Acre. Amapá - Serra do Navio. Amazonas Alvarães; Itaquatiara, Rio Urubu; Maraã, Rio Japurá; São Gabriel. Pará - Bajarú; Barreirinha; Belém; Benevides; Caxinauã; Flona Tapajós; Ipixuna; Melgaço; Mocambo; Ourém; Rio Tapajós; Tucuruí, Rio Tocantins; Serra Norte; Utinga. Rondônia - Rio Janari. Maranhão - Imperatriz, Colômbia (Rio Caquetá). Peru (Avispas-Madre de Dios).

A. obidensis- Brasil (Amazonas - Içá; Estirão do Equador; Japurá; Manaus. Mato Grosso - Chapada dos Guimarães. Pará - Barreirinha; Belém; Oyapoque; Obidos). Guiana Britânica (localidade não especificada). Suriname (localidade não especificada).

${ }^{1} \mathrm{O}$ Holotipo de $A$. zischkai está depositado no AMNH, não no U.S. National Museum, como erroneamente citado por Richards (1978) (ver Carpenter, 1999). 


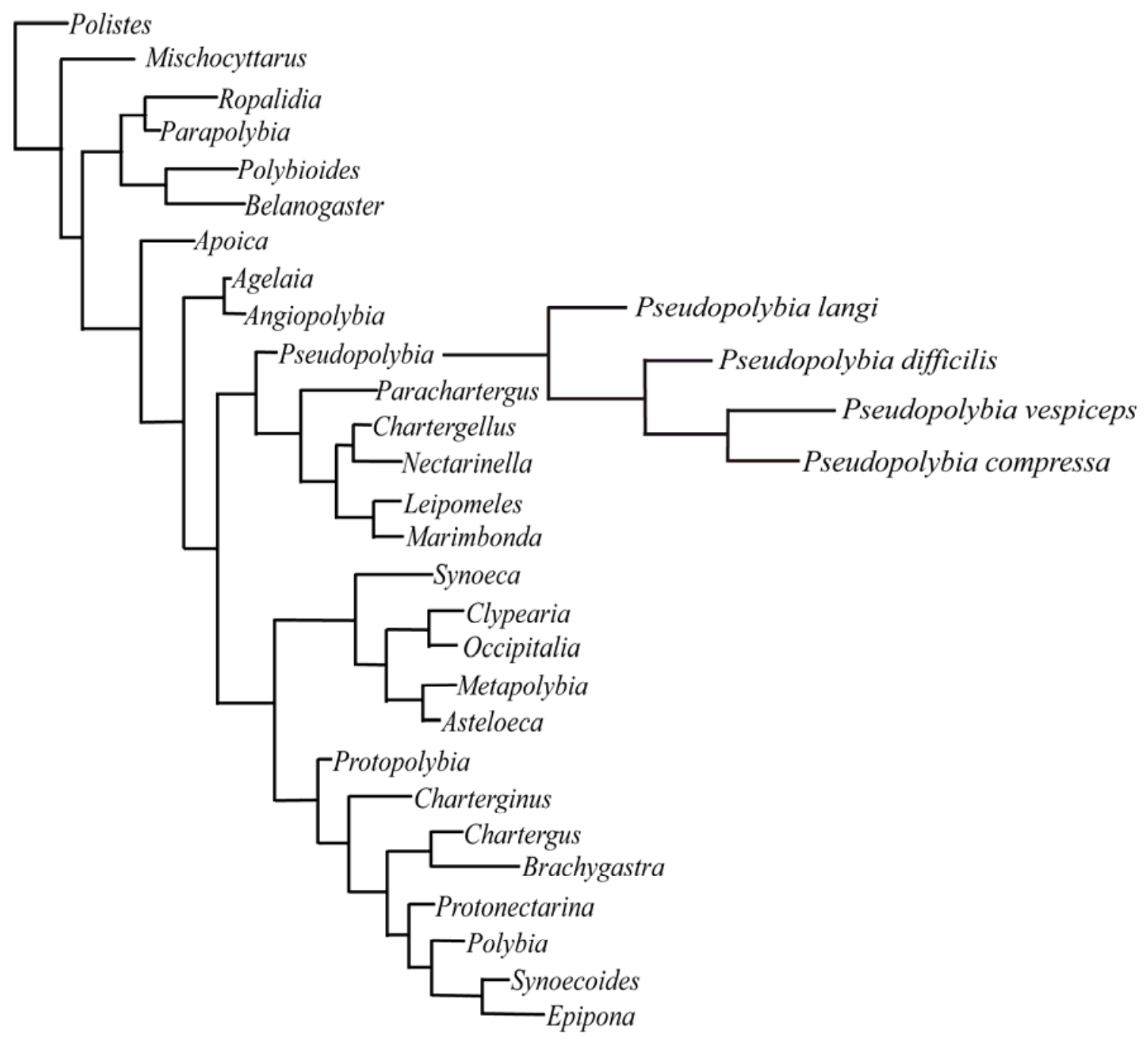

Capítulo 2 - Análise Filogenética do Gênero

Pseudopolybia de Saussure, 1863, com a

Descrição da Genitália do Macho de

Pseudopolybia vespiceps (Hymenoptera:

Vespidae, Epiponini) 


\section{Capítulo 2 - Análise Filogenética do Gênero Pseudopolybia de Saussure, 1863, com a Descrição da Genitália do Macho de Pseudopolybia vespiceps (Hymenoptera: Vespidae, Epiponini)}

\section{1- INTRODUÇÃO}

Pseudopolybia é um gênero de vespas enxameadoras da região Neotropical, reconhecida pelo terceiro segmento labial com uma pequena e forte cerda curvada próximo ao ápice, e com a fórmula palpal 6:4 (seis segmentos maxilares e quatro labiais) (Richards, 1978). O gênero é representado por somente quato espécies que se distribuem desde a Nicarágua até o sul do Brasil, sendo encontradas principalmente em florestas úmidas (Hanson \& Gauld, 1995; Richards \& Richards, 1951; Richards, 1978).

Apesar de somente ter quatro espécies, existem vários problemas taxonômicos, uma vez que tanto $P$. compressa e $P$. vespiceps são similares e apresentam, respectivamente, "variedades” de forma e cor, parecendo, em alguns aspectos, não terem diferenças estruturais (Richards, 1978: 224). Na mais recente revisão, Richards (1978) tratou estas variantes como "morphs": P. compressa possui as variedades compressa, luctuosa e laticincta, e Pseudopolybia vespiceps as variedades vespiceps e testacea. Estes nomes haviam sido descritos primeiramente como espécies distintas ou variedades, posteriormente sendo reduzidas somente a variedades das respectivas espécies (Bequaert, 1938) e agora são consideradas sinônimos, uma vez que o termo “morph” não apresenta validade taxonômica.

Os ninhos de Pseudopolybia são geralmente arbóreos, com um pedicelo fibroso e células marginais (Wenzel, 1998). Cada favo é posicionado um abaixo do outro normalmente por um único pecíolo central, podendo haver alguns pecíolos adicionais 
(Richards, 1978). O envelope esférico não está em contato com os favos. A entrada é simples e se posiciona na região mais inferior do envelope. O ninho de $P$. langi já havia sido mencionado na literatura, proveniente da Guiana Francesa, por Dejean et al. (1998), e o exemplar encontra-se na coleção do “American Museum of Natural History” (AMNH). Este é um ninho não totalmente formado, arbóreo, com um único favo, faltando o envelope e preso ao substrato (uma folha) pelo pedicelo. Um ninho mais completo foi encontrado no estado do Amapá, Brasil, por Orlando Tobias Silveira (Museu Paraense Emílio Goeldi), que nos cedeu uma foto deste exemplar. Este ninho também estava danificado, mas, aspectos essenciais da arquitetura são visíveis (Fig. 4): o ninho consiste de vários favos presos ao substrato (folha); um envelope que não está em contato com os favos, formado por uma camada simples, sem uma entrada aparente. Na "ausência de forma” do envelope, P. langi é primitivo em relação a outras espécies do gênero, uma regra também para outros caracteres como será visto mais adiante.

Carpenter \& Mateus (2004) apresentaram a primeira descrição detalhada da genitália de macho de Pseudopolybia e gêneros relacionados (veja também Charnley, 1973). Provavelmente devido à pequena produção de machos em vespas sociais (Jeanne, 1991), poucos trabalhos têm sido publicados a respeito. Caracteres de macho parecem ser importantes na investigação filogenética, e não tem sido bem explorados nos Polistinae (Carpenter, 1991; Wenzel \& Carpenter, 1994). Neste trabalho, uma análise filogenética de Pseudopolybia usando dados de genitália de macho, além de outros caracteres morfológicos utilizados, é proposta. 


\section{2- MATERIAIS E MÉTODOS}

Os espécimes foram obtidos do Museu Paraense Emilio Goeldi, Belém, Pará, Brasil (MPEG), Museu de Zoologia da Universidade de São Paulo, São Paulo, Brasil, (MZUSP), Universidade Federal do Paraná, Curitiba, Paraná, Brasil (UFPR), e Instituto de “Investigación de Recursos Biológicos Alexander Von Humboldt”, Bogotá, Colômbia (IIRBAVH). Material adicional foi examinado na coleção de Hymenoptera do Instituto Nacional de Pesquisas da Amazônia, Manaus, Amazonas, Brasil (INPA). A localidade dos exemplares analisados encontra-se do apêndice 1.

As espécies dissecadas e ilustradas por Carpenter \& Mateus (2004) foram utilizadas no presente estudo. Machos de Agelaia cajennensis (Guyane: Promenades St. Jean-duMaroni), Parachartergus fraternus (Peru: San Ramon - Valle Chanchamayo) e Pseudopolybia vespiceps (Brasil: S. Paulo) foram mantidos em câmara úmida para relaxamento e a genitália extraída. A cápsula genital foi clareada em lactofenol e examinada imersa em glicerina. A genitália destes táxons está ilustrada na Fig. 3; os espécimes foram depositados no “American Museum of Natural History” (AMNH). Figuras das genitálias de Apoica gelida e Angiopolybia pallens (ambas de Trinidad: Arima Valley), doadas a James M. Carpenter por J. van der Vecht, também foram examinadas. Os caracteres de ninho foram extraídos de Wenzel (1998).

Vinte caracteres morfológicos de fêmeas, seis de genitália de macho e três de ninho foram plotados em uma matriz de dados para a reconstrução filogenética das espécies de Pseudopolybia (Tabela 2). Os caracteres utilizados e seus respectivos estados estão listados na Tabela 1, e parcialmente ilustrados nas Figuras 1-3. Caracteres com múltiplos estados foram tratados como não aditivos, exceto os caracteres 16 e 27, nos quais as evidências da série de transformação foram observadas. Os caracteres foram polarizados pelo 
enraizamento dos grupos-externos (Nixon \& Carpenter, 1993) Apoica, Agelaia, e Angiopolybia, bem como outros quatro gêneros que possuem cerda curvada no ápice do palpo labial: Chartergellus, Leipomeles, Nectarinella e Parachartergus.

\section{3- RESULTADOS E DISCUSSÃO}

As Figuras da genitália de macho de $P$. compressa e $P$. difficilis foram publicadas por Carpenter \& Mateus (2004: Figs. 8-9). A genitália de macho de $P$. vespiceps está ilustrada na Fig. 3. Machos de P. vespiceps foram descritos por Richards (1978) como sendo similar às fêmeas, mas mais amarelados, cabeça quase que inteiramente amarela, exceto a parte superior da fronte, antena enegrecida na região superior e amarelada na região inferior, mesossoma com pequenas manchas amareladas, e metassoma marrom escurecido. O clípeo também possui pêlos prateados, e a gena estreita (tipicamente, a maioria dos machos de Epiponini, incluindo Pseudopolybia, tem pêlos prateados no clípeo, gena estreita, além de um artículo antenal extra e também o sétimo segmento metassomal achatado). Foi observado que alguns espécimens de $P$. vespiceps possuem a antena completamente marrom escura ou amarelada, o que pode indicar uma variação regional. Os machos de P. vespiceps (Fig. 3) possuem Pêlos numerosos e longoes no espinho do parâmero; ângulo basal do parâmero obtuso; ângulo apical do parâmero amplo; processo ventral do edeago pequeno e angular; digito apicalmente pontiagudo; e o processo basal do digito presente. Aparentemente esta espécie possui menos pêlos no parâmero do que outras espécies de Pseudopolybia (Fig. 3; v. tb. Carpenter \& Mateus: figs. 8-9), enquanto que o digito pontiagudo coloca esta espécie mais próxima de $P$. compressa, que também possui essa característica, de $P$. difficilis (ver discussão abaixo). 
A análise da matriz resultou em um único cladograma (Fig. 7), com 56 passos, índice de consistência 0,64, e índice de retenção 0,70. Pseudopolybia se mantém como um grupo monofilético, sendo a relação entre as espécies: $P$. langi $+(P$. difficilis $(P$. vespiceps + P. compressa)).

Segundo estudos anteriores (Carpenter, 1991; Wenzel \& Carpenter, 1994), o terceiro palpômero labial com uma cerda curvada (caráter 1, estado 1; ver lista de caracteres) é apomórfico para o clado Pseudopolybia + (Leipomeles + (Parachartergus + $\left(\right.$ Nectarinella + Chartergellus))), também encontrado em nossos resultados (Fig. 7). ${ }^{1} \mathrm{~A}$ perda da carena occipital (caráter 10, estado 1) é a condição derivada encontrada em Nectarinella, Chartergellus e todas as espécies de Pseudopolybia com, provavelmente, duas origens independentes (Fig. 7). Em análises prévias esse caráter era somente sinapomórfico para Pseudopolybia. Neste estudo a concavidade propodeal ampla e rasa (caráter 17, estado 1) é uma sinapomorfia adicional para Pseudopolybia. Outros caracteres podem ser sinapomorfias potenciais para Pseudopolybia, mas como a genitália do macho de $P$. langi é desconhecida, a otimização destes caracteres é ambígua (Fig. 7).

Richards (1978) posiciona Chartergellus, Leipomeles, Parachartergus e Pseudopolybia em um grupo com longas cerdas no espinho do parâmero (caráter 21, estado 2) mas, como salientado por Carpenter \& Mateus (2004), esta é uma característica exclusiva de Pseudopolybia. Na verdade, Parachartergus fraternus (Fig. 3), P. apicalis e P. griseus (ver Carpenter \& Mateus, 2004: figs. 6-7) possuem cerdas, mas pequenas e menos numerosas que em Pseudopolybia, como também salientado por Carpenter \& Mateus (2004).

\footnotetext{
1 Note que a relação entre os cinco gêneros difere da topologia de Wenzel \& Carpenter (1994), o qual apresenta Pseudopolybia + (Parachartergus + (Leipomeles + (Chartergellus + Nectarinella) $))$. Tanto em Wenzel \& Carpenter (1994) quanto no presente estudo Pseudopolybia é o gênero mais basal. Devido à baixa amostragem das espécies do grupo externo, vamos declinar a discussão desses gêneros.
} 
Pseudopolybia vespiceps possui menos cerdas que $P$. difficilis e $P$. compressa, mas claramente apresenta cerdas longas (Fig. 3). Por não haver a descrição da genitália de macho de $P$. langi, não fica claro se o estado “cerdas longas e numerosas” é sinapomórfico para Pseudopolybia como um todo, ou somente para o clado P. difficilis $+(P$. vespiceps $+P$. compressa). O estado “cerdas curtas” é possivelmente sinapomórfico para Parachartergus (Fig. 7). Carpenter \& Mateus (2004: 298) consideraram o estado "cerdas no espinho do parâmero" com polaridade incerta, pontuando que "Study of additional genera besides those considered here is required to settle this.” Em nossos resultados (Fig. 7), que incluem três outros gêneros além daqueles estudados por Carpenter \& Mateus (2004), o estado plesiomórfico é “cerdas ausentes”, o que pode ser a condição encontrada nos grupos mais basais de Epiponini. Desta forma a perda de cerdas não pode suportar o grupo-irmão de Pseudopolybia, os quais perderam o quarto palpômero labial (caráter 2, estado 1), como sugerido por Carpenter \& Mateus (1994). Nós podemos concluir que diferentes tipos de “cerdas no espinho do parâmero” tiveram origens independentes em Pseudopolybia e Parachartergus.

Segundo Carpenter \& Mateus (2004) o processo ventral do edeago muito estreito, reduzido quase formando um gancho (caráter 24, estado 1), presente na maioria destes gêneros, contrasta com um processo ventral do edeago pequeno e angular (caráter 24, estado 0) em Pseudopolybia - mas também é encontrado em Chartergellus. Se o formato reduzido e estreito é apomórfico, então Chartergellus apresenta uma reversão ou está mal posicionado (Carpenter \& Mateus, 2004). Como P. langi não foi observada, o formato do processo ventral do edeago é ambíguo em nosso cladograma (Fig. 15), mas a condição apomórfica (estreita, reduzida) é encontrada em Angiopolybia, Leipomeles, Parachartergus 
e Nectarinella. Se assumirmos que $P$. langi tem o processo ventral do edeago pequeno, angular, como em outras espécies de Pseudopolybia e Chartergellus, ou não, a otimização do caráter indica duas aquisições independentes para o estado pequeno angular.

O formato do digito (caráter 25) é variável em Pseudopolybia. P.compressa e $P$. vespiceps têm o digito pontiagudo apicalmente; também pontiagudo em Nectarinella e Chartergellus; e arredondado no restante dos taxa estudados. Segundo Carpenter \& Mateus (2004) este não é um padrão fácil de interpretar. Em nossas análises, este caráter é homoplástico, mas suporta o clado $P$. compressa $+P$. vespiceps, com origem independente em Nectarinella + Chartergellus.

O ângulo basal do parâmero agudo (caráter 22, estado 1) parece ser plesiomórfico uma vez que é encontrado na maioria dos gêneros mais basais (Apoica, Agelaia e Angiopolybia), com uma reversão para Nectarinella e Leipomeles. A otimização deste caráter é ambígua no cladograma da Fig. 7, e por não haver dados da genitália de macho de P. langi, não fica claro se uma reversão do ângulo basal do parâmero obtuso poderia ser apomórfico para Pseudopolybia.

Carpenter \& Mateus (2004) citam que o ângulo apical do parâmero (caráter 23) é homoplástico ao nível genérico, para Leipomeles e Parachartergus griseus. Considerando que $P$. fraternus (Fig. 3) possui um ângulo apical amplo, como em outras espécies estudadas aqui, este caráter é homoplástico para as espécies do gênero Parachartergus.

Neste trabalho não observamos um pequeno esclerito na base do edeago em Pseudopolybia vespiceps, como nas espécies próximas estudadas por Carpenter \& Mateus (2004: figs. 8-9). Nas dissecções, nas quais as figuras foram baseadas, esta estrutura não 
foi encontrada, e quando dissecamos um exemplar adicional de $P$. compressa, também não observamos o esclerito como mencionado por Carpenter \& Mateus (2004: fig. 8). Como estes dados diferem dos encontrados por Carpenter \& Mateus (2004), decidimos omiti-los da matriz.

Pseudopolybia langi parece estar corretamente posicionada como a espécie mais basal de Pseudopolybia (ver Fig. 7), uma vez que esta espécie conserva várias plesiomorfias compartilhadas com o grupo-externo. A fóvea pronotal está em uma concavidade rasa em $P$. langi, e em uma concavidade profunda em outras espécies de Pseudopolybia, a gena é relativamente estreita na região inferior (ampla em outras espécies), e uma fraca carena pronotal torna sinapomórfica a “carena pronotal curta” em outras espécies, já que a ausência de carena é o estado encontrado nas espécies mais basais dos Epiponini analisados aqui.

Pseudopolybia difficilis difere de $P$. compressa e $P$. vespiceps em três caracteres, todos homoplásticos, os quais unem as duas últimas espécies. São eles: metanoto (longo, curvado vs. achatado), primeiro segmento metassomal (mais longo do que largo vs. tão longo quanto largo) e o formato do digito (arredondado vs. pontiagudo). A condição derivada em cada caráter é convergentemente adquirida em $P$. compressa $+P$. vespiceps. Estas duas espécies são muito similares, e seu posicionamento no mesmo clado parece ser razoável, mas outras características diagnósticas podem separar as espécies, como indicado na chave de identificação (ver abaixo).

Os dados de genitália de macho publicados por Carpenter \& Mateus (2004) e os novos aqui apresentados provaram ser filogeneticamente informativos e, juntamente com 
caracteres morfológicos, ajudaram a elucidar as relações entre as espécies de Pseudopolybia.

\section{4- CHAVE DE IDENTIFICAÇÃO PARA AS ESPÉCIES DE PSEUDOPOLYBIA}

A chave de identificação apresentada abaixo exclui as "morphs” de Richards (1978), para as quais concluímos que não existe outro mérito a não ser serem tratadas como sinônimos. Ducke (1910) cita que outras formas (“morphs”) de P. compressa poderiam ser encontradas no mesmo ninho, enquanto Richards (1978) cita que estes dados necessitam de maior verificação. Uma colônia, coletada por James M. Carpenter (Equador: Prov. Napo, 8 km W Misahualí) continha tanto as “morphs” laticincta quanto luctuosa. As figuras 2 e 3 mostram caracteres que auxiliam na identificação das espécies.

1 Carena pronotal dorsal muito fraca (evanescente) (Fig. 1 C2); primeiro segmento metassomal mais longo do que largo (Fig. 2 A1); olhos com muitas cerdas; espécies pequenas (6-8 mm); geralmente amareladas com três bandas marrons no escuto; metassoma marrom P. langi Bequaert

- Carena pronotal dorsal lamelada lateralmente (Fig. 1 C1); primeiro segmento metassomal tão longo quanto largo ou muito mais largo do que longo (Fig. 2 A1, A2); olhos com ou sem cerdas; espécies grandes (13-15 mm), amareladas ou enegrecidas

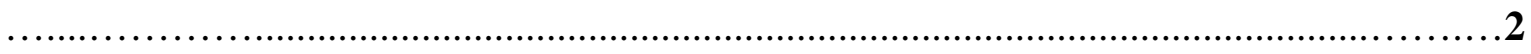

2 Primeiro segmento metassomal um pouco mais longo do que largo (Fig. 2 A1 ); metanoto não achatado; amareladas com manchas enegrecidas na cabeça e mesossoma; três bandas enegrecidas no escuto; metassoma marrom

P. difficilis (Ducke) 
- Primeiro e segundo segmento metassomal tão longo quanto largo (Fig. 2 A2 e B2); metanoto pouco ou muito achatado; espécies amarelo-escuro com três bandas enegrecidas no escuto ou enegrecidas com marcas amareladas...............................................

3 Espécies enegrecidas com manchas amareladas; prestigma tão longo quanto largo; clípeo tocando os olhos; olhos com cerdas; ponta do clípeo fortemente pontiaguda (Fig. 1 A1); metanoto fortemente achatado (Fig. 1 D1); espaço malar tão longo quanto o quarto artículo antenal (Fig. 1 B1) .................................................................. compressa (de Saussure)

- Espécies enegrecidas com manchas marrons; prestigma muito mais longo do que largo; clípeo pouco separado dos olhos; olhos sem cerdas; ponta do clípeo pouco pontiaguda (Fig. 1 A2); espaço malar mais longo do que o quarto artículo antenal (Fig. 1 B2); metanoto pouco achatado (Fig. 1 D2).

P. vespiceps (de Saussure) 
Tabela 1 - Lista de caracteres para Pseudopolybia.

1. Terceiro palpômero labial: sem cerda curvada $=0$; $\operatorname{com}$ cerda curvada $=1$.

2. Palpo maxilar: 6 segmentos $=0 ; 5$ segmentos $=1$.

3. Palpo labial: 4 segmentos $=0 ; 3$ segmentos $=1$.

4. Terceiro artículo antenal: duas vezes mais longo do que o quarto artículo =0; aproximadamente 1,5 vez mais longo do que o quarto artículo $=1$.

5. Olhos: sem cerdas $=0$; com cerdas $=1$.

6. Clípeo: tocando os olhos $=0$; não tocando os olhos $=1$.

7. Ápice clipeal: fortemente pontiagudo (Fig. 1 A1)=0; pouco pontiagudo = 1 (Fig. 1 A2).

8. Gena: na base dos olhos, mais estreita que os olhos = 0 (Fig. 1 B1); na base dos olhos, angulada, mais larga que os olhos $=1($ Fig 1 B1).

9. Espaço malar: menor que o quarto artículo antenal = 0 (Fig. 1 B1); maior que o quarto artículo antenal $=1$ (Fig. 1 B2) .

10. Carena occipital: presente $=0$; ausente $=1$.

11. Carena pronotal dorsal: terminando próximo a margem posterior do pronoto $=0$; terminando próximo da região mediana do pronoto $=1$; fraca, evanescente $=2$; traço, ausente $=3$.

12. Fóvea pronotal: em uma concavidade rasa $=0$; em uma concavidade profunda $=1$.

13. Sulco escrobal: presente $=0$; ausente $=1$.

14. Fenda mesepisternal dorsal: presente $=0$; ausente $=1$.

15. Escutelo: com linha impressa $=0$; sem linha impressa $=1$.

16. Metanoto: longo, curvado $=0$; pequeno, achatado $=1$; vertical $=2$. 
17. Concavidade propodeal: estreita $=0$; ampla, rasa $=1$; ampla, profunda $=2$; propódeo quase reto $=3$.

18. Primeiro segmento metassomal: mais longo do que largo = 0 (Fig. 2 A1); mais largo do que longo = 1 (Fig. 2 A2) .

19. Prestigma: tão longo quanto largo $=0$; mais longo do que largo $=1$.

20. Ponta do prestigma: truncado $=0$; arredondado $=1$.

21. Cerdas no espinho do parâmero: ausente $=0$; presente, curto $=1$; presente, longo $=2$.

22. Ângulo basal do parâmero: obtuso $=0$; agudo $=1$.

23. Ângulo apical do parâmero: amplo = 0 ; estreito $=1$.

24. Processo ventral do edeago: pequeno, angular $=0$; estreito reduzido $=1$.

25. Formato do digito: arredondado $=0$; pontiagudo $=1$.

26. Processo basal do digito: ausente $=0$; presente $=1$.

27. Envelope do ninho: ausente = 0; presente, camada única $=1$; presente, várias camadas $=2$.

28. Pedicelo do ninho: ausente $=0$; presente $=1$.

29. Entrada do ninho: tubo posicionado para baixo $=0$; abertura simples $=1$. 
Tabela 2 - Matriz de caracteres para Pseudopolybia. Os seguintes símbolos são utilizados: ? (não observado); - (não aplicável).

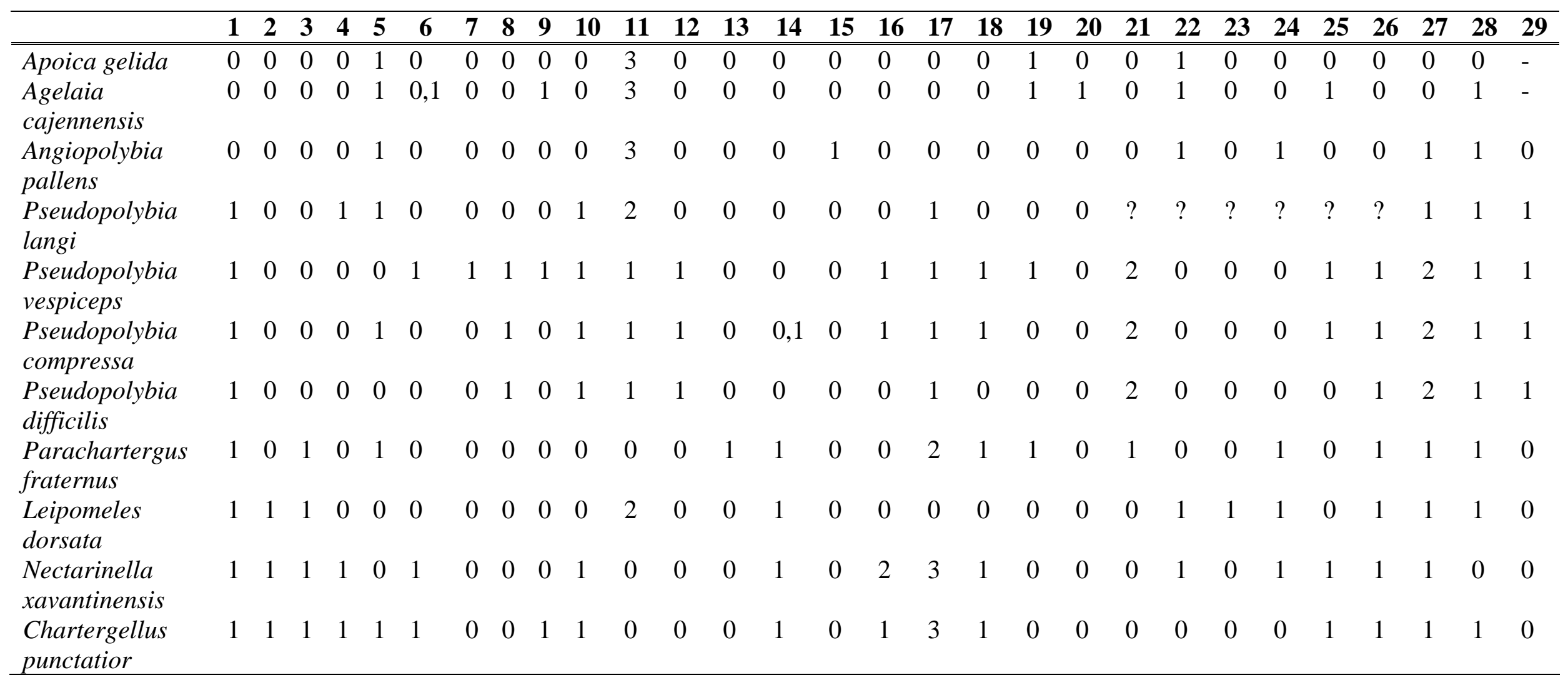



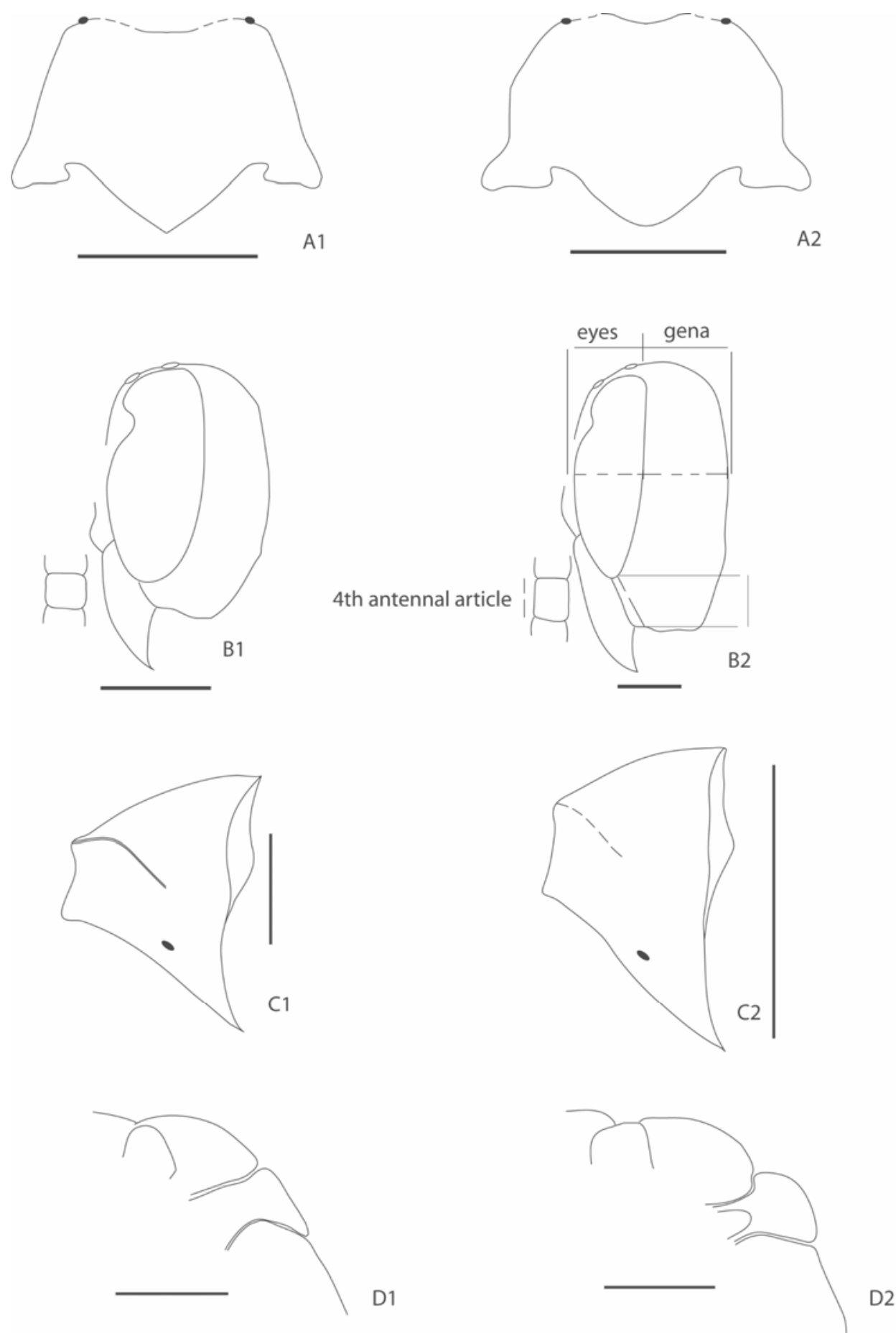

Figura 1 - Caracteres de Pseudopolybia. A, clípeo, visão frontal. A1, P. compressa; A2, P. vespiceps. B, cabeça, visão lateral. B1, P. compressa; B2, P. vespiceps. C, pronoto, visão lateral. C1, P. compressa; C2, P. langi. D, metanoto, visão lateral. D1, P. compressa; D2, P. vespiceps. Escala $=1,0 \mathrm{~mm}$. 

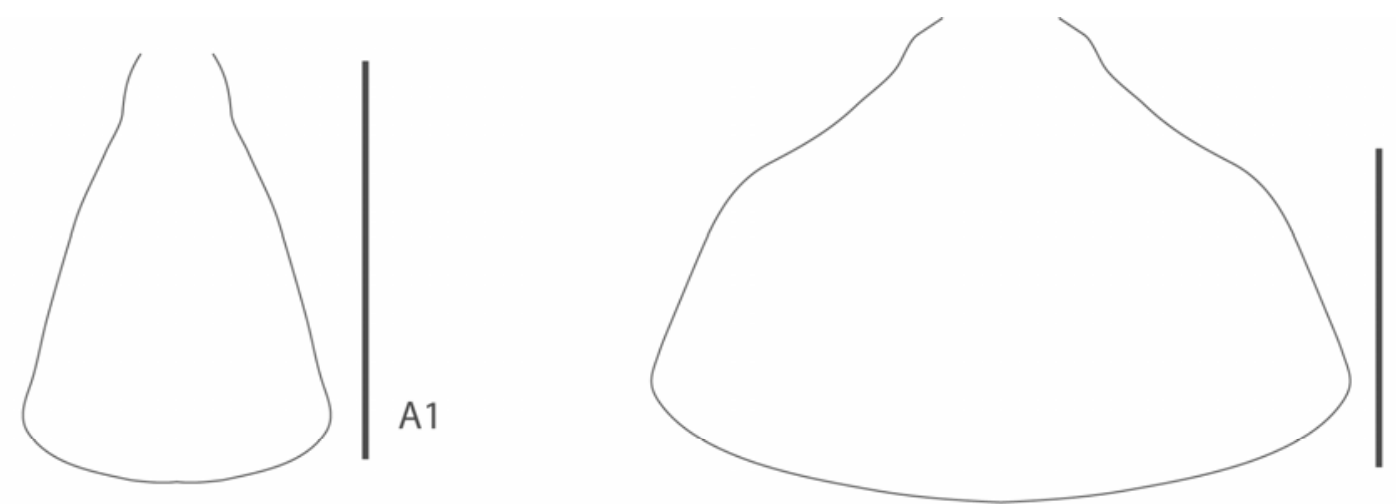

$\mathrm{A} 2$

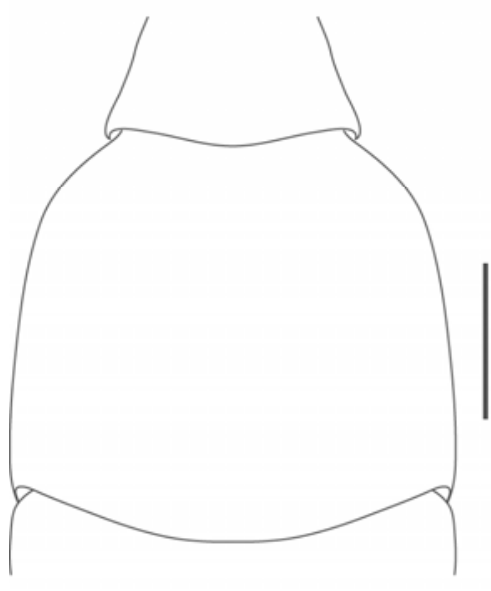

B1

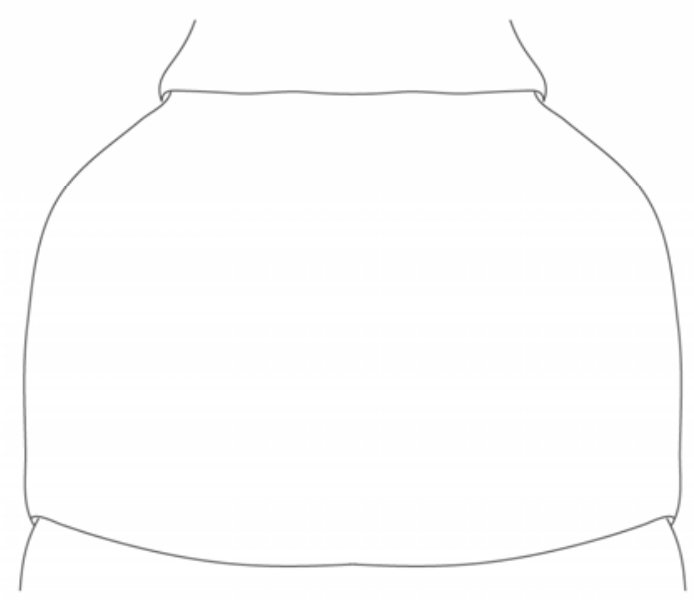

B2

Figura 2 - Caracteres de Pseudopolybia. A, primeiro segmento metassomal, visão dorsal. A1, P. langi; A2, P. vespiceps. B, segundo segmento metassomal, visão dorsal. B1, $P$. difficilis; B2, $P$. vespiceps. Escala $=1,0 \mathrm{~mm}$. 

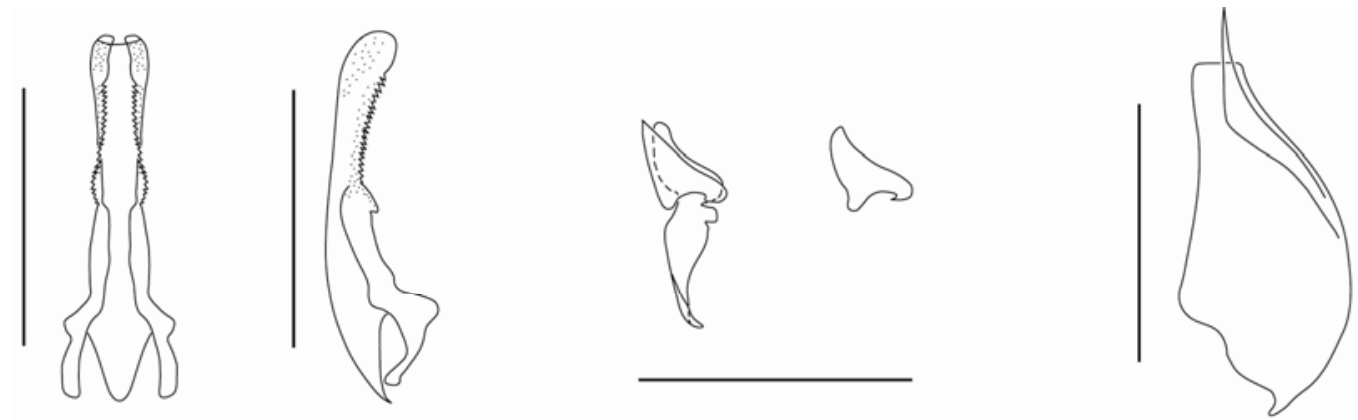

Agelaia cajennensis
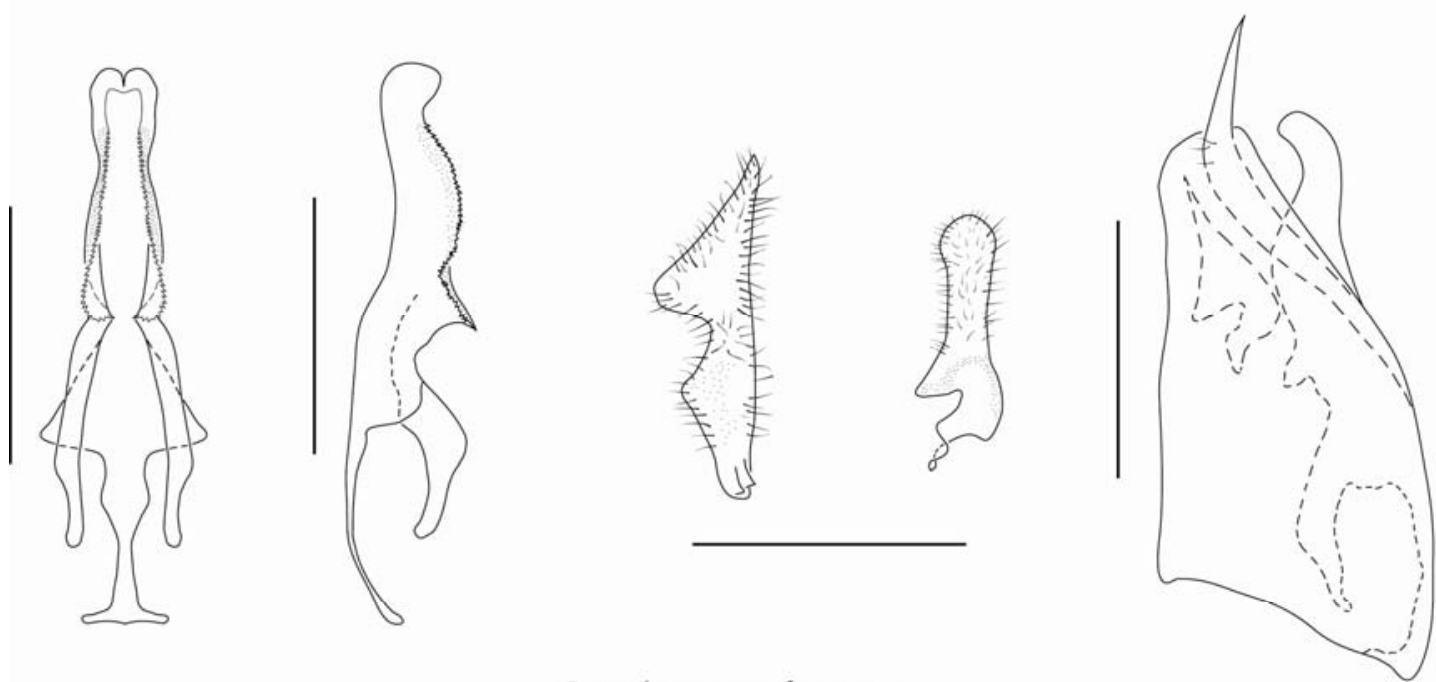

Parachartergus fraternus
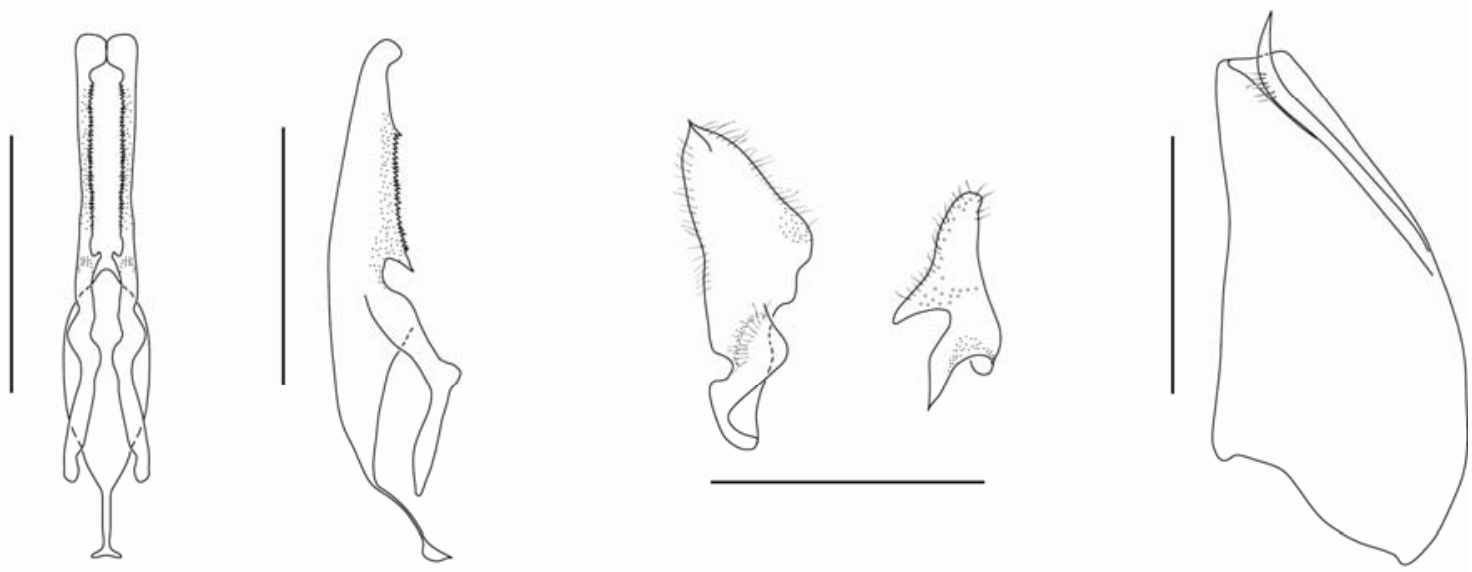

Pseudopolybia vespiceps

Figura 3 - Genitália de macho: da esquerda para a direita = edeago, visão ventral; edeago, visão lateral; cuspis; dígito e parâmero, visão lateral. Escala = 1,0 mm. 


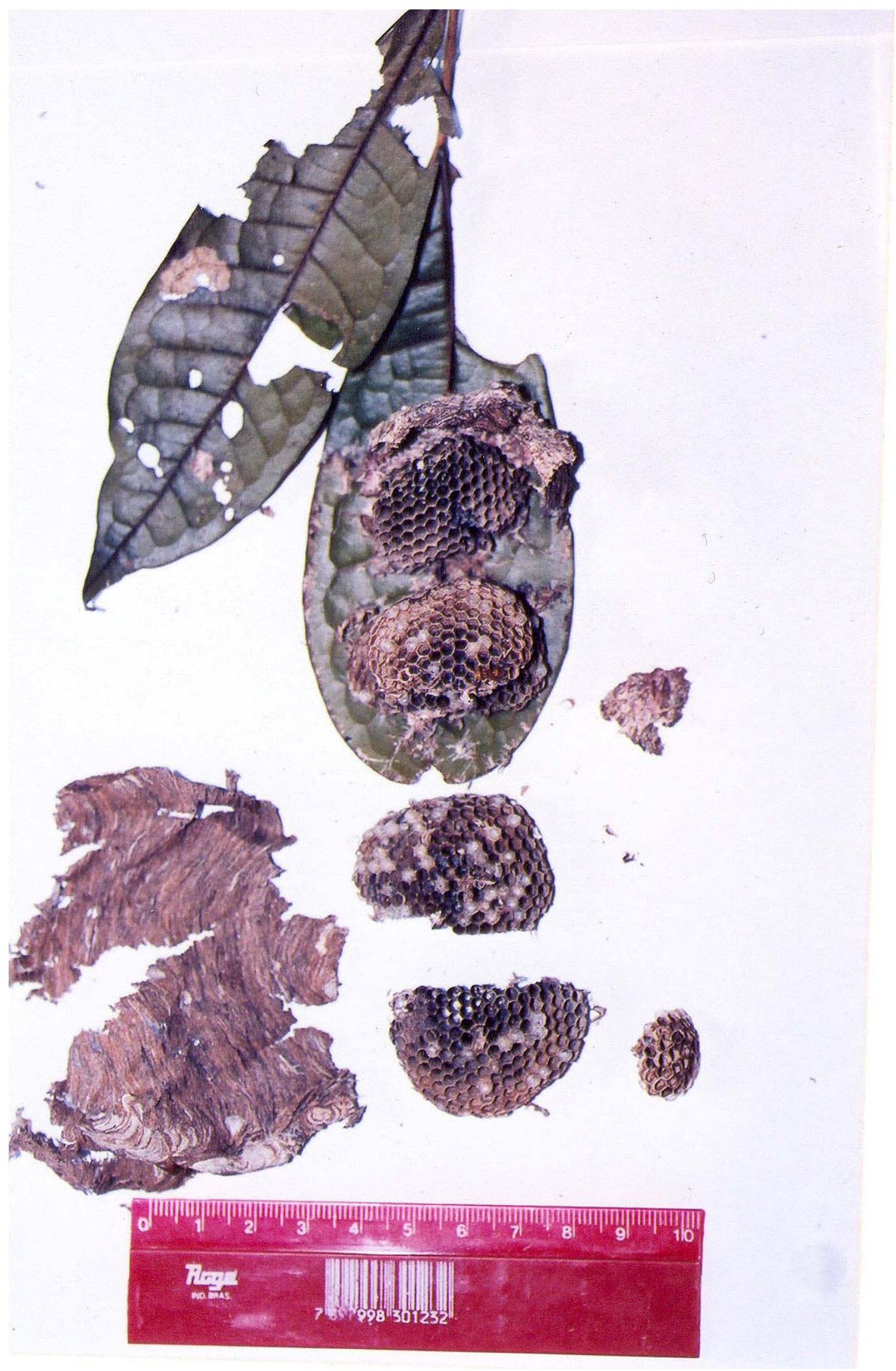

Figura 4 - Ninho de Pseudopolybia langi, coletado por Orlando Tobias Silveira no estado do Amapá, Brasil. 


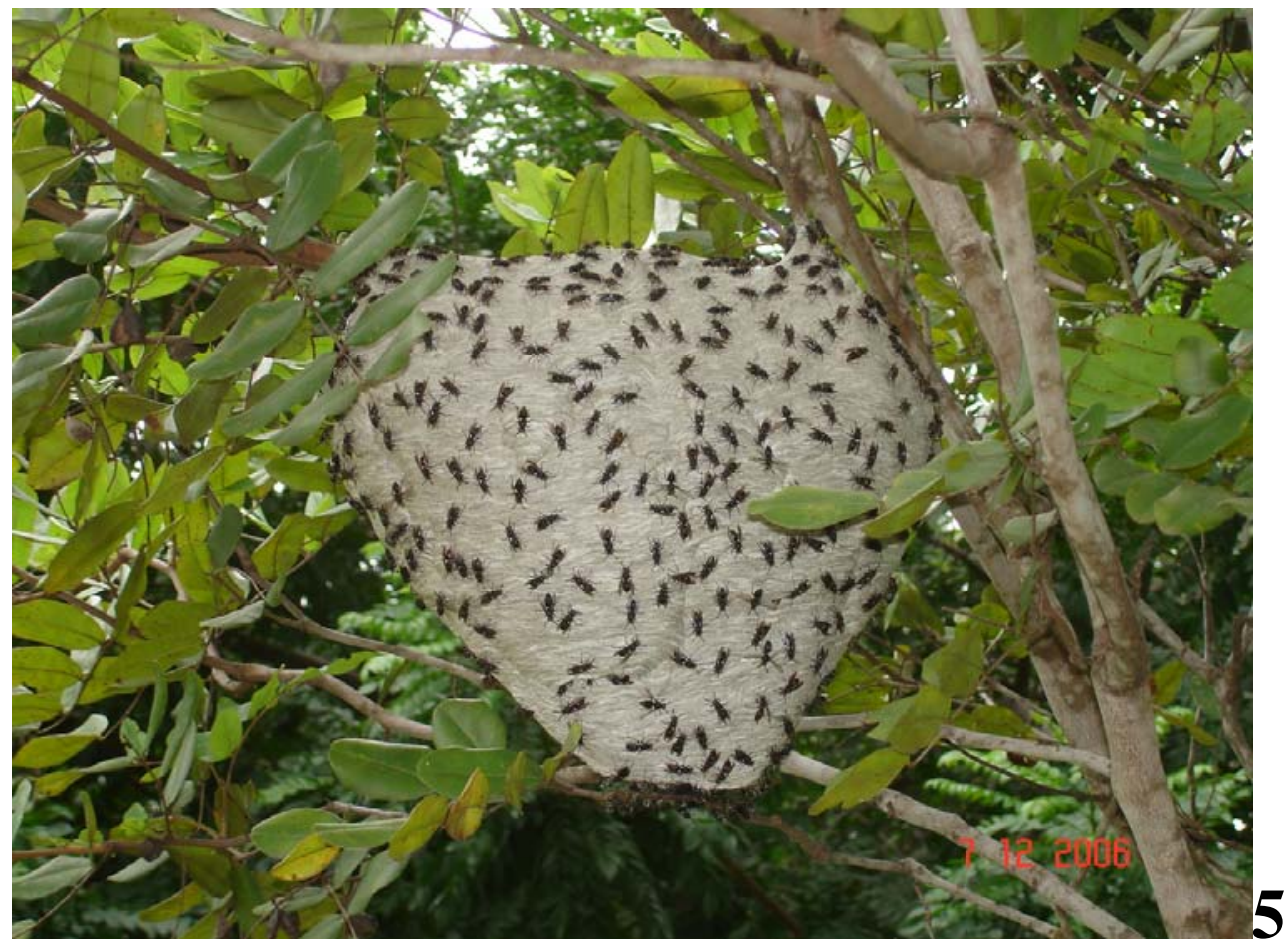

Figura 5 - Ninho de Pseudopolybia compressa, coletado em Nova Xavantina-MT, em 2006. Foto de Sidnei Mateus.

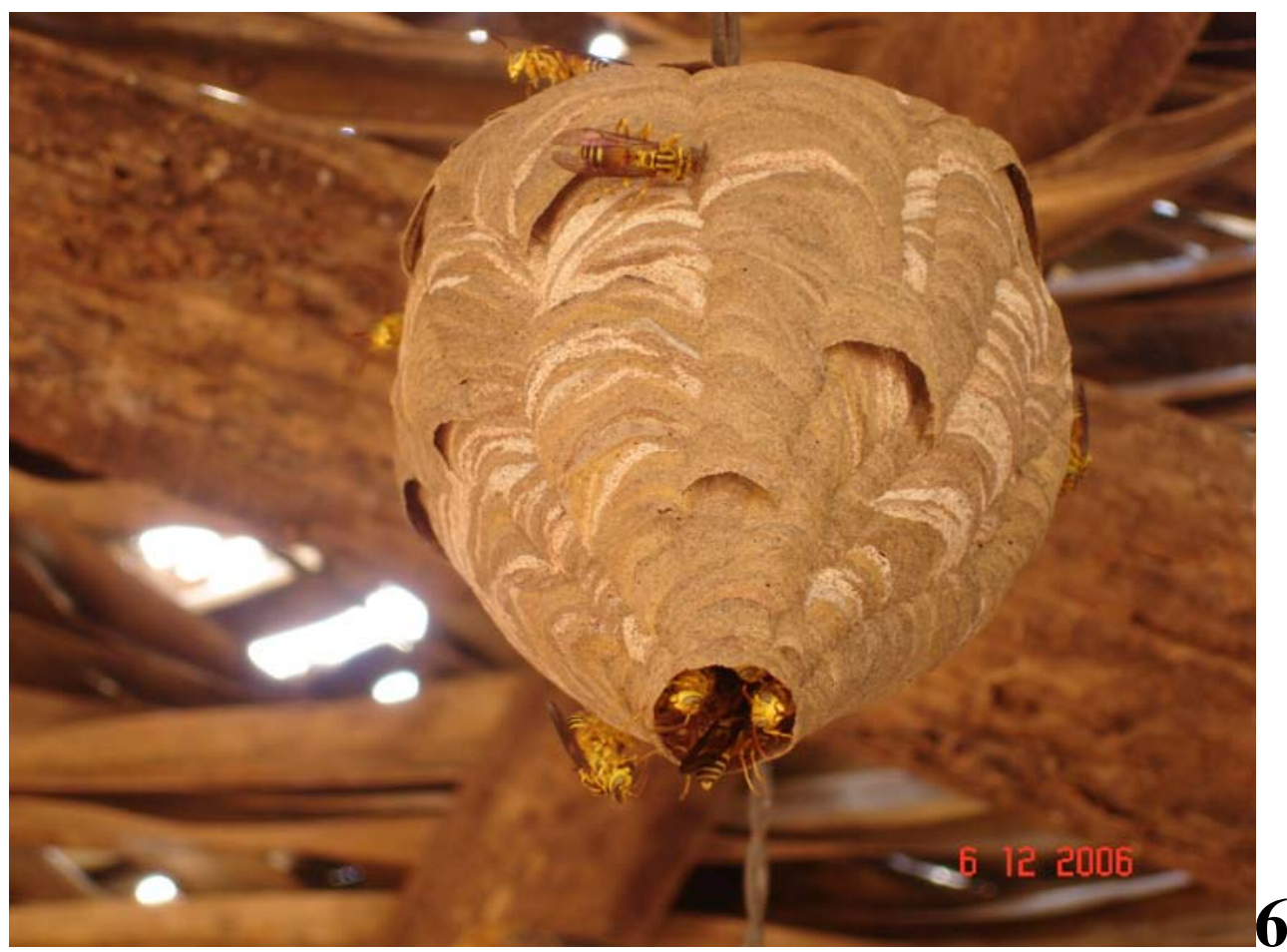

Figura 6 - Ninho de Pseudopolybia vespiceps, coletado em Nova Xavantina-MT, em 2006. Foto de Sidnei Mateus. 


\section{Capítulo 2 - Pseudopolybia}




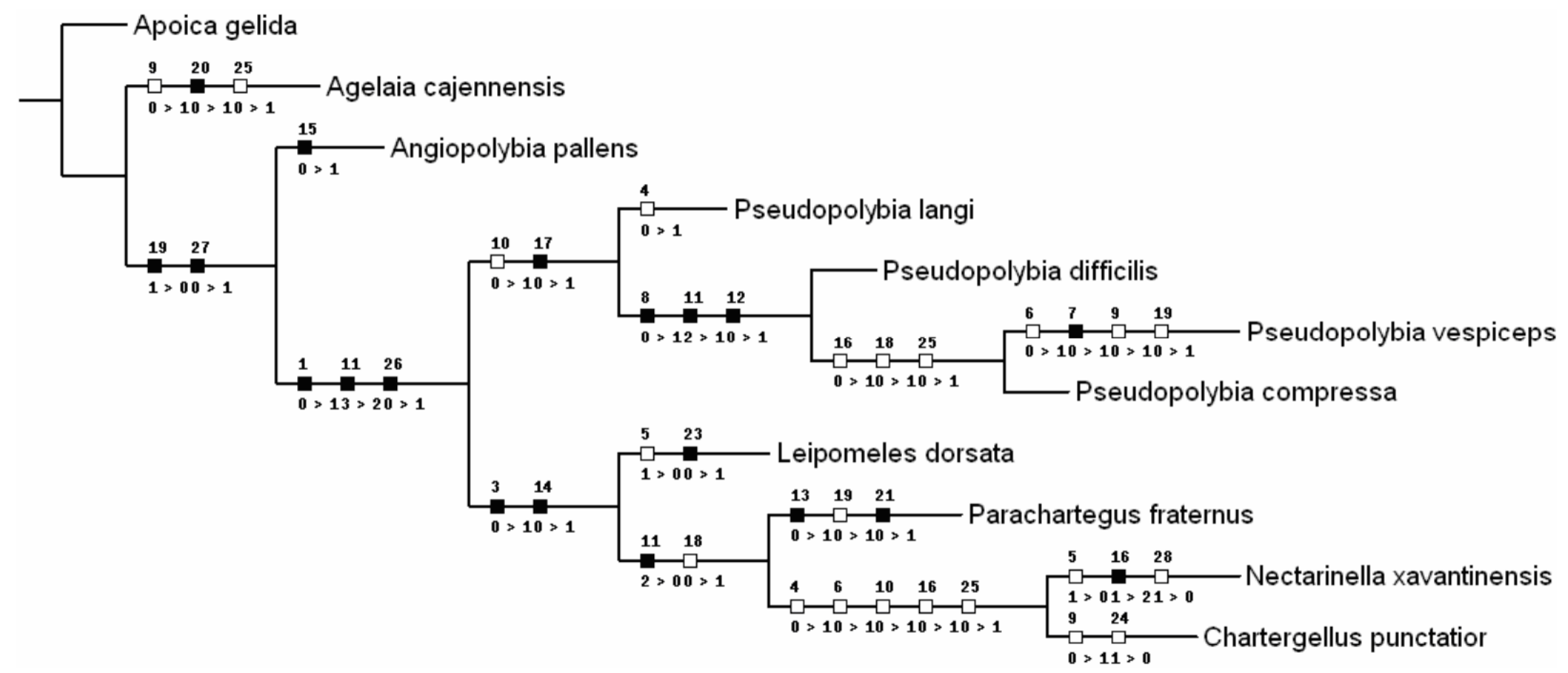

Figura 7 - Cladograma de Pseudopolybia, com 56 passos, índice de consistência 0.64, e índice de retenção 0.70; baseado na matriz de dados da Tabela 2. Somente caracteres não ambíguos estão plotados. O número de cada caráter está sobre os quadrados, enquanto que a transição de cada estado está abaixo, separado por ">.” 

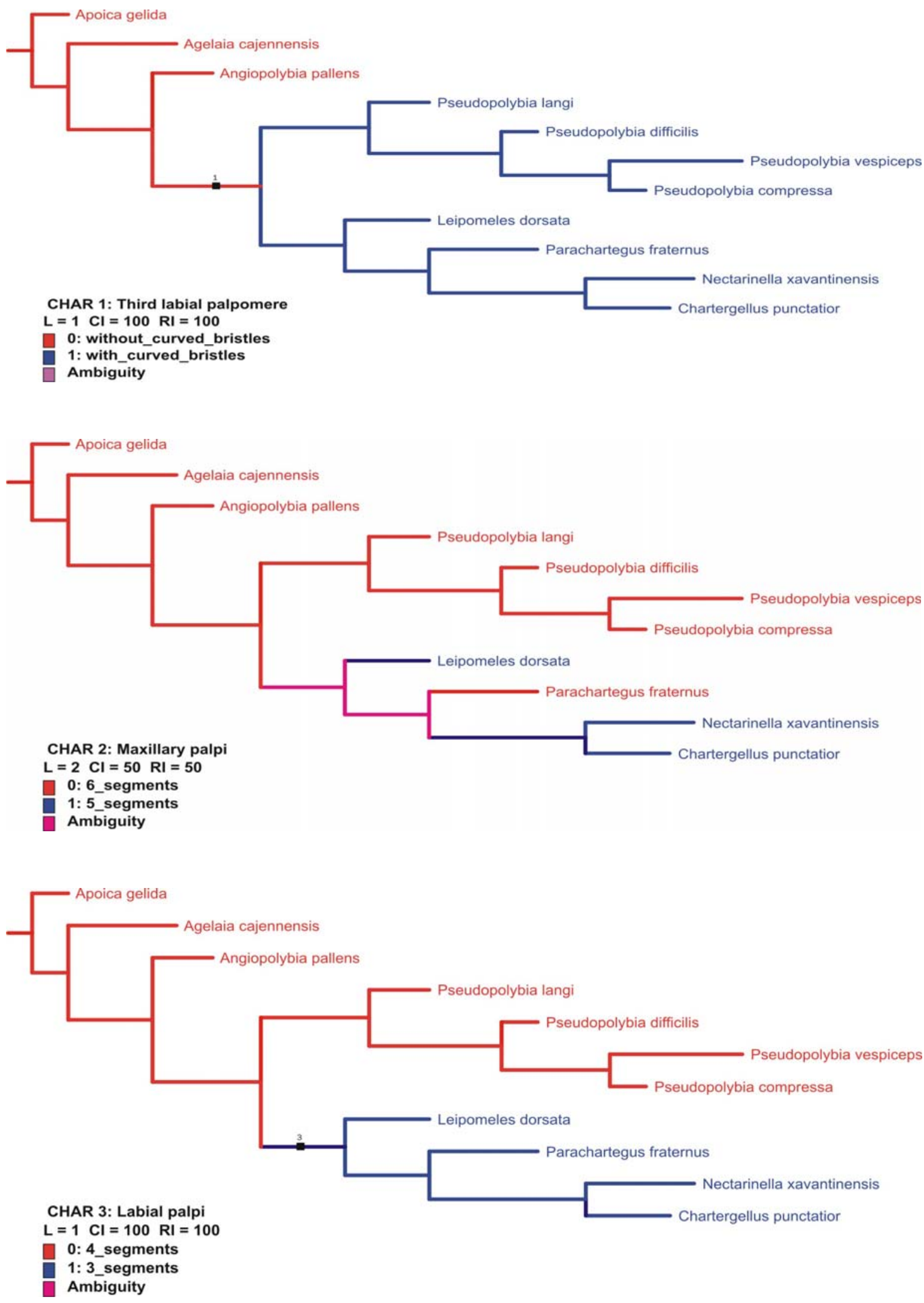

Figura 8 - Otimização dos caracteres 1, 2 e 3. 

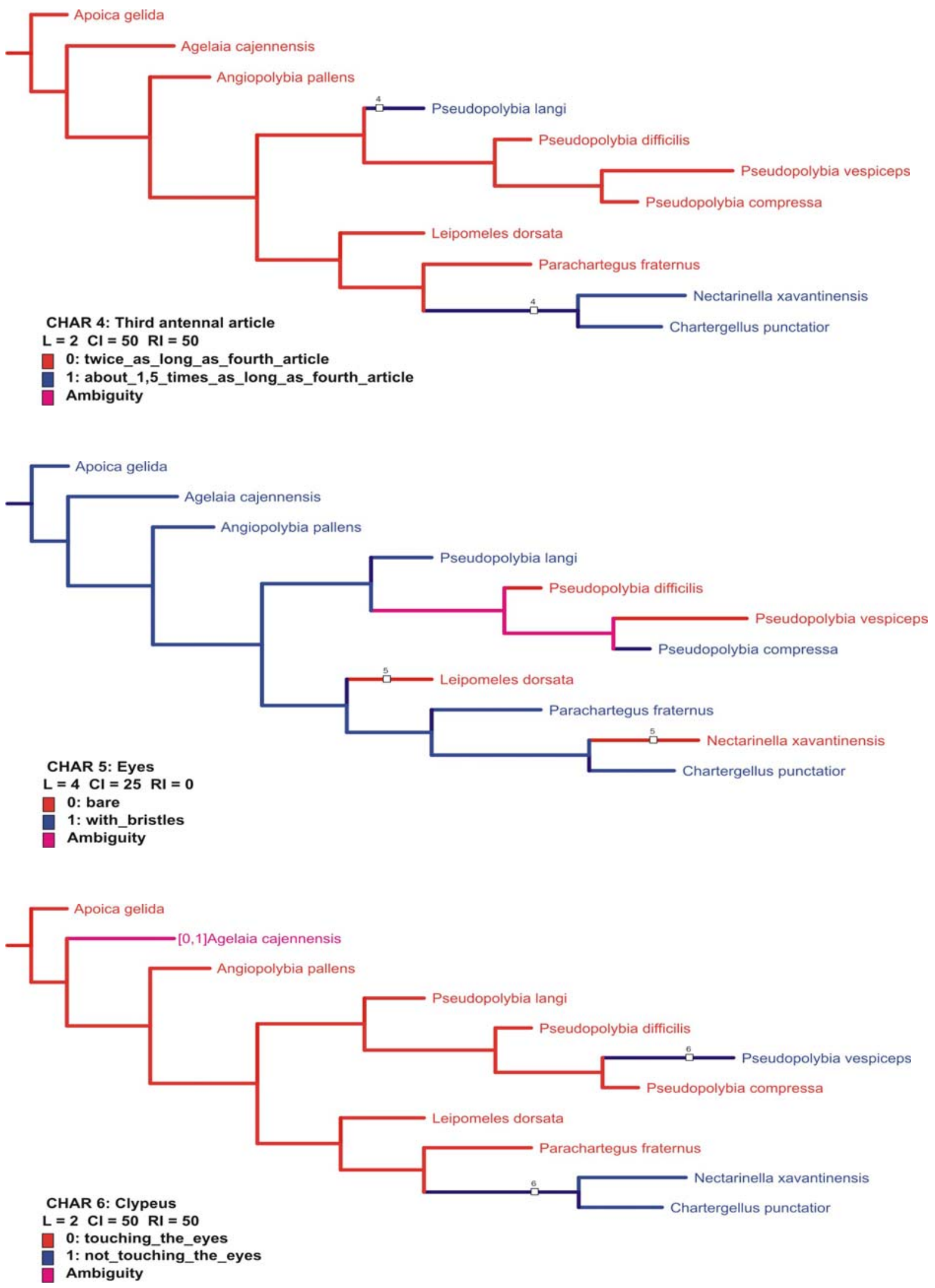

Figura 9 - Otimização dos caracteres 4, 5 e 6. 

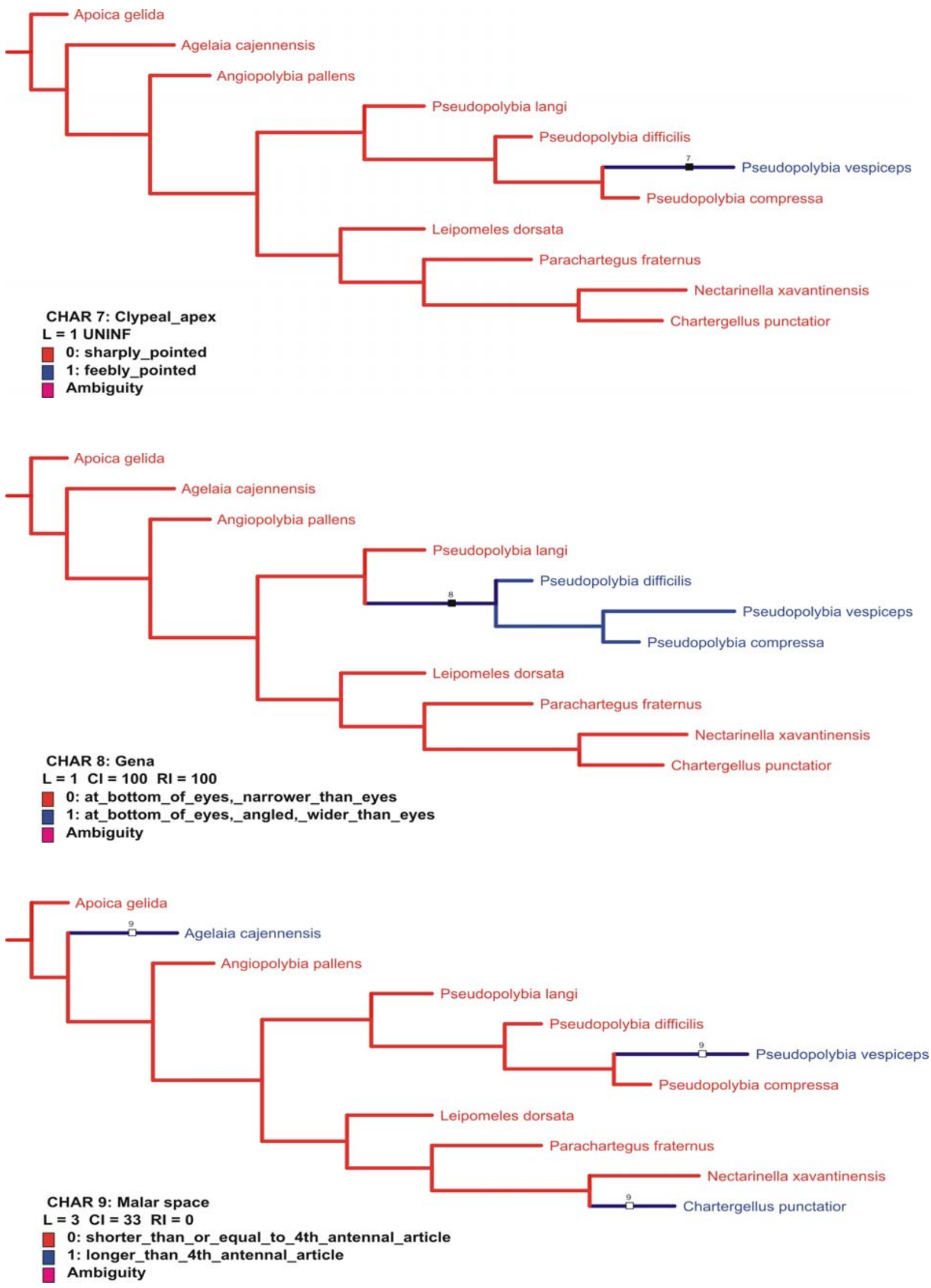

Figura 10 - Otimização dos caracteres 7, 8 e 9. 

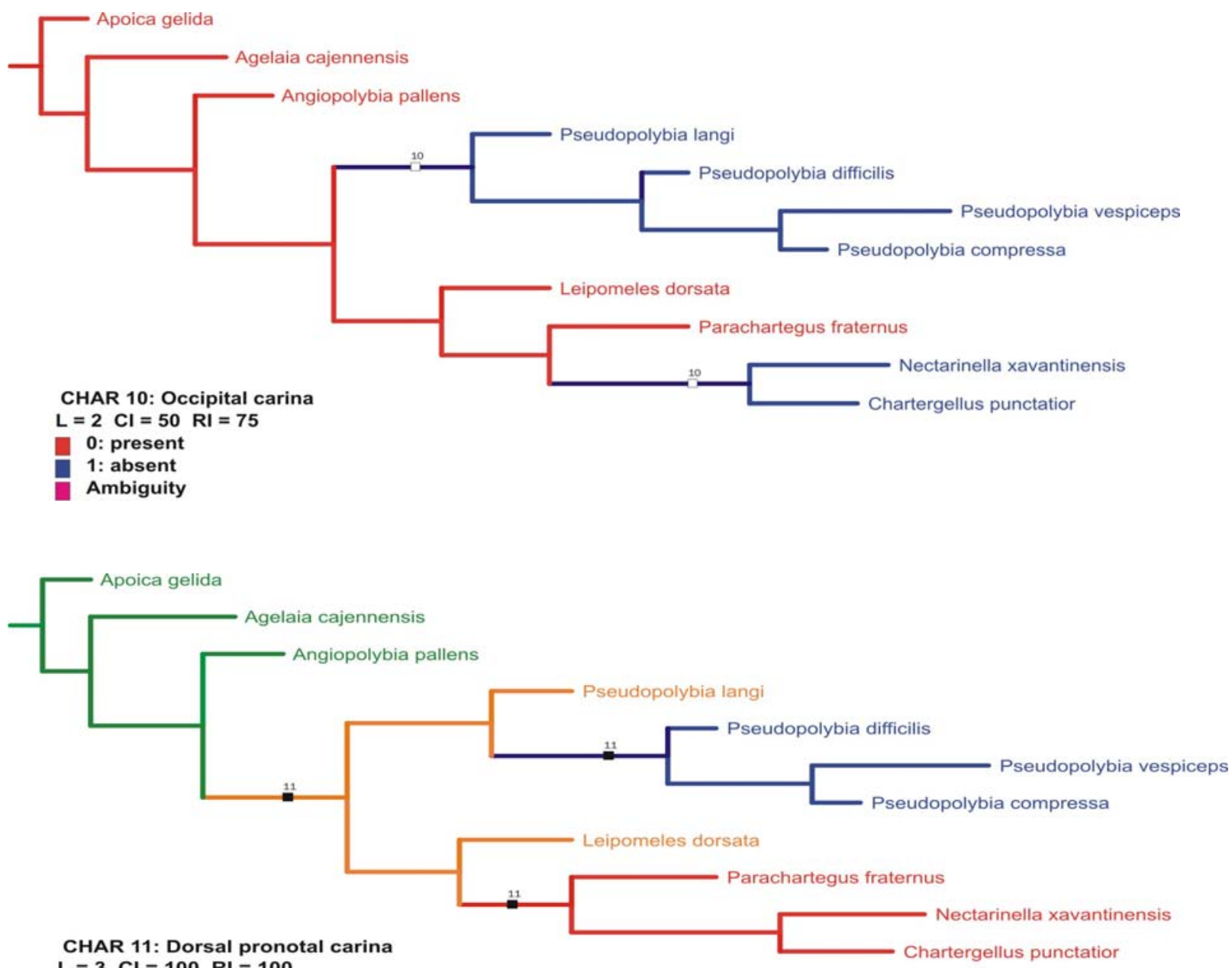

$L=3 \mathrm{Cl}=100 \mathrm{RI}=100$

0: ending_close_to_posterior_margin_of_pronotum

1: ending_close_to_midpoint_of_pronotum

2: weak,_evanescent

3: trace,_absent

Ambiguity

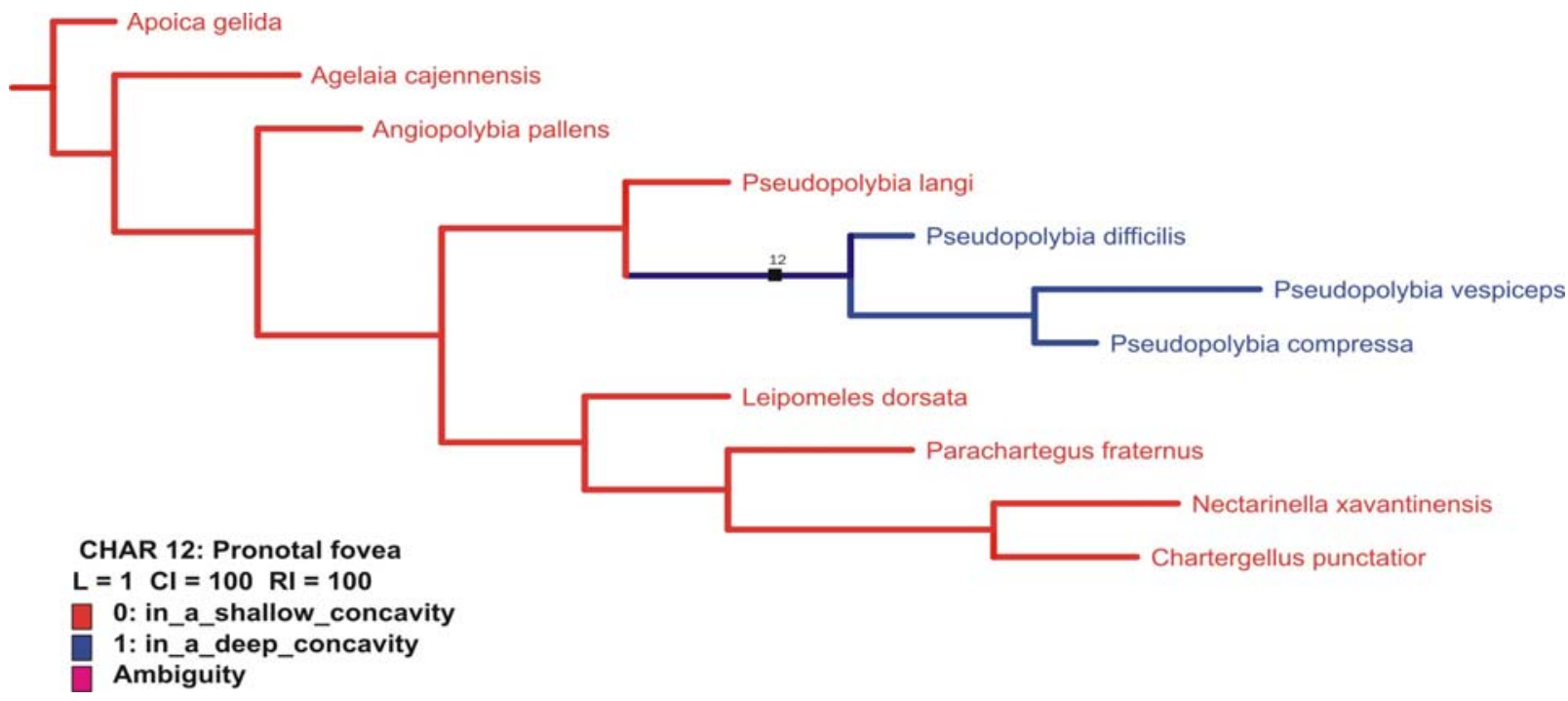

Figura 11 - Otimização dos caracteres 10, 11 e 12. 

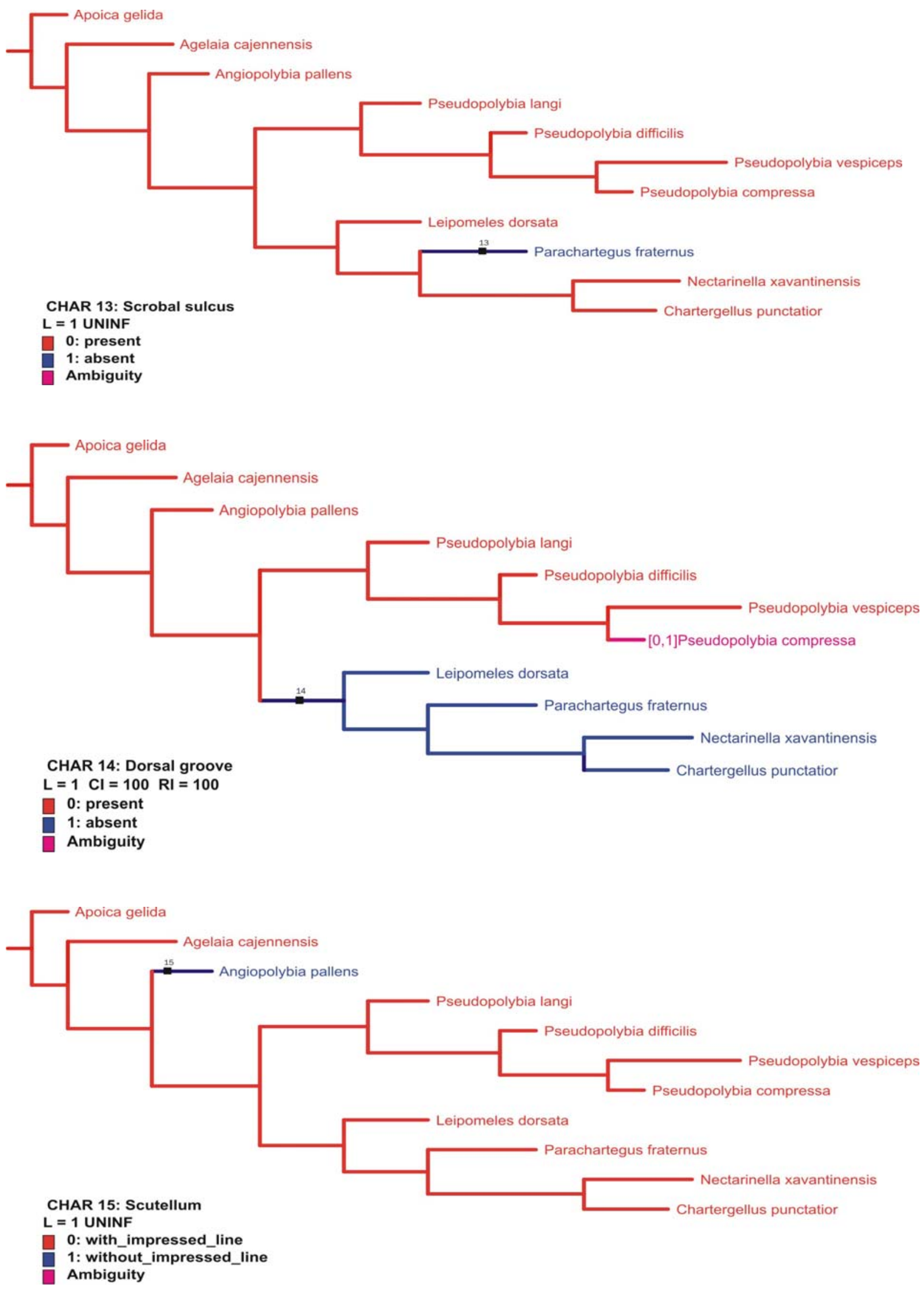

Figura 12 - Otimização dos caracteres 13, 14 e 15. 

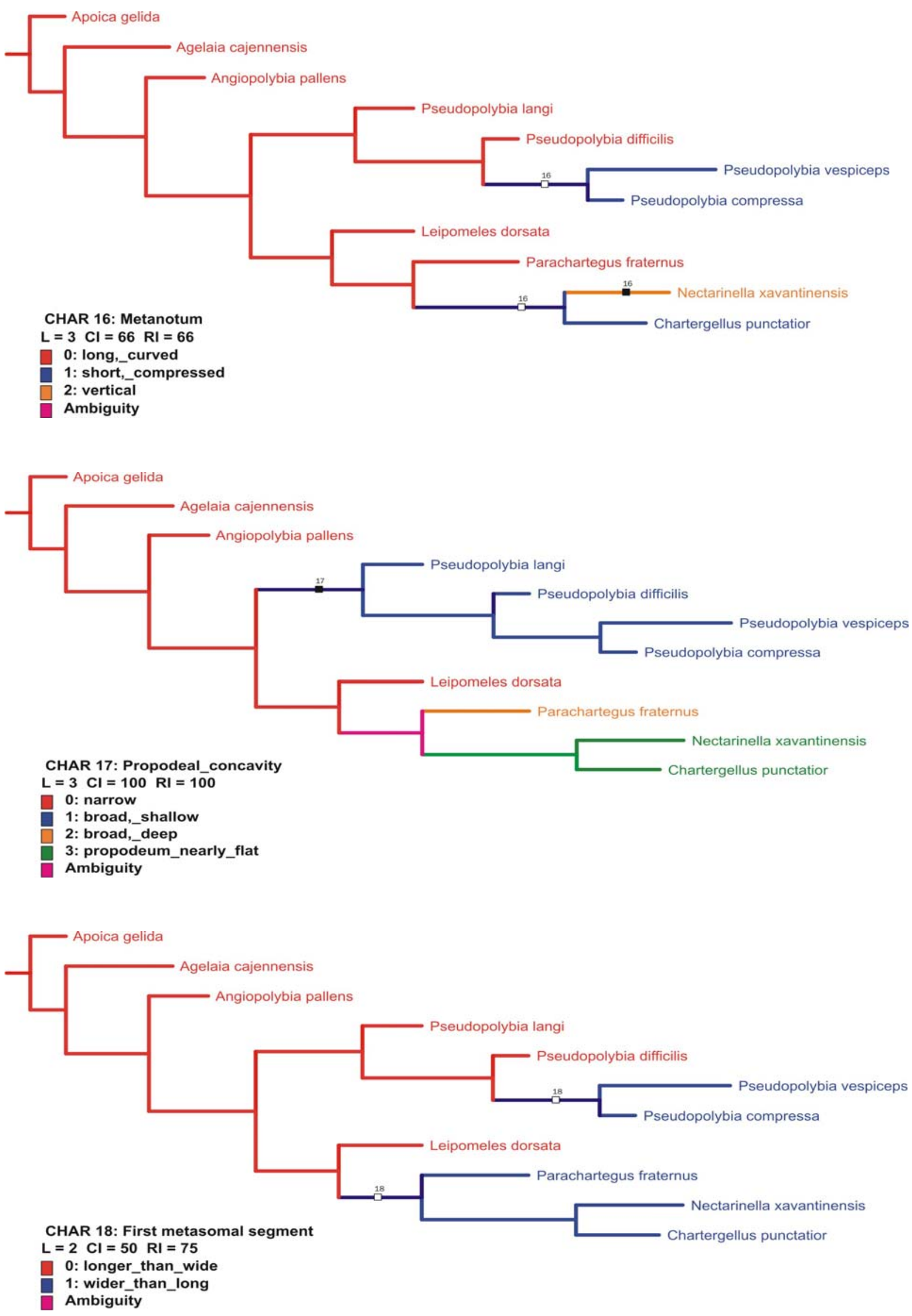

Figura 13 - Otimização dos caracteres 16, 17 e 18. 

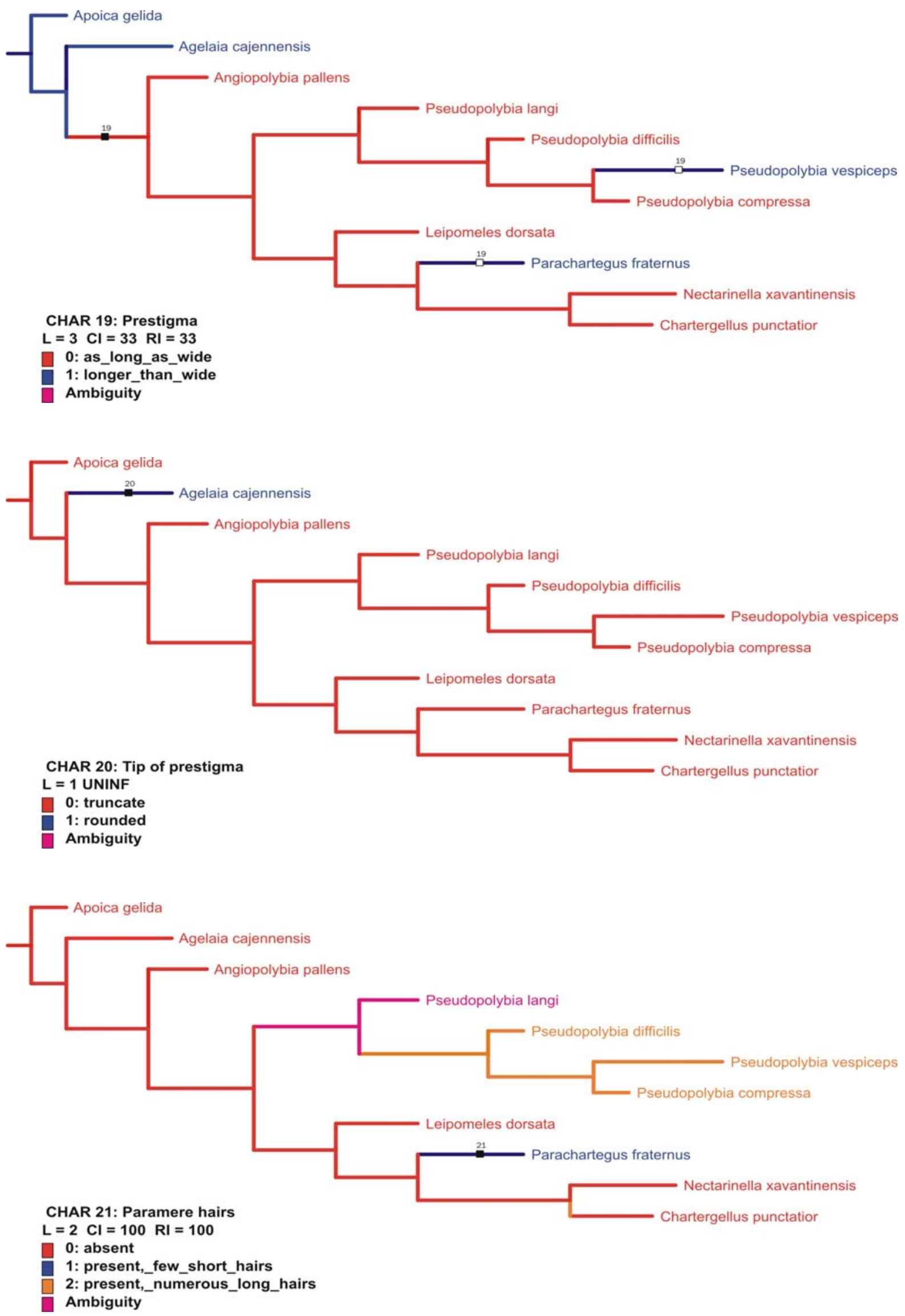

Figura 14 - Otimização dos caracteres 19 e 20 e 21. 

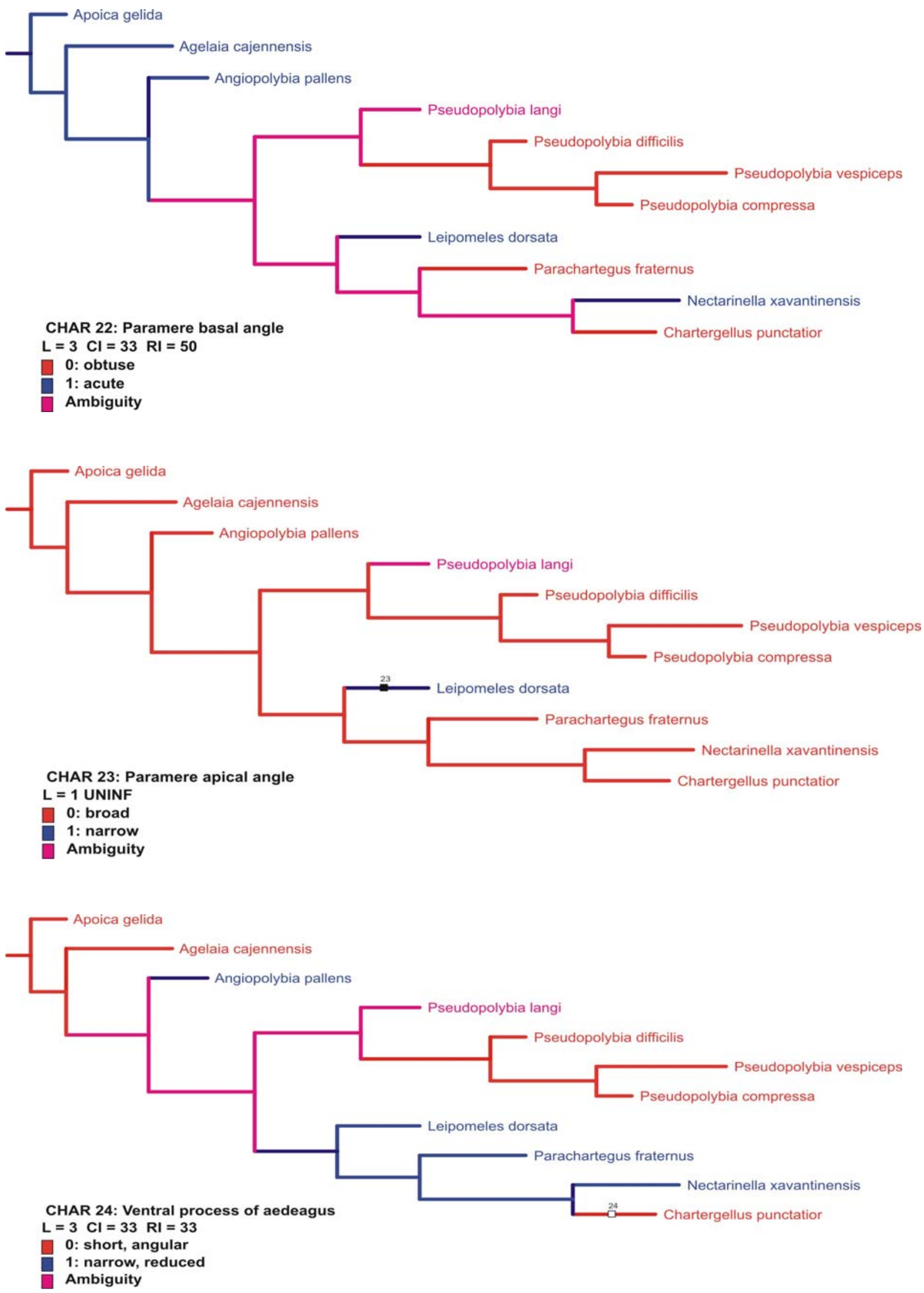
Figura 15 - Otimização dos caracteres 22 e 23 e 24.
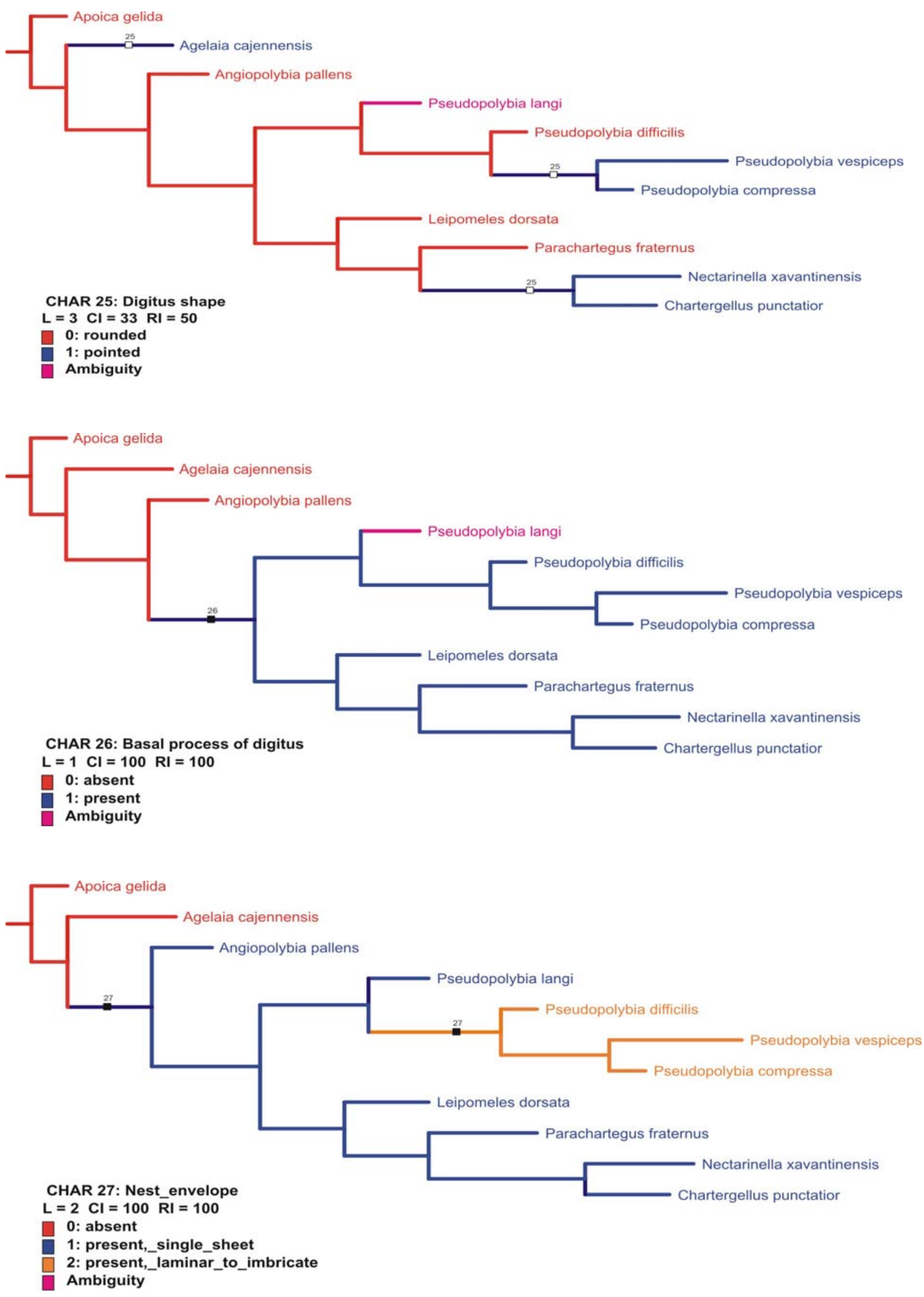

Figura 16 - Otimização dos caracteres 25, 26 e 27. 

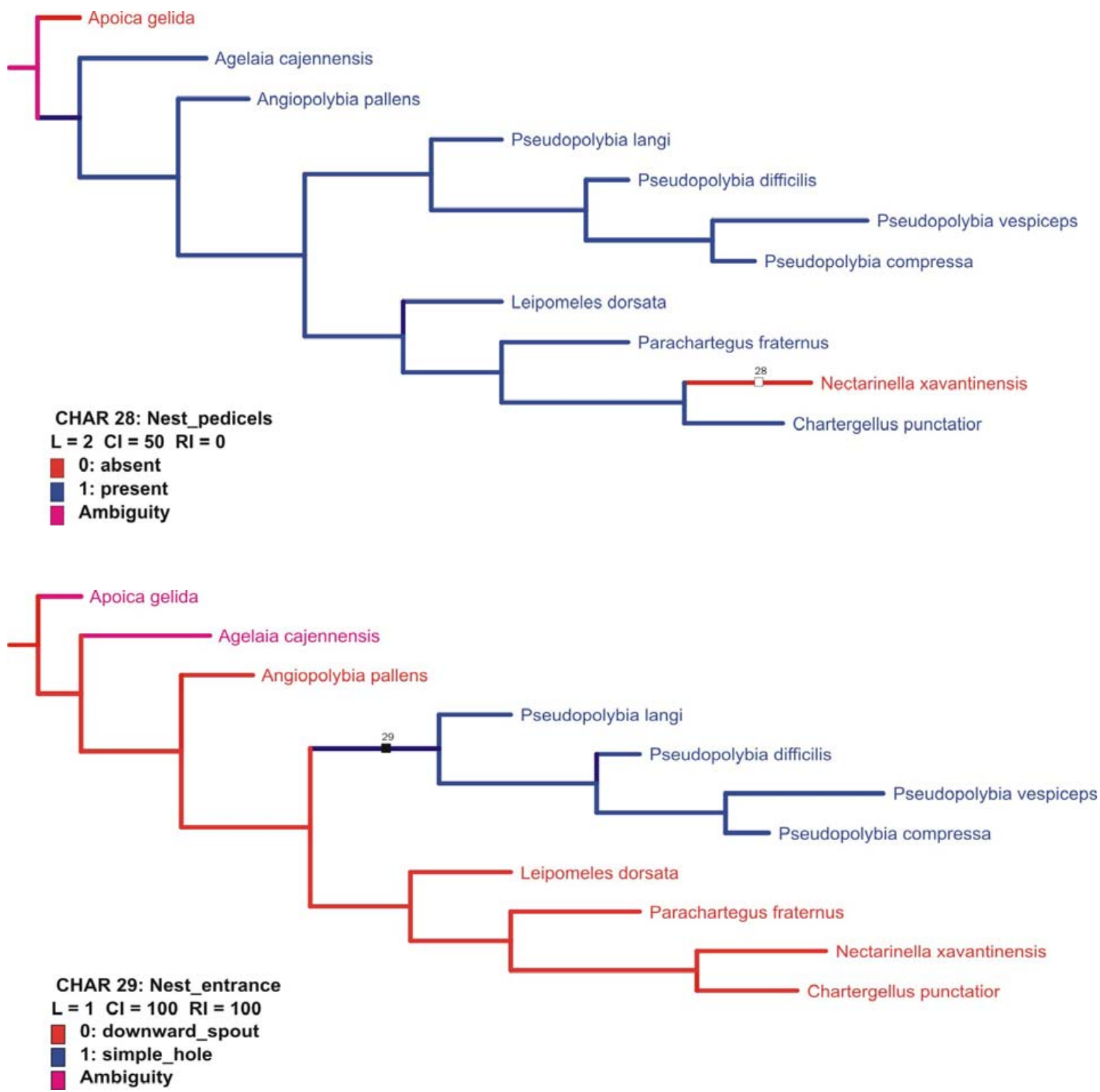

Figura 17 - Otimização dos caracteres 28 e 29. 


\section{5 - REFERÊNCIAS}

Bequaert, J.C. 1938. A new Charterginus from Costa Rica, with notes on Charterginus, Pseudochartergus, Pseudopolybia, Epipona, and Tatua (Hymenoptera, Vespidae). Revista de Entomologia, Rio de Janeiro, 9: 99-117.

Carpenter, J.M. 1991. Phylogenetic relationships and the origin of social behavior in the Vespidae. In: K.G. Ross and R.W. Matthew (editors), The social biology of wasps: 7-32. Ithaca, NY: Cornell University Press.

Carpenter, J.M. \& S. Mateus. 2004. Males of Nectarinella Bequart (Hymenoptera, Vespidae, Polistinae). Revista Brasileira de Entomologia, 48 (3): 297-302.

Ducke, A. 1910. Révision des guêpes sociales polygames d’Amérique. Annales HistoricoNaturalis Musei Nationalis Hungarici, 8: 449-544.

Hanson, P.E. \& I.D. Gauld. 1995. The Hymenoptera of Costa Rita. Oxford: Oxford University Press.

Jeanne R.L. 1991. The swarm-founding Polistinae. In: K.G. Ross and R.W. Matthew (editors), The social biology of wasps: 191-231. Ithaca, NY: Cornell University Press.

Nixon, K.C. \& J.M. Carpenter. 1993. On outgroups. Cladistics, 9: 413-426.

Richards, O.W. 1978. The social wasps of the Americas excluding the Vespinae. London: British Museum (Natural History).

Richards, O.W. \& M.J. Richards. 1951. Observations on the social wasps of South America (Hymenoptera, Vespidae). Transactions of the Royal Entomological Society of London, 102: 1-170.

Wenzel, J.W. 1998. A generic key to the nests of hornets, yellowjackets, and paper wasps worldwide (Vespidade: Vespinae, Polistinae). American Museum Novitates, 3224: 1-39.

Wenzel, J.W. \& J.M. Carpenter. 1994. Comparing methods: adaptative traits and tests of adaptation. In: P. Eggleton, and R. Vane-Wright (editors), Phylogenetics and Ecology: 79-101. London: Academic Press. 
Apêndice 1. Localidade dos exemplares de Pseudopolybia examinados.

P. compressa: Rio Juruá, Reserva Ducke, e Manaus, Amazonas, Brasil (MPEG e AMNH); Espírito Santo (localidade não especificada) (MZUSP); Chapada dos Guimarães, Mato Grosso, Brasil (MPEG); Represa Rio Grande, Guanabara (RJ), Brasil (UFPR); Paramaribo, Suriname (IIBAVH); Arima Valley, Trinidad (AMNH); Madre de Dios, Tambopata Wild. Res., Peru (AMNH); LaChorarra-Putamayo, Peru (AMNH); Prov. Napo, Equador (AMNH); e Boc. Toro - Changuinola distr., Panamá (AMNH).

P. difficilis: Mato Grosso, Brasil (localidade não especificada) (MPEG); Melgaço, Pará, Brasil (MPEG), Manaus, Amazonas, Brasil (UFPR); Ouro Preto do Oeste, Rondônia, Brasil (MPEG); and Peru, LaChorarra-Putamayo (AMNH).

P. langi: Laranjal do Jarí Marinho, Amapá, Brasil (MPEG), Manaus, Amazonas, Brasil (UFPR); e Kamakusa, Guyana (AMNH).

P. vespiceps: Espirito Santo (localidade não especificada), Brasil (MZUSP); Franca, São Paulo, Brasil (MZUSP); Parque Itaituba, Amazonas, Brasil (MPEG); Amazonas, (AM 01 Km 31 and Km 64; ZF 02 Km 20,7; ZF 03 km 23; Estação Amá Km 06; Queraí (Pelotão); Reserva Duck), Brasil (INPA); Rio Trombetas, Amapá, Brasil (INPA); Ouro Preto do Oeste, Rondônia, Brasil; (Garofire, Serra Norte, Mosqueiro e BelémMocambo), Pará, Brasil (MPEG); Pernambuco (localidade não especificada), Brasil (AMNH); e São Paulo (localidade não especificada) Brasil (genitália de macho dissecada) (AMNH); Peru, Oxapampa (AMNH). 


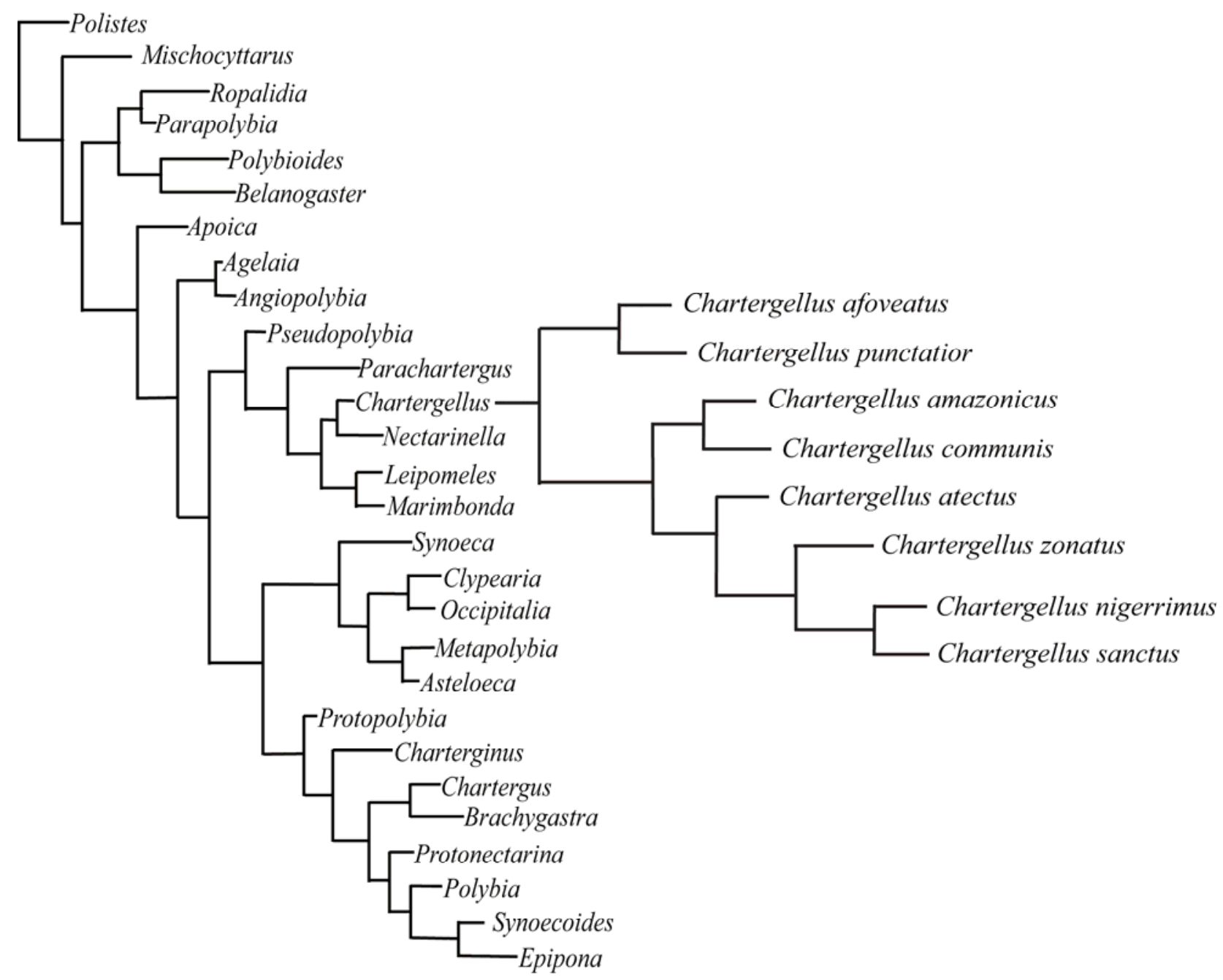

\section{Capítulo 3 - Análise Filogenética do Gênero Chartergellus Bequaert, 1938 (Hymenoptera, Vespidae, Epiponini)}




\section{Capítulo 3 - Análise Filogenética do Gênero Chartergellus Bequaert, 1938 (Hymenoptera, Vespidae, Epiponini)}

\section{1 - INTRODUÇÃO}

Chartergellus é um gênero pertencente à tribo Epiponini (Vespidae: Polistinae), com oito espécies descritas (C. afoveatus Cooper, C. amazonicus Richards, C. atectus Richards, C. communis Richards, C. nigerrimus Richards, C. punctatior Richards, C. sanctus Richards, C. zonatus (Spinola)), que se distribuem do sudeste do Brasil até a região norte da Costa Rica (Hanson \& Gould, 1995; Carpenter \& Marques, 2001). Das oito espécies descritas, seis ocorrem no Brasil, sendo duas delas endêmicas (Carpenter \& Marques, 2001).

Bequaert (1938) havia descrito Chartergus frontalis como uma espécie incomum para o gênero, e a elegeu como um novo subgênero. Richards (1978) verificou esta espécie que, na verdade, tem a fórmula palpal 5:3 e não 6:3 como havia sido citado por Bequaert. Desta forma, Chartergus frontalis passou para o gênero Chartergellus, onde todas as espécies possuem a fórmula palpal 5:3. Richards (1978) cita que Chartergus frontalis de Bequaert apresenta variação e, provavelmente, não seria apenas uma espécie. Analisando essas variações, Richards (1978) elege uma das variações como $C$. amazonicus e a coloca como espécie-tipo do gênero. Realmente, essa espécie é diferente de C. frontalis, principalmente por apresentar uma pontuação distinta no tergito gastral, também observado por Richards (1978).

Os ninhos de Chartergellus são arbóreos, favos múltiplos e com pedicelo fibroso, envelope geralmente cinza e construído com fibras longas (Wenzel, 1998; veja também Figs. 4 e 5). Geralmente são camuflados com o local de nidificação o que confere proteção adicional contra predadores (Mateus et al., 1999). Os favos múltiplos 
crescem gradualmente para a margem, suspensos do substrato, um sob o outro, sem contato com o envelope (Wenzel 1998). O envelope, geralmente, é parcialmente removido para permitir a expansão do ninho, e a entrada é localizada na região inferior do envelope (Wenzel, 1998).

Em Carpenter (1991), Wenzel \& Carpenter (1994) e Noll (2000), o posicionamento deste gênero sempre esteve como grupo-irmão de Nectarinella. Em Wenzel (1993), Chartergellus é posicionado em uma politomia com Nectarinella e Leipomeles (= Marimbonda). De fato, Chartergellus possui o terceiro palpômero labial com uma cerda curvada, que também é compartilhado por Pseudopolybia, Parachartergus, Leipomeles, e Nectarinella, e coloca estes cinco gêneros em um clado distinto (ver também capítulo 2 -Pseudopolybia).

Este trabalho teve como objetivo a reconstrução filogenética das oito espécies de Chartergellus, utilizando caracteres morfológicos e de ninho. Uma nova chave de identificação, baseada na chave de Richards (1978) também é oferecida.

\section{2 - MATERIAIS E MÉTODOS}

Os materiais foram obtidos por empréstimos da Universidade Federal do Paraná, Curitiba, Paraná, Brasil (UFPR) e do Museum of Natural History, London, UK. Localidade dos exemplares analisados encontra-se no Apêndice 1.

Machos de C. communis (Pedregulho, São Paulo, Brasil), e C. atectus (Rio Branco, Acre, Reserva Catuaba) foram mantidos em câmara úmida para relaxamento e a genitália extraída. A cápsula genital foi clareada em lactofenol e examinada imersa em glicerina. A genitália destes taxóns estão ilustradas nas Figs. 2 e 3; os espécimes foram depositados na coleção de Hymenoptera da Faculdade de Filosofia, Ciências e Letras da Universidade de São Paulo (Ribeirão Preto). 
Vinte e três caracteres morfológicos de fêmeas e cinco de arquitetura de ninho foram plotados em uma matriz de dados para a reconstrução filogenética das relações entre as espécies de Chartergellus (Tabela 2). Os caracteres utilizados e seus respectivos estados estão listados na Tabela 1 e parcialmente ilustrados na Figura 1. Os caracteres foram tratados como aditivos, exceto os caracteres 5, 9, 10, $12,13,15,21$ e 22 . Os caracteres foram polarizados pelo enraizamento dos gruposexternos (Nixon \& Carpenter, 1993), sendo Agelaia, Angiopolybia, bem como outros quatro gêneros que possuem cerda curvada no ápice do palpo labial (Pseudopolybia, Leipomeles, Nectarinella e Parachartergus) utilizados para tal fim.

Richards (1978) descreve a genitália de macho para apenas três espécies (C. atectus, C. communis, e C. punctatior). Carpenter \& Mateus (2004: 299) redescrevem a genitália de C. punctatior. Mesmo não sendo utilizado em nossa análise filogenética, devido a poucas espécies descritas, redesenhamos a genitália de $C$. communis e $C$. atectus, uma vez que os desenhos de Richards (1978: 216) são de difícil interpretação.

\section{3 - RESULTADOS}

A análise da matriz resultou em um único cladograma com 60 passos, índice de consistência 0,71 e índice de retenção de 0,73 (Fig. 6). Chartergellus é suportado como grupo monofilético, tendo a seguinte relação entre as espécies: (C. afoveatus $+C$. punctatior $)+(($ C. amazonicus + C. communis $)+($ C. atectus $+($ C. zonatus $+(C$. nigerrimus + C. sanctus)))))).

\section{4 - DISCUSSÃO}

Na filogenia de Carpenter (1991) o ramo (Pseudopolybia + (Parachartergus + $($ Leipomeles $(=$ Marimbonda $)+($ Nectarinella + Chartergellus $))))$ é suportado como 
grupo monofilético por compartilharem uma forte cerda recurvada no terceiro palpômero labial, como já citado anteriormente, e confirmado neste capítulo (caráter 1, estado 1). A redução do número de palpômeros labiais de quatro para três é sinapomórfico para o ramo (Parachartergus + (Leipomeles (= Marimbonda) + (Nectarinella + Chartergellus) (Carpenter, 1991; Carpenter \& Mateus 2004), e o ramo (Leipomeles $(=$ Marimbonda $)+($ Nectarinella + Chartergellus $)$ teve o número de palpômeros maxilares reduzido de seis para cinco (Carpenter, 1991; Carpenter \& Mateus 2004). O clado Chartergellus + Nectarinella é suportado pela perda da carena occipital, característica também compartilhada por Pseudopolybia (Carpenter, 1991; Carpenter \& Mateus, 2004).

A topologia do clado (Pseudopolybia + (Parachartergus + (Leipomeles (= Marimbonda $)+($ Nectarinella + Chartergellus)))) apresentada por Carpenter (1991) e Wenzel \& Carpenter (1994), é bem estabelecida, no entanto, no cladograma para Chartergellus (Fig. 6) o posicionamento dos grupos externos é diferente do apresentado pelos autores citados, devido à pequena amostragem de espécies do grupo-externo, o que também ocorreu na análise de Pseudopolybia (ver capítulo 2).

Além da perda da carena occipital (caráter 11, estado 1) que é ambíguo na figura 6, o clado Chartergellus é suportado pelo espaço malar com aproximadamente o mesmo tamanho que o quarto artículo antenal (caráter 9, estado 1), e metanoto pequeno, achatado (caráter 21, estado 1). A concavidade propodeal quase reta (caráter 22, estado 3) é compartilhada por todas as espécies de Chartergellus, mas por estar presente também em Nectarinella, não é sinapomórfica para Chartergellus (Fig. 6). Mesmo não sendo utilizada nas filogenias de Carpenter (1991) e Wenzel \& Carpenter (1994), a concavidade propodeal é mais um indício de que a filogenia proposta pelos autores citados, posicionando Chartergellus como grupo-irmão de Nectarinella estaria correta. 
Outro caráter que é compartilhado por todas as espécies de Chartergellus, exceto $C$. sanctus, é o prestigma tão longo quanto largo (caráter 16, estado 1), que provavelmente teve origem independente dentro do gênero.

O clado C. afoveatus + C. punctatior compartilha apenas a mandíbula fortemente pronunciada (caráter 10, estado 3), como sinapomorfia. Outras características também são compartilhadas por este clado, mas não aparecem plotadas na figura 6. Estas duas espécies possuem o clípeo convexo (caráter 7, estado 0), e pêlos por toda a extensão do clípeo (caráter 8, estado 0). O clípeo achatado com cerdas somente na margem inferior é um caráter sinapomórfico para o clado (C. amazonicus + C. communis $)+($ C. atectus $+($ C. zonatus $+($ C. nigerrimus + C. sanctus $))))$, e mostra uma clara divisão do gênero em dois clados. O clípeo convexo com pêlos por toda a sua extensão é a característica plesiomófica do grupo, sendo também compartilhada por todas as espécies do grupo-externo. Apesar dos “padrões” clípeo convexo com pêlos por toda a sua extensão vs. clípeo achatado com pêlos somente na margem inferior serem sinapomorfias para os clados citados acima, C. sanctus possui clípeo achatado como caráter autapomórfico, que é compartilhado pelo ramo C. afoveatus + C. punctatior, o que pode representar origens independentes, mas com pêlos somente na margem inferior, que é compartilhado pelo restante do clado, no qual esta espécie está inserida.

C. amazonicus + C. communis compartilham o caráter 4 (estado 0) - olhos sem cerdas, que também é compartilhado por C. nigerrimus dentro de Chartergellus. Este caráter é amplamente variável dentro dos Epiponini, apresentando vários estados (ausentes, poucas cerdas, muitas cerdas), sendo difícil inferir um padrão evolutivo, e o mais aceito, como já discutido em outros capítulos, é assumir que os diversos estados tiveram origens independentes. O caráter 13 (pontuação no escuto, não muito densa, fina, estado 4), também é compartilhado por este clado, mas a otimização deste caráter é 
ambígua na figura 6. Richards (1978) utiliza a pontuação no escuto em sua chave, e é de suma importância para a identificação das espécies, no entanto em nossas análises este caráter não se mostrou informativo.

A base da mandíbula (caráter 10) é uma característica diagnóstica na identificação das espécies de Chartergellus, como salientado na chave de Richards (1978). Essa característica se mostrou elucidativa na separação dos clados e apresenta uma redução dentro de Chartergellus passando do estado fortemente proeminente (estado 3), sinapomórfico para o clado C. afoveatus + C. punctatior, distintamente proeminente (estado 2) no clado C. amazonicus $+C$. communis, e pouco proeminente no clado $C$. atectus $+($ C. zonatus $+($ C. nigerrimus $+C$. sanctus $))$, mesmo não sendo autopomorfias para os dois últimos clados citados foram importantes para o seu agrupamento.

O clípeo amplamente separado dos olhos (caráter 5, estado 2) é sinapomórfico para C. zonatus + (C. nigerrimus + C. sanctus $)$, no entanto, C. sanctus possui o clípeo estreitamente separado dos olhos, sendo homoplástico com C. communis. Além do caráter citado, Richards (1978) cita que C. nigerrimus e C. sanctus são as duas únicas espécies no gênero que possuem asas infuscadas (caráter 15, estado 1), que também foi confirmado em nosso trabalho, sendo a única sinapomorfia para esse clado.

Segundo Carpenter \& Mateus (2004) os cinco gêneros compartilham o processo basal do dígito angular, o que pode ser um indício de mais uma sinapomorfia para este clado; esta condição não é comum para os Polistinae sendo, pelo menos para as espécies descritas, exclusivo para este clado. Carpenter \& Mateus (2004) ainda citam que esta estrutura é menos desenvolvida em C. punctatior (Carpenter \& Mateus, 2004; Fig. 3), e pode ser variável para as espécies do gênero. Ao contrário de Carpenter \& Mateus (2004), não parece haver variações significativas quanto a essa estrutura (Figs. 2 e 3). 
Em C. atectus e C. punctatior a região apical do digito é mais estreita e mais longa do que em C. communis, o ângulo basal do parâmero em C. communis parece ser mais agudo que em C. punctatior e C. atectus. C. communis também se diferencia por apresentar o processo ventral do edeago menos angular que nas outras espécies descritas. Certamente, análises da genitália de macho de mais espécies de Chartergellus serão necessárias para se inferir sobre a evolução dessas estruturas.

\section{5 - CHAVE DE IDENTIFICAÇÃO PARA AS ESPÉCIES DE CHARTERGELLUS}

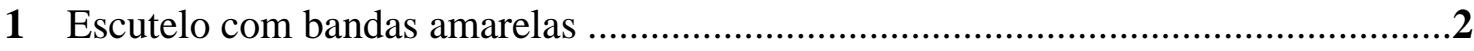

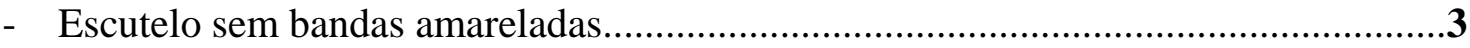

2 Pronoto sem fóvea lateral; tergos metassomais II-V com bandas amareladas largas na região apical afoveatus Cooper

- Metassoma com somente os dois primeiros ou terceiro tergo com bandas amareladas zonatus (Spinola)

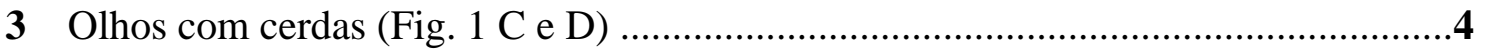

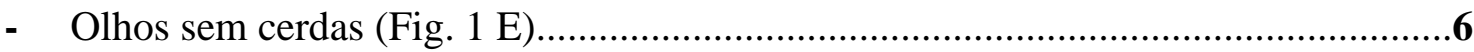

4 Clípeo amplamente separado dos olhos (Fig. 1 C); base da mandíbula pouco proeminente (Fig. 1 F); escuto com pontuação densa, enrugada .......sanctus Richards

- Clípeo estreitamente separado dos olhos (Fig. 1 E); base da mandíbula mais ou menos proeminente, escuto com pontuação menos densa, enrugadas .5

5 Mandíbulas com a margem basal fortemente evidente punctatior Richards

- Mandíbulas gradualmente proeminente (Fig. 1 G), mas não formando uma margem distinta atectus Richards 
6 Fenda escrobal larga, rasa, evanescente na região inferior; base da mandíbula proeminente, mas não forma uma margem distinta; espaço malar claramente mais longo do que o quarto artículo antenal .................................... nigerrimus Richards

- Fenda escrobal estreita, profunda, não evanescente na região inferior; base da mandíbula proeminente (Fig. $1 \mathrm{H}$ ), formando uma margem; espaço malar tão longo quanto o quarto artículo antenal

7 Clípeo tocando os olhos; face amarela, creme .amazonicus Richards

- Clípeo estreitamente separado dos olhos (Fig. 1 E); face avermelhada communis Richards 
Tabela 1 - Lista de caracteres para Chartergellus.

1. Terceiro palpômero labial: sem cerda curvada $=0$; com cerda curvada $=1$.

2. Palpo maxilar: $6=0 ; 5=1$.

3. Palpo labial: $4=0 ; 3=1$.

4. Olhos: sem cerdas $=0$ (Fig. $1 \mathrm{E})$; com cerdas $=1$ (Fig. $1 \mathrm{C} \mathrm{e} \mathrm{D)}$.

5. Clípeo: tocando os olhos $=0$ (Fig. 1 D); estreitamente separado dos olhos $=1$ (Fig. 1 E); amplamente separado dos olhos = 2 (Fig. 1 C).

6. Margem lateral do clípeo: sinuosa = 0 (Fig. 1 D); reta = 1 (Fig. 1 E).

7. Perfil do clípeo: convexo = 0 (Fig. 1 B); achatado = 1 (Fig. 1 A).

8. Cerdas no clípeo: presente em toda a extensão = 0 (Fig. 1 B); presente somente na margem inferior $=1$ (Fig. $1 \mathrm{~A})$.

9. Espaço malar: menor do que o quarto artículo antenal =0; aproximadamente com o mesmo tamanho do quarto artículo antenal $=1$; maior do que o quarto artículo antenal $=2$.

10. Base da mandíbula: não proeminente = 0; pouco proeminente = 1 (Fig. 1 F e G); distintamente proeminente $=2$ (Fig. $1 \mathrm{H})$; fortemente proeminente $=3$ (Fig. $1 \mathrm{I})$.

11. Carena occipital: presente $=0$; ausente $=1$.

12. Carena pronotal dorsal: terminando próxima à margem posterior do pronoto = 0 ; terminando próximo da região mediana do pronoto $=1$; fraca, evanescente $=$ 2; traço, ausente $=3$.

13. Pontuação no escuto: ausente $=0$; densa, fortemente enrugada $=1$; densa, enrugada $=2$; densa, fina $=3$; não muito densa, fina $=4$; esparsa, fina $=5$.

14. Carena pré-tegular: presente $=0$; ausente $=1$.

15. Cor da asa: hialina $=0$; infuscada $=1$; escura $=2$; enegrecida $=3$. 
16. Prestigma: tão longo quanto largo $=0$; mais longo do que largo $=1$.

17. Fenda dorsal: presente $=0$; ausente $=1$.

18. Sulco escrobal: presente $=0$; ausente $=1$

19. Escutelo: sem linha impressa $=0$; com linha impressa $=1$.

20. Forma do escutelo: angular $=0$; arredondado $=1$.

21. Metanoto: longo curvado $=0$; curto, achatado $=1$; vertical $=2$.

22. Concavidade propodeal: estreita $=0$; ampla, rasa $=1$; ampla, profunda $=2$; propódeo quase reto $=3$.

23. Primeiro segmento metassomal: mais longo do que largo = 0; tão longo quanto largo, ou mais largo do que longo $=1$.

24. Envelope do ninho: ausente $=0$; presente, camada única $=1$; presente, várias camadas $=2$

25. Pedicelo do ninho: ausente $=0$; presente $=1$.

26. Entrada do ninho: tubo posicionado para baixo $=0$; entrada simples $=1$

27. Favo: séssil $=0$; pedicelado $=1$

28. Posição dos favos pedicelados: horizontal suspenso pelo centro = 0; inclinado, suspenso pelo substrato. 
Tabela 2 - Matriz de dados para Chartergellus. (-) = não aplicável.

\begin{tabular}{lllllllllllllllllllllllllllllll}
\hline & $\mathbf{1}$ & $\mathbf{2}$ & $\mathbf{3}$ & $\mathbf{4}$ & $\mathbf{5}$ & $\mathbf{6}$ & $\mathbf{7}$ & $\mathbf{8}$ & $\mathbf{9}$ & $\mathbf{1}$ & $\mathbf{1}$ & $\mathbf{1}$ & $\mathbf{1}$ & $\mathbf{1}$ & $\mathbf{1}$ & $\mathbf{1}$ & $\mathbf{1}$ & $\mathbf{1}$ & $\mathbf{1}$ & $\mathbf{2}$ & $\mathbf{2}$ & $\mathbf{2}$ & $\mathbf{2}$ & $\mathbf{2}$ & $\mathbf{2}$ & $\mathbf{2}$ & $\mathbf{2}$ & $\mathbf{2}$ \\
& & & & & & & & & & $\mathbf{0}$ & $\mathbf{1}$ & $\mathbf{2}$ & $\mathbf{3}$ & $\mathbf{4}$ & $\mathbf{5}$ & $\mathbf{6}$ & $\mathbf{7}$ & $\mathbf{8}$ & $\mathbf{9}$ & $\mathbf{0}$ & $\mathbf{1}$ & $\mathbf{2}$ & $\mathbf{3}$ & $\mathbf{4}$ & $\mathbf{5}$ & $\mathbf{6}$ & $\mathbf{7}$ & $\mathbf{8}$ \\
\hline Agelaia cajennensis & 0 & 0 & 0 & 1 & 0,1 & 0 & 0 & 0 & 0 & 0 & 0 & 3 & 0 & 0 & 0 & 1 & 0 & 0 & 1 & 0 & 0 & 0 & 0 & 0 & 1 & - & 0 & 0 \\
Angiopolybia pallens & 0 & 0 & 0 & 1 & 0 & 0 & 0 & 0 & 0 & 0 & 0 & 3 & 0 & 0 & 0 & 0 & 0 & 0 & 0 & 0 & 0 & 0 & 0 & 1 & 1 & 0 & 0 & 0 \\
Pseudopolybia difficilis & 1 & 0 & 0 & 0 & 0 & 0 & 0 & 0 & 0 & 0 & 1 & 1 & 0 & 0 & 0 & 0 & 0 & 0 & 1 & 0 & 0 & 1 & 0 & 2 & 1 & 1 & 0 & 0 \\
Parachartergus fraternus & 1 & 0 & 1 & 1 & 0 & 1 & 0 & 0 & 0 & 2 & 0 & 0 & 2 & 1 & 3 & 1 & 1 & 1 & 1 & 0 & 0 & 2 & 1 & 1 & 1 & 0 & 0 & 1 \\
Leipomeles dorsata & 1 & 1 & 1 & 0 & 0 & 0 & 0 & 0 & 0 & 1 & 0 & 2 & 0 & 0 & 0 & 0 & 1 & 0 & 1 & 0 & 0 & 0 & 0 & 1 & 1 & 0 & 0 & 1 \\
Nectarinella xavantinensis & 1 & 1 & 1 & 0 & 1 & 1 & 0 & 0 & 0 & 0 & 1 & 0 & 1 & 0 & 0 & 0 & 1 & 0 & 1 & 1 & 2 & 3 & 1 & 1 & 0 & 0 & 1 & - \\
Chartergellus afoveatus & 1 & 1 & 1 & 1 & 0 & 0 & 0 & 0 & 1 & 3 & 1 & 0 & 4 & 0 & 0 & 0 & 1 & 0 & 1 & 0 & 1 & 3 & 1 & 1 & 1 & 0 & 0 & 1 \\
Chartergellus amazonicus & 1 & 1 & 1 & 0 & 0 & 1 & 1 & 1 & 1 & 2 & 1 & 0 & 3 & 0 & 0 & 0 & 1 & 0 & 1 & 0 & 1 & 3 & 1 & 1 & 1 & 0 & 0 & 1 \\
Chartergellus atectus & 1 & 1 & 1 & 1 & 0 & 0 & 1 & 1 & 1 & 1 & 1 & 0 & 3 & 0 & 0 & 0 & 1 & 0 & 1 & 0 & 1 & 3 & 1 & 1 & 1 & 0 & 0 & 1 \\
Chartergellus communis & 1 & 1 & 1 & 0 & 1 & 1 & 1 & 1 & 1 & 2 & 1 & 0 & 4 & 0 & 0 & 0 & 1 & 0 & 1 & 0 & 1 & 3 & 1 & 1 & 1 & 0 & 0 & 1 \\
Chartergellus nigerrimus & 1 & 1 & 1 & 0 & 1 & 1 & 1 & 1 & 2 & 1 & 1 & 0 & 3 & 0 & 1 & 0 & 1 & 0 & 1 & 0 & 1 & 3 & 1 & 1 & 1 & 0 & 0 & 1 \\
Chartergellus punctatior & 1 & 1 & 1 & 1 & 0 & 1 & 0 & 0 & 2 & 3 & 1 & 0 & 3 & 0 & 0 & 0 & 1 & 0 & 1 & 0 & 1 & 3 & 1 & 1 & 1 & 0 & 0 & 1 \\
Chartergellus sanctus & 1 & 1 & 1 & 1 & 2 & 1 & 0 & 1 & 2 & 1 & 1 & 0 & 2 & 0 & 1 & 1 & 1 & 0 & 1 & 0 & 1 & 3 & 1 & 1 & 1 & 0 & 0 & 1 \\
Chartergellus zonatus & 1 & 1 & 1 & 1 & 2 & 1 & 1 & 1 & 1 & 1 & 1 & 0 & 5 & 0 & 0 & 0 & 1 & 0 & 1 & 0 & 1 & 3 & 1 & 1 & 1 & 0 & 0 & 1 \\
& & & & & & & & & & & & & & & & & & & & & & & & & &
\end{tabular}




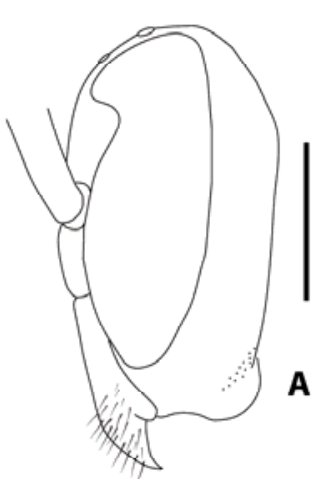

C. communis

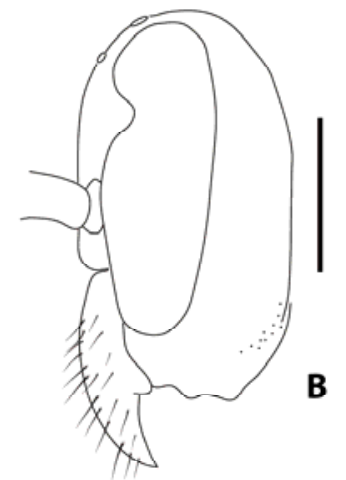

C. sanctus
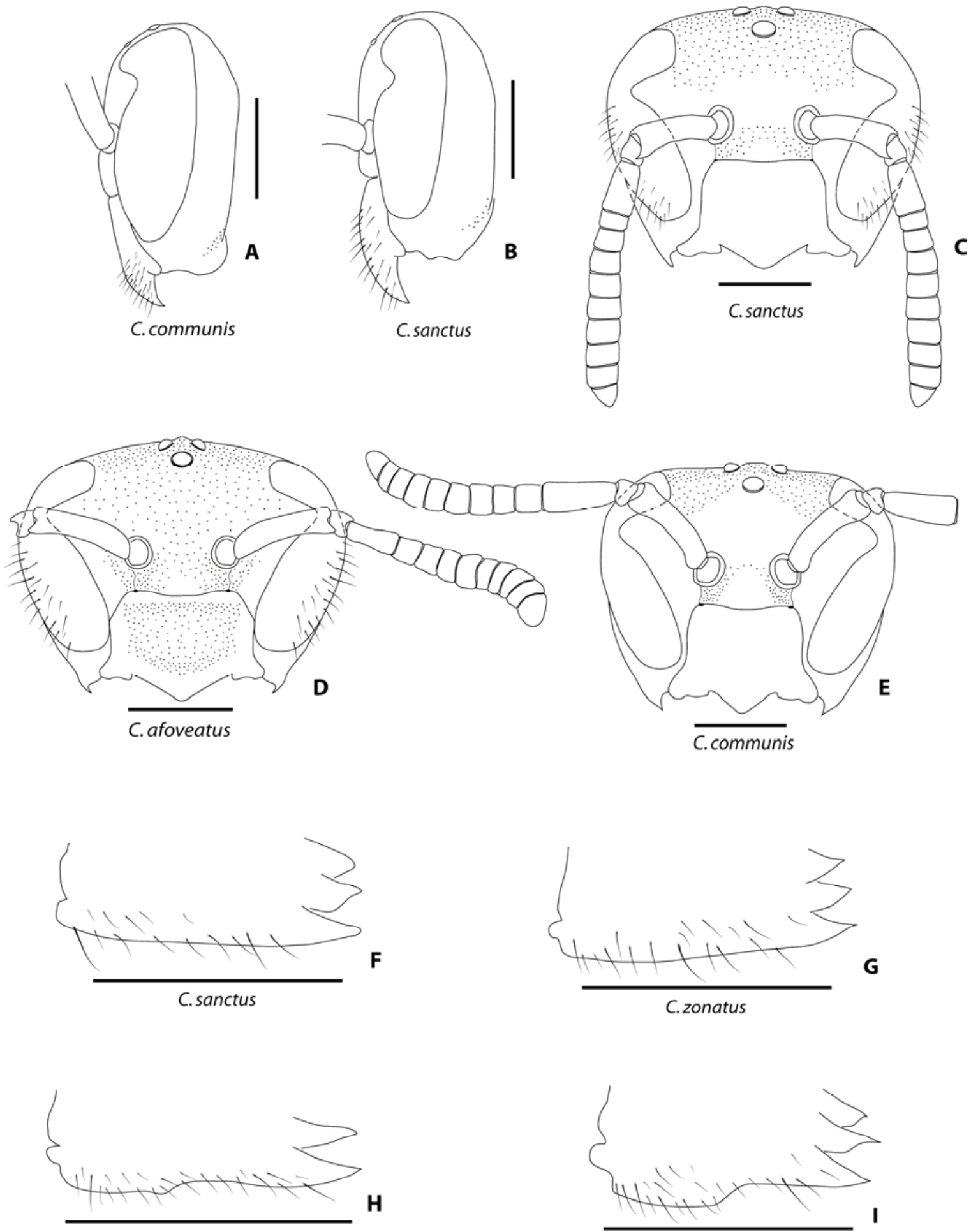

C. communis

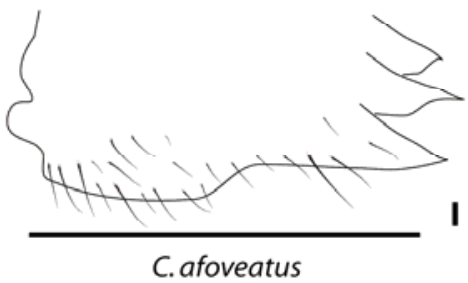

Figura 1 - Cabeça e mandíbula de Chartergellus. A e B = cabeça, visão lateral; C, D e E = cabeça, visão frontal; F, G, H e I = Mandíbula, visão frontal. Escala = 1,0 mm. 


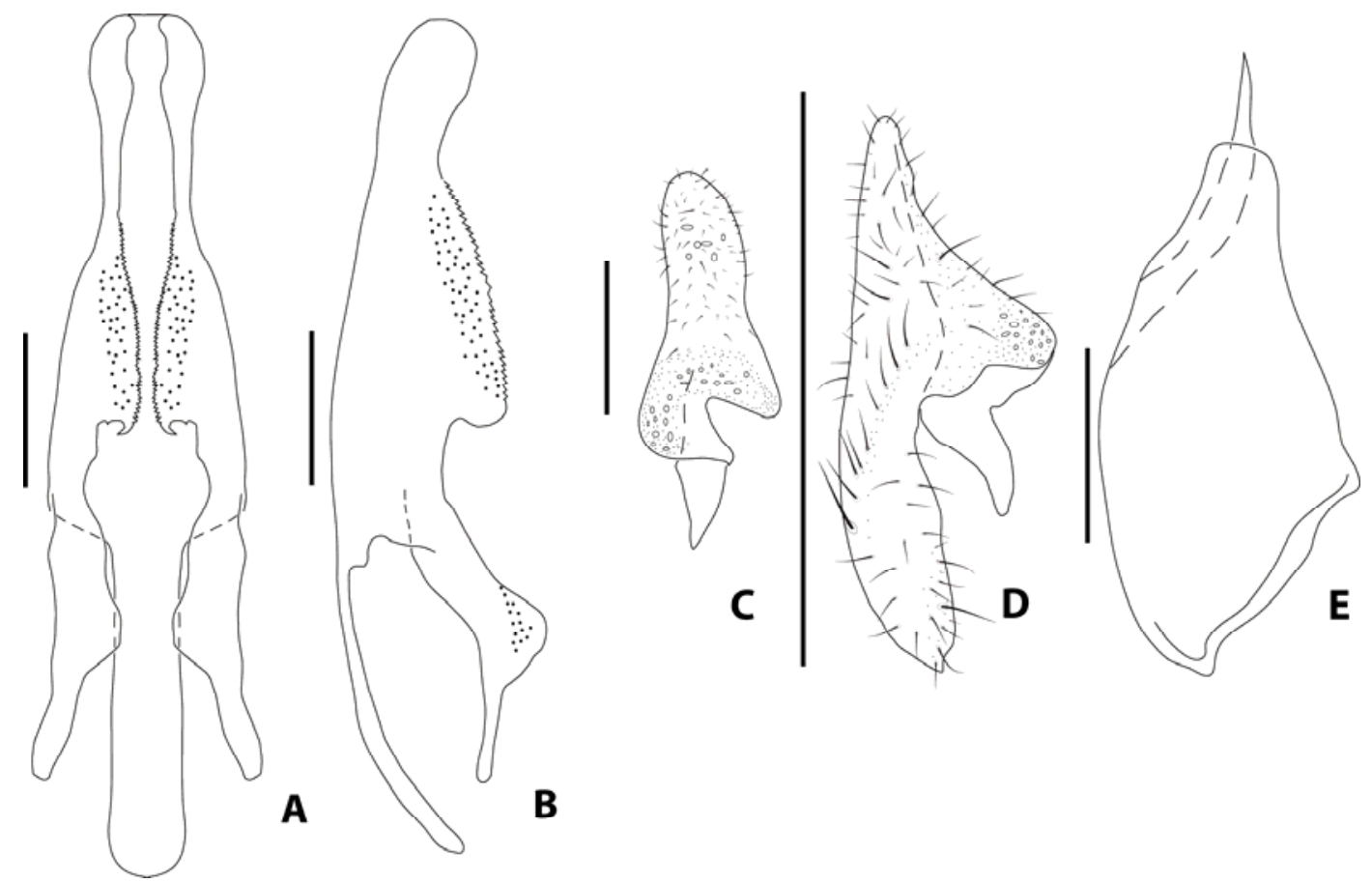

Figura 2 - Chartergellus communis. A = edeago, visão ventral; B = edeago, visão lateral; $\mathrm{C}$ = dígito, visão lateral; $\mathrm{D}$ = cuspis, visão lateral; $\mathrm{E}$ = parâmero, visão lateral. Escala $=0,25 \mathrm{~mm}$.
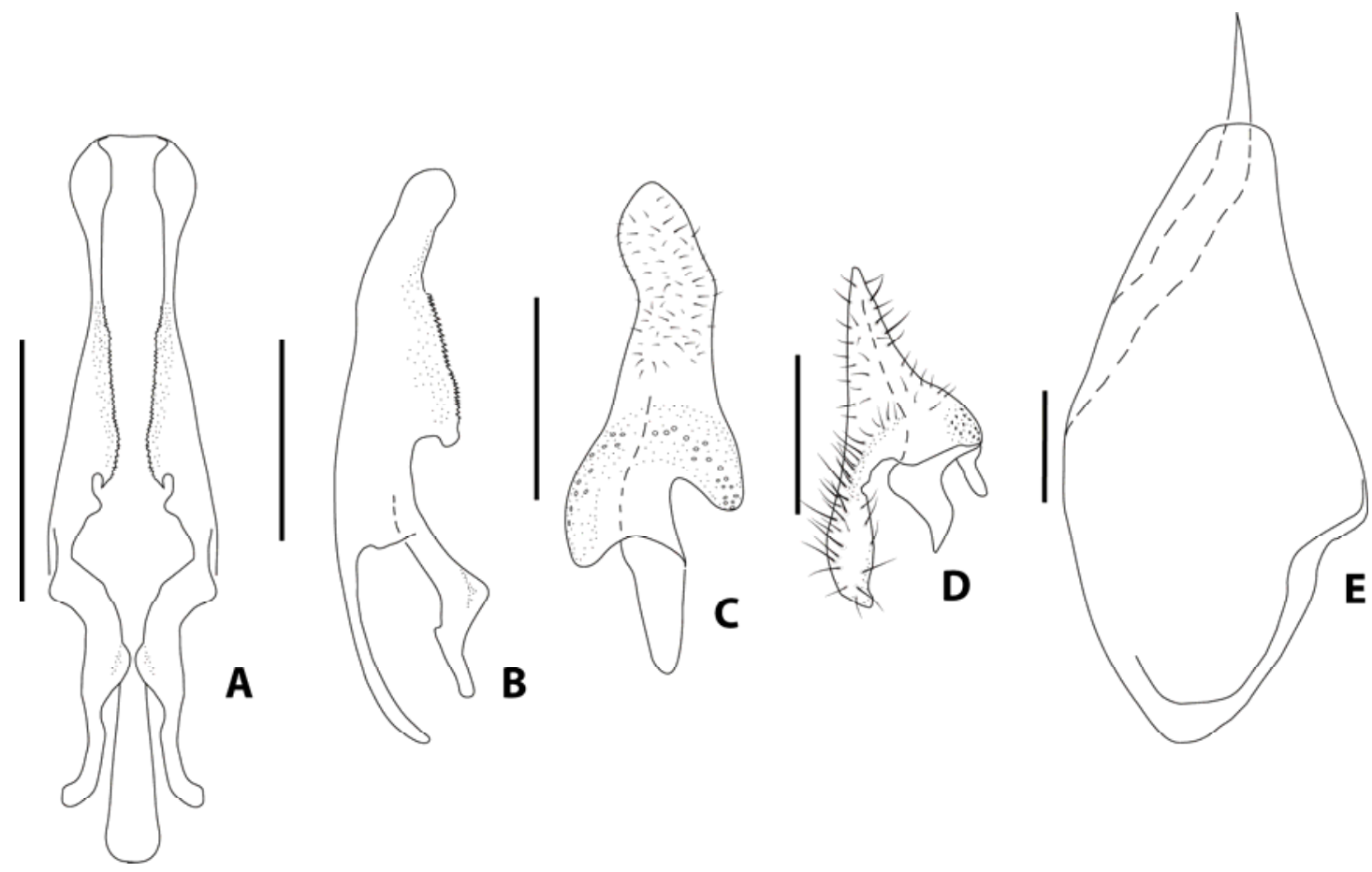

Figura 3 - Chartergellus atectus. A = edeago, visão ventral; B = edeago, visão lateral; $\mathrm{C}$ = dígito, visão lateral; $\mathrm{D}$ = cuspis, visão lateral; $\mathrm{E}$ = parâmero, visão lateral. Escala = $0,25 \mathrm{~mm}$. 


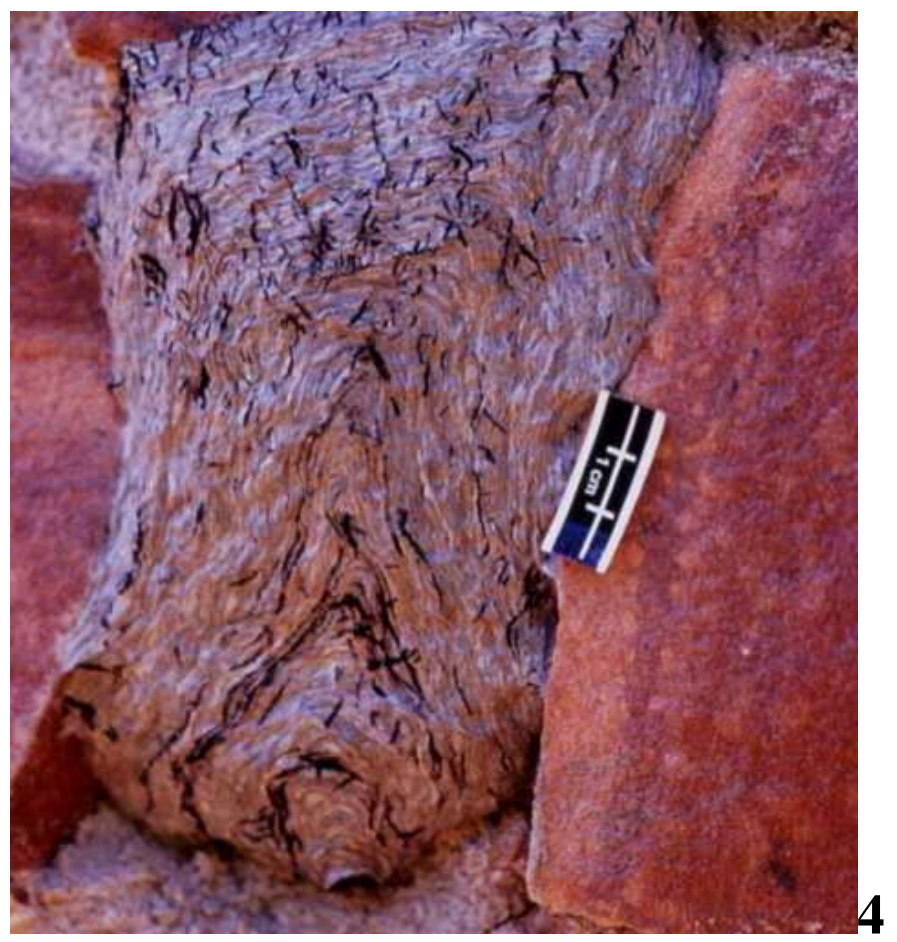

Figura 4 - Ninho de Chartergellus communis coletado em Pedregulho-SP, em 2005. Foto: Sidnei Mateus

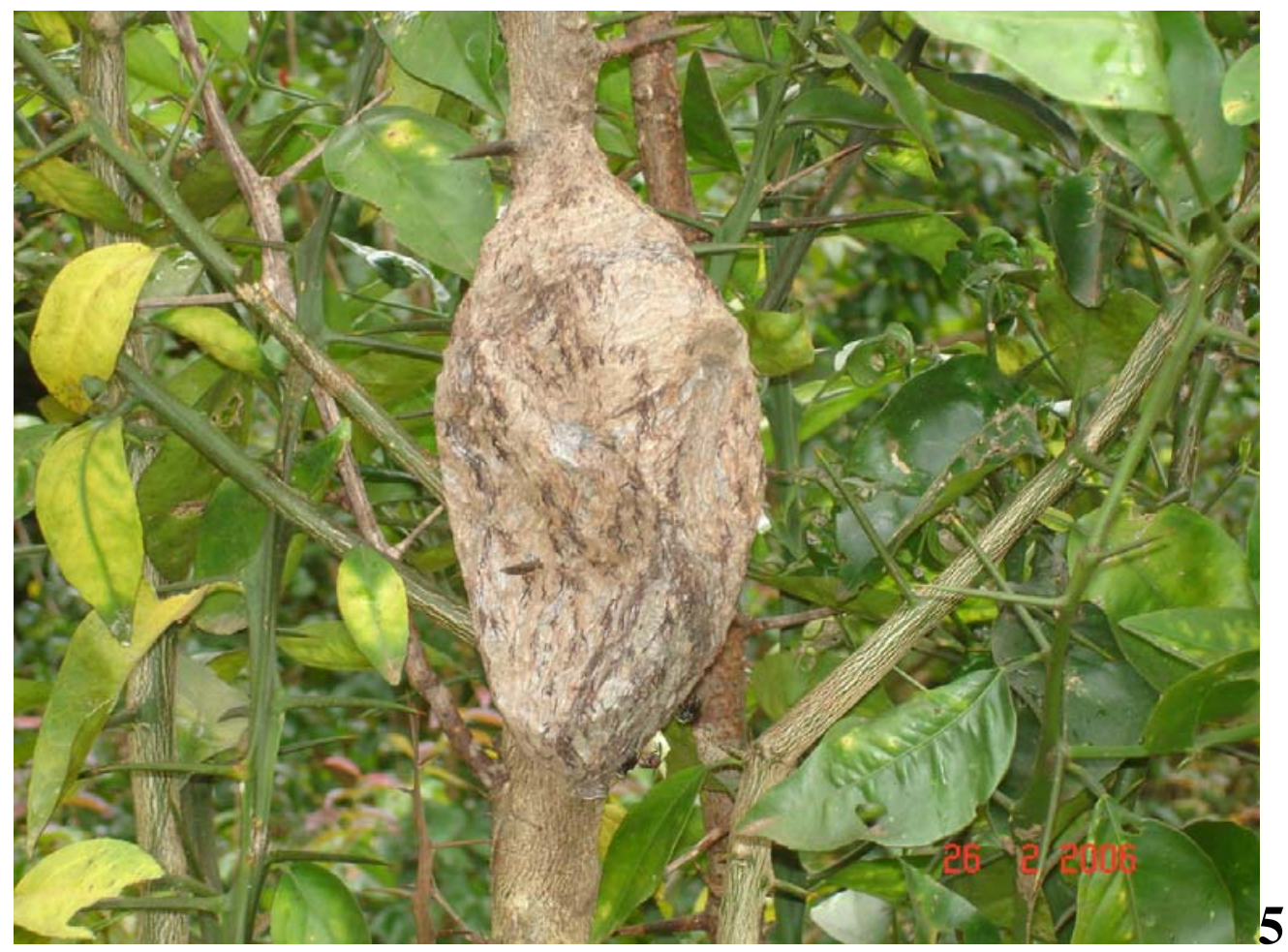

Figura 5 - Ninho de Chartergellus communis coletado em Pedregulo-SP, em 2005. Foto: Sidnei Mateus 


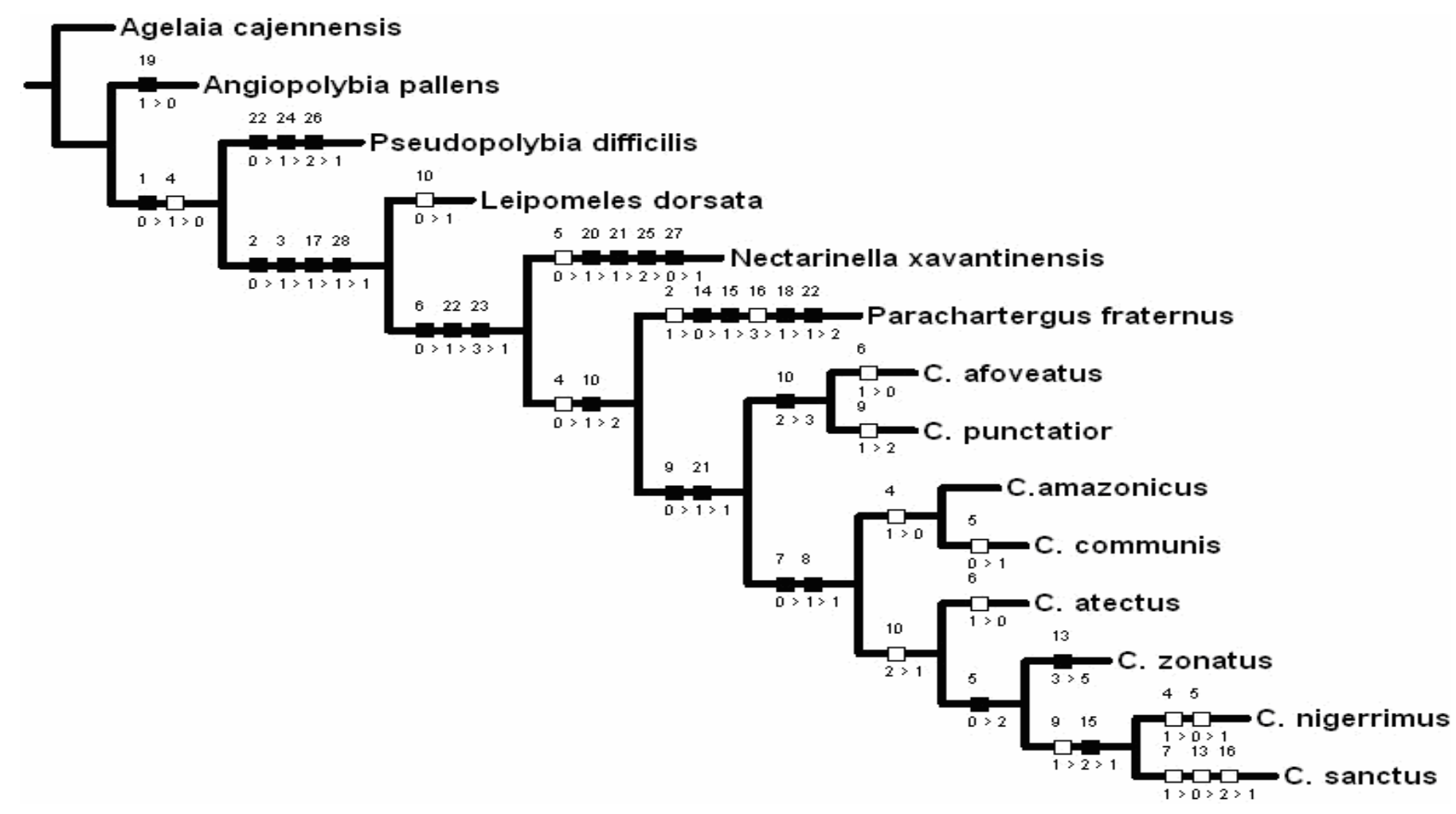

Figura 6 - Cladograma de Chartergellus com 60 passos, índice de consistência 0,71 e índice de retenção de 0,73; baseado na matriz de dados da Tabela 2. Somente caracteres não ambíguos estão plotados. O número de cada caráter está sobre os quadrados, enquanto que a transição de cada estado está abaixo, separado por “>.” 
Capítulo 3 - Chartergellus 

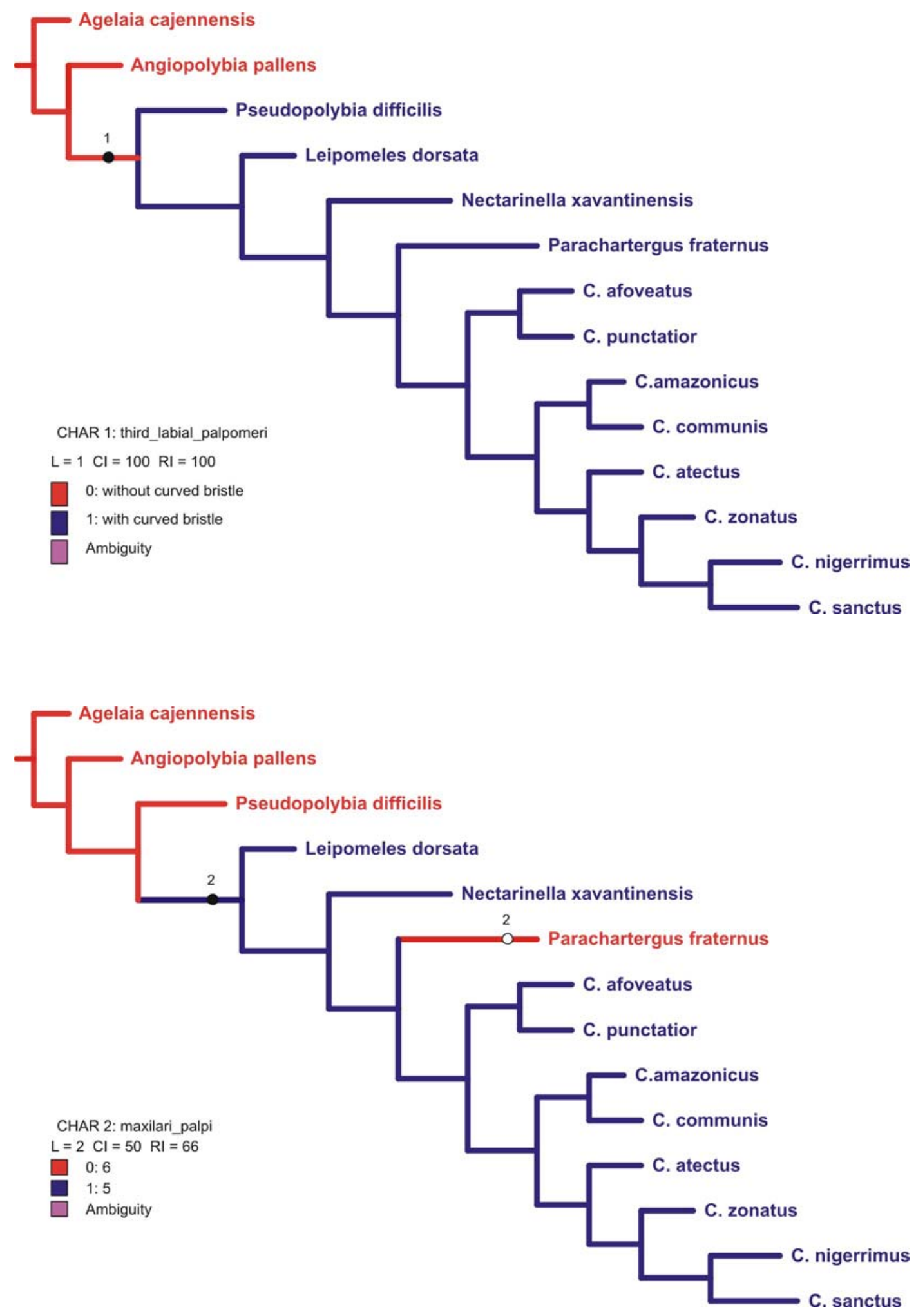

Figura 7 - Otimização dos caracteres 1 e 2. 

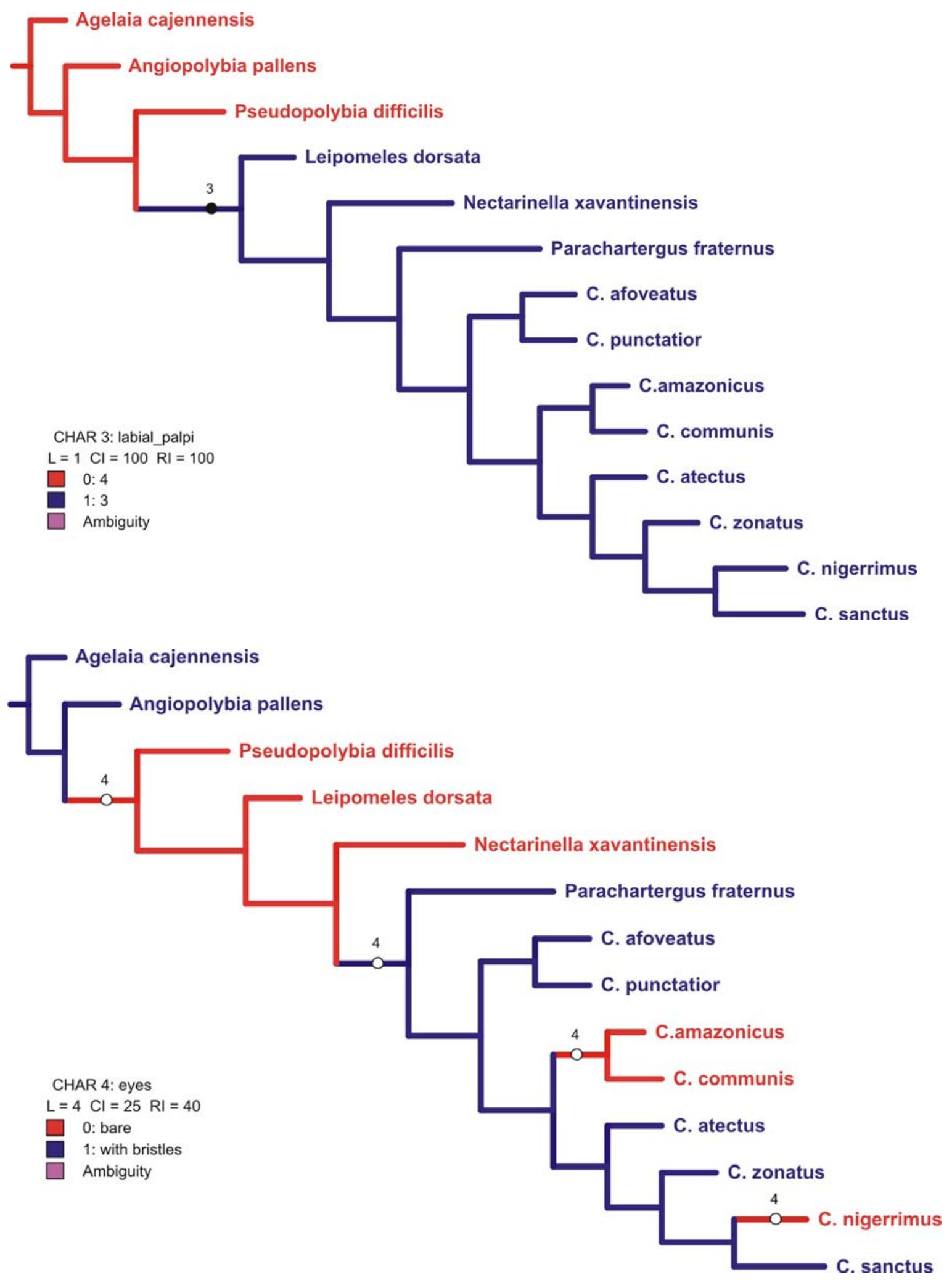

Figura 8 - Otimização dos caracteres 3 e 4. 

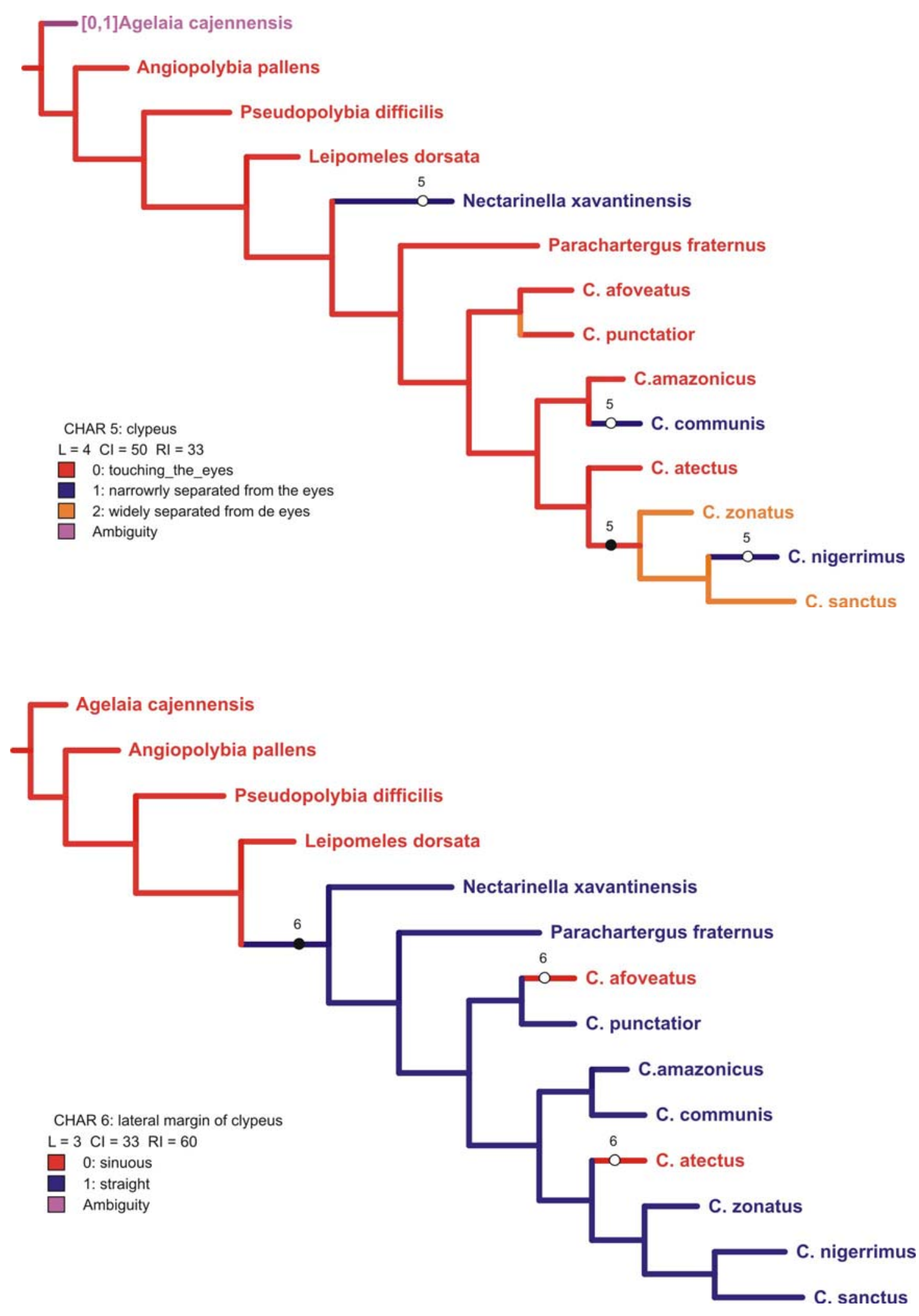

Figura 9 - Otimização dos caracteres 5 e 6. 

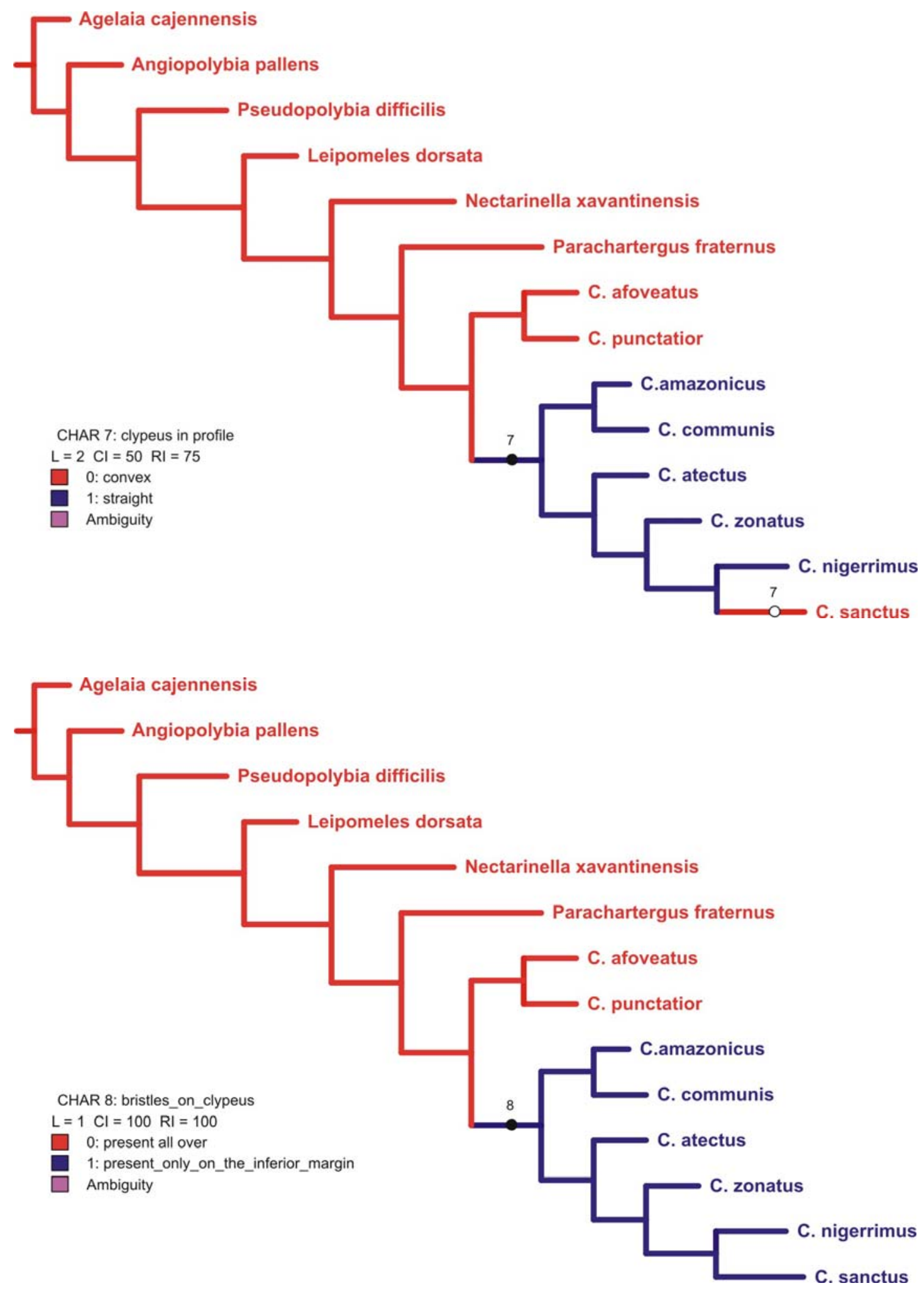

Figura 10 - Otimização dos caracteres 7 e 8. 

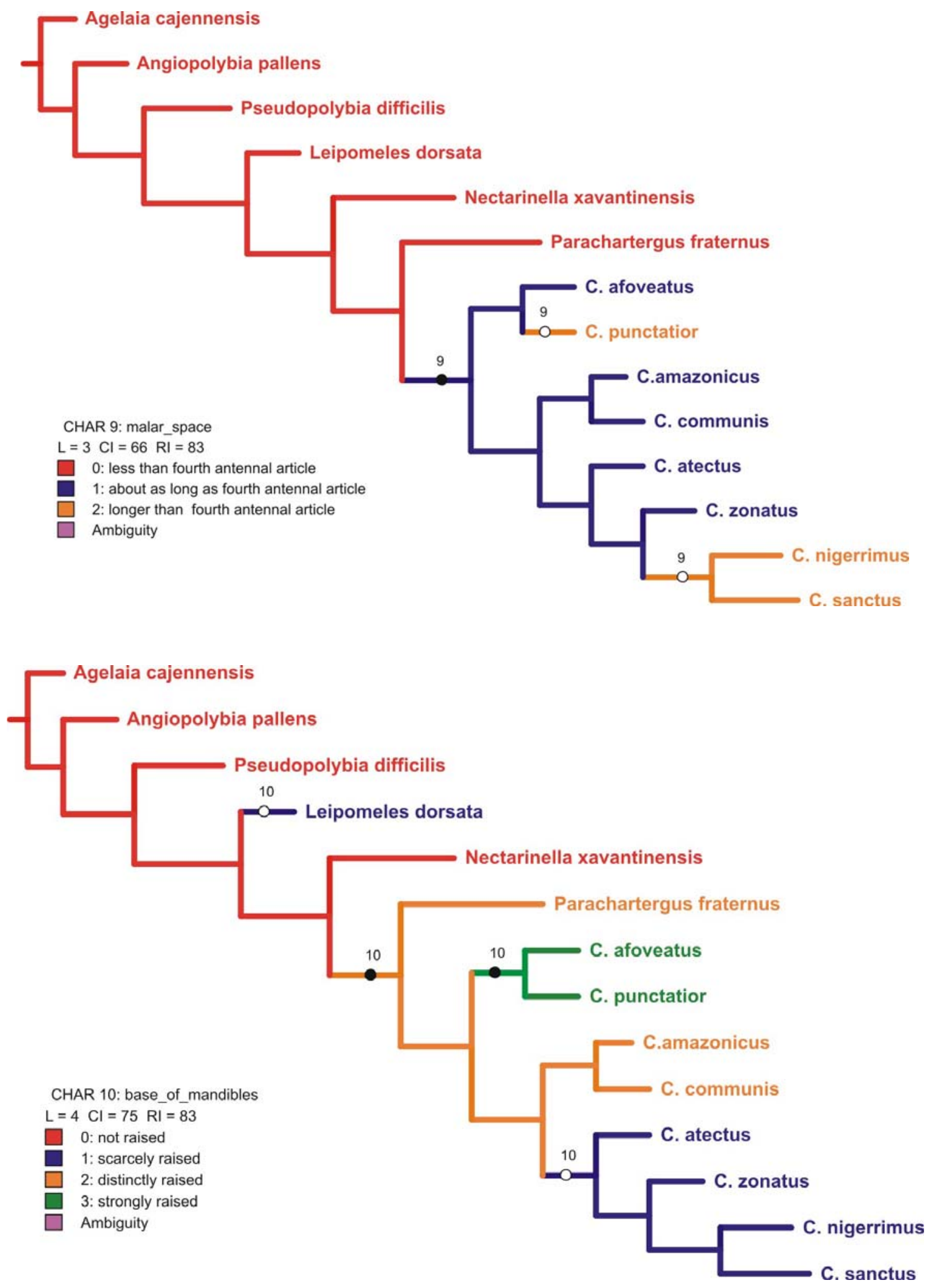

Figura 11 - Otimização dos caracteres 9 e 10. 

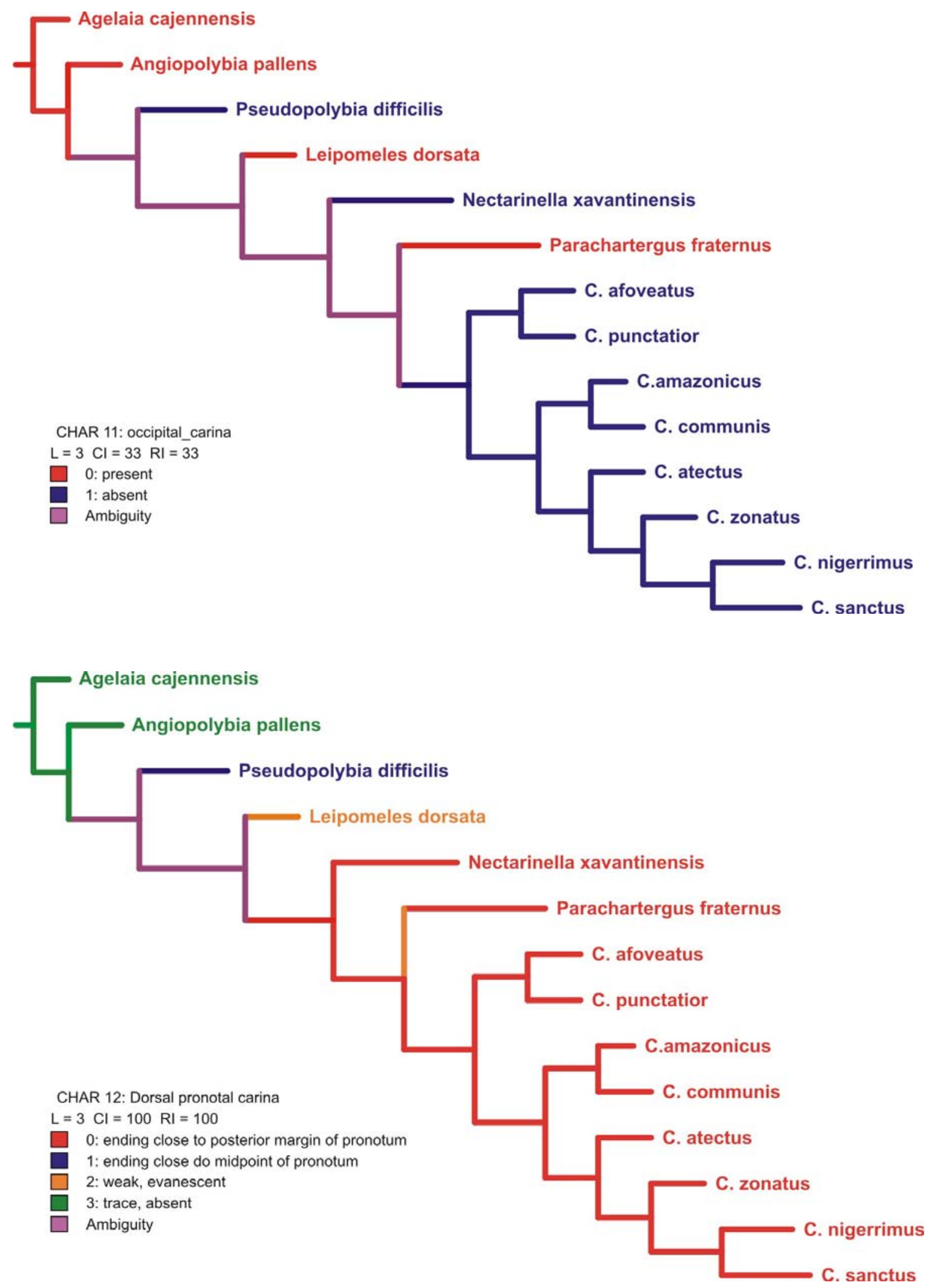

Figura 12 - Otimização dos caracteres 11 e 12. 

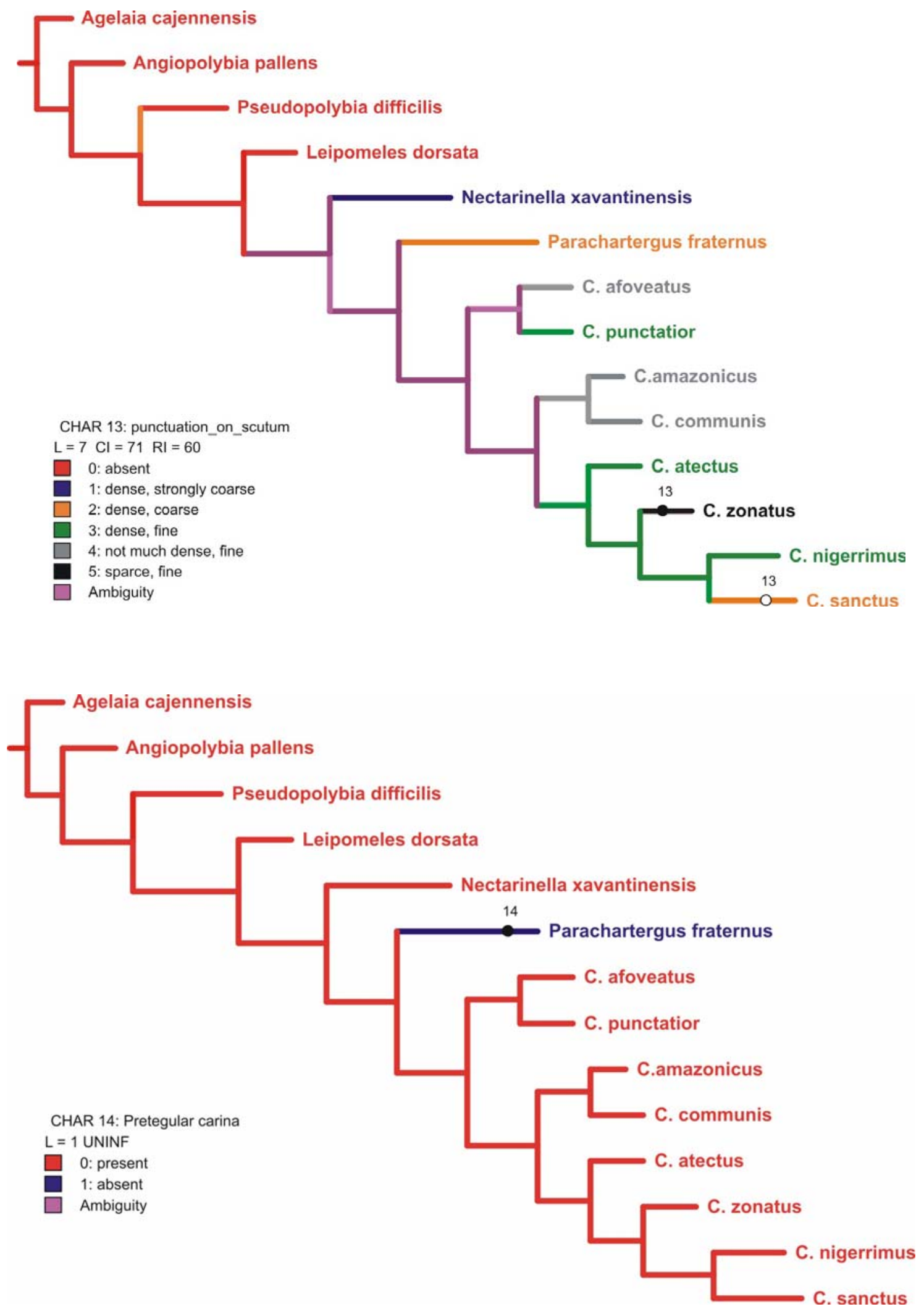

Figura 13 - Otimização dos caracteres 13 e 14. 

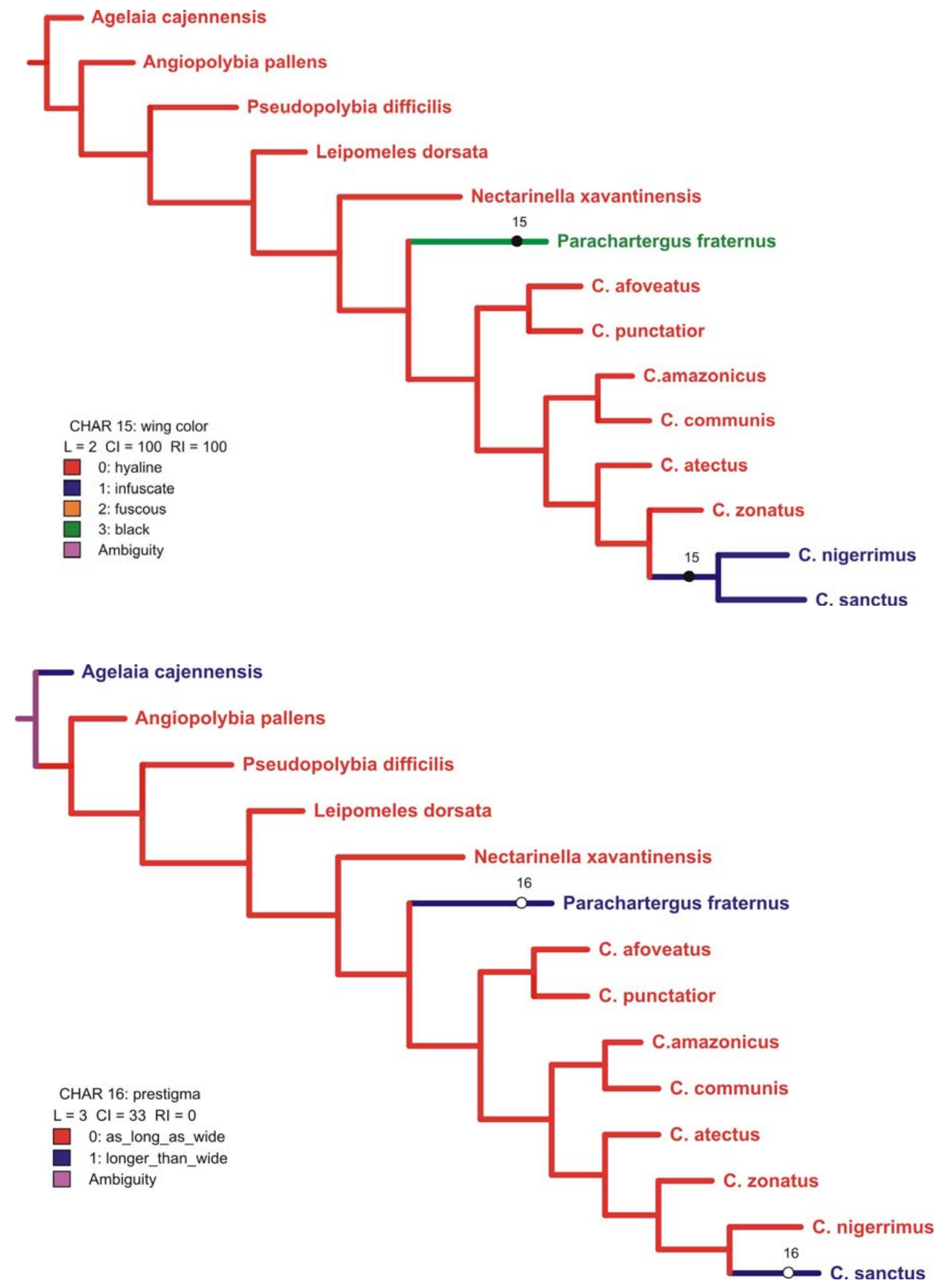

Figura 14 - Otimização dos caracteres 15 e 16. 

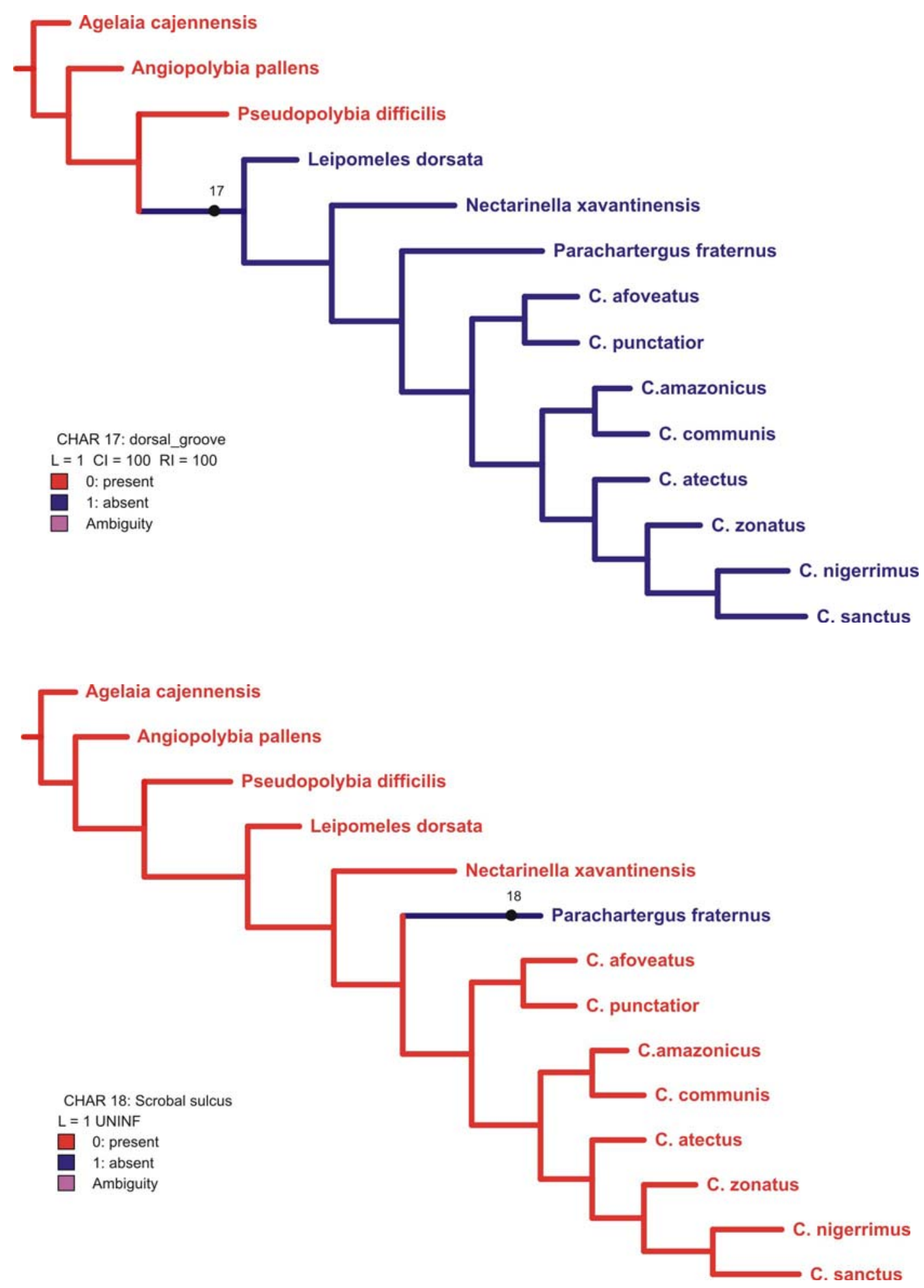

Figura 15 - Otimização dos caracteres 17 e 18. 


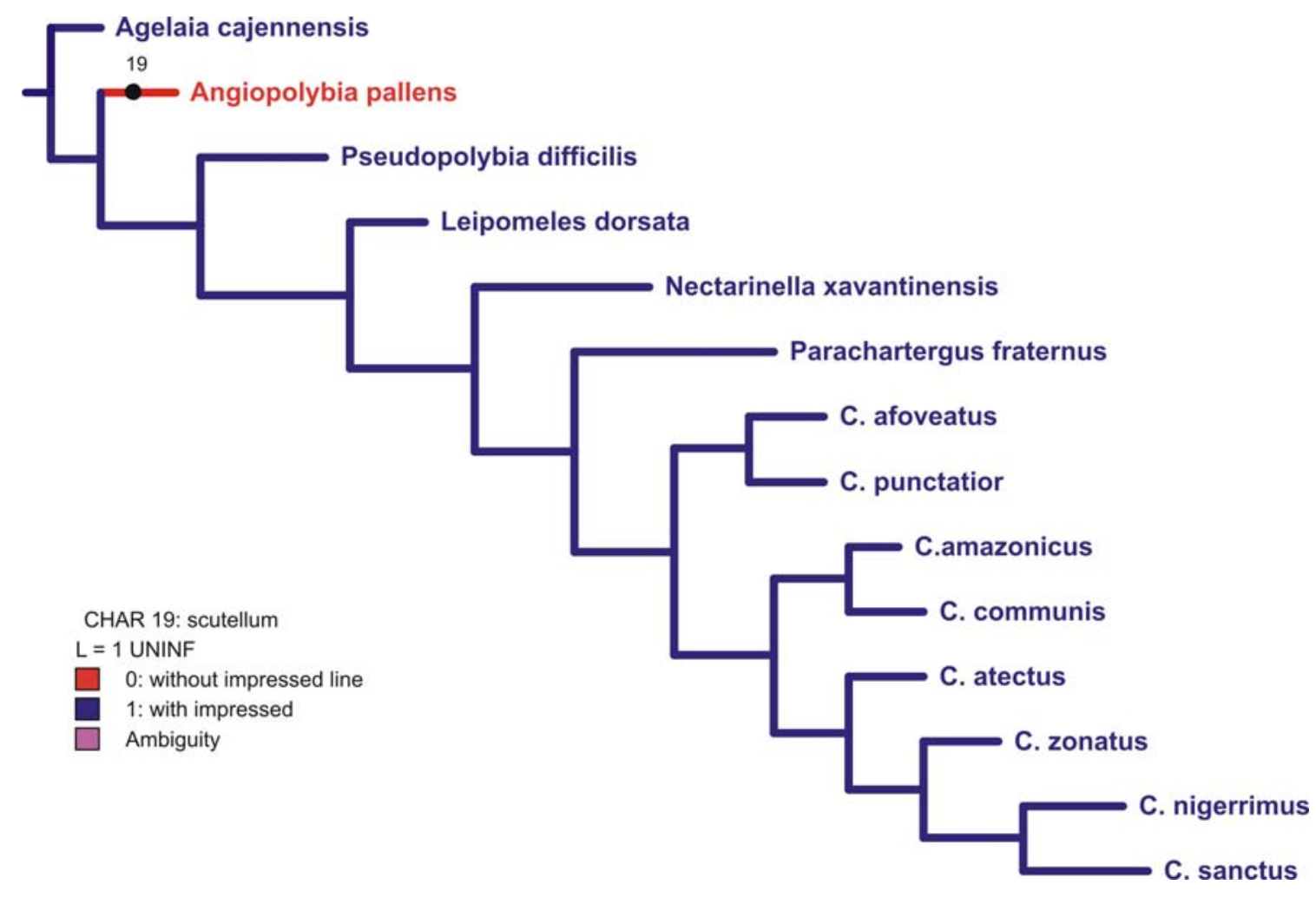

Agelaia cajennensis

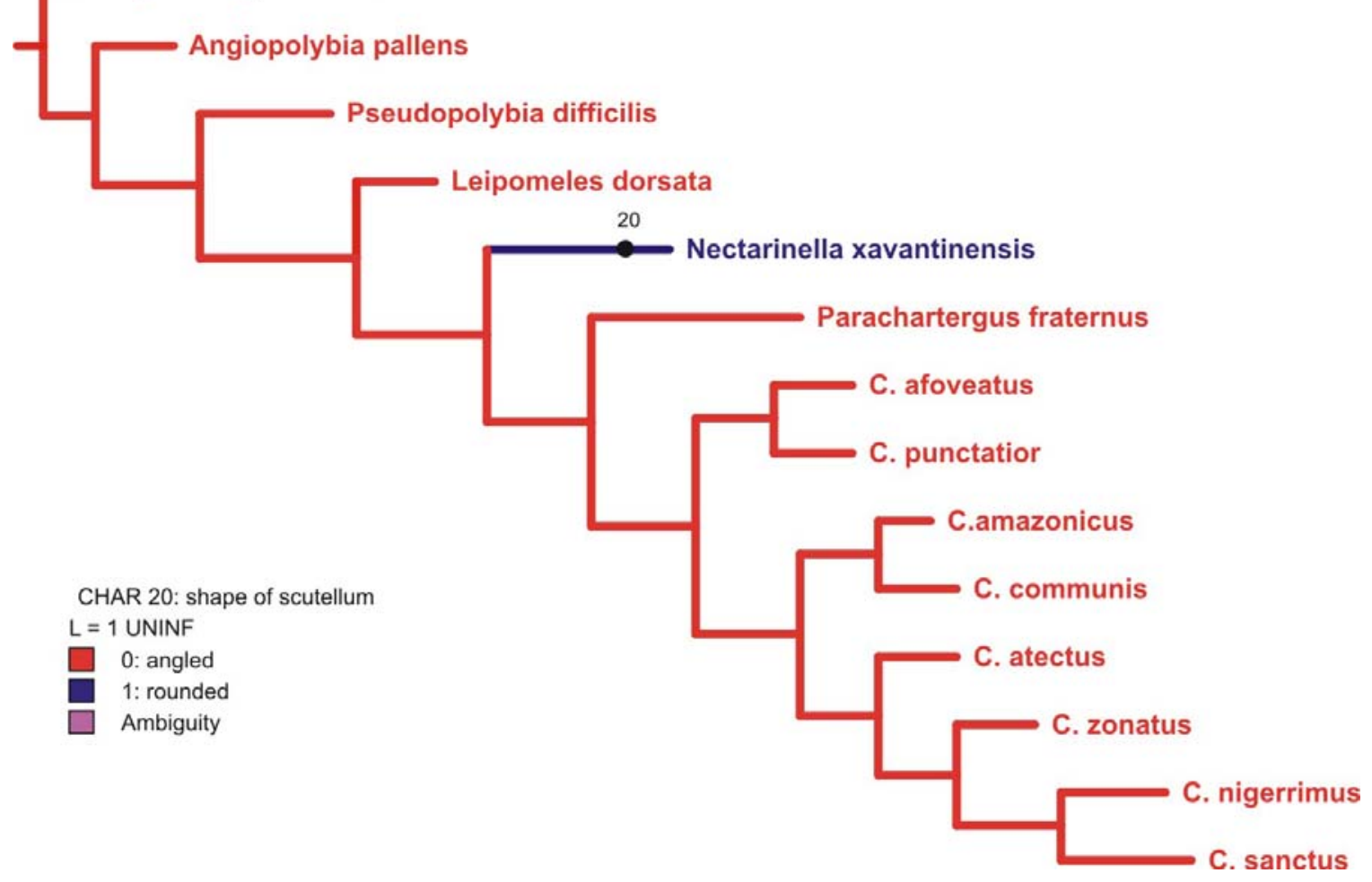

Figura 16 - Otimização dos caracteres 19 e 20. 

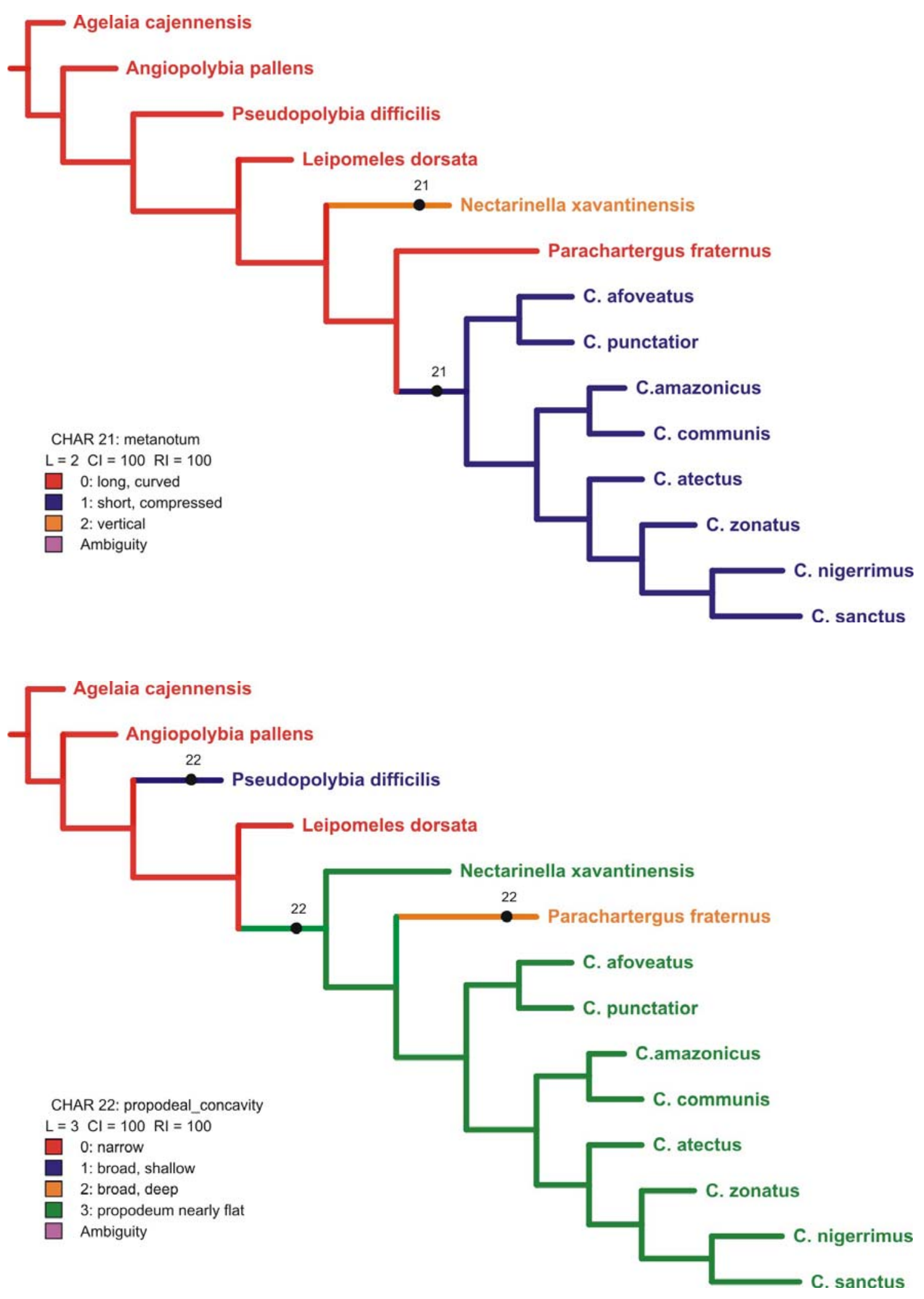

Figura 17 - Otimização dos caracteres 21 e 22. 

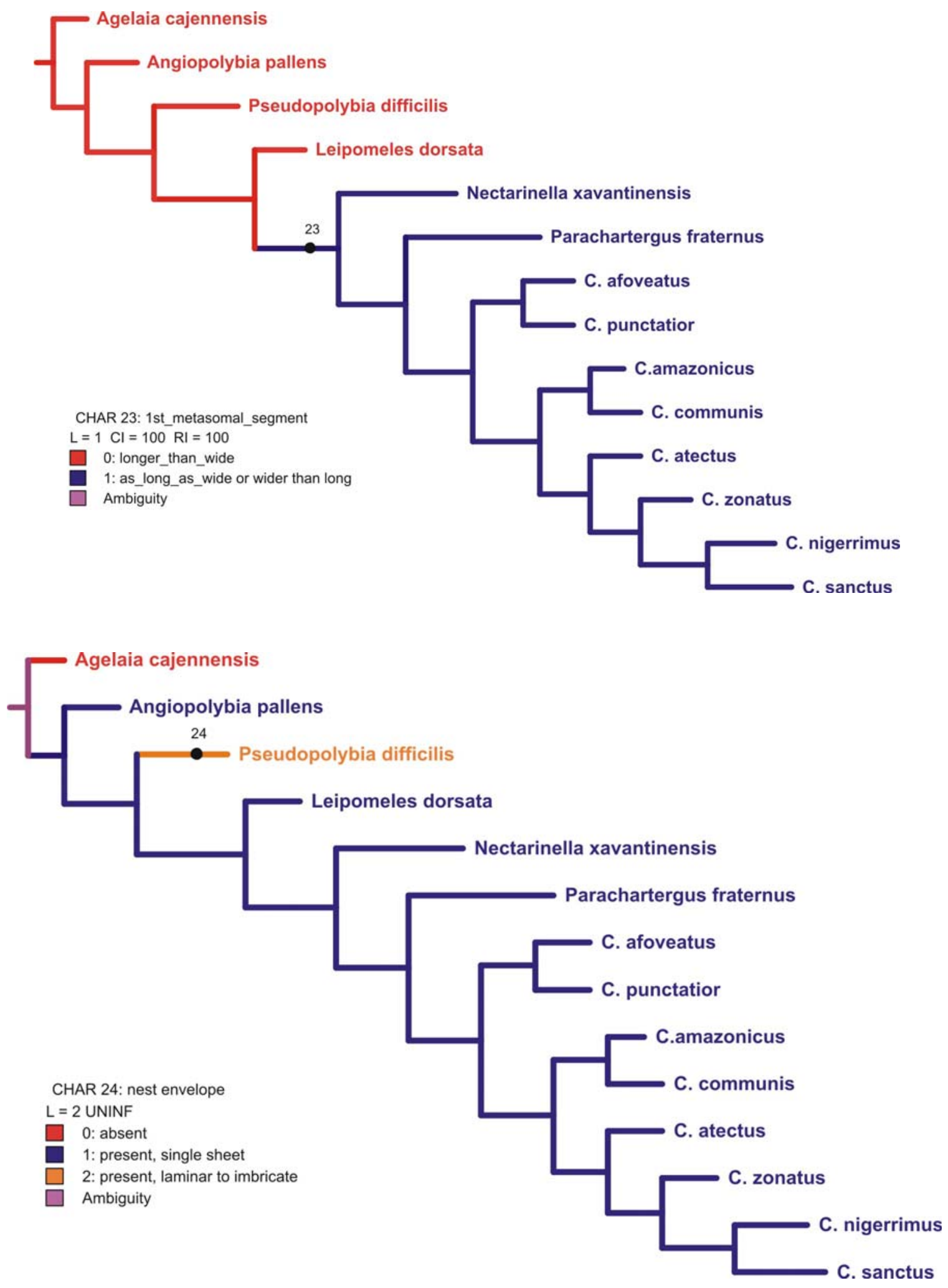

Figura 18 - Otimização dos caracteres 23 e 24. 


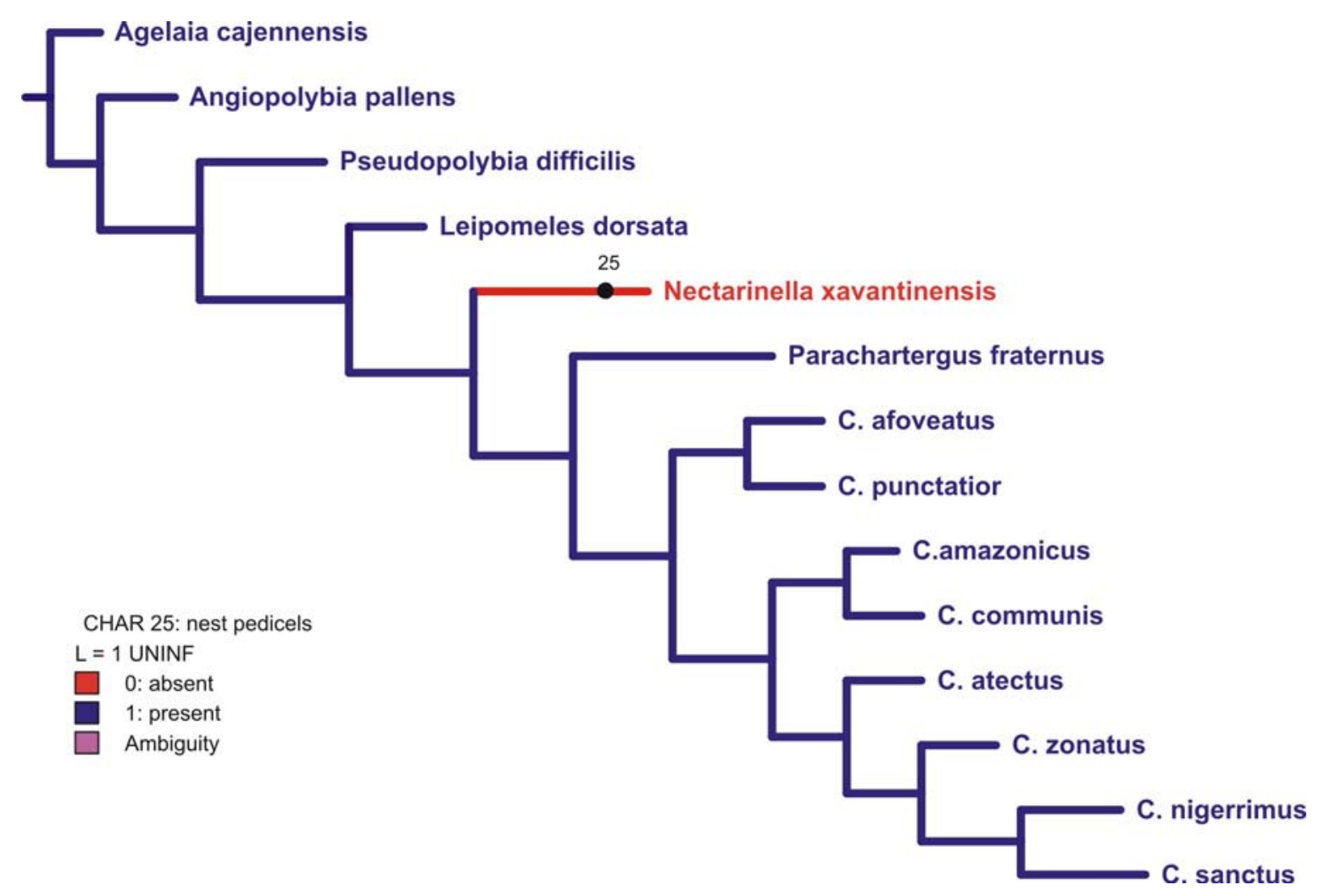

Agelaia cajennensis

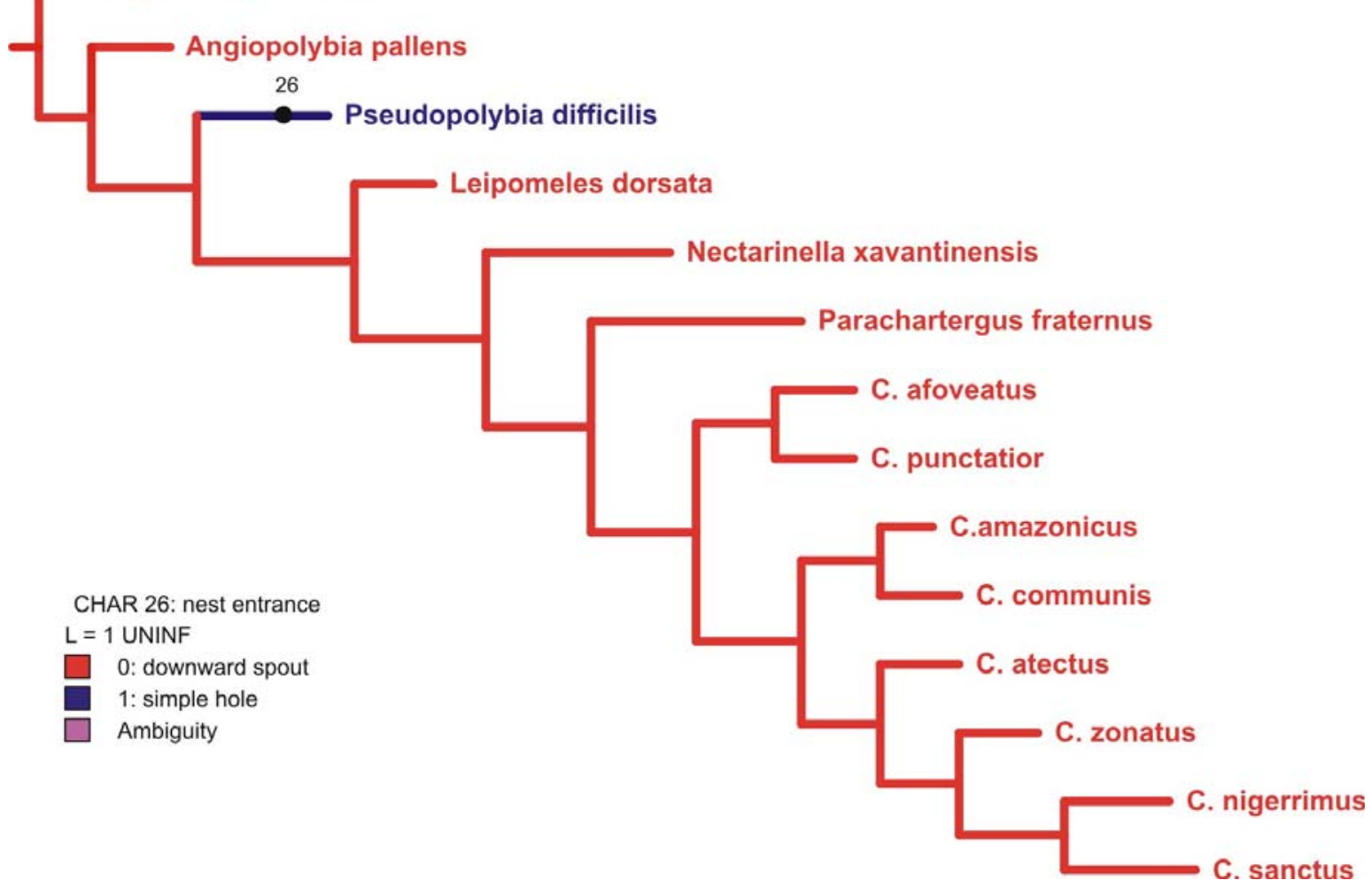

Figura 19 - Otimização dos caracteres 25 e 26. 

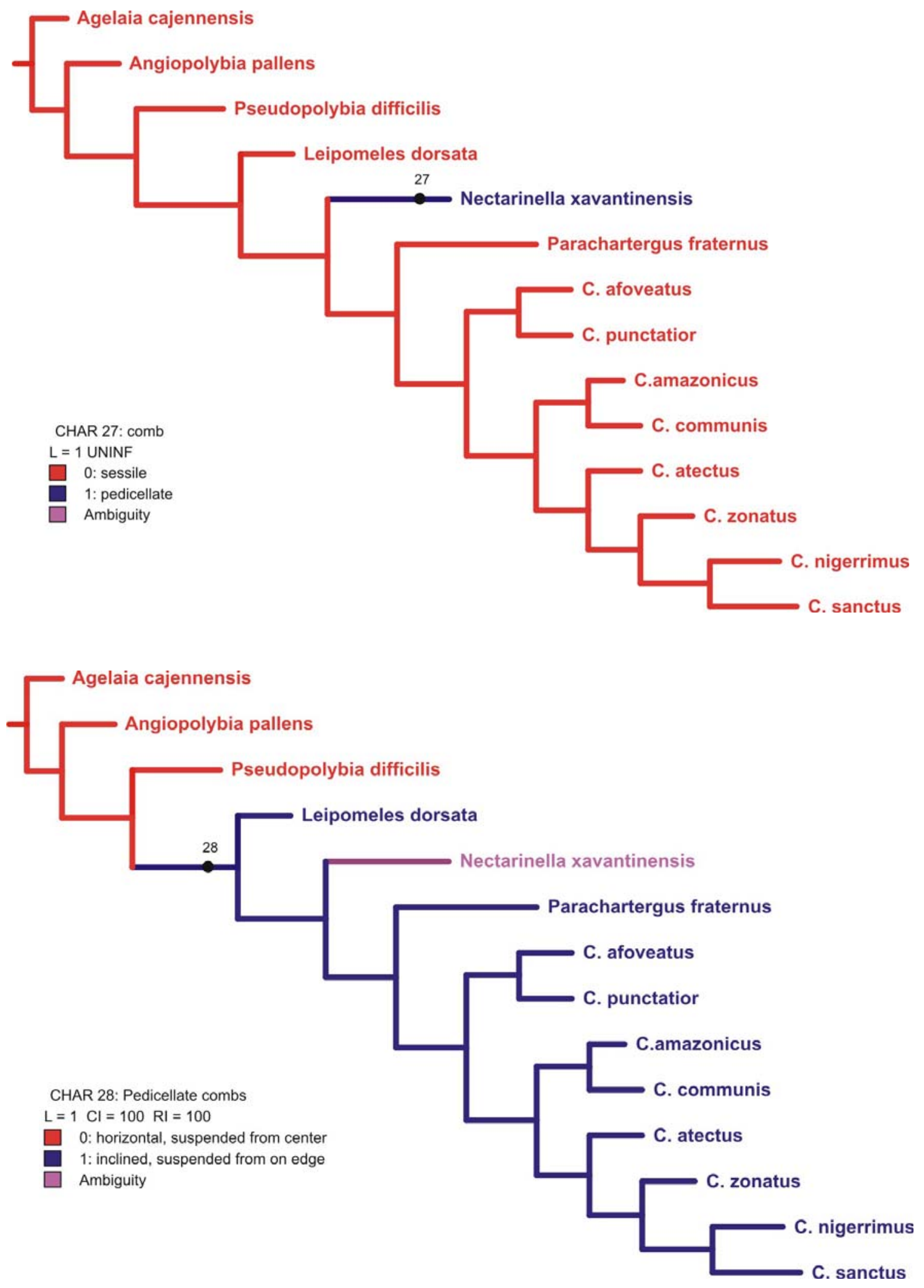

Figura 20 - Otimização dos caracteres 27 e 28. 


\section{6 - REFERÊNCIAS}

Bequaert, J.C. 1938. A new Charterginus from Costa Rica, with notes on Charterginus, Pseudochartergus, Pseudopolybia, Epipona, and Tatua (Hymenoptera, Vespidae). Revista Entomologica do Rio de Janeiro, 9: 99-117.

Carpenter, J.M. 1991. Phylogenetic relationships and the origin of social behavior in the Vespidae. pp. 7-32, In: K.G. Ross and R.W. Matthews (eds), The social biology of wasps, Cornell University Press, Ithaca, New York.

Carpenter, J.M. \& Marques, O.M. 2001. Contribuição ao Estudo dos Vespídeos do Brasil (Insecta, Hymenoptera, Vespoidea, Vespidade). Série Publicações Digitais vol. 2. Universidade Federal da Bahia. 144 pp.

Carpenter, J.M. \& S. Mateus. 2004. Males of Nectarinella Bequart (Hymenoptera, Vespidae, Polistinae). Revista Brasileira de Entomologia, 48 (3): 297-302.

Hanson, P.E. \& I.D. Gauld. 1995. The Hymenoptera of Costa Rita. Oxford: Oxford University Press.

Mateus, S.; Noll, F.B. \& Zucchi, R. 1999. Caste difference and related bionomic aspects of Chartergellus communis. A neotropical swarm-founding Polistinae wasp (Hymenoptera: Vespidade: Polistinae: Epiponini). Journal of the New York Entomological Society, 107 (4): 390-405.

Nixon, K.C. \& J.M. Carpenter. 1993. On outgroups. Cladistics, 9: 413-426.

Noll, F.B. 2000. Uma análise da evolução das castas nos Epiponini (Hymenoptera: Vespidae). Tese de Doutorado. Ribeirão Preto, 217 pp.

Richards O.W. 1978. The social wasps of the Americas excluding the Vespinae. London British Museum (Natural History): 580 pp.

Wenzel, J.W. 1993. Application of the biogenetic law to behavioral ontogeny: a test using nest architecture in paper wasps. Journal of Evolutionary Biology, 6: 229247.

Wenzel, J.W. 1998. A generic key to the nests of hornets, yellowjackets, and paper wasps worldwide (Vespidade: Vespinae, Polistinae). American Museum Novitates, 3224: 1-39.

Wenzel, J.W. \& Carpenter, J. M. 1994. Comparing methods: adaptative traits and tests of adaptation.In: P. Eggleton, \& R. Vane-Wright (eds.), Phylogenetics and Ecology. Pp 79-101. Academis Press, London. 
Apêndice 1 - Localidade dos exemplares de Chartergellus examinados

C. afoveatus - Bolívia (Pando).

C. amazonicus- Peru (Avispas- Madre de Dios); Ecuador (Napo Limoncocha).

C. actetus- Guiana Francesa ( Rio Mama); Rio Branco, Acre (Reserva Catuaba).

C. communis- Brasil, Mato Grosso(Serra Roncada); Brasil, São Paulo (Pedregulho).

C. punctator- Peru (Oxapampa).

C. nigerrimus- Peru (Yacu Yacu).

C. zonatus - Brasil, Minas Gerais (Uberlandia); Espirito Santo, Brasil (Conceição da Barra) [Parátipo].

C. sanctus - Brasil, Espirito Santo (Santa Tereza) [Holótipo]. 


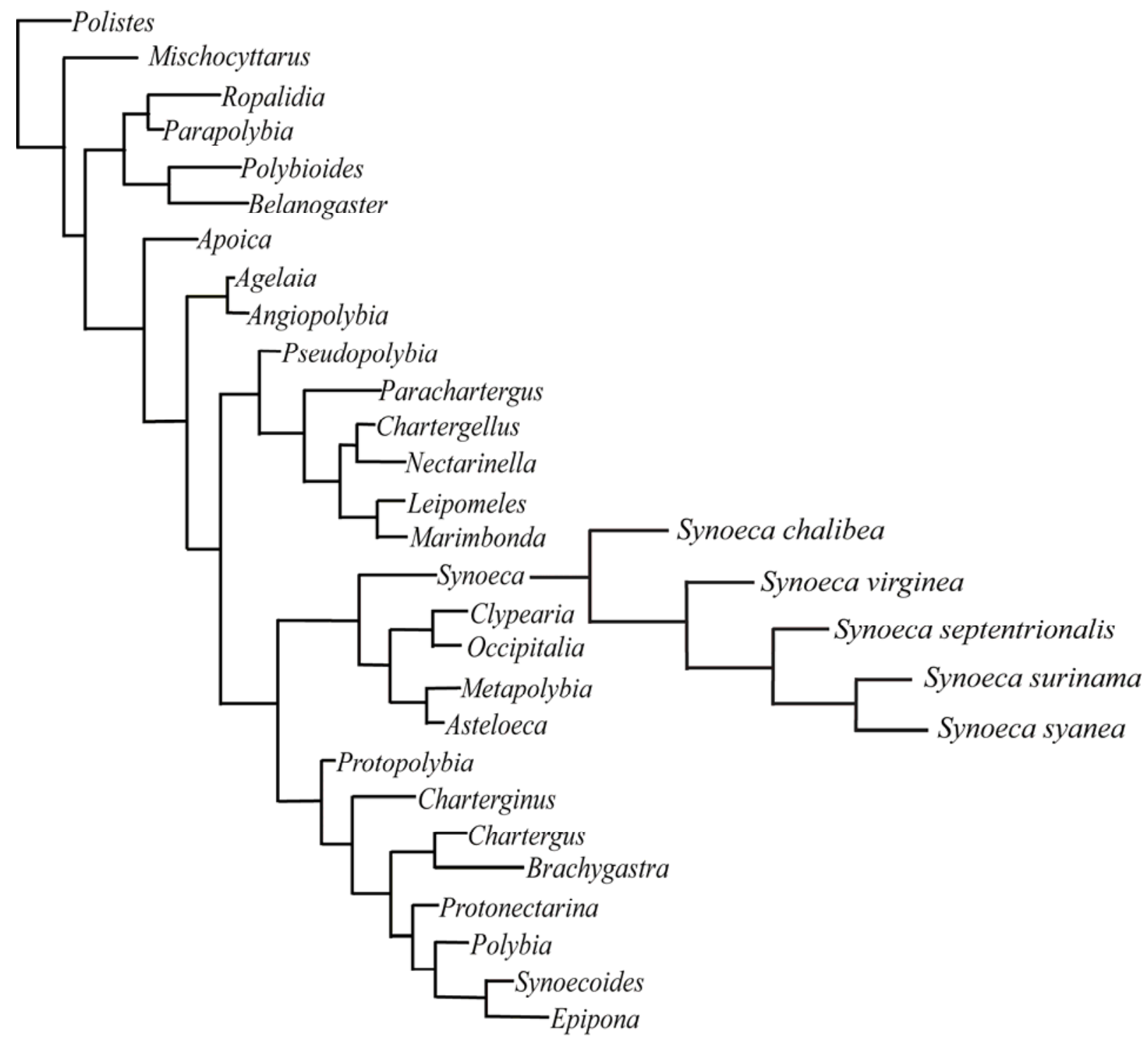

\section{Capítulo 4 - Análise Filogenética do Gênero Synoeca De Saussure, 1852 (Hymenoptera, Vespidae, Epiponini)}




\section{Capítulo 4 - Análise Filogenética do Gênero Synoeca De Saussure, 1852}

\section{(Hymenoptera, Vespidae, Epiponini)}

\section{1 - INTRODUÇÃO}

Synoeca é um pequeno gênero de vespas sociais da tribo Epiponini, com cinco espécies descritas: Synoeca chalibea de Saussure, S. virginea Fabricius, S. surinama Linnaeus, S. septentrionalis Richards e S. cyanea Fabricius. Os indivíduos geralmente são de tamanho médio (1,5 a 3,5 cm) e algumas espécies possuem cores metálicas. O gênero possui uma ampla distribuição na América Central e América do Sul, estendendo-se do México até a Argentina (Richards, 1978; Carpenter \& Marques, 2001). Os ninhos são arbóreos, geralmente sobre uma superfície ampla e inclinada e com um único favo séssil preso geralmente ao tronco (Wenzel, 1998; ver também Fig. 4). Quando são perturbadas, as operárias exibem um comportamento de defesa dentro do ninho, geralmente envolvendo batidas que produzem um som percussivo, sendo consequentemente denominadas popularmente de “guitarron” em países de língua hispânica (Overal, 1982; O’Donnell et. al., 1997).

Carpenter (1991) apresentou a primeira análise filogenética dos gêneros de Polistinae, sendo Synoeca posicionada como grupo-irmão de Clypearia (= Occipitalia; sinonimizada com Clypearia por Carpenter et. al., 1996), Asteloeca e Metapolybia, mas sem resolução entre esses gêneros. Wenzel (1993) e Wenzel \& Carpenter (1994) posteriormente apresentaram outras análises com diferentes resoluções dos quatro gêneros citados (ver discussão abaixo).

Recentes estudos comportamentais têm sido publicados sobre Synoeca (Schremmer, 1973; Bermúdez, 1980a, 1981a\&b, 1982; West-Eberhard, 1981; Thiago et. al., 2005), incluindo análises detalhadas sobre diferenciação de castas (Noda et. al., 
2003; Noll et. al., 2004) e arquitetura de ninho (Bermúdez, 1980b; Overal, 1982; Schremmer, 1986; Wenzel, 1991, 1998), mas, até agora, nada foi publicado sobre a interrelação entre suas espécies. Neste trabalho, foi realizada uma análise filogenética das espécies de Synoeca utilizando caracteres de morfologia externa de fêmeas adultas, genitália de macho e arquitetura de ninho. Também foi feita uma nova chave de identificação, baseada na análise filogenética apresentada combinada com dados da chave de identificação anteriormente disponível na literatura (Richards, 1978).

\section{2 - MATERIAIS E MÉTODOS}

Vinte e três caracteres de morfologia externa, um de genitália de macho e doze de ninho foram utilizados na matriz de dados para a reconstrução filogenética (Tabelas 1 e 2). A genitália de macho foi dissecada, enquanto que os dados de arquitetura de ninho foram obtidos a partir de Wenzel $(1993,1998)$. Alguns dos caracteres utilizados estão ilustrados na figuras 1. As figuras da genitália do macho de S. virginea (Brasil-PA, Fig. 2), e S. surinama (localidade não especificada, Fig. 3), são parte dos dados não publicados de J. van der Vecht doados à J.M. Carpenter. Caracteres de múltiplos estados foram tratados como aditivos, exceto os caracteres $3,5,18,19,21,24$ e 31 . O enraizamento dos grupos-externos (Nixon \& Carpenter, 1993) foi feito através dos seguintes táxons: Charterginus nevermanni, Epipona guerini, Metapolybia docilis, Asteloeca traili, e Clypearia weyrauchi.

\section{3 - RESULTADOS}

A análise da matriz resultou em um único cladograma com 65 passos, índice de consistência 0,84 e índice de retenção de 0,82 (Fig. 5). Pela análise, confirma-se o 
monofiletismo de Synoeca, havendo a seguinte relação entre as espécies: S. chalibea + (S. virginea $+($ S. septentrionalis $+($ S. surinama + S. cyanea $)))$.

\section{4 - DISCUSSÃO}

Carpenter (1991), em sua filogenia para os gêneros de Polistinae, utilizando caracteres morfológicos, estabeleceu um grupo monofilético, não resolvido internamente, compreendendo Asteloeca, Clypearia e Metapolybia, tendo como suporte a carena pronotal pronunciada (caráter 10 em nossa matriz). Em nossa análise, outros caracteres morfológicos também suportam este clado: escutelo achatado (caráter 17, estado 1), primeiro tergo metasomal sem cerdas (caráter 20, estado 1) e reforço do ninho através de aplicação de secreção (caráter 28, estado 1). O grupo-irmão destes três gêneros é Synoeca, como também proposto por Carpenter (1991) baseando-se em caracteres de ninho: favos construídos diretamente, sem uma fundação feita de polpa vegetal (caráter 27, estado 1; ver Wenzel, 1998 para maiores detalhes), envelope não alargado na base (caráter 29, estado 1), entrada como um pequeno colarinho (caráter 30, estado 1) e fechamento do envelope durante a construção dos favos (caráter 36, estado $0)$.

Wenzel (1993), utilizando caracteres de arquitetura de ninho, também reconheceu um clado com estes quatro gêneros, baseando-se em três caracteres: favo construido diretamente sobre a casca da árvore sem uma fundação feita de polpa vegetal, lascas de material grosseiro e reforço do envelope feito por secreção (Carpenter et. al., 1996). Na verdade, o envelope do ninho de Synoeca é reforçado por emendas e não por secreção (Wenzel, 1993; Tabela 2), então este caráter suporta somente o clado com os gêneros Metapolybia, Asteloeca e Clypearia. Material de construção de ninho composto por 
lascas curtas é uma característica compartilhada por estes quatro gêneros, mas ela está presente também em Epipona, não sendo, deste modo, uma sinapomorfia (Fig. 5).

Wenzel \& Carpenter (1994), combinando as matrizes de Carpenter (1991) e Wenzel (1993), mais caracteres larvais não publicados (J. Kojima), resolveram este clado em sua árvore de consenso, posicionando Asteloeca + Metapolybia como grupo-irmão de Clypearia e Synoeca como grupo-irmão destes três. Em todos estes estudos Synoeca é o gênero mais basal, exceto em Wenzel (1993), que apresenta a topologia para estes gêneros como: Clypearia + (Asteloeca + (Metapolybia + Synoeca $)))$. O posicionamento mais basal de Synoeca é confirmado neste trabalho.

Neste trabalho, Synoeca é suportado por vértex projetado (caráter 1, estado 0; Figs. 1 A e B), que também é uma característica diagnóstica para Synoeca, como salientado por Richards (1978); entrada do ninho formado por uma fenda na construção (caráter 32, estado 1; homoplástico na Fig. 5 por estar presente também em Metapolybia). Alguns outros caracteres são compartilhados por todas as espécies de Synoeca, incluíndo coxa anterior arredondada (caráter 14, estado 1; também citado por Carpenter, 1991), propódeo com uma pequena concavidade abaixo do orifício propodeal (caráter 18, estado 1) e o primeiro segmento metassomal filiforme, se tornando largo gradualmente após os espiráculos (caráter 19, estado 2). Estes estados são exclusivos para Synoeca, mas por haver variações nos grupos-externos, a otimização destes caracteres é ambígua e não são plotadas na Fig. 5. Outro caráter, o prestigma (caráter 23), é também ambíguo e segundo a chave de Richards (1978), S. septentrionalis e $S$. cyanea teriam o estado tão longo quanto largo (estado 0), no entanto, nós observamos que estas espécies possuem o prestigma mais longo do que largo, como as outras espécies de Synoeca. 
Na chave de Richards (1978), a pontuação no pronoto, no escuto, no escutelo e no propódeo são importantes características diagnósticas para a identificação das espécies de Synoeca, e algumas destas características provaram ser sinapomorfias em nosso cladograma. Em relação à pontuação propodeal (caráter 16), Synoeca poderia ser separada em dois grupos: (1) S. chalibea e S. virginea, com pontuação presente e densa (estado 0, Fig. 1 C); e (2) S. surinama, S. cyanea e S. septentrionalis, com pontuação reduzida em parte, dorsalmente e lateralmente (estado 2, Fig. 1D). Como já apresentado pela chave de Richards (1978), as espécies destes dois grupos possuem as seguintes diferenças diagnósticas: clípeo tocando os olhos vs. clípeo estreitamente separado dos olhos (caráter 4, contato clípeo-olho); espaço malar menor do que o pedicelo (Fig. 1 A) vs. aproximadamente tão longo quanto o pedicelo (Fig. 1 B) (caráter 5, espaço malar); e asas amareladas/marrom, escurecidas anteriormente vs. totalmente infuscada (caráter 24, cor da asa). Além disso, estes dois grupos são diferenciados pela coloração do corpo como um todo (amarelado vs. azulado/enegrecido), mas este caráter não foi incluído em nossa matriz por apresentar variação.

Synoeca chalibea é a única espécie de Synoeca em que a pontuação no pronoto, no escuto, no escutelo e no propódeo é densa, compartilhando este estado com a maioria das espécies do grupo-externo, sendo então posicionada como a espécie mais basal do gênero. S. virginea compartilha outras características com S. chalibea, mas, como a pontuação no pronoto e no escuto é esparsa (Fig. 1 F), que também é compartilhado com S. surinama, S. cyanea e $S$. septentrionalis, coloca $S$. virginea como espécie intermediária entre S. chalibea e o clado S. septentrionalis + (S. surinama + S. cyanea). Provavelmente, existiu uma redução ou perda na pontuação do corpo, dentro do gênero. Finalmente, outra redução no caráter, primeiro tergo metassomal sem cerdas basalmente, 
que resolveu S. surinama e $S$. cyanea como grupos-irmãos. No entanto, este estado é homoplástico, sendo também encontrado em vários grupos-externos.

Outros caracteres também merecem atenção especial. Até o momento, a genitália de macho de Synoeca não havia sido propriamente descrita, e o único caráter incluído em nossa matriz (caráter 22, digito da genitália de macho), suportou o agrupamento de $S$. surinama, S. cyanea e S. septentrionalis. Estas espécies compartilham o lobo posterolateral pontiagudo (estado 1), enquanto que $S$. chalibea e $S$. virginea compartilham com os grupos externos o lobo arredondado (Figs. 2-3, e du Buysson, 1906: Figs. 8-9). Estados semelhantes têm sido descritos para outras espécies de outros gêneros não incluídos neste trabalho (Carpenter \& Mateus, 2004; Andena et. al., 2007), mas que não são idênticos, sendo provável a origem independente de estados similares nos Epiponini.

A estrutura chamada tirídio é uma pequena área de cutícula diferenciada, localizada em ambos os lados da base do segundo tergo metassomal conectado com a margem da frente (Richards, 1978). O formato dessa estrutura é variável em Synoeca, mas Richards (1978: 178) cita: "Its shape, though variable, is of some taxonomic importance.” Essa característica está incluída em nossa matriz como o caráter 20, e não foi informativa. Em S. virginea e S. cyanea este caráter está codificado como alongada, linear (caráter 20, estado 3), enquanto que no restante das espécies o formato é subcircular (estado 2). Nós observamos variações no formato subcircular do tirídio, mas não apresenta variações significativas para serem codificadas diferentemente. Dentro de Synoeca, esse caráter, evidentemente, teve origens independentes. 


\section{5 - CHAVE DE IDENTIFICAÇÃO PARA AS ESPÉCIES DE SYNOECA}

1 Espaço malar menor do que o pedicelo (Fig. $1 \mathrm{~A}$ ); todo o propódeo com pontuação fina (Fig. $1 \mathrm{C}$ ); asas amareladas/marrom, escurecidas anteriormente, corpo amarelado/marrom ou azulado/esverdeado...................................................2

- $\quad$ Espaço malar aproximadamente tão longo quanto o pedicelo (Fig. 1 B); propódeo com pontuação esparsa ou evanescente lateralmente (Fig. $1 \mathrm{D}$ ); asas totalmente infuscadas, corpo azulado/enegrecido. .3

2 Pronoto, escuto e escutelo com pontuação fina e densa (Fig. 1 E)

chalibea de Saussure

- Pronoto, escuto e escutelo com pontuação esparsa, algumas vezes não pontuada.... virginea (Fabricius)

3 Pronoto, escuto e escutelo não pontuado; propódeo com pontuação esparsa; clípeo enegrecido, mandíbulas, espaço malar e região inferior da gena enegrecida surinama (Linnaeus)

- $\quad$ Pronoto, escuto e escutelo com pontuação esparsa; propódeo com pontuação densa; clípeo, mandibula, espaço malar e região inferior da gena avermelhada....4

4 Primeiro tergo metassomal sem cerdas basalmente; clípeo avermelhado cyanea (Fabricius)

Primeiro tergo metassomal com numerosas cerdas eretas basalmente; clípeo com uma região mais ou menos triangular enegrecida dorsalmente ..septentrionalis Richards 
Tabela 1 - Lista de caracteres para Synoeca.

Caráter Estados

1. Vértex: projetado $=0$; arredondado $=1$.

2. Formato do clípeo: mais longo do que largo $=0$; pelo menos tão longo quanto $\operatorname{largo}=1$

3. Ápice do clípeo: arredondado-truncado $=0$; arredondado $=1$; emarginado $=2$; truncado $=3$.

4. Contato do clípeo com os olhos: clípeo tocando os olhos =0; clípeo estreitamente separado dos olhos $=1$.

5. Espaço malar: menor do que o pedicelo (Fig. $1 \mathrm{~A}$ ) = 0; tão longo quanto o pedicelo = 1 (Fig. $1 \mathrm{~B})$.

6. Gena: mais estreita que os olhos $=0$; igual ou maior que os olhos $=1$ (Figs. 1 A e B).

7. Carena occipital: presente $=0$; ausente $=1$.

8. Margem mandibular: arredondada $=0$; salientada nas bordas $=1$.

9. Pontuação pronotal: densa, áspera $=0$; densa, fina $=1$ (Fig. $1 \mathrm{E})$; evanescente ou ausente $=2$ (Fig. 1 F).

10. Carena pronotal anterior: pequena, rombuda $=0$; pronunciada $=1$.

11. Carena pronotal dorsal: presente $=0$; ausente $=1$.

12. Fóvea pronotal: presente $=0$; ausente $=1$.

13. Carena pretegular: ausente $=0$; presente $=1$.

14. Coxa anterior: fortemente pronunciada lateralmente $=0$; arredondada $=1$.

15. Pontuação no escuto: densa, áspera = 0; fina = 1 (Fig. $1 \mathrm{E}$ ); evanescente ou ausente $=2$ (Fig. $1 \mathrm{~F})$. 
16. Pontuação propodeal: presente $=0$ (Fig. $1 \mathrm{C}$ ); rugosa $=1$; reduzida em parte dorsal e lateralmente $=2$ (Fig. 1 D).

17. Escutelo: arredondado $=0$; achatado $=1$.

18. Concavidade propodeal: rasa, ampla $=0$; profunda, baixa $=1$; com uma pequena concavidade acima do orifício propodeal = 2; estreita, não atingindo o metanoto $=3$; rasa, estreita $=4$; profunda, estreita $=5$.

19. Primeiro segmento metassomal: peciolado, com uma região larga posteriormente $=0$; filiforme $=1$; filiforme basalmente, se alargando gradualmente após os espiráculos $=2$; filiforme basalmente, alargando-se abruptamente após os espiráculos $=3$; filiforme basalmente, pouco alargado após os espiráculos $=4$.

20. Primeiro tergo metassomal: com numerosas cerdas eretas na base $=0$; sem cerdas $=1$.

21. Tirídeo no segundo tergo metassomal: basal $=0$; subcircular, amplamente separado da margem $=1$; subcircular $=2$; alongado $=3$; pequeno, linear $=4$; subperiforme $=5$.

22. Digito da genitália do macho: lobo postero-dorsal arredondado = 0 (Fig. 2 C); lobo postero-dorsal pontiagudo $=1$ (Fig. $3 \mathrm{C})$

23. Prestigma: tão longo quanto largo $=0$; mais longo do que largo $=1$

24. Cor da asa: hialina, infuscada anteriormente $=0$; amarelada/marrom, escurecida anteriormente $=1$; infuscada $=2$; hialina $=3$

25. Material do ninho: fibras longas $=0$; lascas curtas $=1$

26. Fundação do favo: séssil, lembrando um pecíolo = 0; séssil = 1

27. Favo com fundação com polpa: presente $=0$; ausente $=1$

28. Reforço no envelope: através de emendas $=0$; por secreção $=1$

29. Largura do envelope: mais largo na base $=0$; não largo na base $=1$ 
30. Entrada: orifício simples $=0$; pequeno colarinho $=1$

31. Posição da entrada: periférica ou dorsal $=0$; ventral $=1$; central ou em direção à periferia do envelope $=2$

32. Construção da entrada: formada pela abertura restante da construção do envelope $=0$; construída como uma estrutura separada, independente da abertura restante da construção do envelope $=1$

33. Favos secundários: ausentes ou contíguos com o primeiro favo $=0$; presente, no envelope $=1$

34. Envelopes secundários: ausente $=0$; presente $=1$

35. Expansão dos favos: gradual $=0$; blocos sucessivos $=1$

36. Células: maioria das células construídas antes do fechamento do envelope $=0$; o envelope é fechado durante a construção das células = 1 
Tabela 2. Matriz para as espécies de Synoeca. Interrogação (?) = não observado.

\begin{tabular}{|c|c|c|c|c|c|c|c|c|c|c|c|c|c|c|c|c|c|c|c|c|c|c|c|c|c|c|c|c|c|c|c|c|c|}
\hline & 1 & 2 & 3 & 4 & 5 & 6 & 78 & 8 & $\begin{array}{ll}9 & 1 \\
& 0 \\
\end{array}$ & $\begin{array}{ll}1 & 1 \\
0 & 1 \\
\end{array}$ & $\begin{array}{ll}1 & 1 \\
1 & 2 \\
\end{array}$ & $\begin{array}{l}1 \\
3 \\
\end{array}$ & $\begin{array}{l}1 \\
4 \\
\end{array}$ & $\begin{array}{l}1 \\
5 \\
\end{array}$ & $\begin{array}{ll}1 & 1 \\
6 & 7 \\
\end{array}$ & $\begin{array}{ll}1 & 1 \\
7 & 8 \\
\end{array}$ & $\begin{array}{ll}1 & 1 \\
8 & 9 \\
\end{array}$ & $\begin{array}{l}2 \\
0 \\
0\end{array}$ & $\begin{array}{l}2 \\
1 \\
\end{array}$ & $\begin{array}{l}2 \\
2 \\
\end{array}$ & $\begin{array}{l}2 \\
3 \\
\end{array}$ & $\begin{array}{l}2 \\
4 \\
\end{array}$ & $\begin{array}{l}2 \\
5 \\
\end{array}$ & $\begin{array}{ll}2 & 2 \\
6 & 2 \\
\end{array}$ & $\begin{array}{ll}2 & 2 \\
7 & 8\end{array}$ & $\begin{array}{ll}2 & 2 \\
8 & 9\end{array}$ & 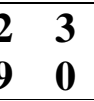 & $\begin{array}{l}3 \\
1\end{array}$ & $\begin{array}{l}3 \\
2 \\
\end{array}$ & $\begin{array}{l}3 \\
3 \\
\end{array}$ & $\begin{array}{l}3 \\
4 \\
\end{array}$ & $\begin{array}{l}3 \\
5\end{array}$ & $\begin{array}{l}3 \\
6\end{array}$ \\
\hline $\begin{array}{l}\text { Charterginus } \\
\text { nevermanni }\end{array}$ & 1 & 0 & 0 & 0 & 0 & 0 & 0 & 0 & $\begin{array}{ll}0 & 0\end{array}$ & $\begin{array}{ll}0 & 0\end{array}$ & $\begin{array}{ll}0 & 0\end{array}$ & 0 & 0 & 0 & 0 & $\begin{array}{ll}0 & 0\end{array}$ & $\begin{array}{ll}0 & 0\end{array}$ & 0 & 0 & 0 & 0 & 0 & 0 & 0 & $\begin{array}{ll}0 & 0\end{array}$ & 0 & $\begin{array}{ll}0 & 0\end{array}$ & 0 & 0 & 0 & 0 & 0 & 1 \\
\hline $\begin{array}{l}\text { Epipona } \\
\text { guerini }\end{array}$ & 1 & 1 & 2 & 0 & 0 & 1 & 1 & 0 & 10 & $\begin{array}{ll}0 & 1\end{array}$ & $\begin{array}{ll}1 & 1\end{array}$ & 1 & 0 & 1 & 10 & $\begin{array}{ll}0 & 1\end{array}$ & $\begin{array}{ll}1 & 1\end{array}$ & 10 & 1 & 0 & 1 & 0 & 1 & 1 & $\begin{array}{ll}0 & 0\end{array}$ & $\begin{array}{ll}0 & 0\end{array}$ & $\begin{array}{ll}0 & 0\end{array}$ & 1 & 0 & 1 & 1 & 1 & 1 \\
\hline $\begin{array}{l}\text { Synoeca } \\
\text { surinama }\end{array}$ & 0 & 1 & 1 & 1 & 1 & 1 & 1 & 0 & 20 & $\begin{array}{ll}0 & 1\end{array}$ & $\begin{array}{ll}1 & 1\end{array}$ & 1 & 1 & 2 & 20 & $0 \quad 2$ & 22 & 21 & 2 & 1 & 1 & 2 & 1 & 1 & 10 & $\begin{array}{ll}0 & 1\end{array}$ & $\begin{array}{ll}1 & 1\end{array}$ & 2 & 1 & 0 & 0 & 0 & 0 \\
\hline $\begin{array}{l}\text { Synoeca } \\
\text { cyanea }\end{array}$ & 0 & 1 & 1 & 1 & 1 & 1 & 1 & 0 & 20 & $\begin{array}{ll}0 & 1\end{array}$ & $\begin{array}{ll}1 & 1\end{array}$ & 1 & 1 & 2 & 20 & $0 \quad 2$ & 22 & 21 & 3 & 1 & 1 & 2 & 1 & 1 & 10 & $\begin{array}{ll}0 & 1\end{array}$ & $\begin{array}{ll}1 & 1\end{array}$ & 2 & 1 & 0 & 0 & 0 & 0 \\
\hline $\begin{array}{l}\text { Synoeca } \\
\text { septentrionalis }\end{array}$ & 0 & 1 & 1 & 1 & 1 & 1 & 10 & 0 & 20 & $\begin{array}{ll}0 & 1\end{array}$ & $\begin{array}{ll}1 & 1\end{array}$ & 1 & 1 & 2 & 20 & $\begin{array}{ll}0 & 2\end{array}$ & 22 & 20 & 2 & 1 & 1 & 2 & 1 & 11 & 10 & $\begin{array}{ll}0 & 1\end{array}$ & $\begin{array}{ll}1 & 1\end{array}$ & 2 & 1 & 0 & 0 & 0 & 0 \\
\hline $\begin{array}{l}\text { Synoeca } \\
\text { chalibea }\end{array}$ & 0 & 1 & 1 & 0 & 0 & 1 & 10 & 0 & 10 & 0 & $\begin{array}{ll}1 & 1\end{array}$ & 1 & 1 & 1 & 0 & 0 & 2 & 20 & 2 & 0 & 1 & 1 & 1 & 11 & 10 & 1 & $\begin{array}{ll}1 & 1\end{array}$ & 2 & 1 & 0 & 0 & 0 & 0 \\
\hline $\begin{array}{l}\text { Synoeca } \\
\text { virginea }\end{array}$ & 0 & 1 & 1 & 0 & 0 & 1 & 10 & 02 & 20 & $\begin{array}{ll}0 & 1\end{array}$ & $\begin{array}{ll}1 & 1\end{array}$ & 1 & 1 & 2 & $0 \quad 0$ & $0 \quad 2$ & 2 & 20 & 3 & 0 & 1 & 1 & 1 & 11 & 10 & 1 & $\begin{array}{ll}1 & 1\end{array}$ & 2 & 1 & 0 & 0 & 0 & 0 \\
\hline Asteloeca traili & 1 & 0 & 1 & 0 & 0 & 1 & 11 & 12 & 21 & 11 & 11 & 1 & 0 & 2 & $\begin{array}{ll}0 & 1\end{array}$ & 13 & 33 & 1 & 4 & 0 & 0 & 3 & 1 & 11 & 11 & 11 & 11 & 2 & 0 & 0 & 0 & 0 & 0 \\
\hline $\begin{array}{l}\text { Metapolybia } \\
\text { docilis }\end{array}$ & 1 & 1 & 1 & 0 & 0 & 1 & 11 & 11 & 11 & 11 & 11 & 1 & 0 & 1 & $\begin{array}{ll}0 & 1\end{array}$ & 14 & 44 & 41 & 4 & 0 & 0 & 3 & 1 & 11 & 11 & 11 & 11 & 2 & 1 & 0 & 0 & 0 & 0 \\
\hline $\begin{array}{l}\text { Clypearia } \\
\text { weyrauchi }\end{array}$ & 1 & 0 & 3 & 0 & 0 & 0 & 10 & 01 & 11 & 1 & 11 & 1 & 1 & 1 & $\begin{array}{ll}0 & 1\end{array}$ & 1 & 53 & 1 & 5 & ? & 0 & 3 & 1 & 11 & 11 & 11 & 11 & 2 & 0 & 0 & 0 & 0 & 0 \\
\hline
\end{tabular}




\section{Capítulo 4 - Synoeca}




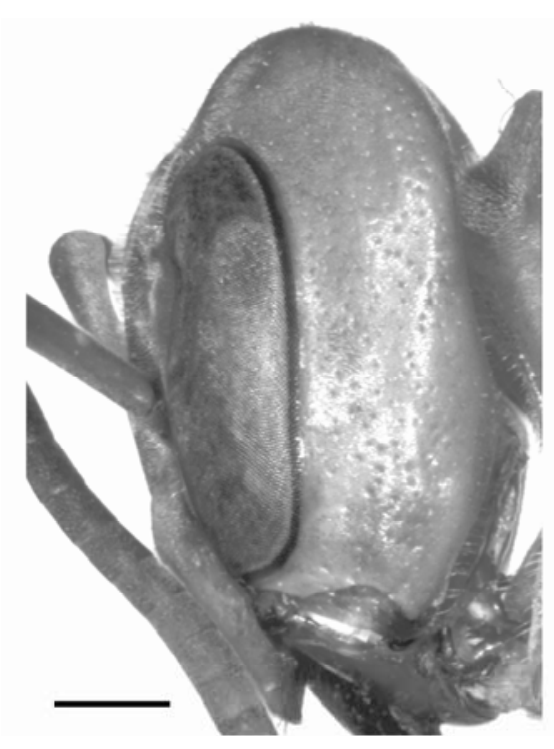

A
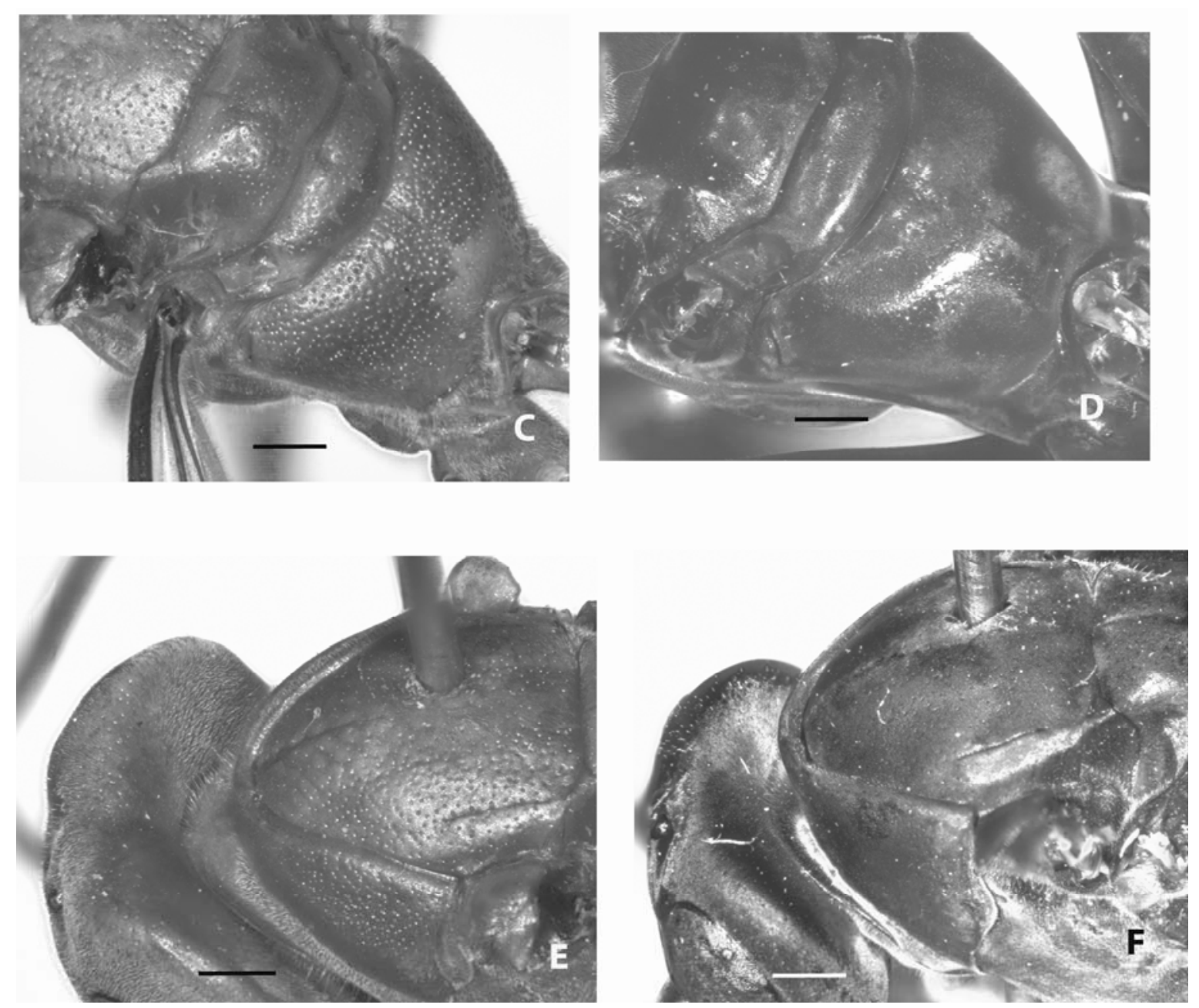

Figura 1 - A e B = Cabeça, visão lateral de S. virginea e $S$. cyanea, respectivamente; C e D = Propódeo,visão dorso-lateral de $S$. chalibea e $S$. surinama, respectivamente; E e F $=$ Escuto,visão dorso-lateral de $S$. chalibea e $S$. cyanea, respectivamente. Escala = 1,0 $\mathrm{mm}$. 

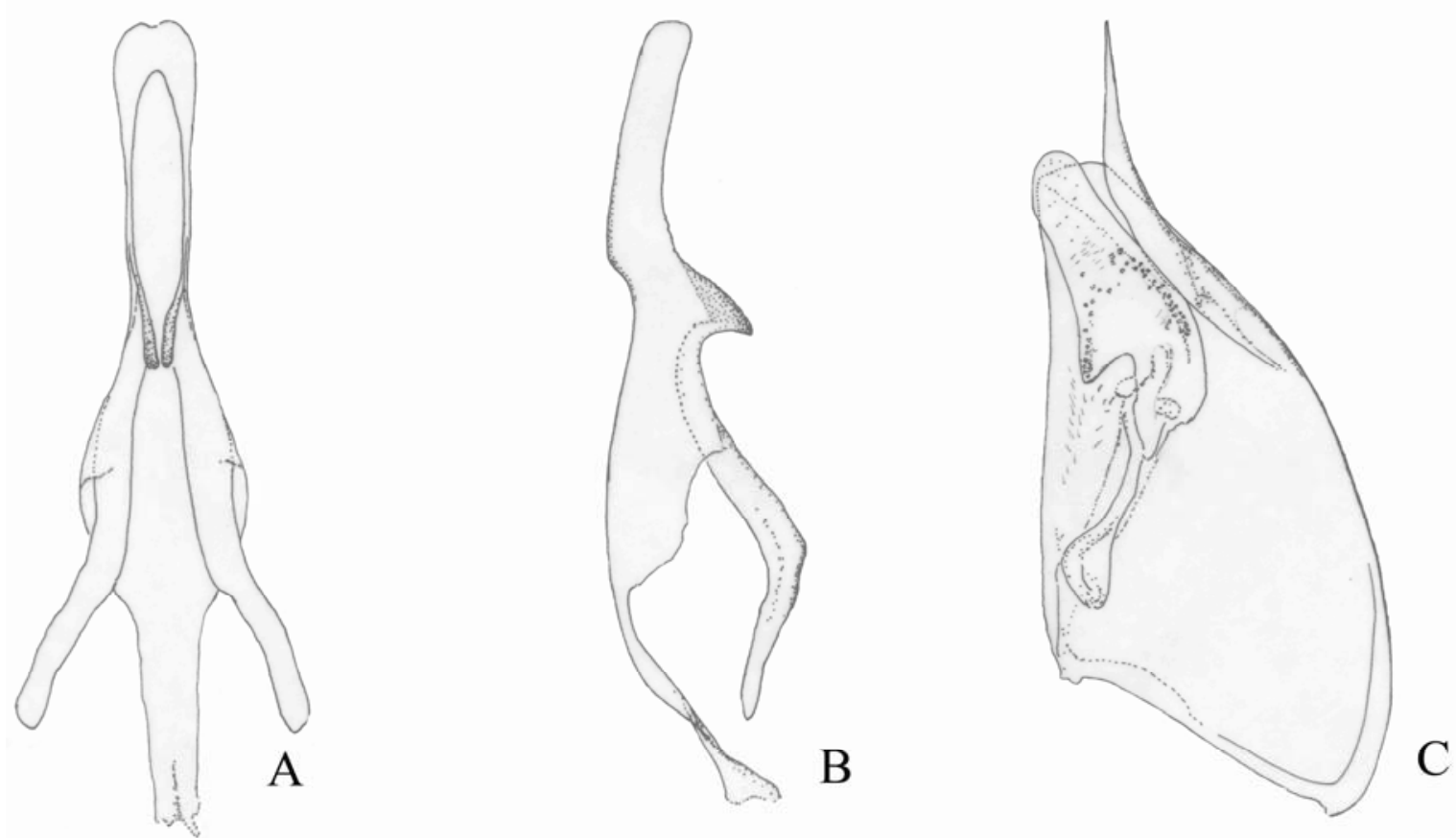

Figura 2 - Genitália de macho de Synoeca virginea Fabricius. A = edeago, visão ventral; $\mathrm{B}=$ edeago, visão lateral; $\mathrm{C}=$ parâmero e volsela. Escala = 1,0 mm.
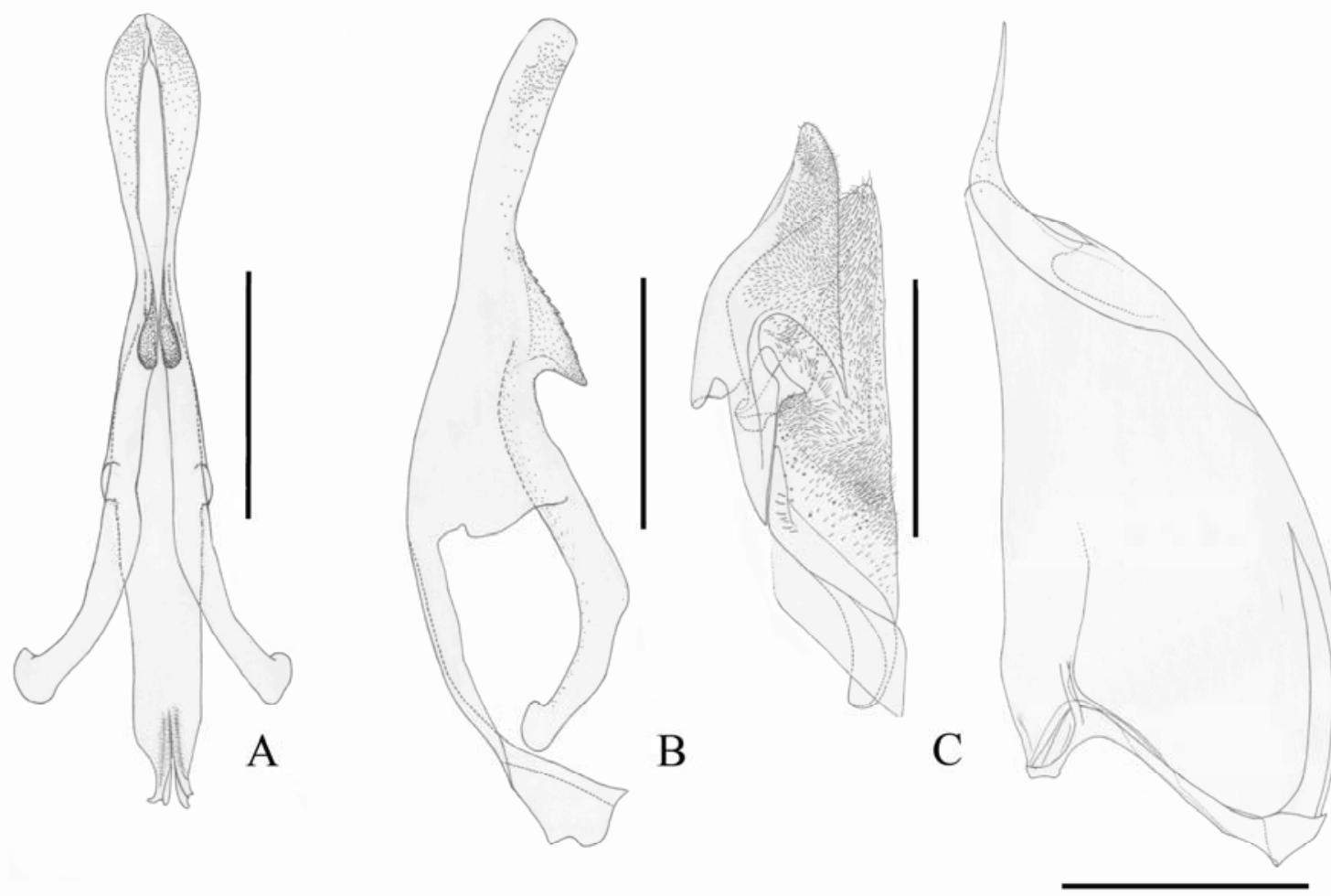

Figura 3 - Genitália de macho de Synoeca surinama Linnaeus. A = edeago, visão ventral; $\mathrm{B}=$ edeago, visão lateral; $\mathrm{C}=$ volsela; $\mathrm{D}=$ parâmero. Escala $=1,0 \mathrm{~mm}$ 


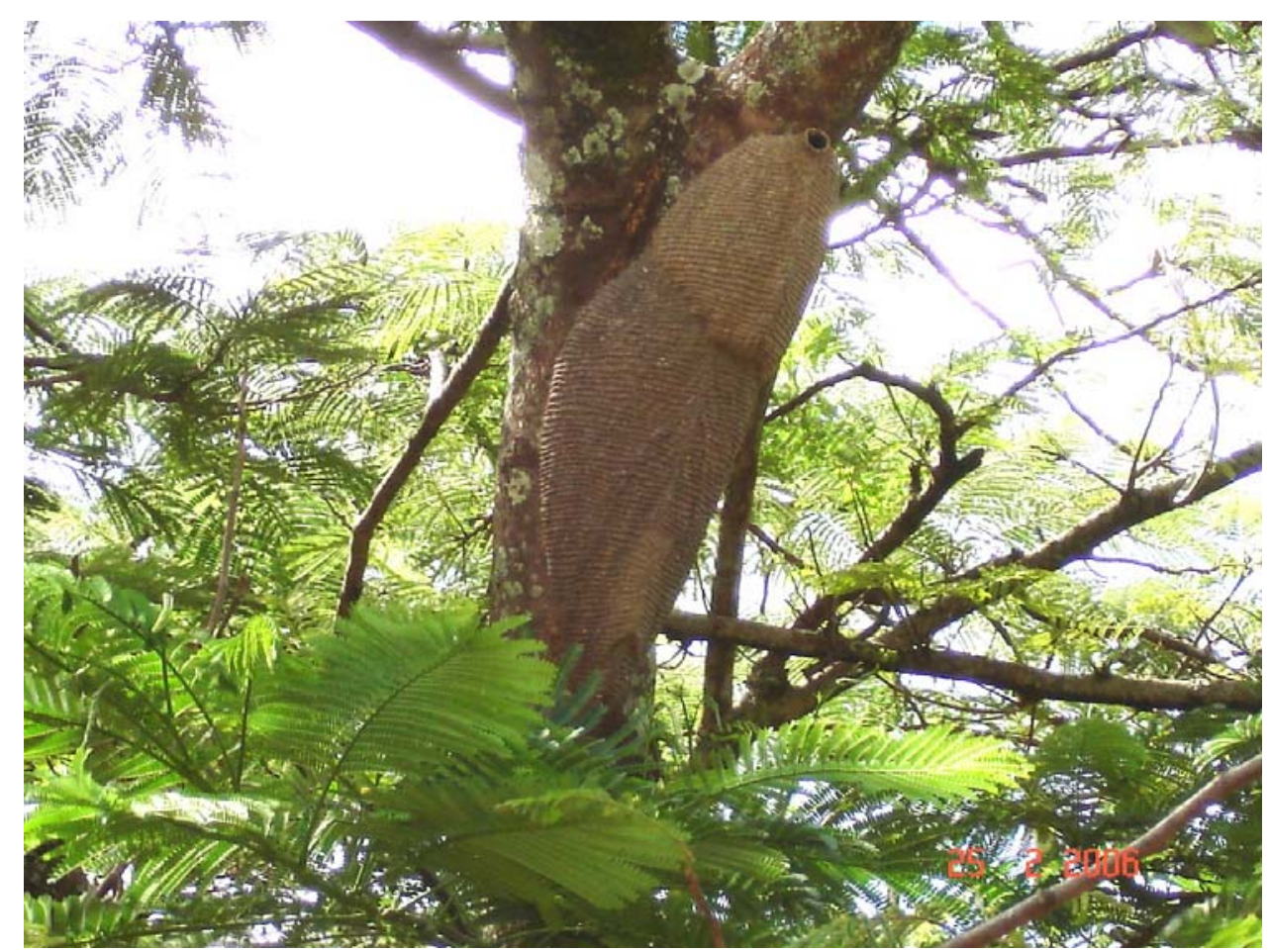

Figura 4 - Ninho de Synoeca cyanea, coletado em Pedregulho-SP. Foto de Sidnei Mateus. 


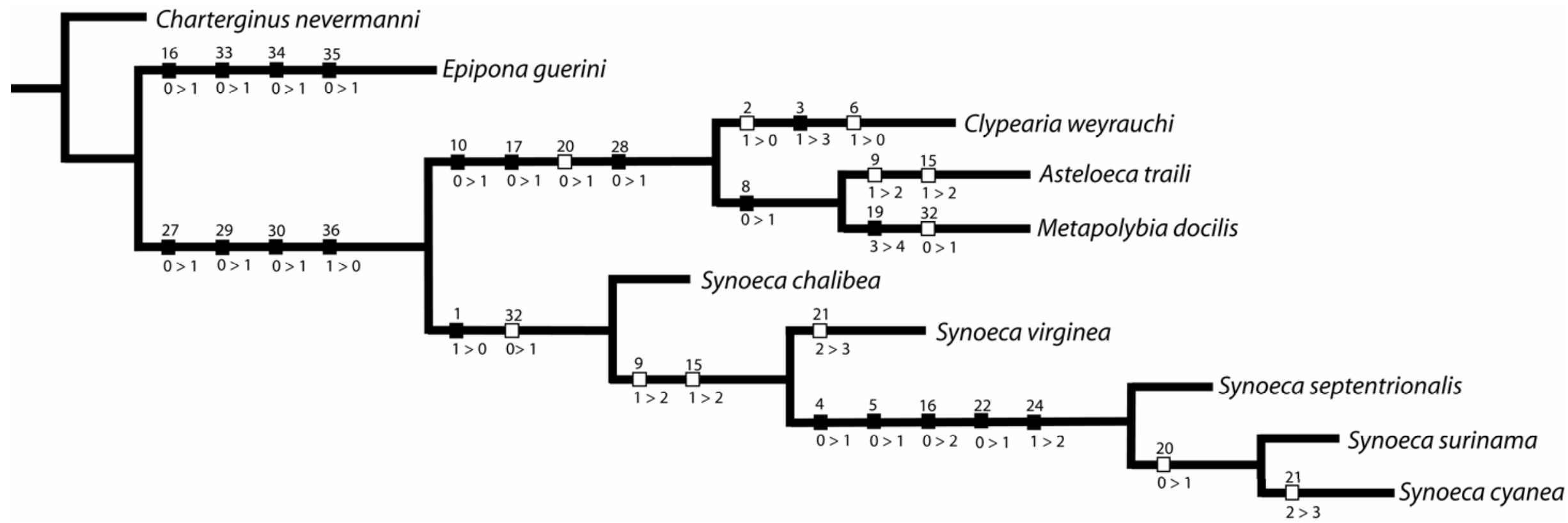

Figure 5. Cladograma de Synoeca, , com 65 passos, índice de consistência 0,84 e índice de retenção de 0,82 ; baseado na Tabela 2. Somente caracteres não ambiguos estão plotados. O número de cada caráter está sobre os quadrados, enquanto que a transição de cada estado está abaixo, separado por “>”. 
Capítulo 4 - Synoeca 

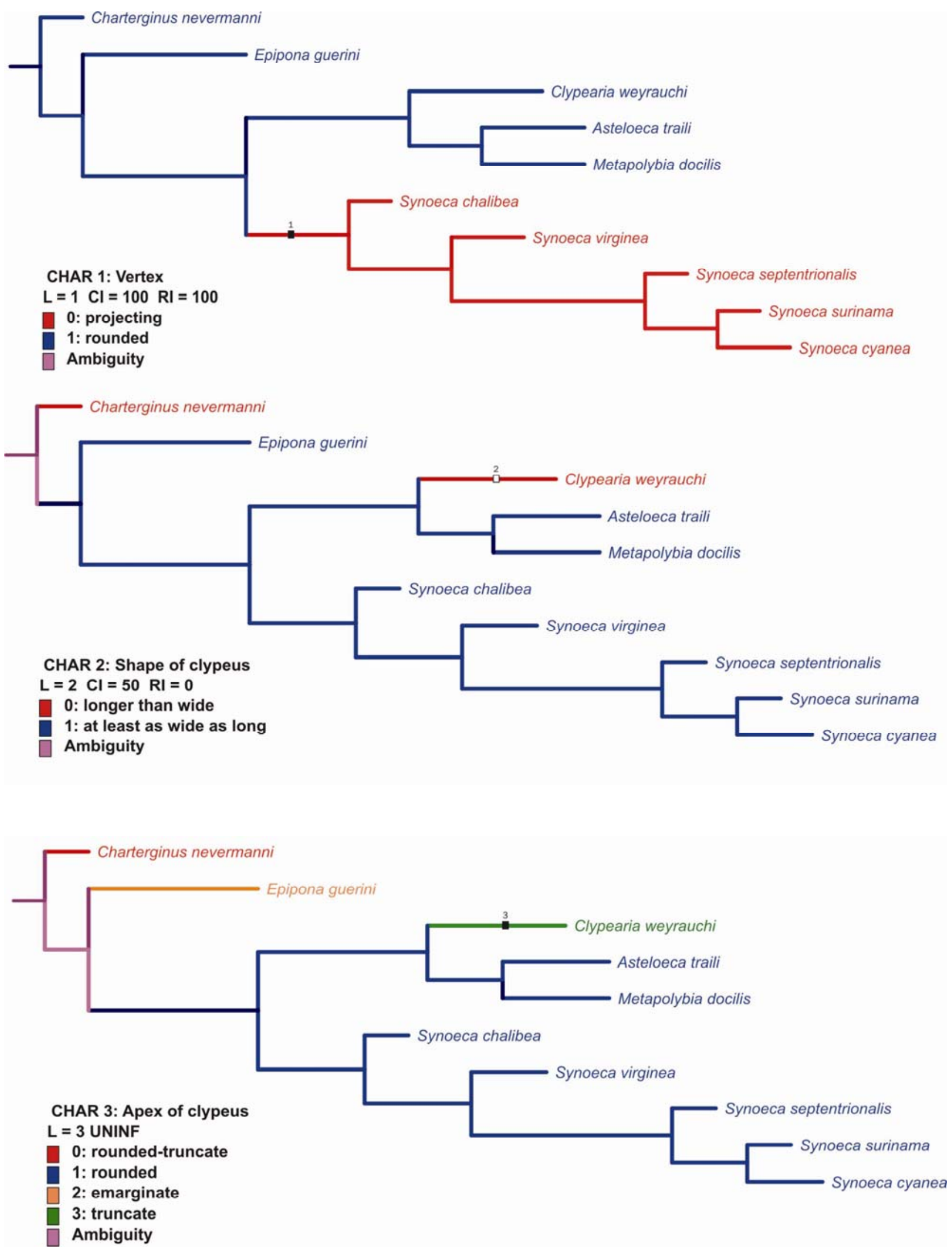

Figura 6 - Otimização dos caracteres 1, 2 e 3. 

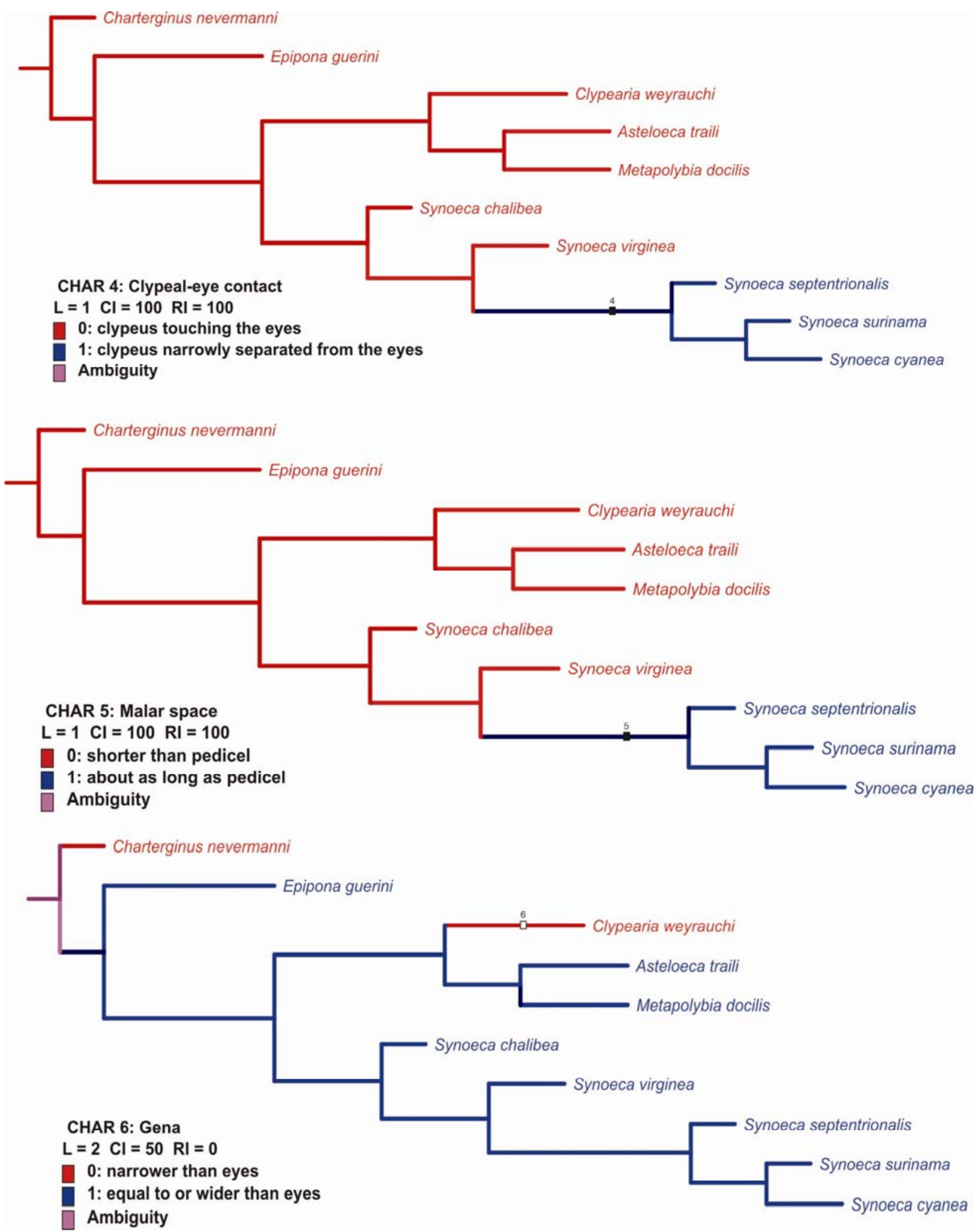

Figura 7 - Otimização dos caracteres 4, 5 e 6 . 

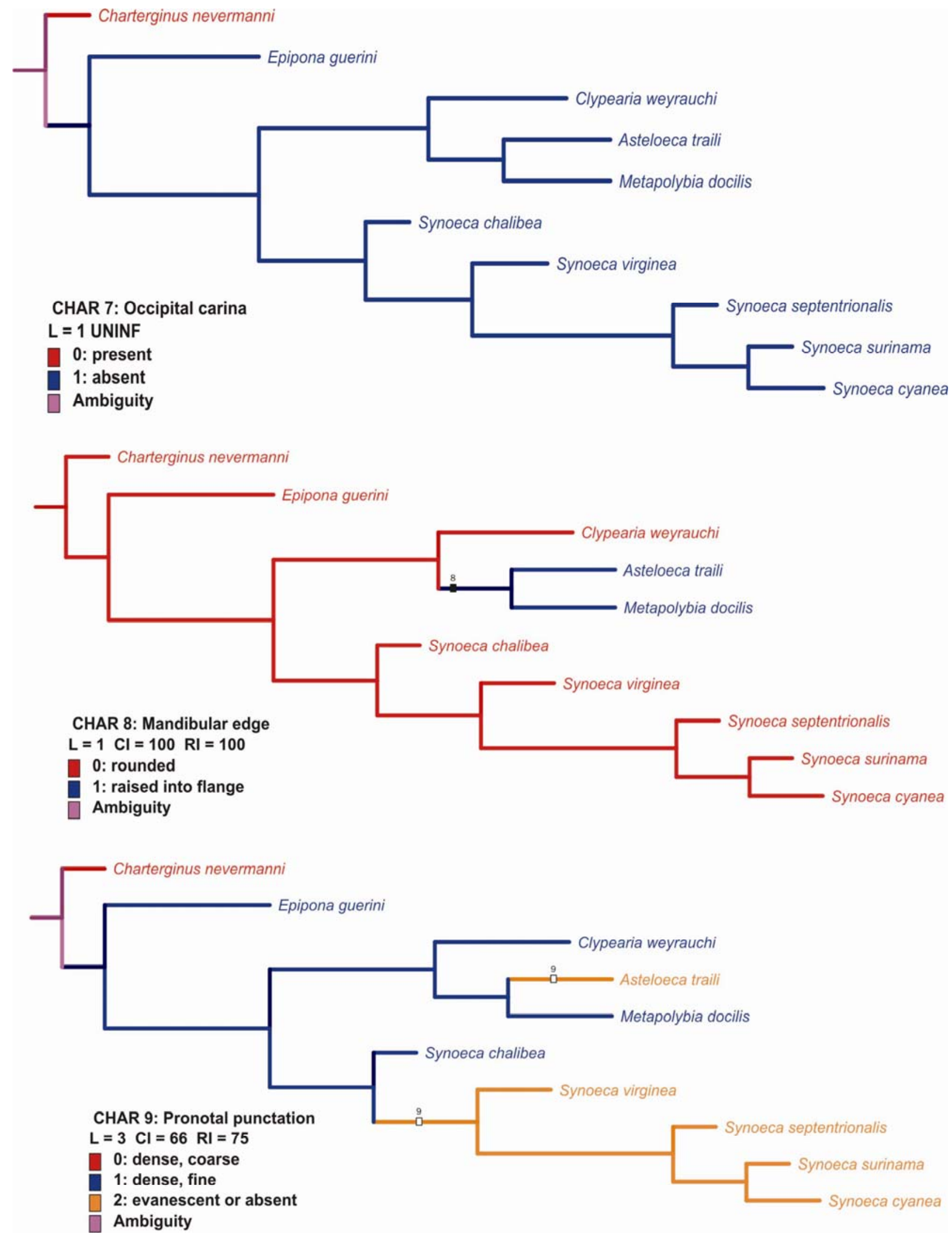

Figura 8 - Otimização dos caracteres 7, 8 e 9. 

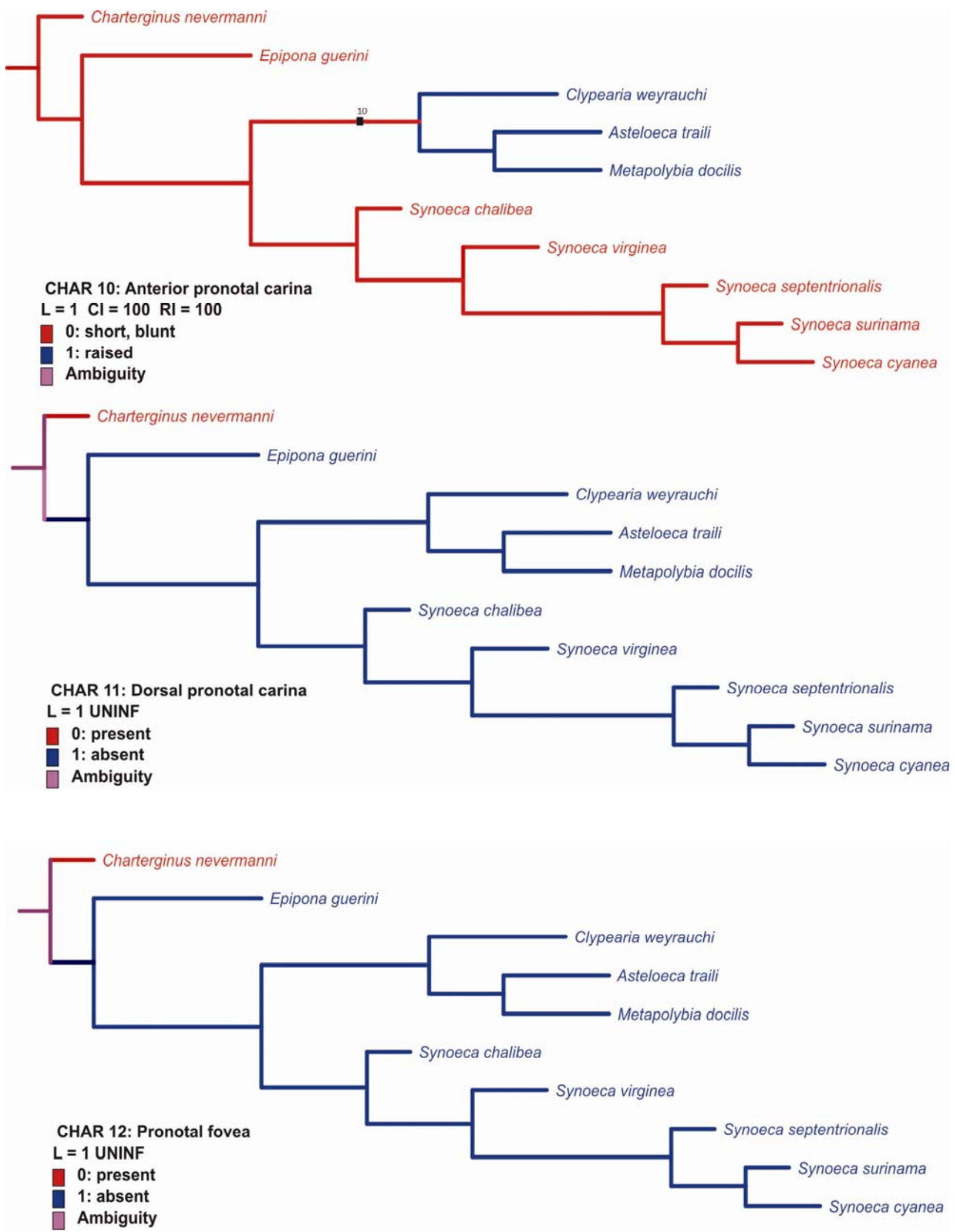

Figura 9 - Otimização dos caracteres 10, 11 e 12. 

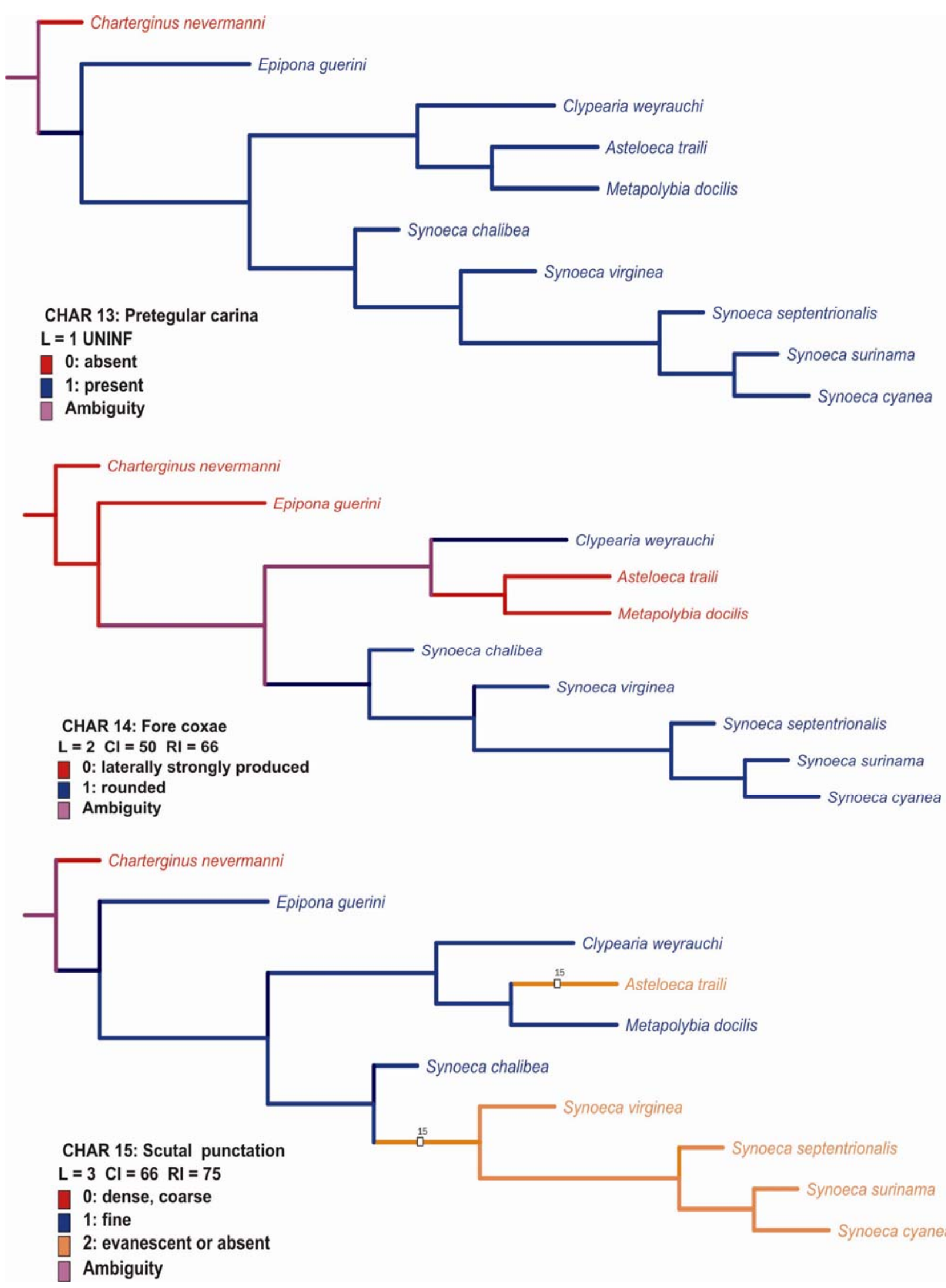

Epipona guerini

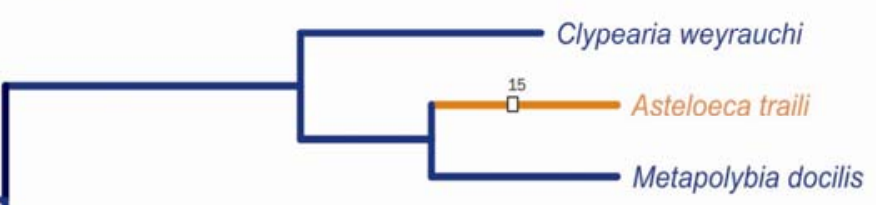

Figura 10 - Otimização dos caracteres 13, 14 e 15. 

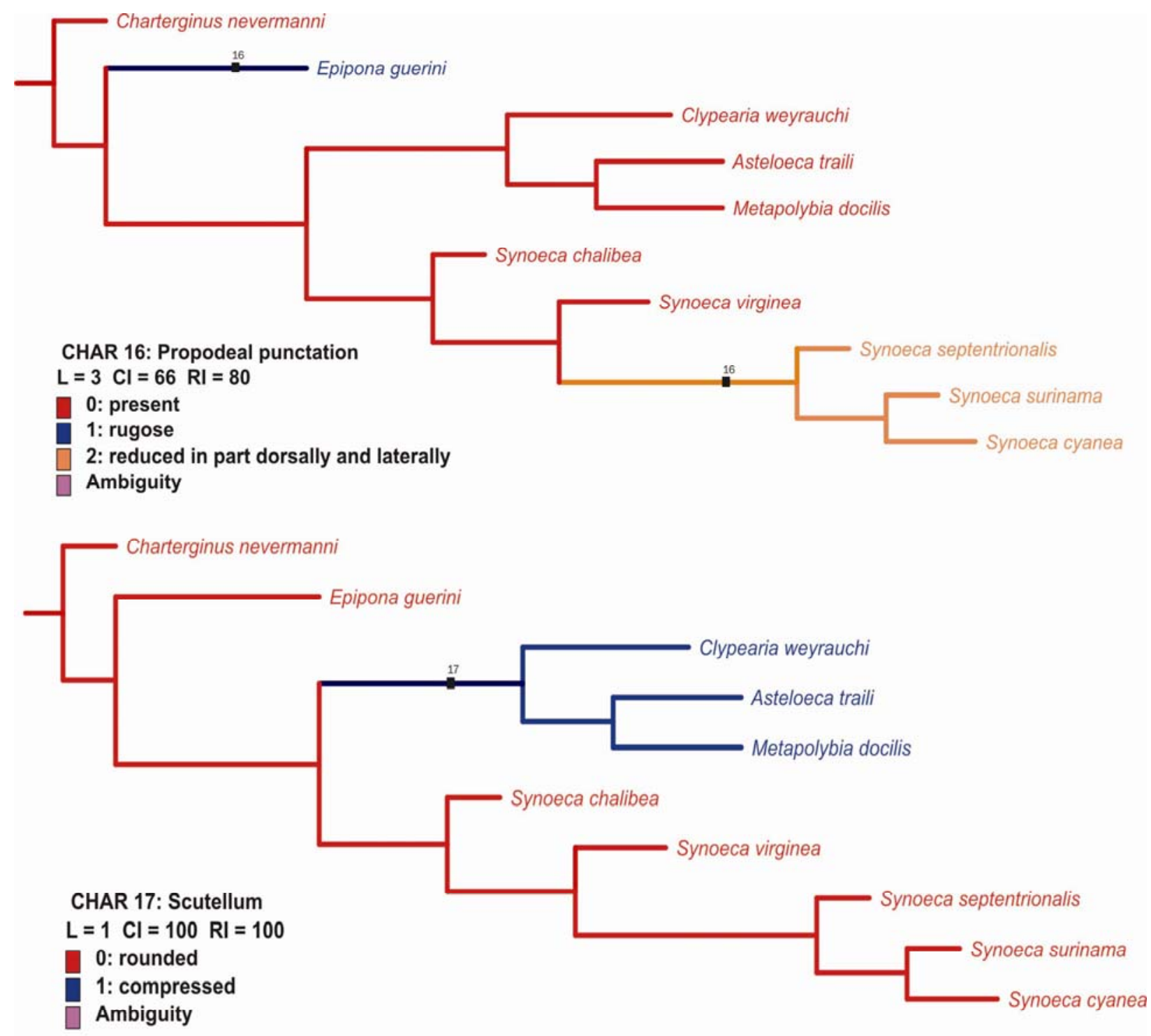

Charterginus nevermanni

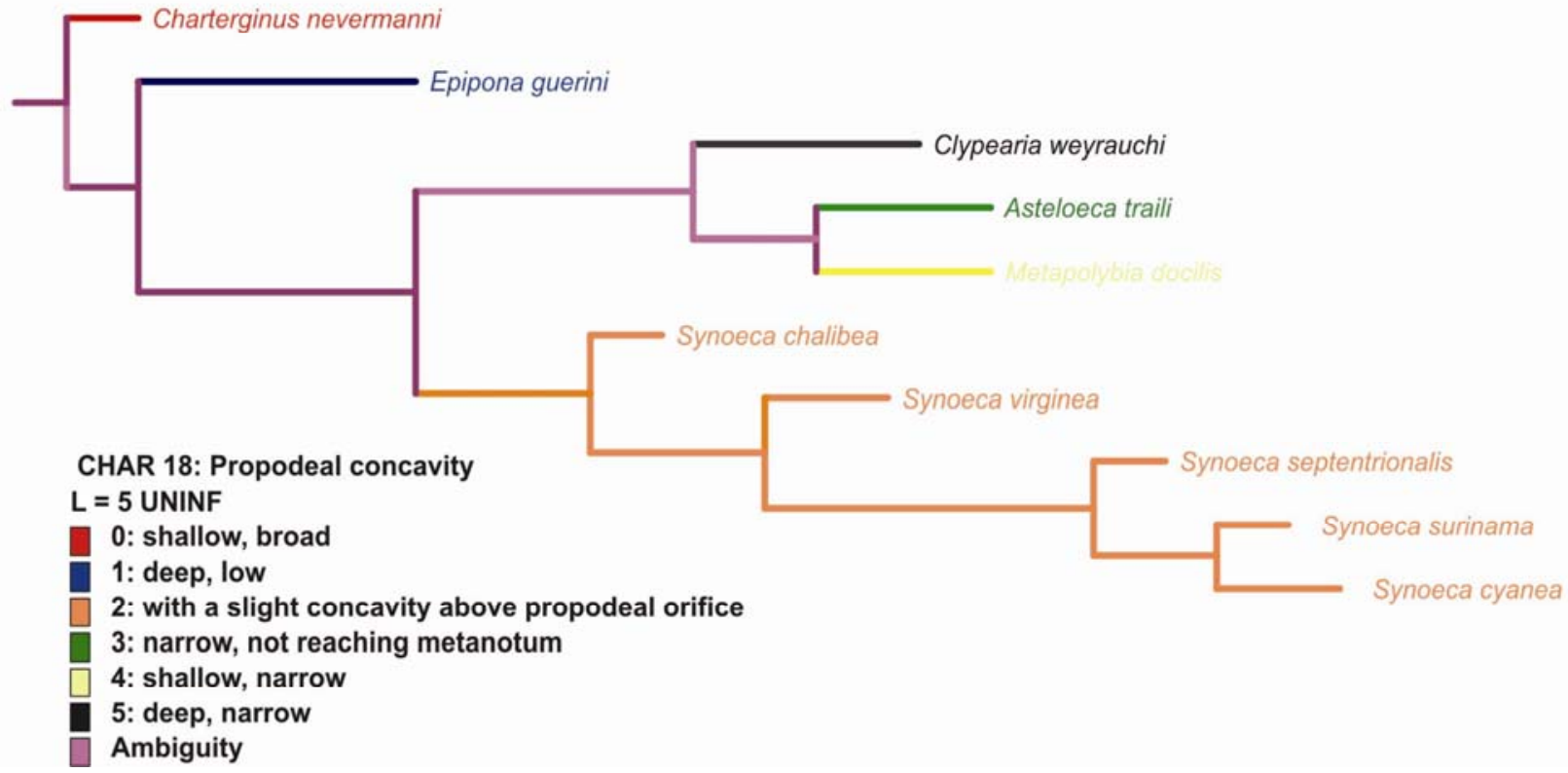

Figura 11 - Otimização dos caracteres 16, 17 e 18. 

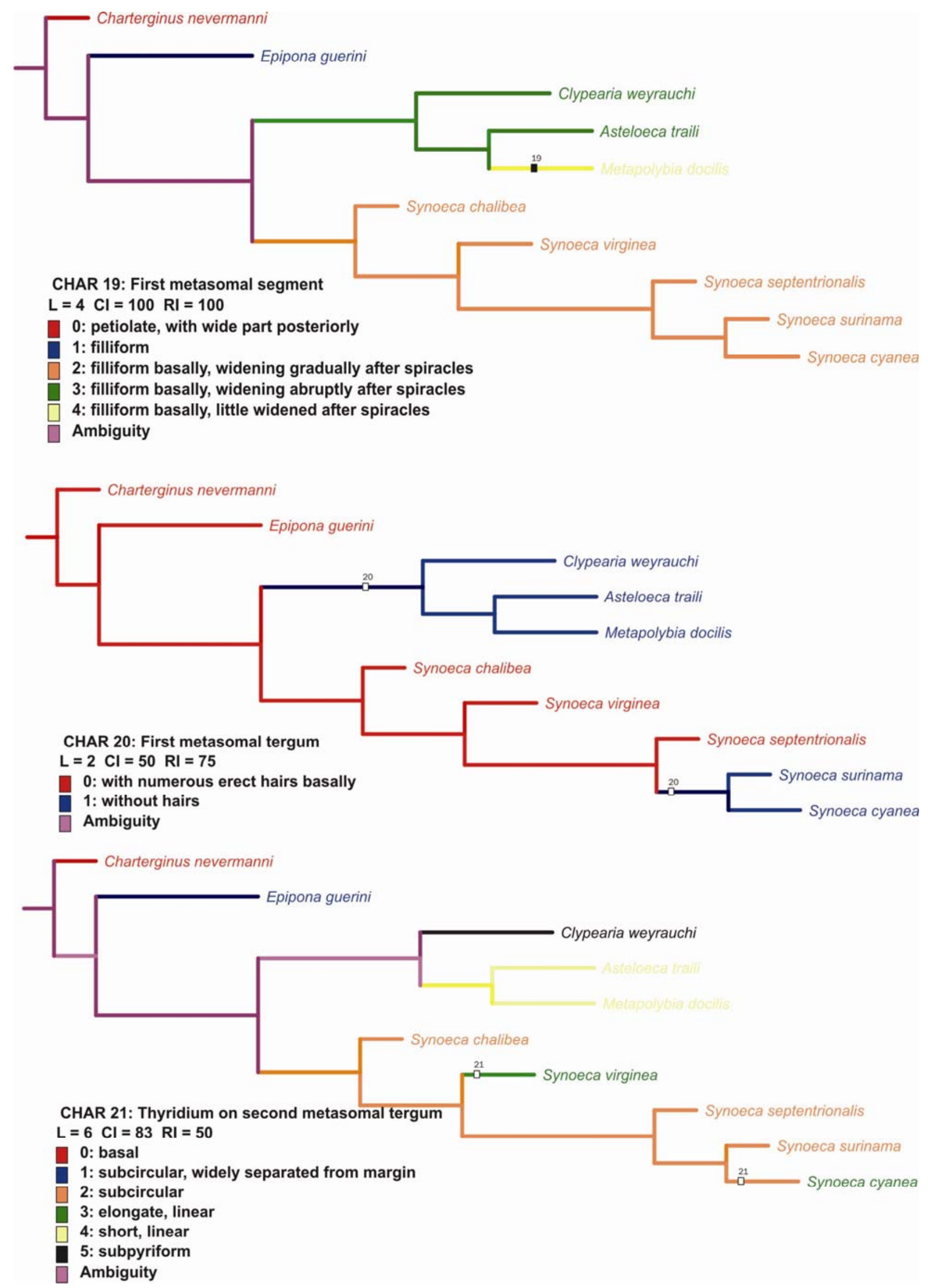

Figura 12 - Otimização dos caracteres 19, 20 e 21. 

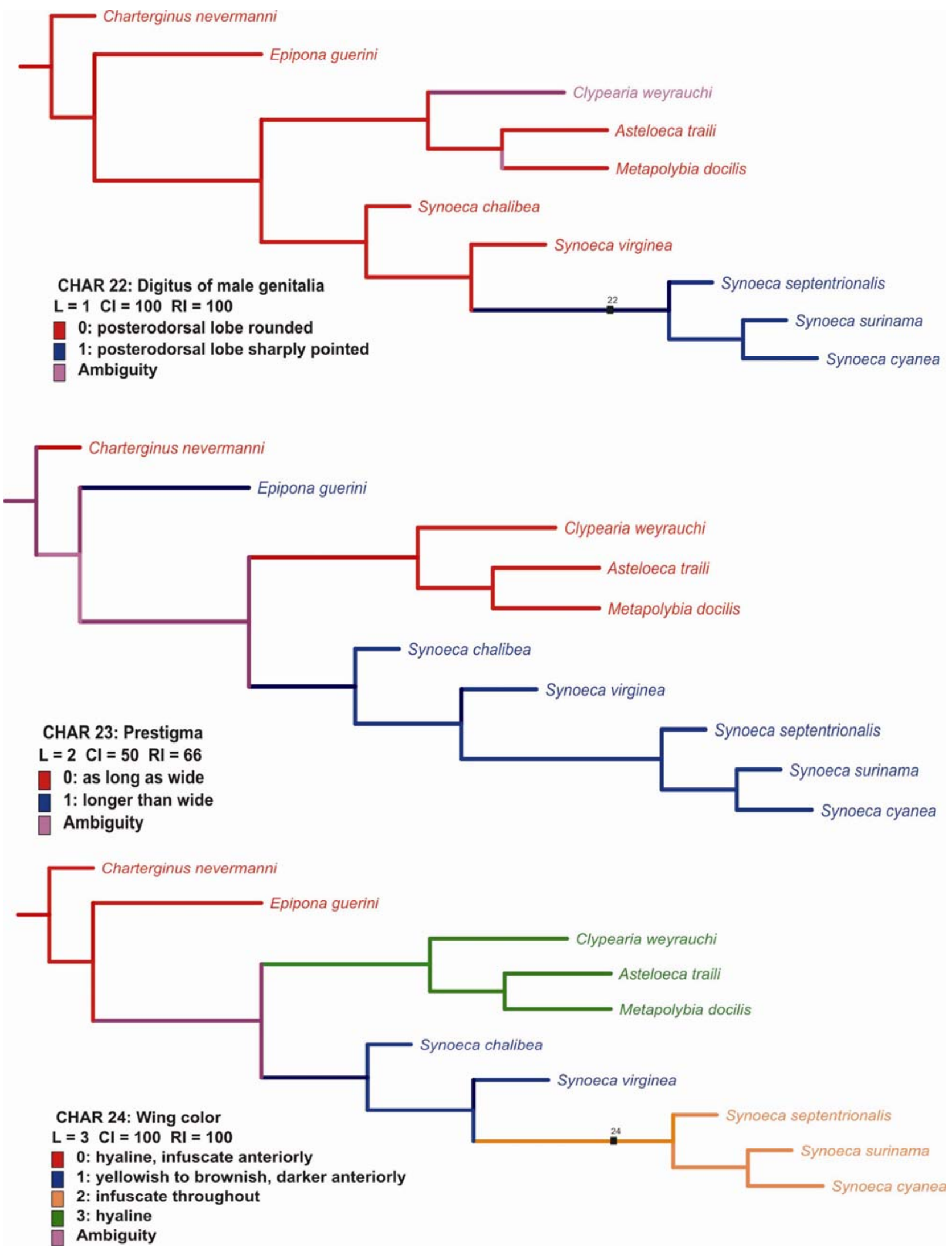

Figura 13 - Otimização dos caracteres 22, 23 e 24. 


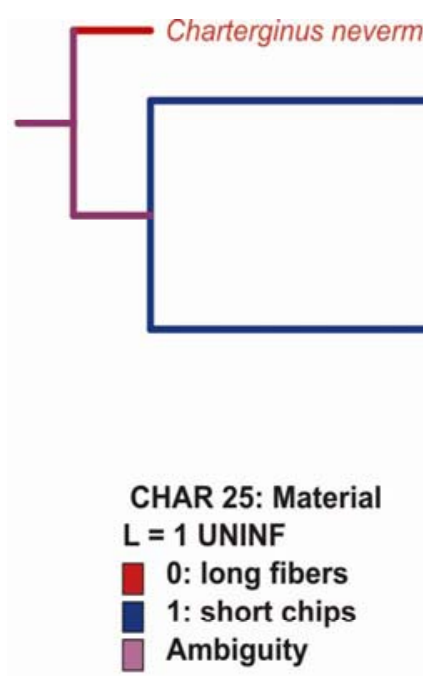

Epipona guerini

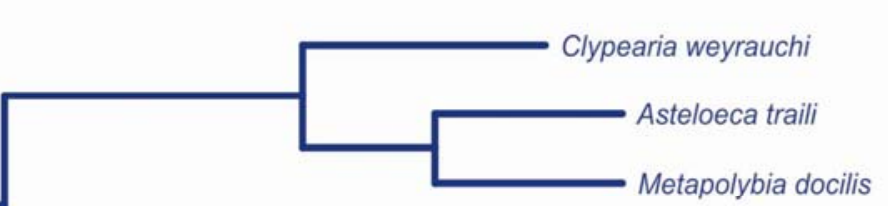

Synoeca chalibea
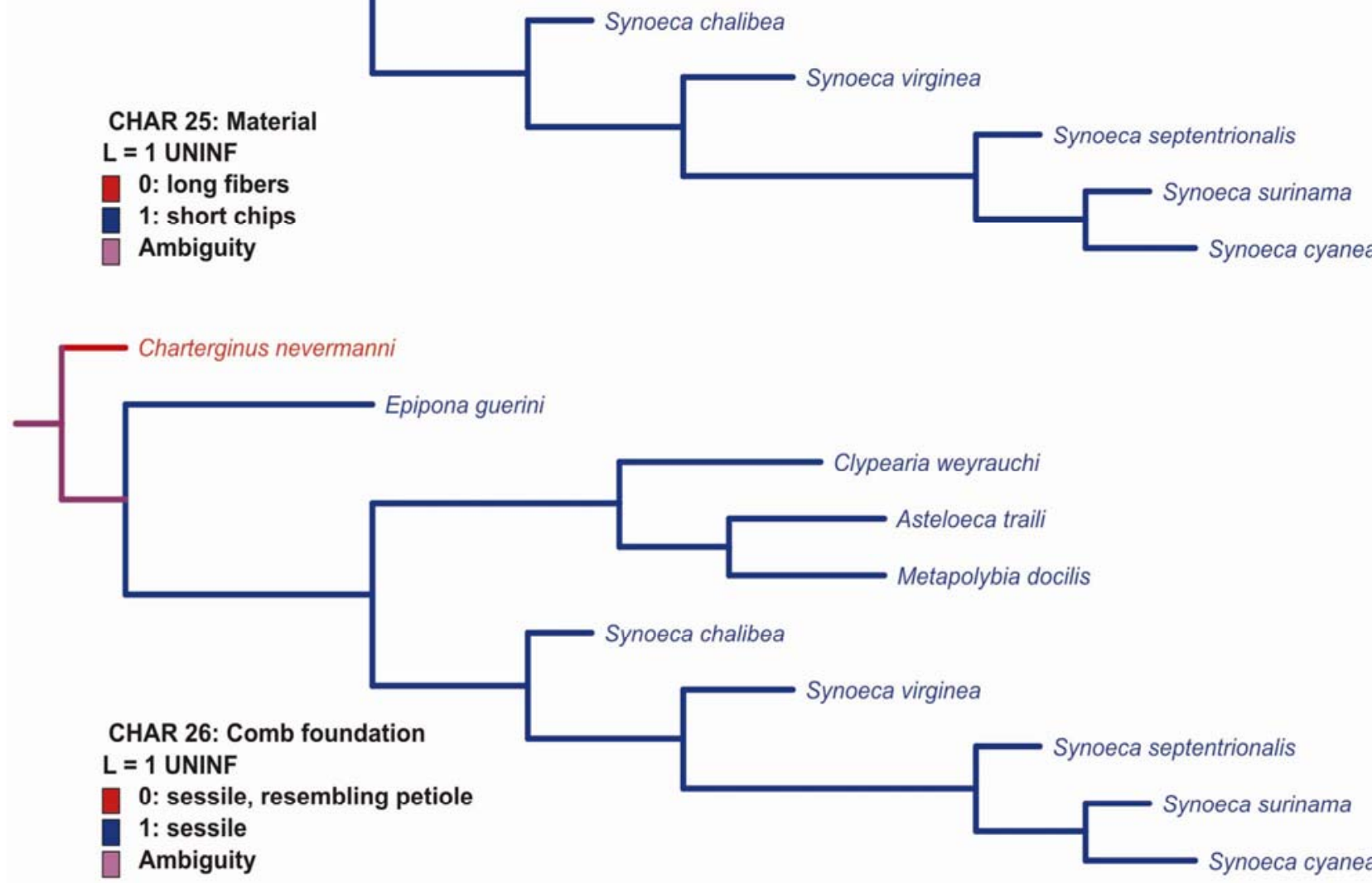

Clypearia weyrauchi

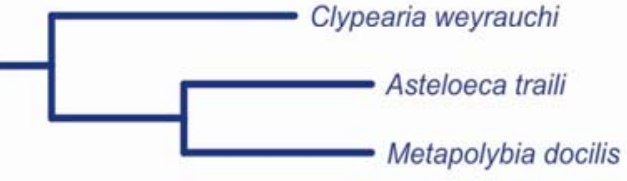

Synoeca chalibea
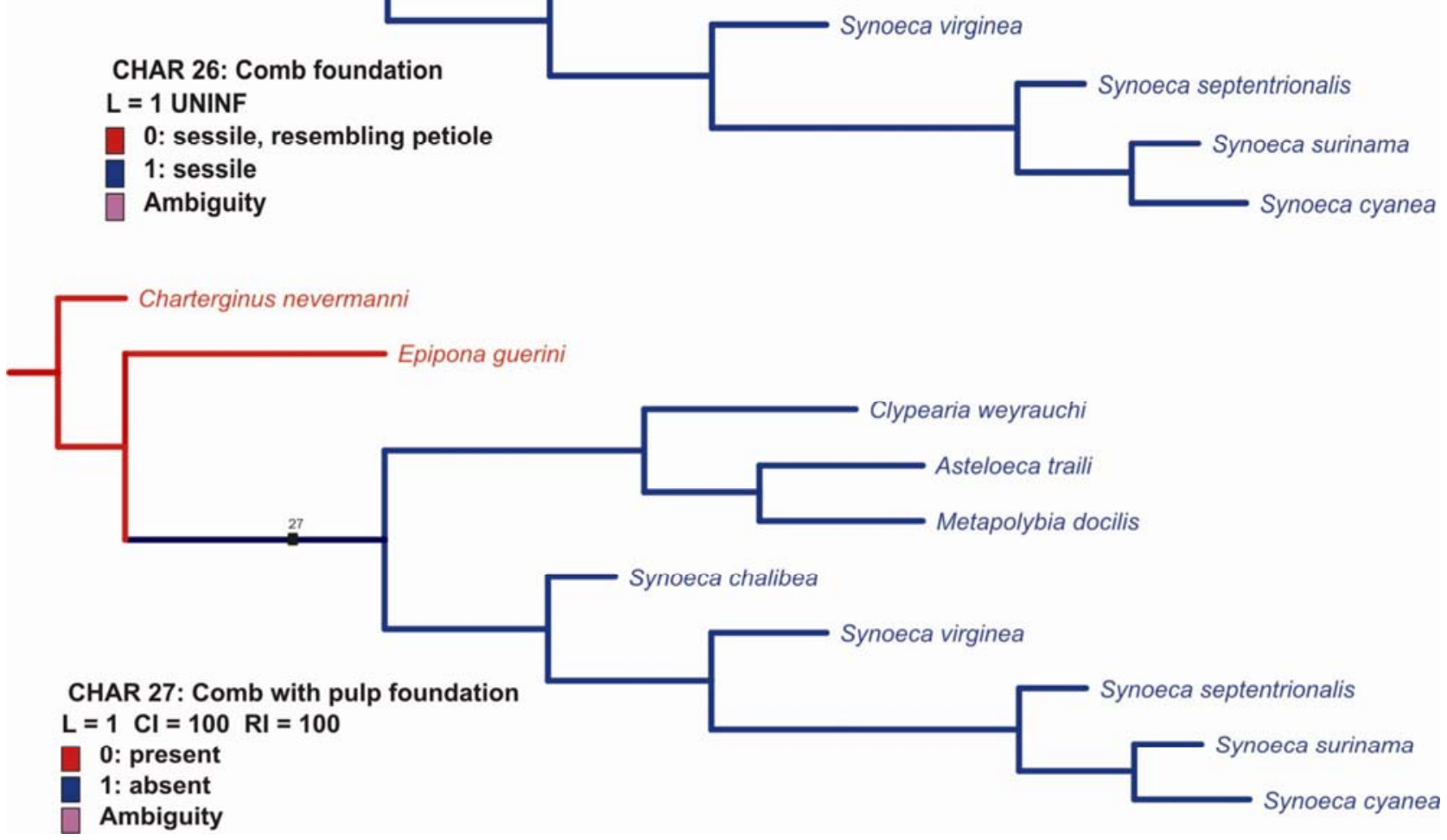

Figura 14 - Otimização dos caracteres 25, 26 e 27. 

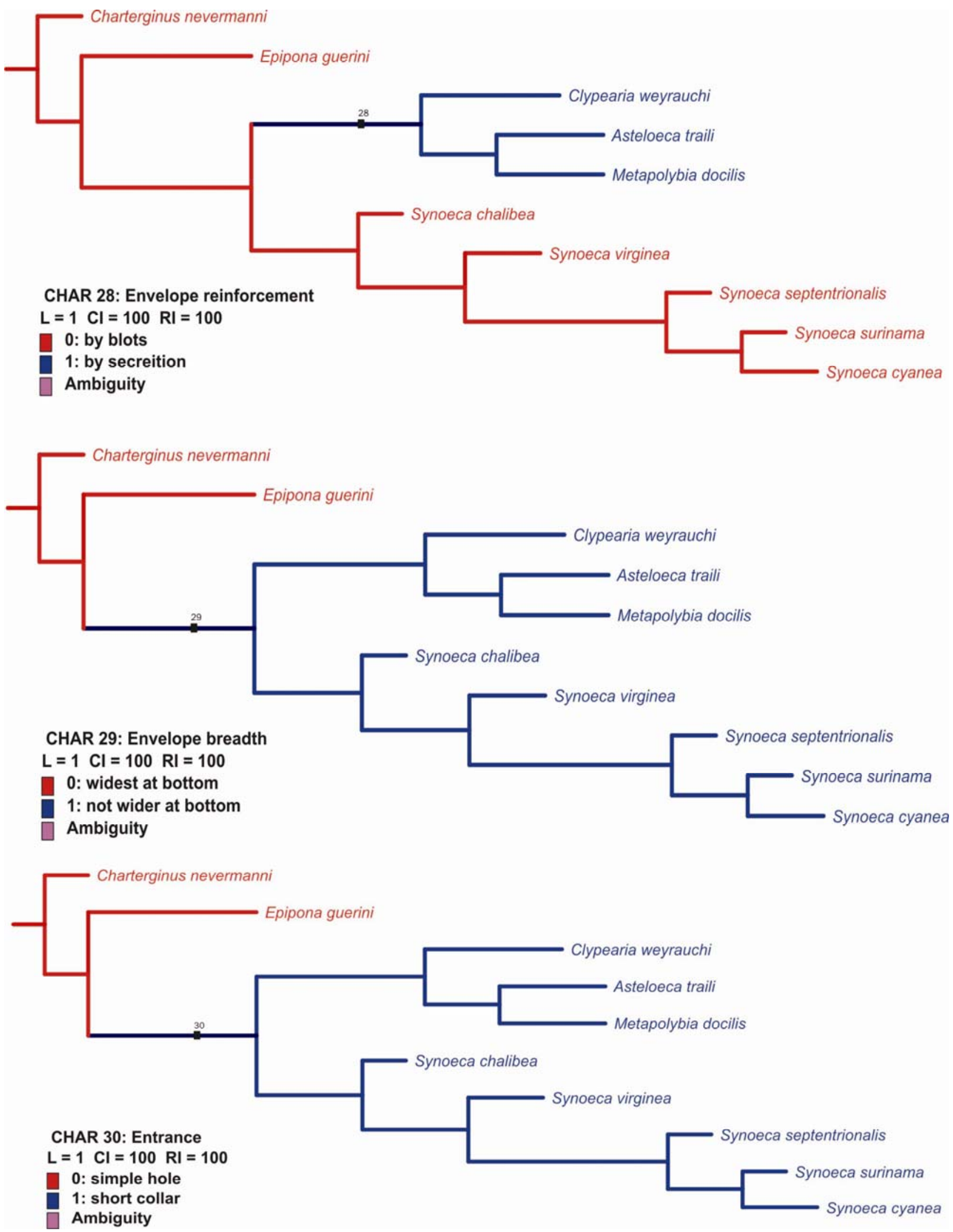

Figura 15 - Otimização dos caracteres 27, 28 e 29. 

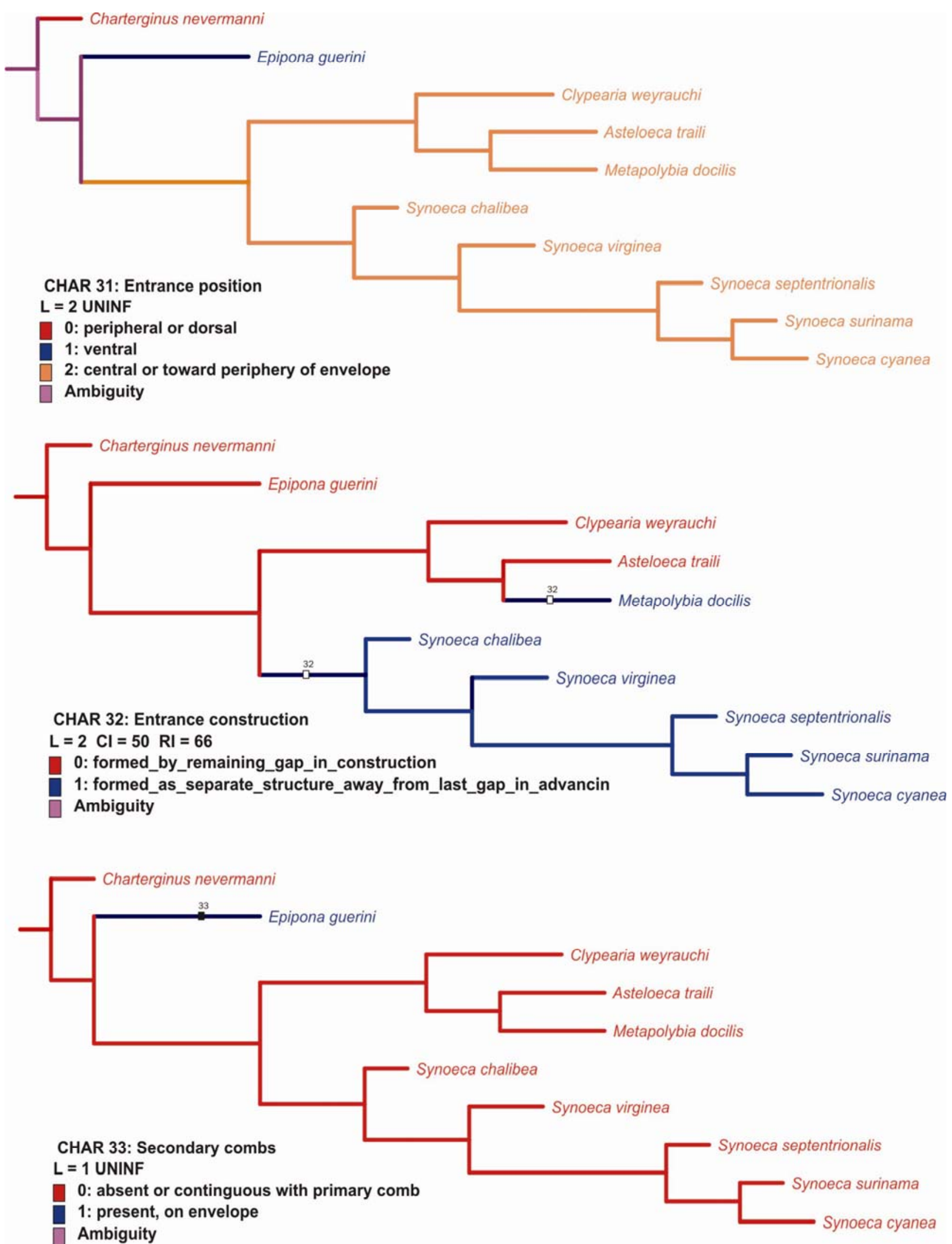

Figura 16 - Otimização dos caracteres 31, 32 e 33. 

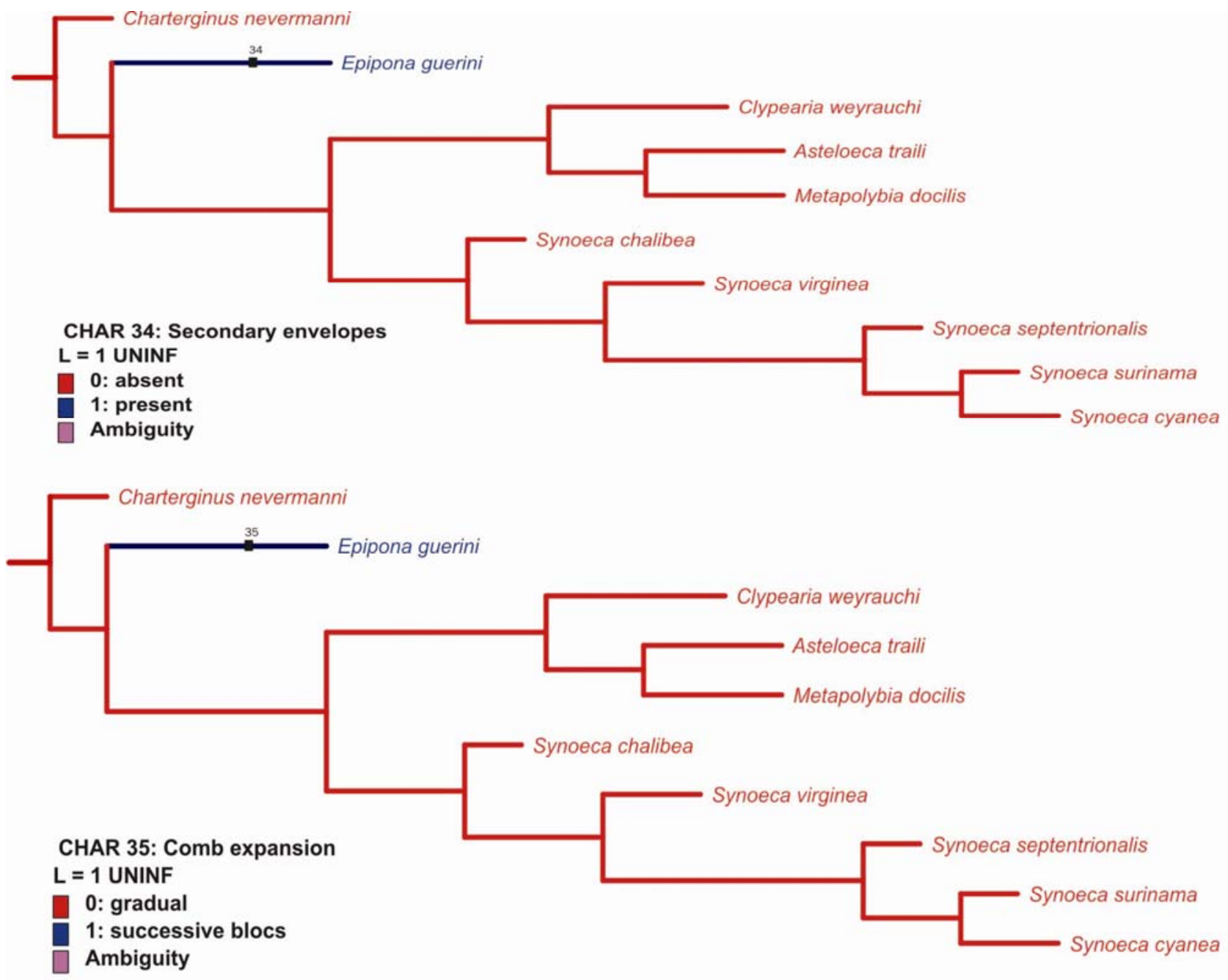

Charterginus nevermanni

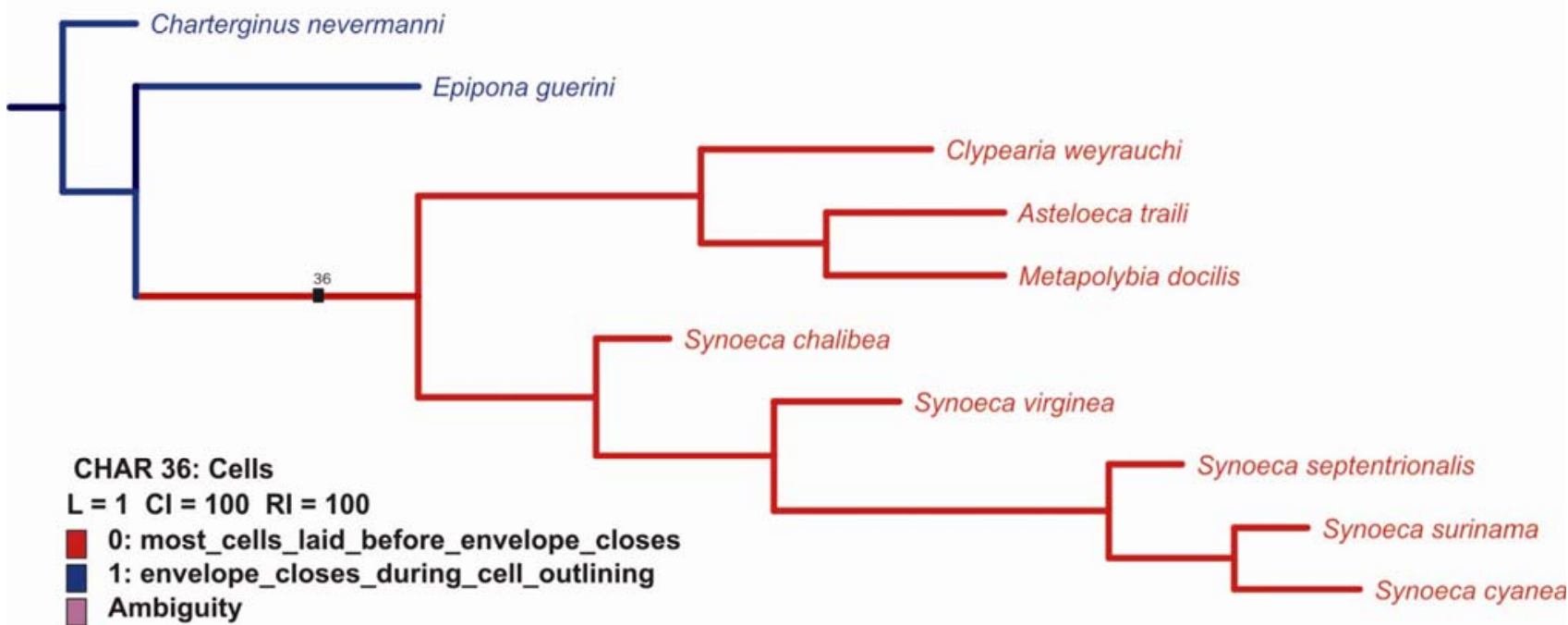

Figura 17 - Otimização dos caracteres 34, 35 e 36. 


\section{6 - REFERÊNCIAS}

Andena, S. R.; Noll, F. B.; Carpenter, J. M. \& Zucchi, R. 2007. Phylogenetic analysis of the neotropical Pseudopolybia de Saussure, 1863, with description of the male genitalia of Pseudopolybia vespiceps (Hymenoptera: Vespidae, Epiponini). American Museum Novitates (in press).

Bermúdez, E. G. C. 1980a. Reprodução e dinâmica de população em Synoeca surinama (Hymenoptera: Vespidae). Acta Amazônica, 10 (3): 679-690.

Bermúdez, E. G. C. 1980b. Orientação, arquitetura e construção dos ninhos por Synoeca surinama L. (hymenoptera: Vespidae). Acta Amazônica, 10 (4): 883-896.

Bermúdez, E. G. C. 1981a. Comportamento e causas da migração de Synoeca surinama L. (Hymenooptera: Vespidae) na amazônia Brasileira. Revista Brasileira de Biologia, 26 (1), 71-74.

Bermúdez, E. G. C. 1981b. Alarme e defesa no ninho de Synoeca surinama (Hymenoptera: Vespidae). Acta Amazônica, 11 (2), 377-382.

Bermúdez, E. G. C. 1982. Evidências sobre o comportamento de copula dos machos de Synoeca surinama L. (Hymenoptera: Vespidae) fora do ninho. Acta Amazônica, 12 (3): 665-666.

Buysson, R. du 1906. Monographie de Vespides appartenant aux genres Apoica et Synoeca. Annales de la Société Entomologique de France, 75: 333-362.

Carpenter, J. M. 1991. Phylogenetic relationships and the origin of social behavior in the Vespidae. In: K.G. Ross \& Matthew, R.W. (editors), The Social Biology of Wasps: 7-32. Ithaca, NY: Cornell University Press.

Carpenter, J.M. \& Marques, O.M. 2001. Contribuição ao Estudo dos Vespídeos do Brasil (Insecta, Hymenoptera, Vespoidea, Vespidade). Série Publicações Digitais vol. 2. Universidade Federal da Bahia. 144 pp.

Carpenter, J. M. \& Mateus, S. 2004. Males of Nectarinella Bequaert (Hymenoptera, Vespidae; Polistinae). Revista Brasileira de Entomologia, 48 (3): 297-302.

Carpenter, J. M.; Wenzel, J. W. \& Kojima, J. 1996. Synonymy of the genus Occipitalia Richards, 1978, with Clypearia de Saussure, 1854 (Hymenoptera: Vespidae; Polistinae, Epiponini). Journal of Hymenoptera Research, 5: 157-165.

Nixon, K. C. \& Carpenter, J. M. 1993. On outgroups. Cladistics, 9: 413-426.

Noda, S. C. M.;. Shima, S. N \& Noll, F.B.. 2003. Morphological and physiological caste differences in Synoeca cyanea (Hymenoptera, Vespidae, Epiponini) according to the ontogenetic development of the colonies. Sociobiology, 41: 547-570. 
Noll, F.B.; Wenzel, J. W.; \& Zucchi, R. 2004. Evolution of Caste in Neotropical Swarm-Founding Wasps (Hymenoptera: Vespidae; Epiponini). American Museum Novitates, 3467: 1-24.

O’Donnell, S., J.; Hunt, H. \& Jeanne, R. L. 1997. Gaster-flagging during colony defense in neotropical swarm-founding wasps (Hymenoptera: Vespidae, Epiponini). Journal of the Kansas Entomological Society, 70 (3): 175-180.

Overal, W. L. 1982. Acoustical behavior and variable nest architecture in Synoeca virginea (Hymenoptera: Vespidae). Journal of the Georgia Entomological Society, 17 (1): 1-4.

Richards, O. W. 1978. The social wasps of the Americas excluding the Vespinae. London: British Museum (Natural History).

Schremmer, F. 1973. Synoeca cyanea (Vespidae). Alarmverhalten und Nestreparatur (Freilandaufnahmen). in G. Wolf (ed), Encyclopaedia Cinematographica, Film E 1886. Institut für Wissenschaftlichen Film, Göttingen.

Schremmer, F. 1986. Die Bautenvielfalt der sozialen Wespen. Öko-L . 8 (2-3): 49-59.

Thiago, E.; Ribeiro Junior, C.; Guimaraes, D. L. \& Prezoto, F.. 2005. Foraging activity and nesting of swarm-founding wasp Synoeca cyanea (Hymenoptera: Vespidae, Epiponini). Sociobiology, 46 (2): 317-327.

Wenzel, J. W. 1991. Evolution of nest architecture in social vespids. In Ross, K. G. and R. W. Matthews (editors), The Social Biology of Wasps: 480-519. Ithaca, NY: Cornell University Press.

Wenzel, J. W. 1993. Application of the biogenetic law to behavioral ontogeny: a test using nest architecture in paper wasps. Journal of Evolutionary Biology, 6: 229-247.

Wenzel, J. W. 1998. A generic key to the nests of hornets, yellowjackets, and paper wasps worldwide (Vespidade: Vespinae, Polistinae). American Museum Novitates, 3224: 1-39.

Wenzel, J.W. \& Carpenter, J.M. 1994. Comparing methods: adaptative traits and tests of adaptation. In: Eggleton, P. \& Vane-Wright, R. (editors), Phylogenetics and Ecology: 79-101. London: Academic Press.

West-Eberhard, M. J. 1981. Intragroup selection and the evolution of insect societies. In: R. D. Alexander and D. W. Tinkle (editors), Natural Selection and Social Behavior: Recent Research and New Theory: 3-17 New York: Chiron. 
Apêndice 1. Localidade dos exemplares de Synoeca examinados.

S. chalibea: Brasil (Obidos-AM; Rio Branco-AC); Costa Rica (Golfito, Puntarenas); Peru (Col. Perene, Pasco; Rio Santiago, Loreto; Satipo, Junín; El Campeziento).

S. cyanea: Brasil (Nova Teutonia-SC; Pedregulho-SP; Osório-RS); Paraguai (Villa Rica, Guairá).

S. septentrionalis: Colômbia (Rio Frio, Magdalena); Guatemala (Sta Emilia, Pochuta), Honduras (Zamorano); México (Muste, Chiapas); Panamá (Coanguinola Dist.).

S. surinama: Bolívia (El Porvenir, Beni); Brasil (Oidos-PA; Rio Araguaia-GO; Nova Mutum-MT; Lizarda-TO); Suriname (Paramaribo; Raleighvallen-Voltzberg); Trinidad (St. Augustine).

S. virginea: Brasil (localidade não especificada; Rio Branco-AC; Nova Mutum-MT); Colômbia (La Chorerra, Amazonas); Equador (Coca, Orellana; Limoncocha, Napo); Suriname (Raleighvallen-Voltzberg). 


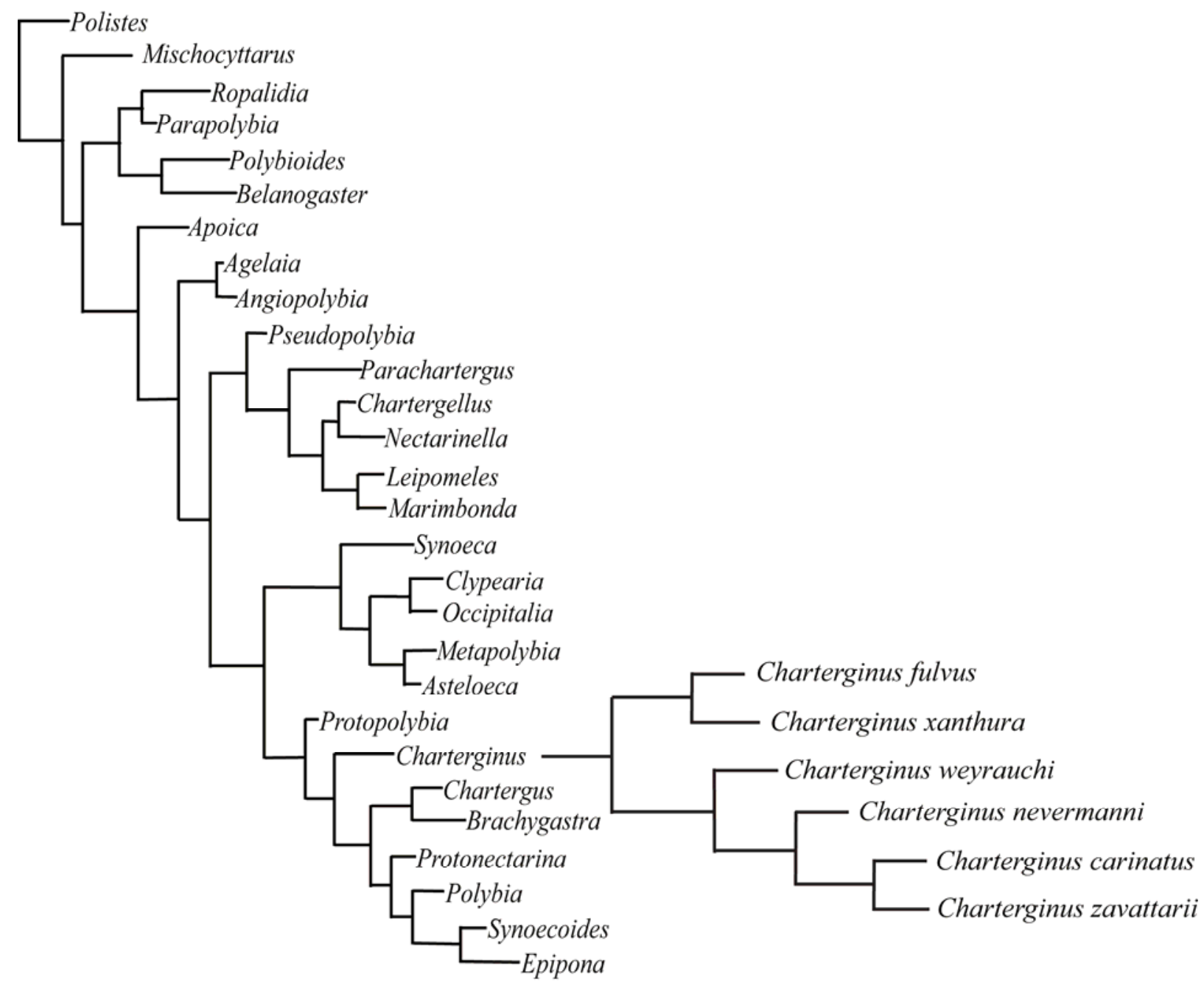

\section{Capítulo 5 - Análise Filogenética do Gênero Charterginus Fox 1898 (Hymenoptera, Vespidae, Epiponini)}




\section{Capítulo 5 - Análise Filogenética do Gênero Charterginus Fox 1898 (Hymenoptera, Vespidae, Epiponini)}

\section{1- INTRODUÇÃO}

Charterginus é um pequeno gênero de vespas sociais neotropicais, pertencente à tribo Epiponini de Polistinae, que se distribuem desde o sul de Honduras até a região equatorial da América do Sul (Carpenter \& Marques, 2001). No Brasil, somente duas espécies são encontradas, predominantemente distribuídas na Região Norte, Bacia Amazônica.

Apesar de apresentar somente seis espécies, este gênero apresenta diferenças estruturais no músculo propodeal e, segundo Richards (1978), poderia ser subdividido em subgêneros.

Os ninhos são arbóreos, ovulados, e geralmente são construídos em grandes folhas (Richards, 1978). O início dos ninhos é séssil e são presos por um forte pedicelo (Wenzel, 1993, 1998). São compostos por fibras longas e possuem envelope simples (Wenzel, 1998). A margem do envelope é parcialmente removida para permitir a expansão do ninho (Wenzel, 1998). A entrada consiste de uma simples abertura, situada na região periférica ou dorsal (Wenzel, 1998). Geralmente os ninhos são brancos ou marrons (Richards, 1978; Wenzel, 1998; ver também Figs. 3 e 4).

Charterginus xanthura (de Saussure), é a espécie do gênero que apresentou maiores problemas taxonômicos, pela dificuldade de se encontrar o "verdadeiro" holótipo. De Saussure (1853) descreveu Icaria xanthura. Magretti (1884) fez referência

a Icaria xanthura, mas ele havia identificado erroneamente Ropalidia cincta (Lepeletier, 1836, ver Bequaert, 1918). Richards incluiu essa espécie no subgênero Polistratus do gênero Ropalidia, citando, inclusive, características diagnósticas (Kojima 
\& Carpenter, 1998). Van der Vecht \& Carpenter (1990) apontam o erro de Richards (1978) quanto à inclusão em Polistratus. Kojima \& Carpenter (1998) encontram o verdadeiro holótipo no Museu de História Natural de Londres, e concluem que esta espécie não pertence ao gênero Ropalidia Guérin-Méneville, 1831 (=Icaria de Saussure, 1853), mas sim ao gênero Charterginus Fox, 1898. Esses autores ainda citam que Charterginus xanthura é sinônimo sênior de Charterginus aberrans (Griboldo, 1892).

Atualmente reconhecem-se seis espécies para Charterginus: C. carinatus (Zavattari), C. fulvus Fox, C. nevermanni Bequaert, C. weyrauchi Richards, C. xanthura (De Saussure), e C. zavanttarii Richards. No Brasil somente C. fulvus e C. xanthura são encontradas.

Desde a primeira filogenia para os Polistinae (Carpenter, 1991), como nas subseqüentes (Wenzel, 1993; Wenzel \& Carpenter 1994; Noll, 2000) o posicionamento de Charterginus sofreu mudanças. Em Carpenter (1991) Charterginus é grupo irmão de uma politomia entre (Protopolybia + Pseudochartergus), (Epipona + Synoeca + (Clypearia, Asteloeca, Metapolybia, Occipitalia), Protonectarina, (Chartergus + Brachygastra), Synoecoides e Polybia. Em Wenzel (1993) parte dessa politomia é resolvida e Charterginus é grupo irmão de (Epipona + Synoecoides), Chartergus, (Brachygastra + (Polybia + Protonectarina)). Já em Wenzel \& Carpenter (1994), Protopolybia é o gênero mais basal do clado, sendo Charterginus grupo irmão de $($ Chartergus + Brachygastra $)+($ Protonectarina $+($ Polybia + (Synoecoides + Epipona). Na filogenia de Noll (2000), utilizando a matriz de Wenzel \& Carpenter (1991), mais dados de diferenciação de castas, Charterginus é o gênero mais basal, sendo grupo irmão de Protopolybia. Neste mesmo trabalho de Noll (2000), dados de diferenciação de castas de C. fulvus são amplamente estudados, mas, no entanto, este 
gênero tem tido pouca atenção, não só taxonomicamente, como também quanto a dados ecológicos e comportamentais.

Neste trabalho, realizamos a análise filogenética das seis espécies do gênero, utilizando dados de morfologia, e arquitetura de ninho. Uma nova chave de identificação é apresentada, baseada na análise filogenética deste trabalho, mais os caracteres diagnósticos presentes na chave de Richards (1978).

\section{2 - MATERIAIS E MÉTODOS}

Vinte e oito caracteres de morfologia externa e quatro de arquitetura de ninho foram utilizados na matriz de dados para a reconstrução filogenética (Tabelas 1 e 2). Os dados de ninhos foram consultados a partir de Wenzel $(1993,1998)$. Os caracteres de mútiplos estados foram tratados como aditivos, exceto os caracteres 2, 5, 6, 11, 13, 24, e 27. O enraizamento dos grupos-externos (Nixon \& Carpenter, 1993) foi realizado através dos seguintes táxons: Angiopolybia pallens, Pseudopolybia difficilis, Epipona guerini, Protonectarina sylveirae, e Chartergus chartarius.

\section{3 - RESULTADOS}

A análise da matriz resultou em um único cladograma com 54 passos, índice de consistência 0,75 e índice de retenção de 0,81 (Fig. 5). Confirma-se Charterginus como grupo monofilético tendo a seguinte relação entre as espécies: (C. xanthura $+C$. fulvus) $+($ C. weyrauchi $+($ C. nevermanni $+($ C. carinatus + C. zavattarii $))))$.

\section{4- DISCUSSÃO}

Segundo Carpenter (1991), o monofiletismo de Charterginus é bem estabelecido pelas sinapomorfias: têmpora estreita, carena pré-tegular ausente, metanoto achatado, e 
tirídio transverso e basal. Além desses caracteres, Carpenter (1991) cita as sinapormofias de Charterginus mais o seu grupo-irmão que inclui uma politomia entre vários gêneros (denominada aqui de componente Polybia) que são: ápice clipeal arredondado, lobos laterais do clípeo arredondado, fenda dorsal perdida, e lamela escutal reduzida.

Neste trabalho Charterginus é estabelecido pelas seguintes sinapormofias: gena menor que $1 / 2$ dos olhos (caráter 7 , estado 1 ), tégula (caráter 18) um pouco mais que duas vezes mais longa do que larga (estado 1); margem posterior da tégula truncada ou pontiaguda (caráter 19, estado 1), fenda pré-apical transversa no tergo 1 (caráter 23) evanescente (estado 1) e presente (estado2), primeiro segmento metasomal com a região posterior alargada (caráter 24, estado 0), e carena pré-tegular ausente (caráter 28, estado 1), caráter este, também salientado por Carpenter (1991). O caráter 2 (ápice clipeal) truncado (estado 1), também observado por Carpenter (1991), e compartilhado por Epipona guerini, e o caráter 25 (segundo segmento metassomal), estado 1 (mais longo do que largo), compartilhado por Angiopolybia pallens e Pseudopolybia difficilis, são caracteres presentes em todas as espécies de Charterginus, mas por também estarem presentes nas espécies dos grupos externos citados, são homoplásticos na Fig. 5. Os caracteres citados são de difícil padronização, uma vez que tanto o clípeo, quanto o segundo segmento metassomal apresentam grande diversidade nos Epiponini, e, provavelmente, tiveram origens independentes.

As espécies do clado (C. fulvus + C. xanthura) compartilham várias características, mas como a otimização desses caracteres é ambígua em nossa filogenia, não são plotadas na Fig. 5. Nestas espécies o caráter 17 (metanoto) é tuberculado na região mediana anterior (estado 0), enquanto que no restante das espécies o metanoto não apresenta tubérculo ou é evanescente. Apesar de essas duas espécies possuírem o 
metanoto com tubérculo, apresentam variação entre elas. Em C. fulvus o tubérculo é menor, arredondado e mais estreito (Richards, 1978), enquanto que em C. xanthura o tubérculo é mais pronunciado, truncado e mais largo (Richards, 1978; Kojima \& Carpenter, 1998), no entanto não possuem diferenças significativas para serem codificados diferentemente. A tégula (caráter 18, ver também Figs. 1 e 2) é outro caráter compartilhado por este clado, sendo pouco mais que duas vezes mais longa do que larga (estado 1). Esta caráter separa dois grupos dentro de Charterginus : (1) C. fulvus $+C$. xanthura, e (2) C. nevermanni $+($ C. carinatus $+C$. zavattarii), que possuem a tégula mais de três vezes mais longa do que larga. Em C. weyrauchi a tégula possui um tamanho intermediário entre esses dois grupos (quase três vezes mais longa do que larga, estado 2), sendo autapomórfico para esta espécie. Nas espécies de Charterginus a tégula passou, gradativamente, do estado de pouco maior que duas vezes mais longa do que larga, para mais de três vezes mais longa do que larga. Richards (1978), sem uma perspectiva filogenética, já havia observado essas diferenças na medida da tégula nos Charterginus, e a utilizou em sua chave de identificação para as espécies.

Na maioria dos Epiponini a tégula é tão longa quanto larga, ou pouco mais longa do que larga, no entanto existem variações no formato, e provavelmente teve origens independentes. Em algumas espécies de Agelaia, por exemplo, a margem anterior da tégula é pontiaguda. Já em outros gêneros a margem posterior apresenta variação, sendo truncada, arredondada ou pontiaguda.

A paratégula é um lobo achatado horizontalmente, localizada no canto pósterolateral do escuto (ver Fig. 2 modificada de Kojima \& Carpenter, 1998). Kojima \& Carpenter (1998) ilustram e descrevem esta estrutura em cinco espécies (C. fulvus, C. xanthura, C. weyrauchi, C. nevermanni, C. zavattarii). Neste trabalho complementamos o trabalho de Kojima \& Carpenter (1998), ilustrando a paratégula em C. carinatus 
(Figura 1 A e B). Em C. carinatus a projeção da paratégula é mais vertical que em $C$. fulvus e menos que em C. zavattarii (ver descrição da paratégula em Kojima \& Carpenter, 1988), se estendendo um pouco além da margem posterior da tégula. Kojima \& Carpenter (1998) citam que o formato da paratégula de C. xanthura é muito similar à de Eumeninae, mas certamente não tem a mesma origem sendo uma provável convergência. Parece não haver uma correlação entre o tamanho da tégula e a forma da paratégula, uma vez que espécies que compartilham o mesmo tamanho da tégula possuem paratégulas diferentes (C. nevermanni, C. zavattarii e C. carinatus). Como já citado por Kojima \& Carpenter (1998), não há um padrão evolutivo para esta estrutura, e o mais sensato é assumir que esta estrutura teve origens independentes. Mesmo se este caráter tivesse sido plotado na matriz do presente trabalho, os diferentes estados seriam autapomórficos para as espécies do gênero, não alterando a topologia da Fig. 5.

Charterginus weyrauchi parece ser uma espécie intermediária entre o grupo 1 e o grupo 2. Além dos caracteres citados anteriormente, a sutura subantenal (caráter 3) marcada (estado 1), e a proeminência do metanoto (caráter 17) evanescente ou ausente na região anterior (estado 1) é compartilhado pelo ramo C. nevermanni + (C. zavattarii + C. carinatus). Em alguns exemplares observados de C. carinatus, a proeminência no metanoto parecia ser evanescente, como em $C$. weyrauchi, e não ausente como citado por Richards (1978). Devido à pequena amostragem não foi possível determinar se este estado é realmente polimórfico para a espécie citada, e desta forma adotamos o estado “ausente ou evanescente”.

O clado C. nevermanni $+($ C. carinatus $+C$. zavattarii $)$ é bem estabelecido e possui a tégula (caráter 18) mais de três vezes mais longa do que larga; fenda apical transversa no tergo I (caráter 23) presente (estado 1), e a proeminência no segundo segmento metassomal (caráter 26) presente (estado 1) como sinapomorfias. Estes 
caracteres já haviam sido citados por Richards (1978), mas a proeminência no segundo segmento metassomal é menos pronunciada em $C$. nevermanni. Novamente, devido à pequena amostragem, não foi possível verificar a variação neste caráter.

Richards (1978) em sua chave agrupa C. carinatus e C. zavattarii utilizando como uma das características a "gena com 1/3 do tamanho do olho", o que poderia sugerir uma sinapomorfia agrupando essas duas espécies. Nas medidas realizadas nos três exemplares de $C$. carinatus a gena tem $1 / 2$ da largura dos olhos, estando em desacordo com a descrição de Richards (1978). Devido à dificuldade em se determinar medidas exatas para essa estrutura, já que, segundo descrições, apresentariam, pelos menos, mais dois estados (1/3 e 1/4 da largura do olho), e por haver variações nos exemplares estudados, decidimos utilizar apenas dois estados para este caráter. Mesmo se os vários estados tivessem sido plotados na matriz resultariam em uma homoplasia, e que sugere que ocorreram origens independentes para o tamanho da gena.

\section{5 - CHAVE DE IDENTIFICAÇÃO PARA AS ESPÉCIES DE CHARTERGINUS}

1 Tergito gastral 1 com uma distinta fenda transversa pré-apical; tergito 2 com tubérculo ápico-discal; tégula mais de três vezes mais longa do que larga; metanoto sem tubérculo ou apenas traços de tubérculo; olhos com pêlos; carena occipital marginada dorsalmente e ausente ou evanescente lateralmente. 2

- Tergito gastral 1 com fenda transversa pré-apical evanescente ou ausente; tergito 2 com tubérculo ápico-discal evanescente ou ausente; tégula 2-3 vezes mais longa do que larga; metanoto com tubérculo evanescente ou forte; olhos sem pêlos; carena occipital marginada dorsal e lateralmente lateralmente. 4

2 Espécies enegrecidas; asas enegrecidas; tergitos gastrais fortemente pontuado, carena occipital marginada até a metade dos olhos; gena com $1 / 4$ da largura dos olho. 
- Espécies amareladas; tergitos gastrais com pontuação esparsa .3

3 Asas hialinas, amareladas; tergitos e esternitos amarelados, com manchas enegrecidas; metanoto com traços de traços de tubérculo carena occipital marginada dorsalmente, não marginada lateralmente; gena com $1 / 2$ da largura dos olhos carinatus (Zavattari)

- Primeiro e segundo segmento gastral marrom/amarelados; asas marrom escurecidas; carena occipital marginada dorsalmente se estendendo fortemente até a região superior do olho; gena com $1 / 3$ da largura dos olhos. zavattarii Richards

4 Tergito gastral 1 com traços da fenda pré-apical transversa; tergito 2 sem tubérculo; cabeça e mesossoma com pubescência alaranjada; gena com $1 / 2 \mathrm{da}$ largura dos olhos; tégula quase três vezes mais longa do que larga; metanoto com tubérculo evanescente weyrauchi Richards

- Cabeça e mesossoma com pubescência esparsa alaranjada; tégula com pouco maior que duas vezes mais longa do que larga; carena occipital marginada até a altura da região superior dos olhos; tergo 1 com fenda pré-apical transversa evanescente tergo 2 com tubérculo evanescente. 5

5 Espécies enegrecidas; clípeo avermelhado na metade ventral, com mancha amarelada em formato de "U"; asas semi-hialina, pouco infuscadas, mas fortemente infuscadas na margem anterior; gena com 1/3 da largura dos olhos; tergo 2 com tubérculo evanescente; metanoto com proeminência ampla e truncada. xanthura (de Saussure)

- Espécies amareladas com manchas enegrecidas na cabeça e mesossoma; asas semi-hialinas, região costal enegrecida; gena com $1 \frac{1}{2}$ da largura dos olhos; metanoto com proeminência estreita e arredondada.

fulvus Fox 
Tabela 1 - Lista de Caracteres para Charterginus

\section{Caráter}

\section{Estado}

1. Formato do clípeo: tão longo quanto largo $=0$; mais longo do que largo $=1$.

2. Ápice do clípeo: pontiagudo ou arredondado $=0$; truncado $=1$.

3. Sutura subantenal: evanescente $=0$; marcada $=1$.

4. Distância ocelar: separado pela distância maior que o diâmetro de um ocelo = 0; separado pela distância menor que o diâmetro de um ocelo = 1 .

5. Pêlos na fronte e no vértex: curtos e esparsos $=0$; longos $=1$; ausentes $=3$.

6. Pontuação na fronte e no vértex: ausente $=0$; esparsa $=1$; densa $=2$.

7. Gena: maior que $1 / 2$ dos olhos $=0$; menor que $1 / 2$ dos olhos $=1$.

8. Carena occipital: presente $=0$; ausente $=1$.

9. Espaço malar: estreito $=0$; largo $=1$.

10. Fóvea pronotal: presente $=0$; ausente $=1$.

11. Pontuação no pronoto: ausente $=0$; esparsa $=1$; densa $=2$.

12. Lamela escutal: presente $=0$; reduzida $=1$.

13. Pontuação no escuto e escutelo: ausente $=0$; esparsa $=1$; densa $=2$.

14. Escutelo: com linha impressa $=0$; sem linha impressa $=1$.

15. Pêlos no escutelo: ausente $=0$; presente $=1$.

16. Fenda dorsal: presente $=0$; ausente $=1$.

17. Metanoto: tuberculado na região médio-anterior = 0; não tuberculado na região médio-anterior $=1$.

18. Tégula: tão longa quanto larga $=0$; quase 2 vezes mais longa do que larga $=1$; quase três vezes mais longa do que larga $=2$; mais de 3 vezes mais longa do que $\operatorname{larga}=3$.

19. Margem posterior da tégula: arredondada $=0$; truncada ou pontiaguda $=1$. 
20. Prestigma: tão longo quanto largo = 0 ; mais longo do que largo $=1$.

21. Região posterior do prestigma: truncada $=0$; arredondada $=1$.

22. Concavidade propodeal: com concavidade rasa $=0$; com concavidade profunda $=1$; com concavidade profunda, formando dois lobos laterais distintos $=2$.

23. Fenda pré-apical transversa no tergo 1 : ausente $=0$; evanescente $=1$; presente $=2$.

24. Primeiro segmento metassomal: peciolado, com região alargada posteriormente $=0$; mais longo do que largo $=1$; filiforme $=2$.

25. Segundo segmento metassomal: tão longo quanto largo = 0; mais longo do que $\operatorname{largo}=1$.

26. Proeminência no segundo segmento metassomal: ausente $=0$; presente $=1$.

27. Pecíolo metassomal: ausente $=0$; segmento $\mathrm{I}$ menor do que a metade do segmento II = 1 ; linear $=2$.

28. Carena pré-tegular: presente $=0$; ausente $=1$.

29. Favo hexagonal iniciado da seguinte forma 1: pecíolo em forma de haste = 0; séssil $=1$

30. Pedicelo: geralmente fibroso na região marginal da parede da primeira célula construída $=0 ;$ perdido $=1$

31. Favos: separados $=0$; fundidos $=1$.

32. Favos maduros: separados da entrada $=0$; atravessados pela entrada $=1$. 
Tabela 2 - Matriz de dados para Charterginus

$\begin{array}{llllllllllllllllllllllllllllllll}1 & 2 & 3 & 4 & 5 & 6 & 7 & 8 & 9 & 1 & 1 & 1 & 1 & 1 & 1 & 1 & 1 & 1 & 1 & 2 & 2 & 2 & 2 & 2 & 2 & 2 & 2 & 2 & 2 & 3 & 3 & 3\end{array}$ $\begin{array}{lllllllllllllllllllllll}0 & 1 & 2 & 3 & 4 & 5 & 6 & 7 & 8 & 9 & 0 & 1 & 2 & 3 & 4 & 5 & 6 & 7 & 8 & 9 & 0 & 1 & 2\end{array}$

Angiopolybia pallens Pseudopolybia difficilis

Charterginus carinatus

Charterginus fulvus

Charterginus nevermanni

Charterginus weyrauchi

Charterginus xanthura

Charterginus zavattarii

Epipona guerini

Protonectarina sylveirae

Chartergus chartarius

$\begin{array}{lllllllllllllllllllllllllllllllll}0 & 0 & 0 & 1 & 2 & 0 & 0 & 0 & 0 & 0 & 0 & 1 & 0 & 1 & 0 & 0 & 1 & 0 & 0 & 1 & 1 & 0 & 0 & 1 & 1 & 0 & 1 & 0 & 0 & 0 & 1 & 0 \\ 0 & 0 & 1 & 1 & 2 & 0 & 0 & 1 & 1 & 0 & 0 & 0 & 0 & 0 & 0 & 0 & 1 & 0 & 0 & 0 & 0 & 1 & 0 & 1 & 1 & 0 & 0 & 0 & 0 & 0 & 0 & 0 \\ 1 & 1 & 1 & 0 & 1 & 2 & 1 & 0 & 0 & 0 & 2 & 1 & 2 & 0 & 1 & 1 & 1 & 3 & 1 & 0 & 0 & 2 & 2 & 0 & 1 & 1 & 0 & 1 & 1 & 1 & 0 & 1 \\ 1 & 1 & 0,1 & 0 & 0 & 2 & 1 & 0 & 0 & 0 & 2 & 1 & 2 & 0 & 1 & 1 & 0 & 1 & 1 & 0 & 0 & 2 & 1 & 0 & 1 & 0 & 0 & 1 & 1 & 1 & 0 & 1 \\ 1 & 1 & 1 & 0 & 0 & 2 & 1 & 0 & 0 & 0 & 2 & 1 & 2 & 0 & 1 & 1 & 1 & 3 & 1 & 0 & 0 & 2 & 2 & 0 & 1 & 1 & 0 & 1 & 1 & 1 & 0 & 1 \\ 0 & 1 & 1 & 0 & 1 & 2 & 1 & 0 & 0 & 0 & 2 & 1 & 2 & 0 & 1 & 1 & 1 & 2 & 1 & 0 & 0 & 2 & 1 & 0 & 1 & 0 & 0 & 1 & 1 & 1 & 0 & 1 \\ 1 & 1 & 0 & 0 & 0 & 2 & 1 & 0 & 0 & 0 & 2 & 1 & 2 & 0 & 1 & 1 & 0 & 1 & 1 & 0 & 0 & 2 & 1 & 0 & 1 & 0 & 0 & 1 & 1 & 1 & 0 & 1 \\ 1 & 1 & 1 & 0 & 1 & 2 & 1 & 0 & 0 & 0 & 2 & 1 & 2 & 0 & 1 & 1 & 1 & 3 & 1 & 0 & 0 & 2 & 2 & 0 & 1 & 1 & 0 & 1 & 1 & 1 & 0 & 1 \\ 0 & 1 & 1 & 0 & 2 & 1 & 0 & 1 & 1 & 1 & 1 & 1 & 1 & 0 & 0 & 1 & 1 & 0 & 0 & 0 & 0 & 1 & 0 & 2 & 0 & 0 & 1 & 0 & 1 & 1 & 0 & 1 \\ 0 & 0 & 0 & 0 & 1 & 1 & 0 & 0 & 0 & 0 & 1 & 1 & 1 & 0 & 1 & 1 & 1 & 0 & 0 & 0 & 0 & 1 & 0 & 1 & 0 & 0 & 0 & 0 & 1 & 1 & 0 & 1 \\ 1 & 0 & 0 & 0 & 0 & 2 & 0 & 0 & 0 & 1 & 2 & 1 & 2 & 1 & 1 & 1 & 0 & 0 & 0 & 0 & 0 & 2 & 0 & 1 & 0 & 0 & 0 & 0 & 1 & 1 & 0 & 1\end{array}$



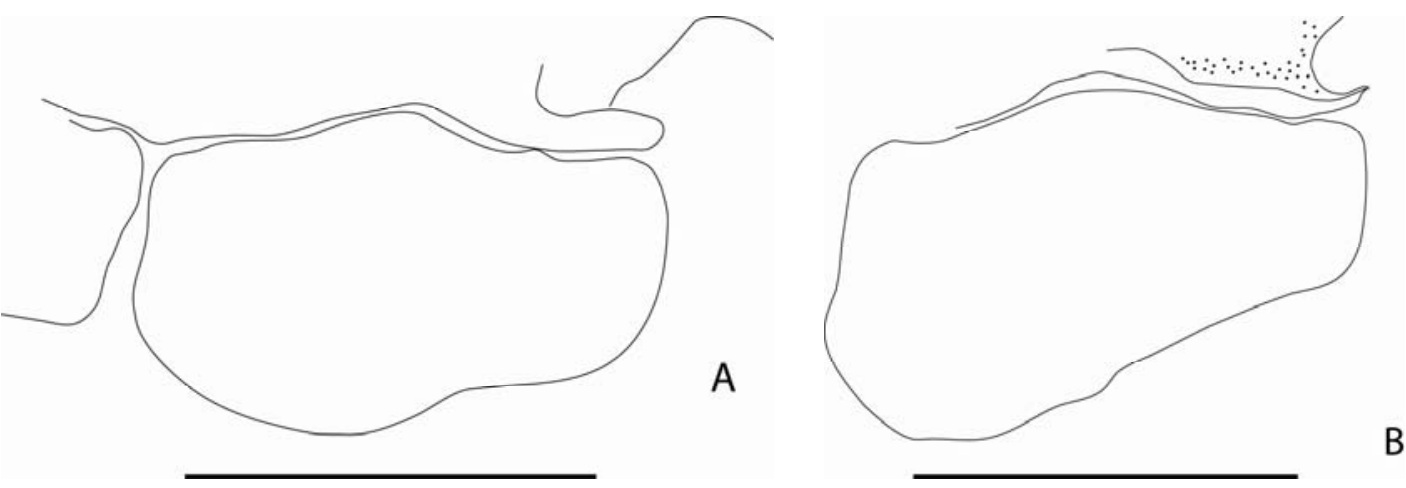

Figura 1 -Charterginus carinatus. A = Tégula, visão dorsal. $\mathrm{B}=$ Paratégula, visão dorso-lateral. Escala $=0,5 \mathrm{~mm}$.
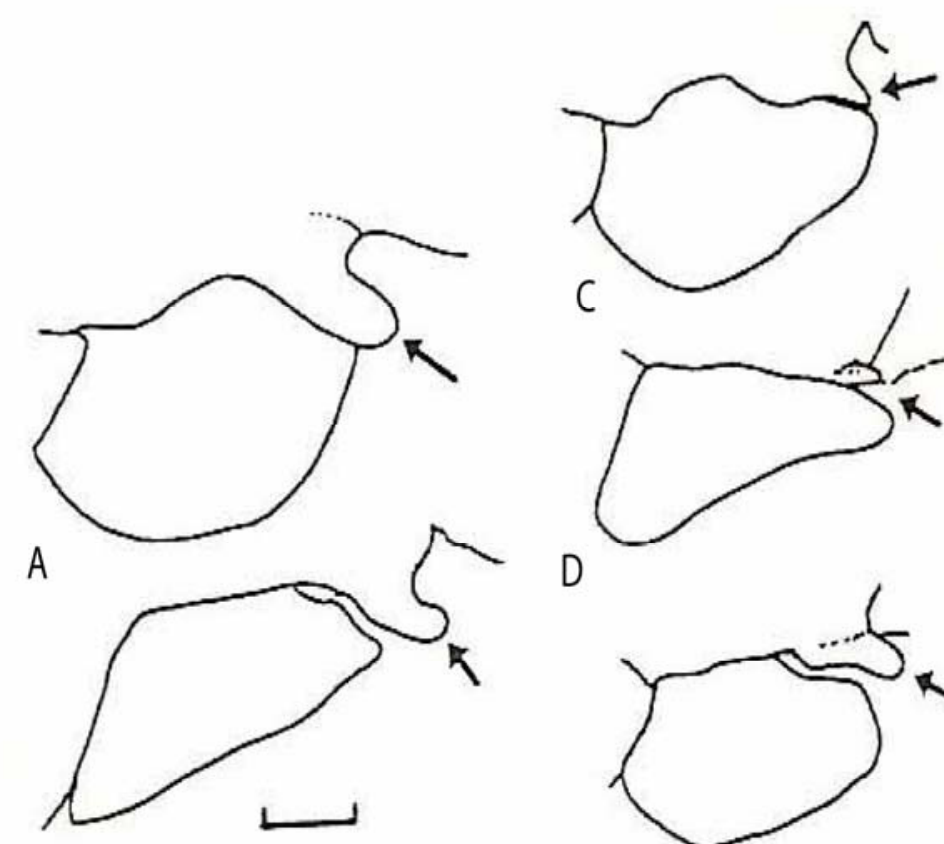

D
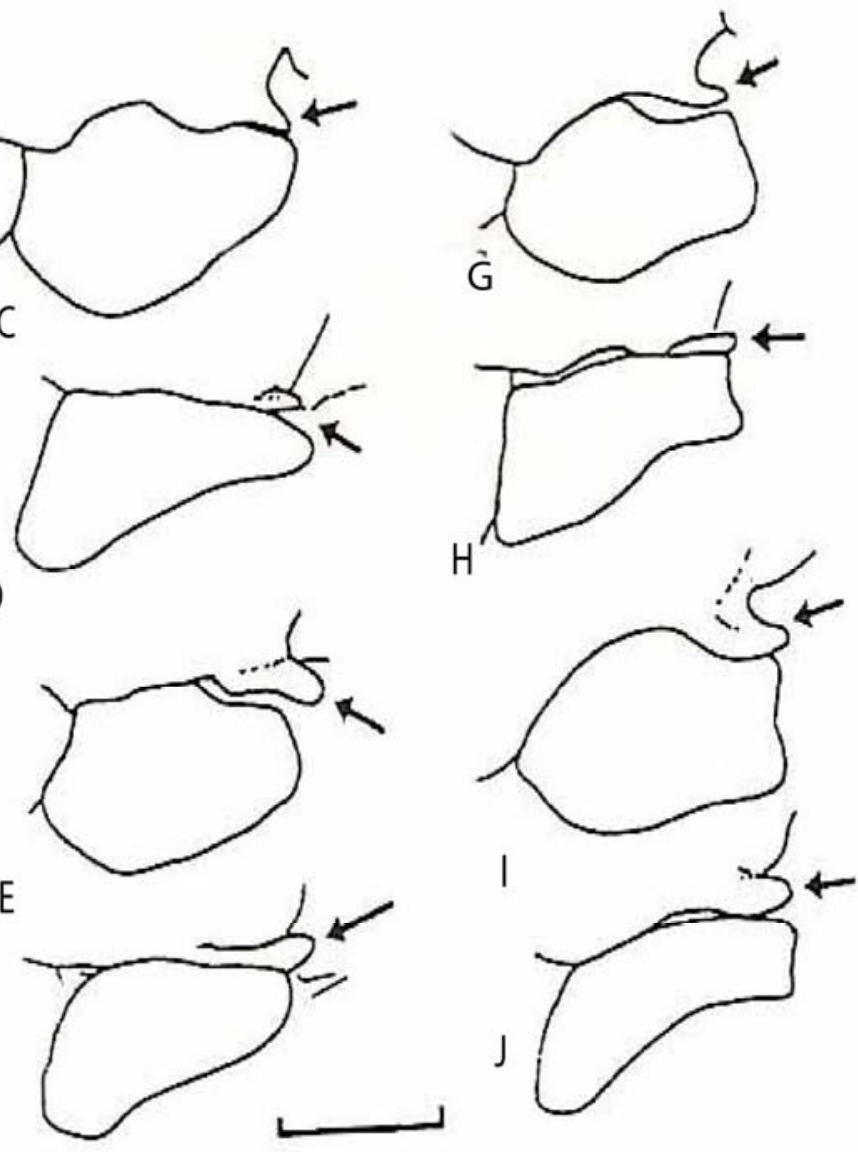

$\mathrm{F}$

Figura 2 - (modificado de Kojima e Carpenter, 1998). Tégula e projeção postero-lateral do escuto (A, C, G, E, I, visão dorsal; B, D, H, F, J, visão dorso-lateral ). - A, B, eumenine Anterhynchium flavomarginatum; C, D, Charterginus weyrauchi; G, H, C. fulvus; E, F, C. nevermanni; I, J, C. xanthura. Setas indicam a projeção postero-lateral do escuto. Escala $=0,5 \mathrm{~mm}$. 

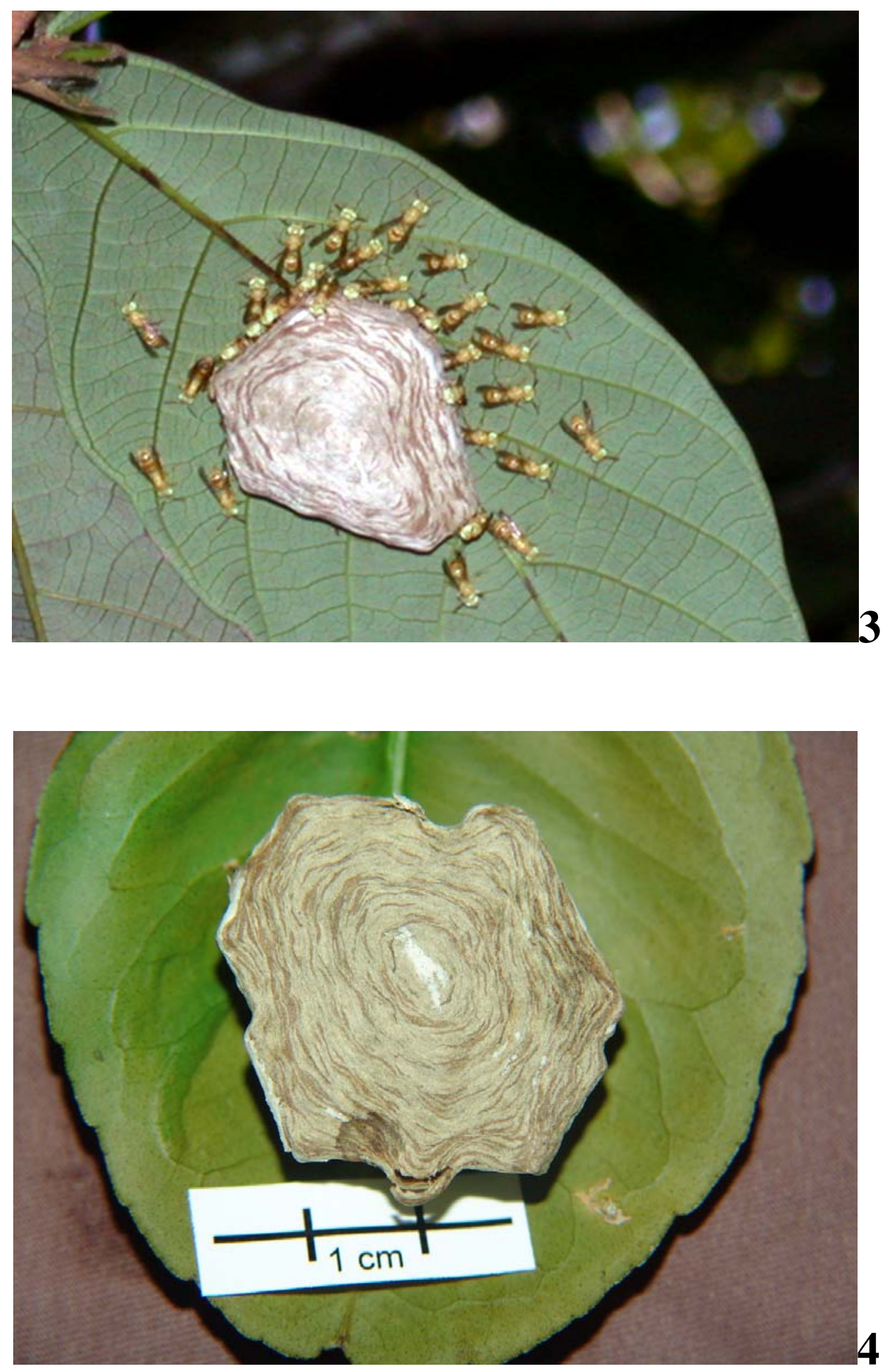

Figuras 3 e 4 - Ninhos de Charterginus fulvus, coletado em Presidente Figueiredo-AM, em 2005. Foto: Sidnei Mateus 


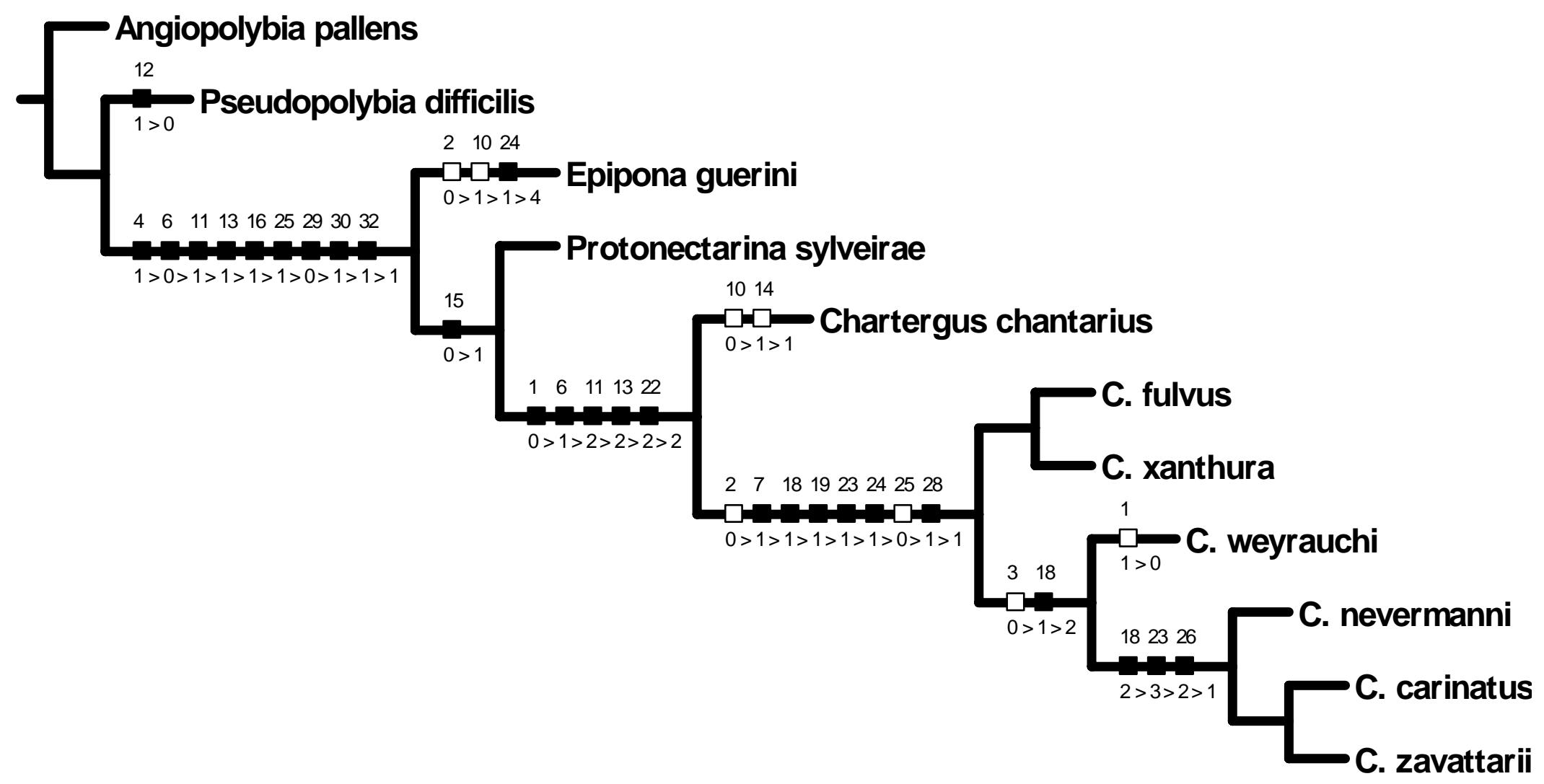

Figura 5- Cladograma de Charterginus, com 54 passos, índice de consistência 0,75 e índice de retenção de 0,81; baseado na Tabela 2. Somente caracteres não ambiguos estão plotados. O número de cada caráter está sobre os quadrados, enquanto que a transição de cada estado está abaixo, separado por ">." 
Capítulo 5 - Charterginus 

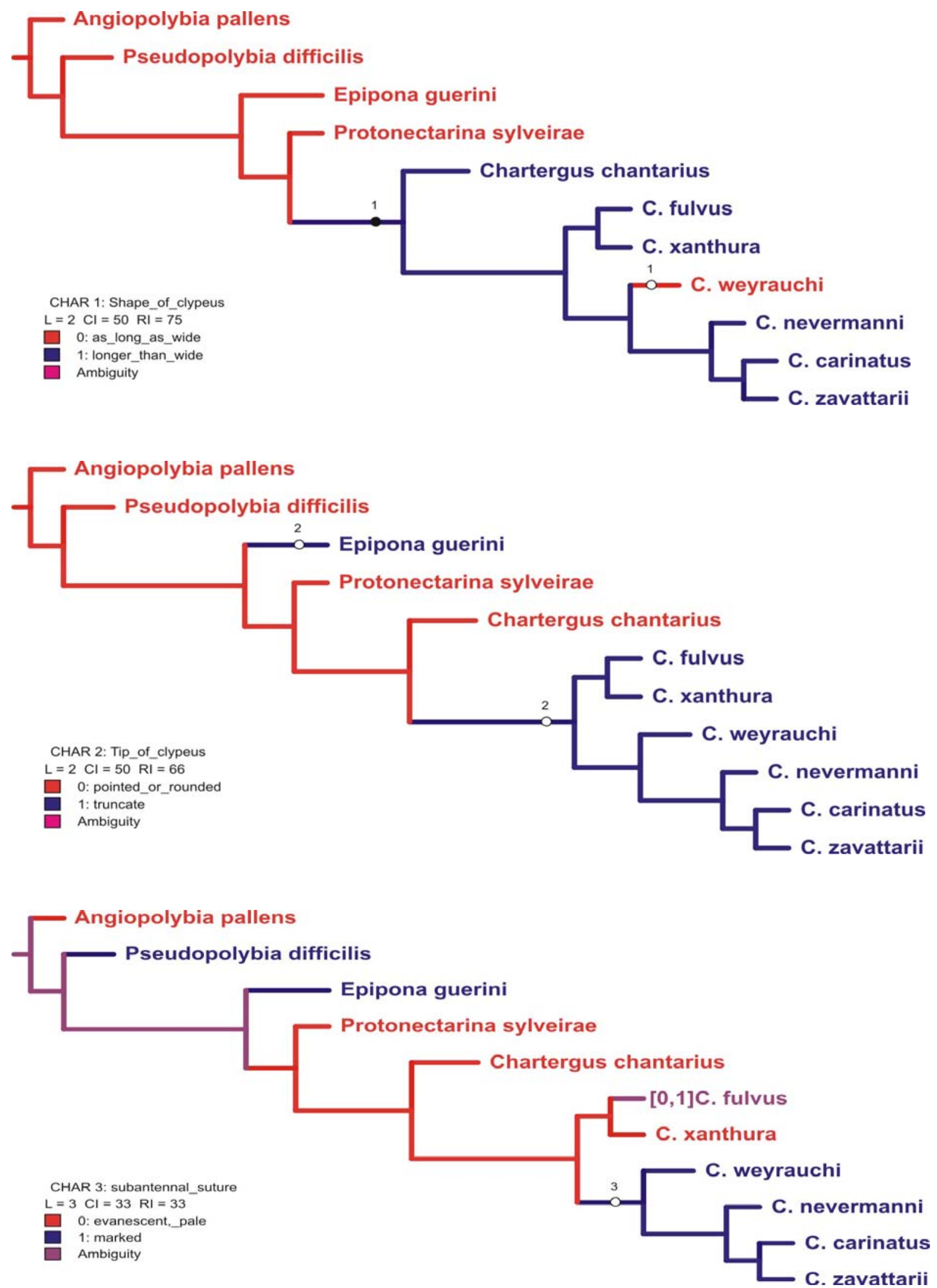

Figura 6 - Otimização dos caracteres 1, 2 e 3. 

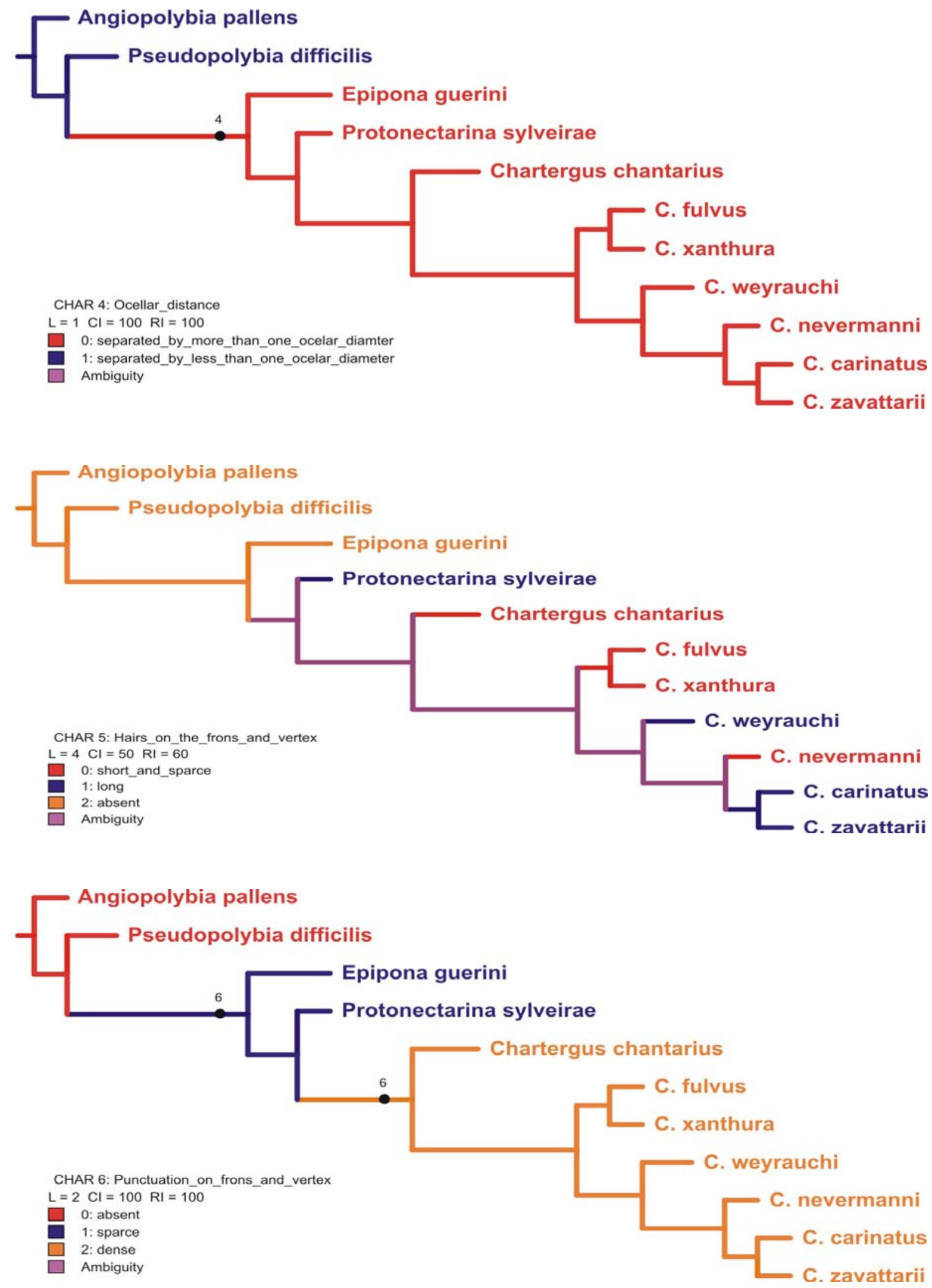

Figura 7 - Otimização dos caracteres 4 , 5 e 6 . 

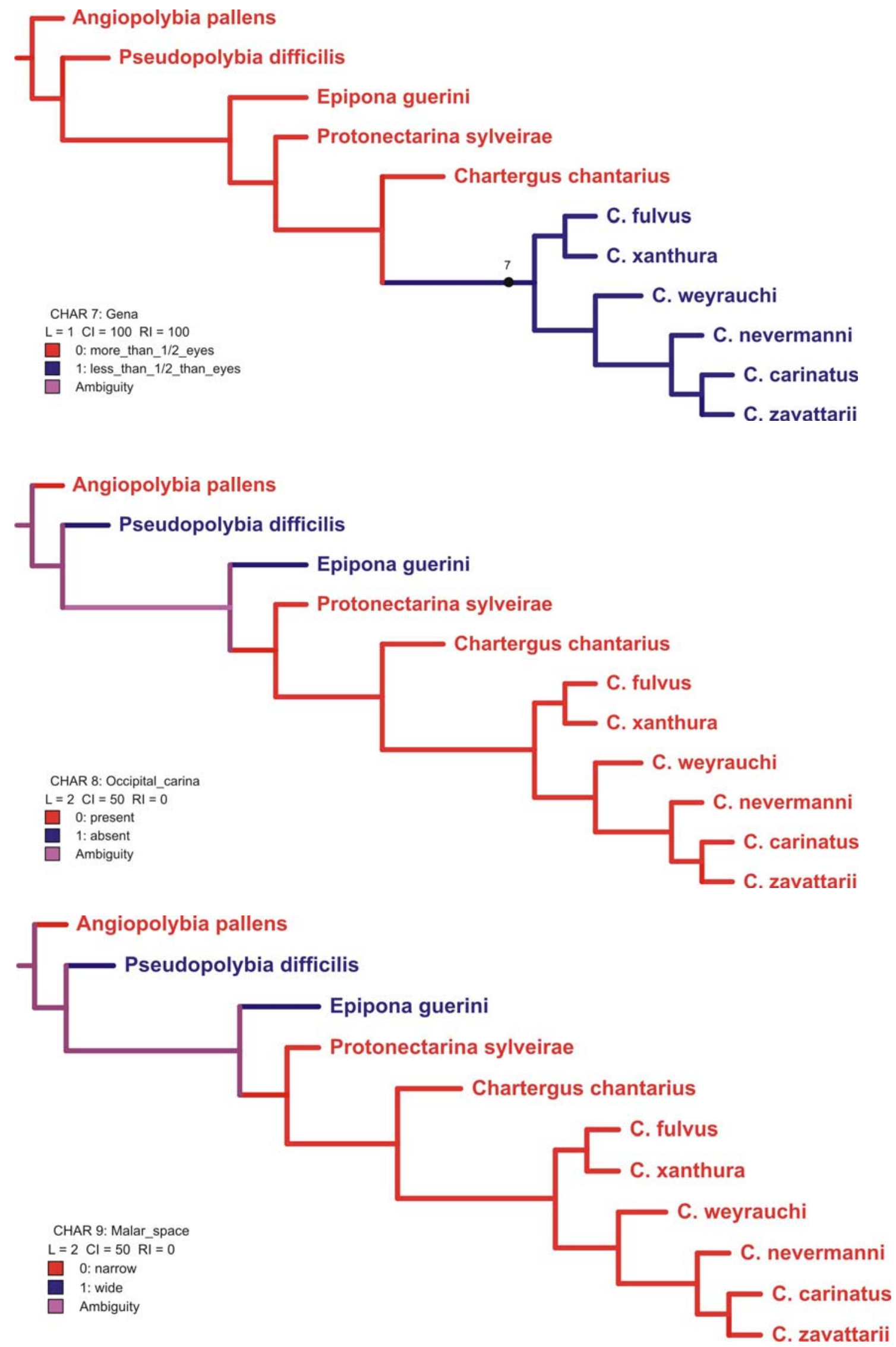

Figura 8 - Otimização dos caracteres 7, 8 e 9. 

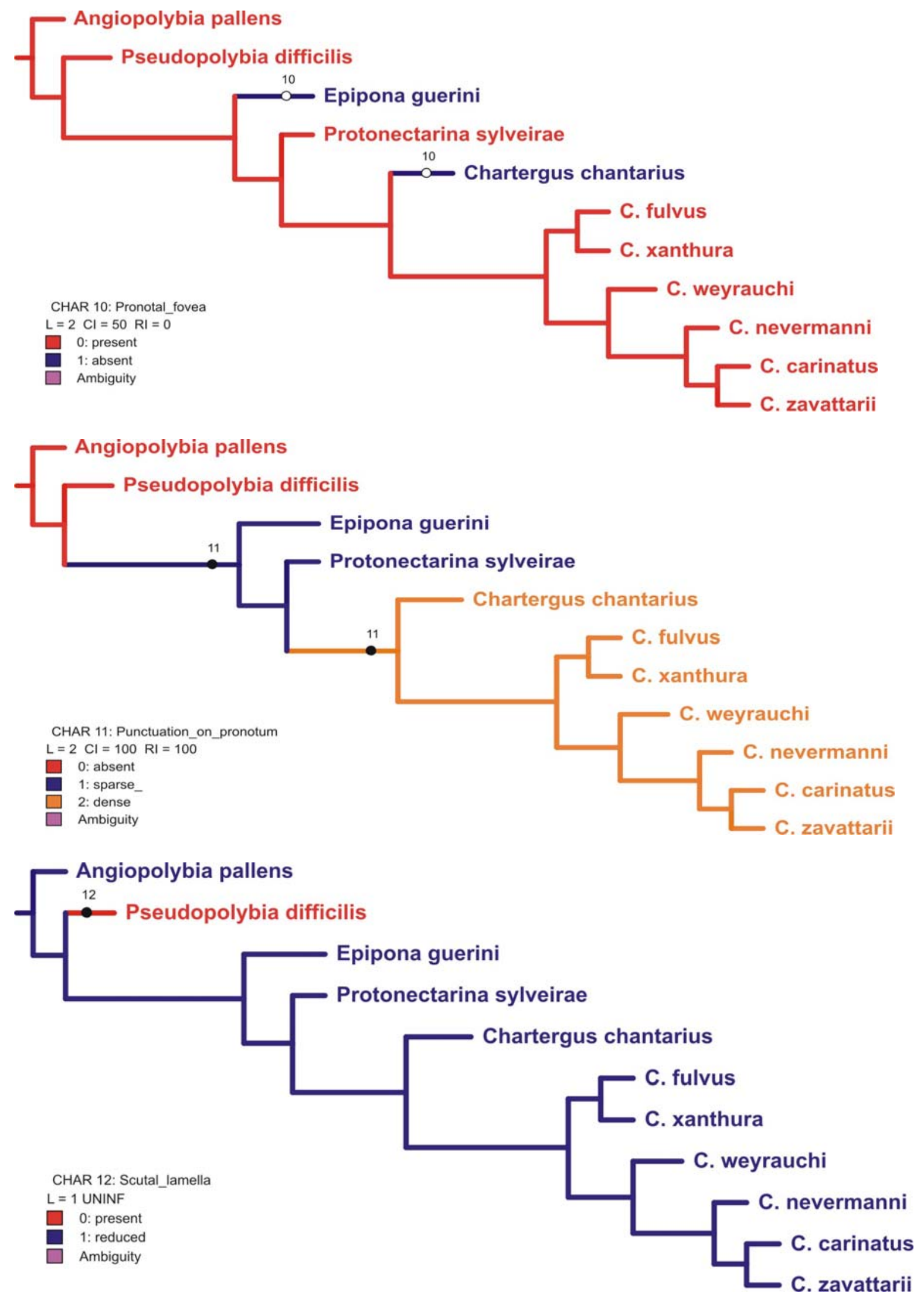

Figura 9 - Otimização dos caracteres 10, 11 e 12. 

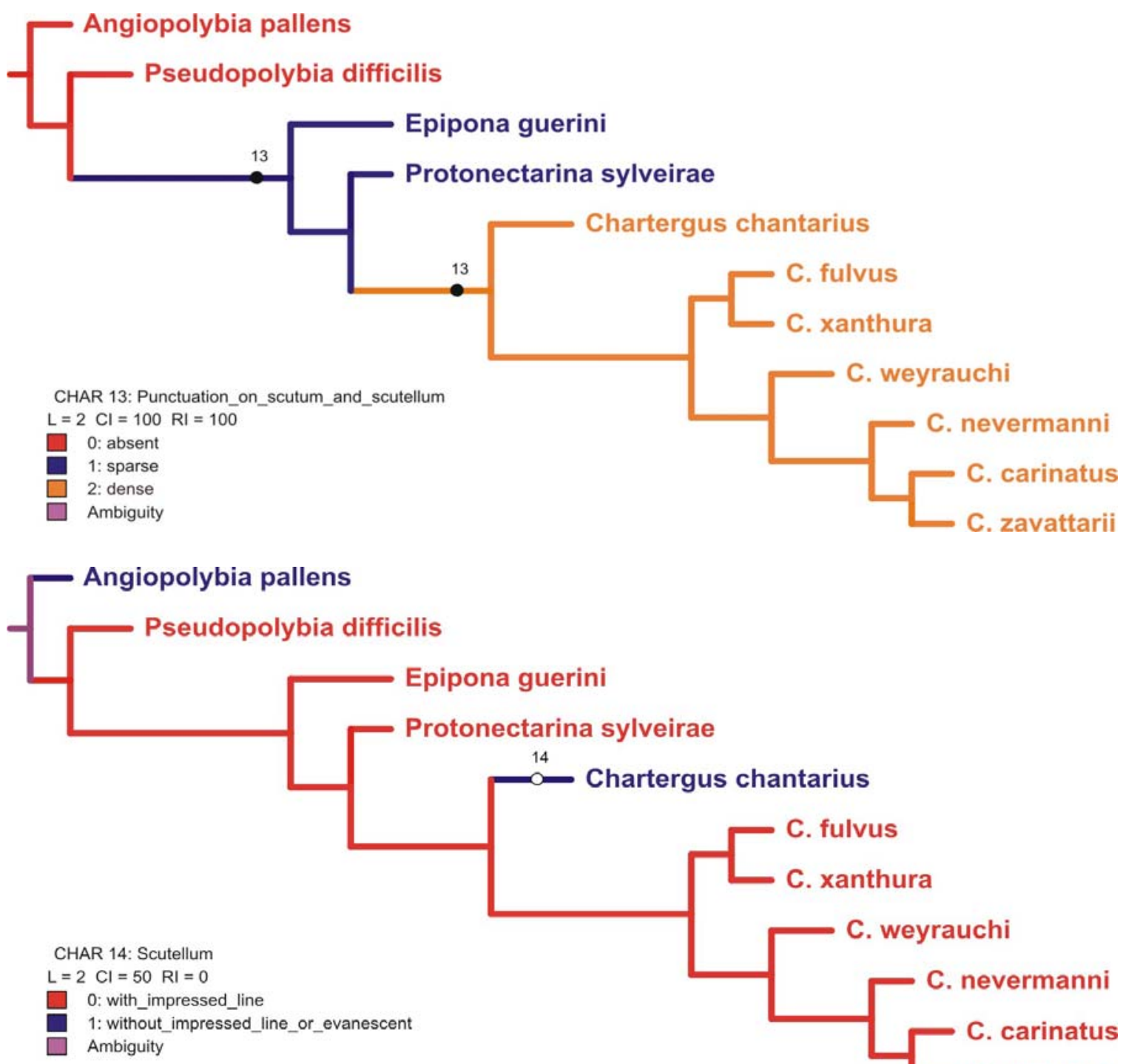

Epipona guerini

Protonectarina sylveirae
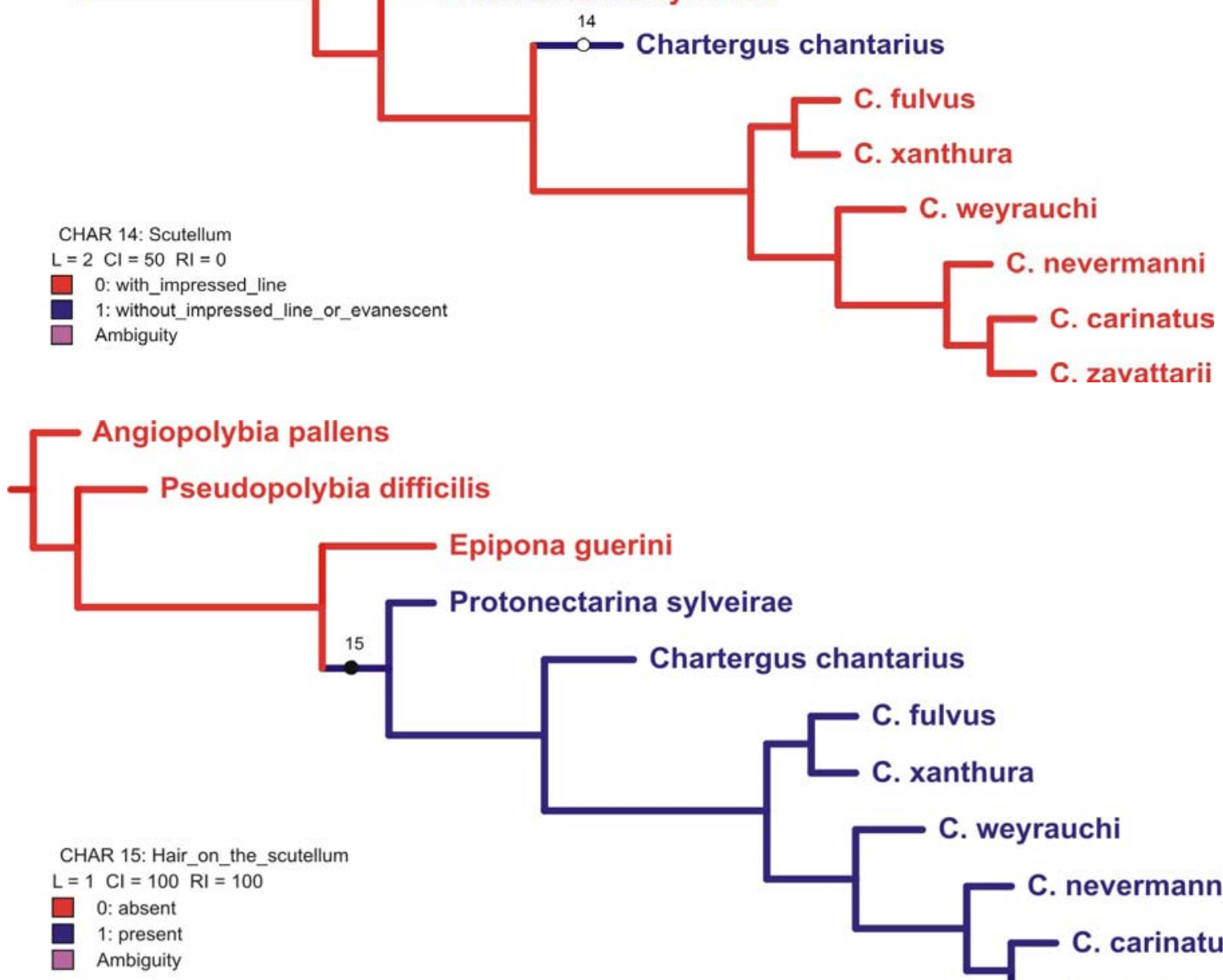

difficilis

\section{Epipona guerini}

Protonectarina sylveirae

15

Chartergus chantarius

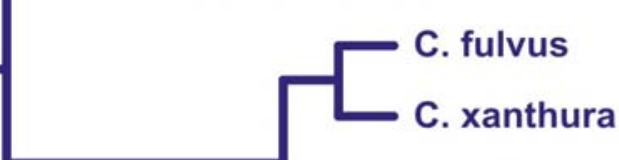

CHAR 15: Hair on the scutellum

$\mathrm{L}=1 \mathrm{Cl}=100 \mathrm{RI}=100$

C. weyrauchi

1: present

Ambiguity

C. nevermanni

C. carinatus

C. zavattarii

Figura 10 - Otimização dos caracteres 13, 14 e 15. 

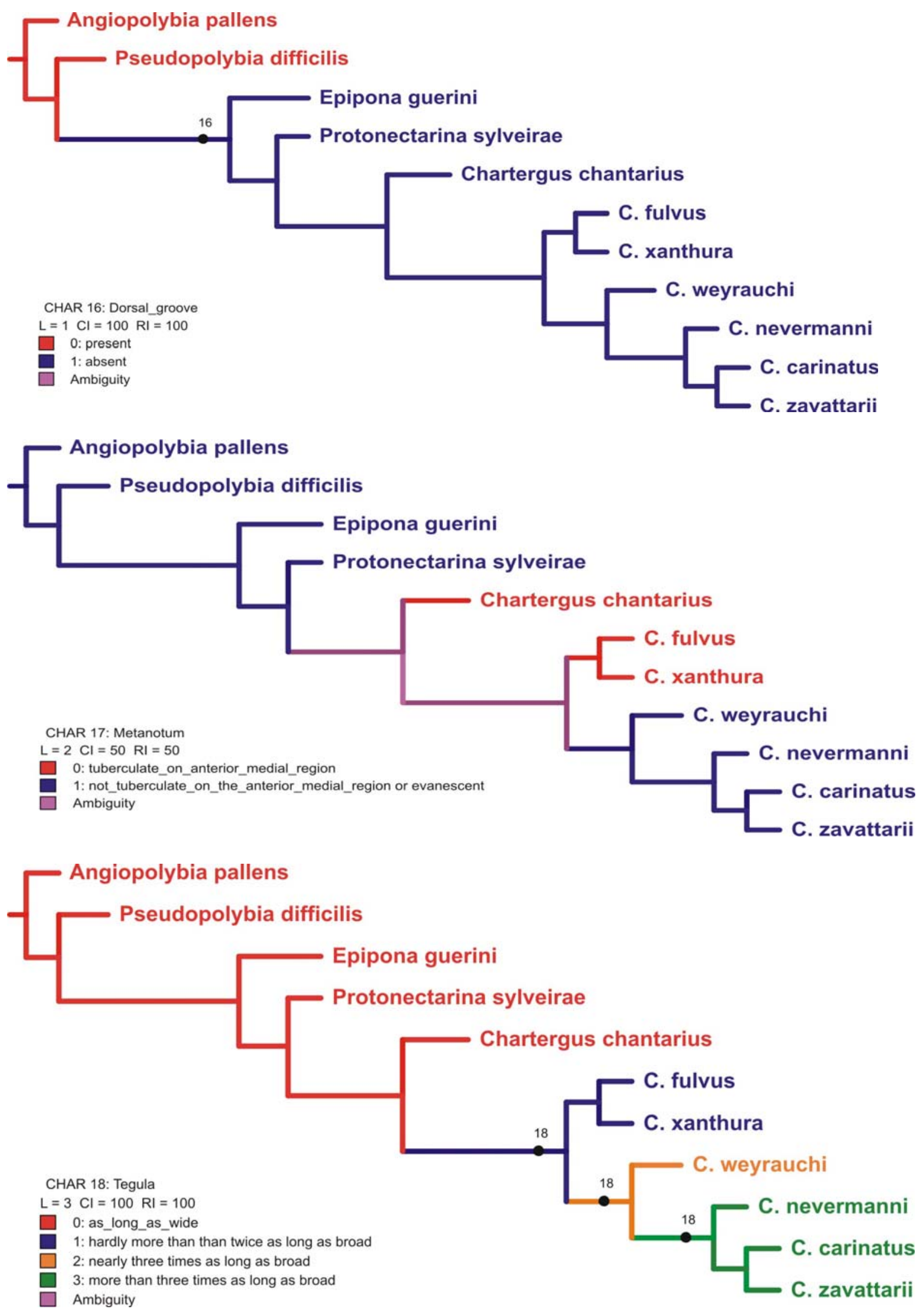

Figura 11 - Otimização dos caracteres 16, 17 e 18. 

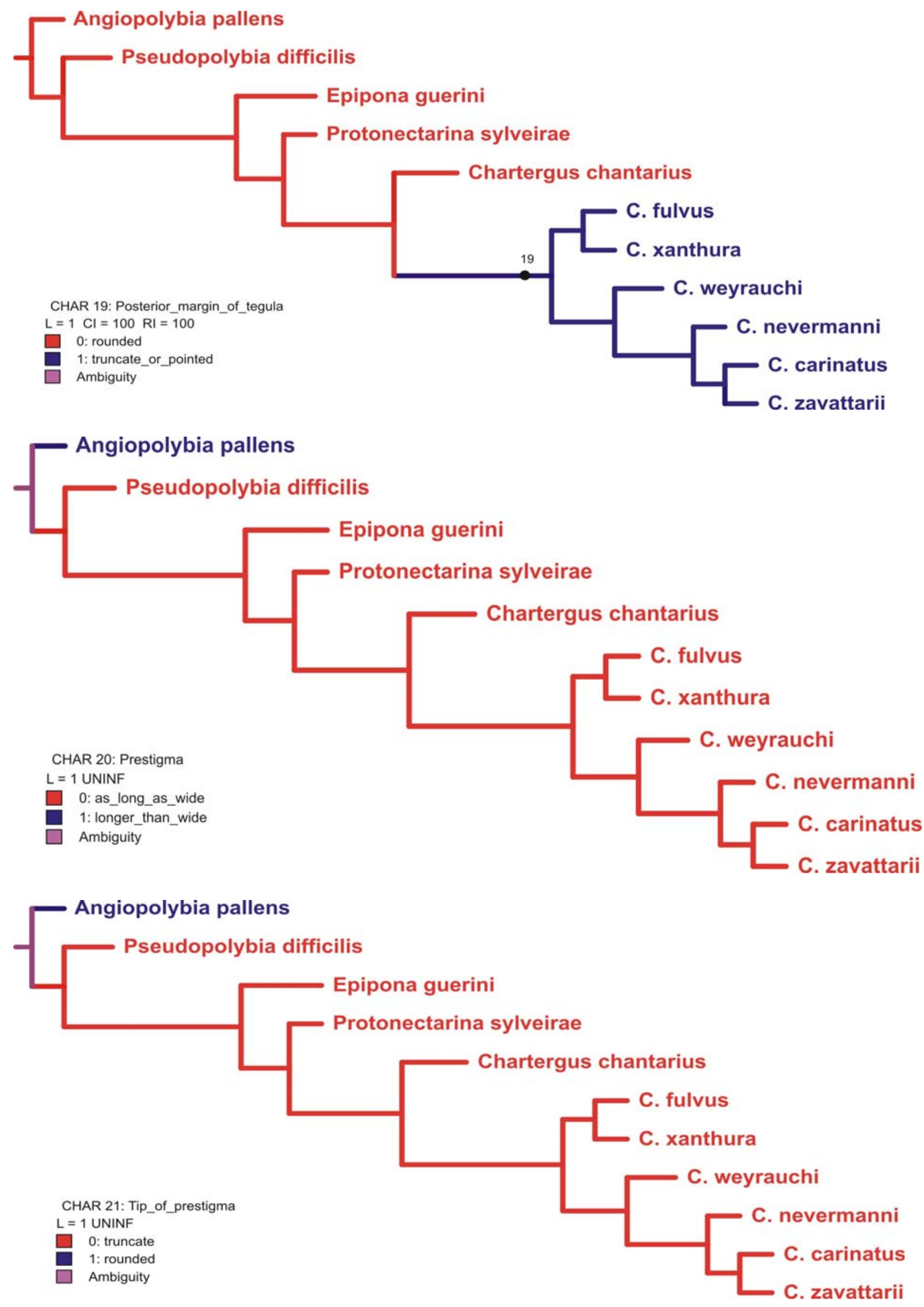

Figura 12 - Otimização dos caracteres 19, 20 e 21. 


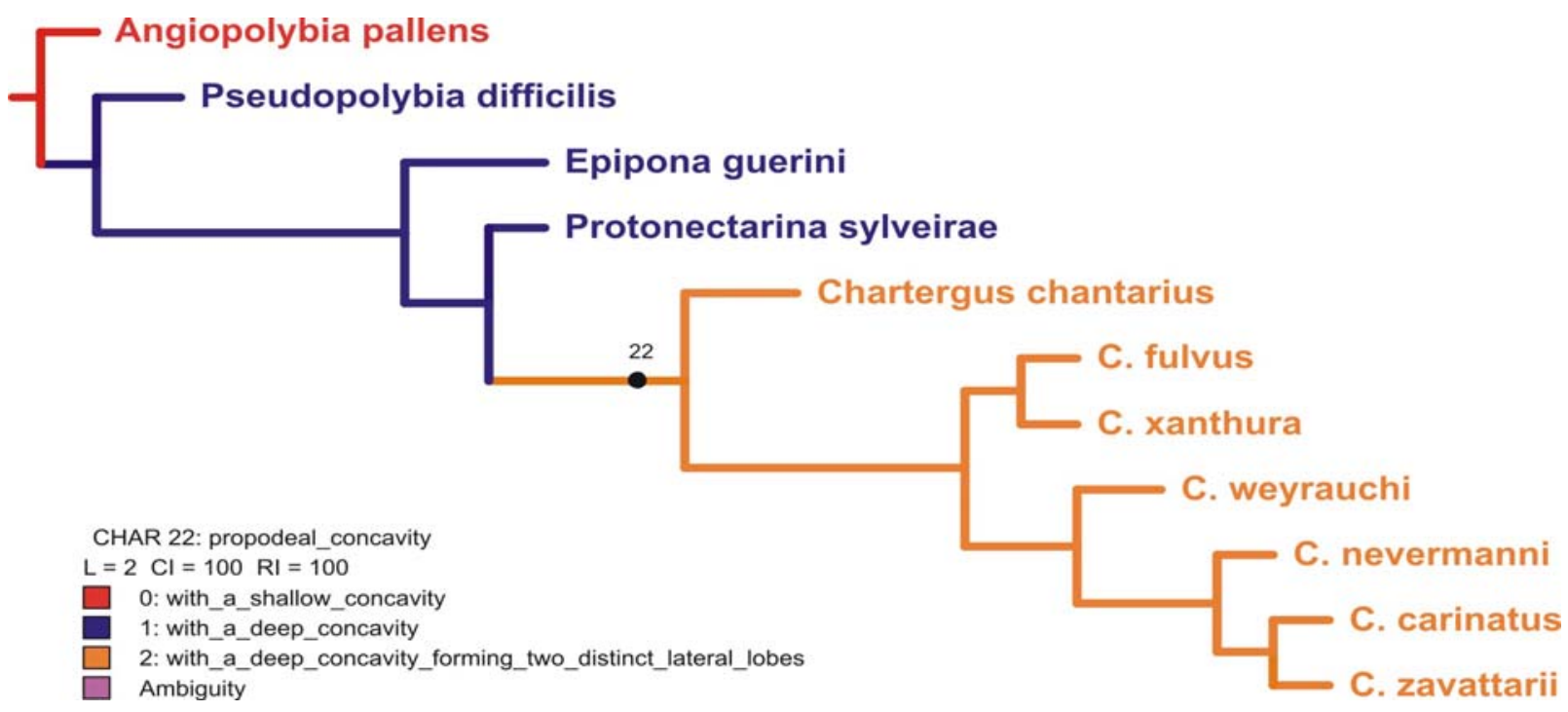

Angiopolybia pallens
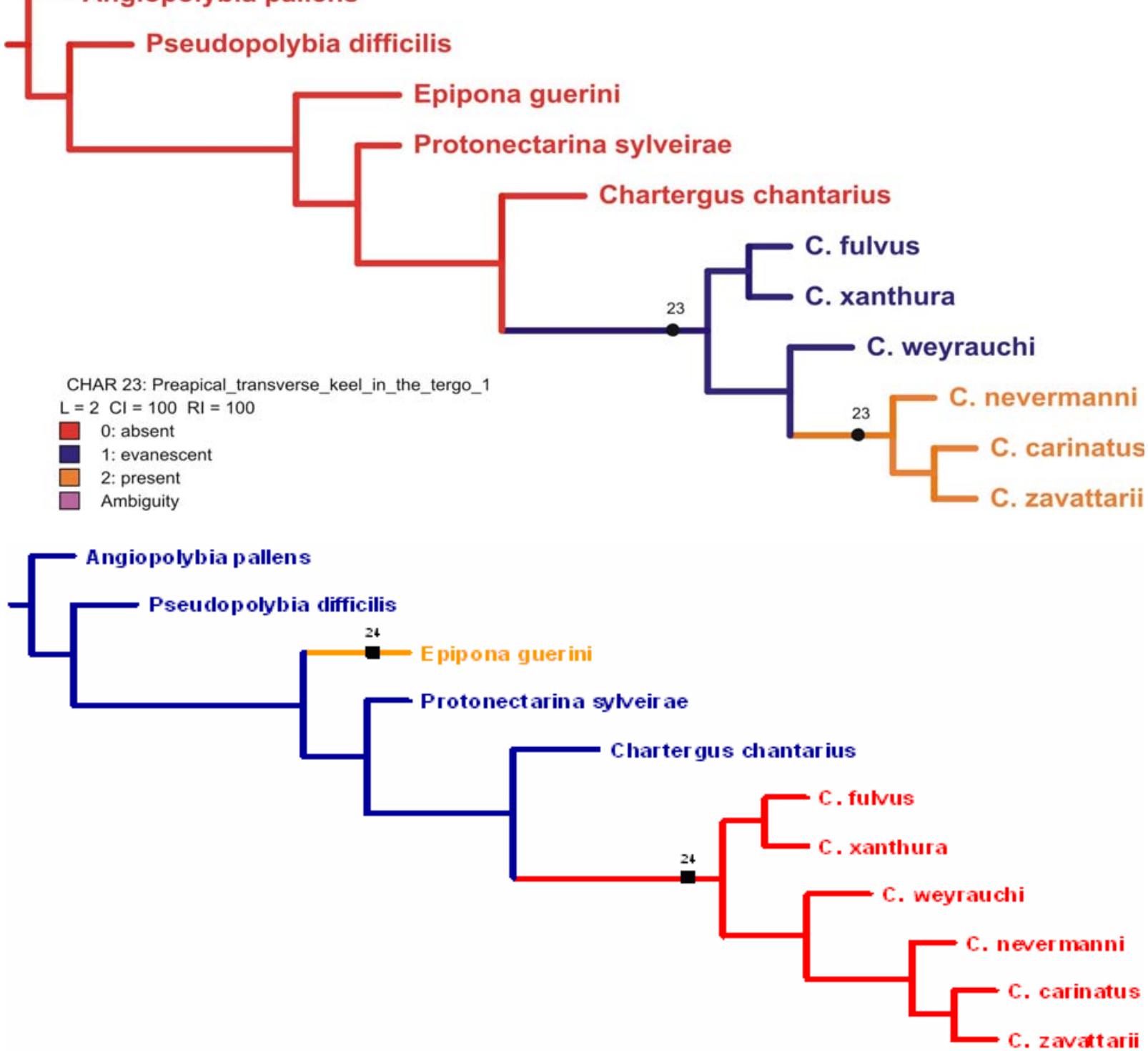

Figura 13 - Otimização dos caracteres 22, 23 e 24. 

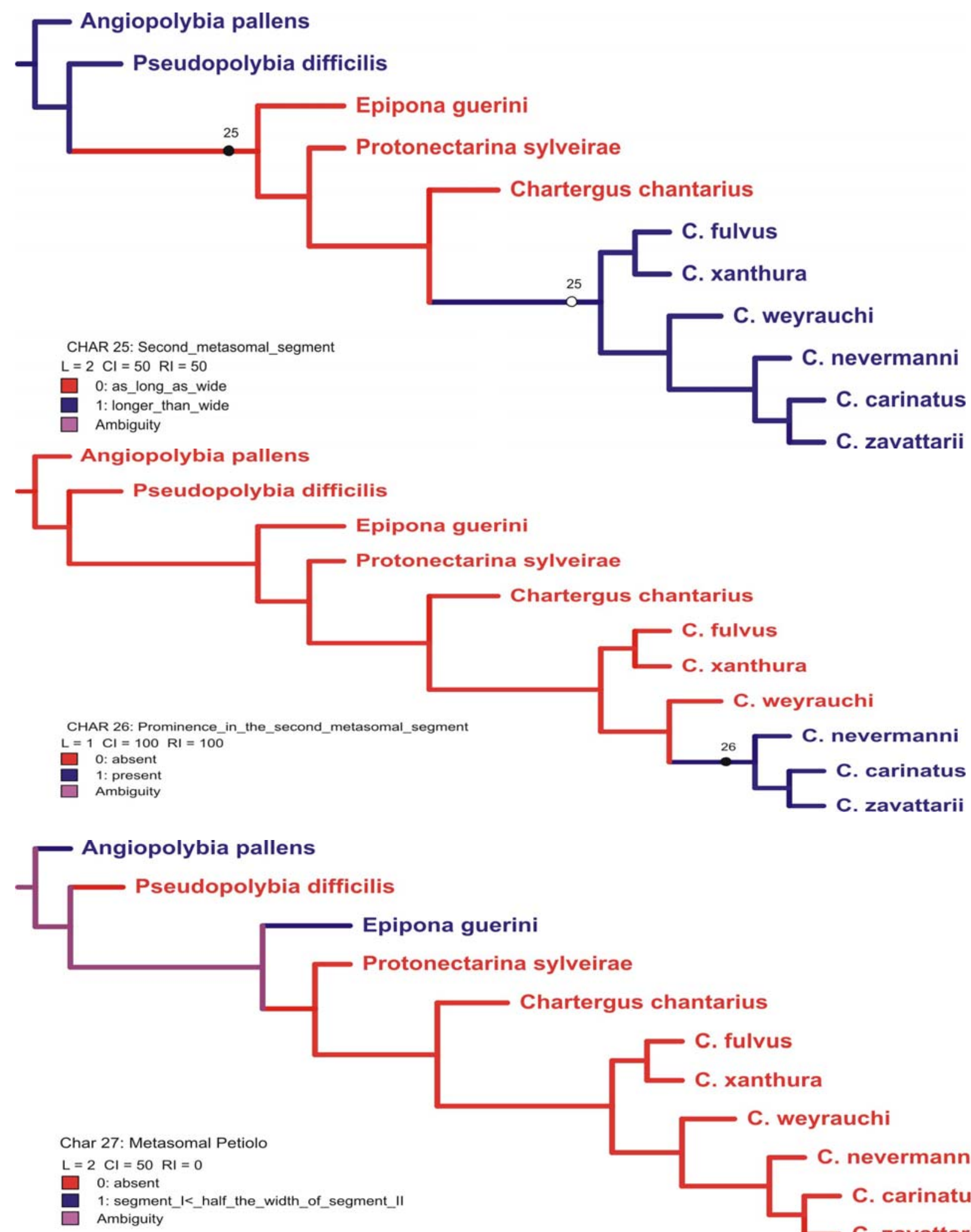

Figura 14 - Otimização dos caracteres 25, 26 e 27. 

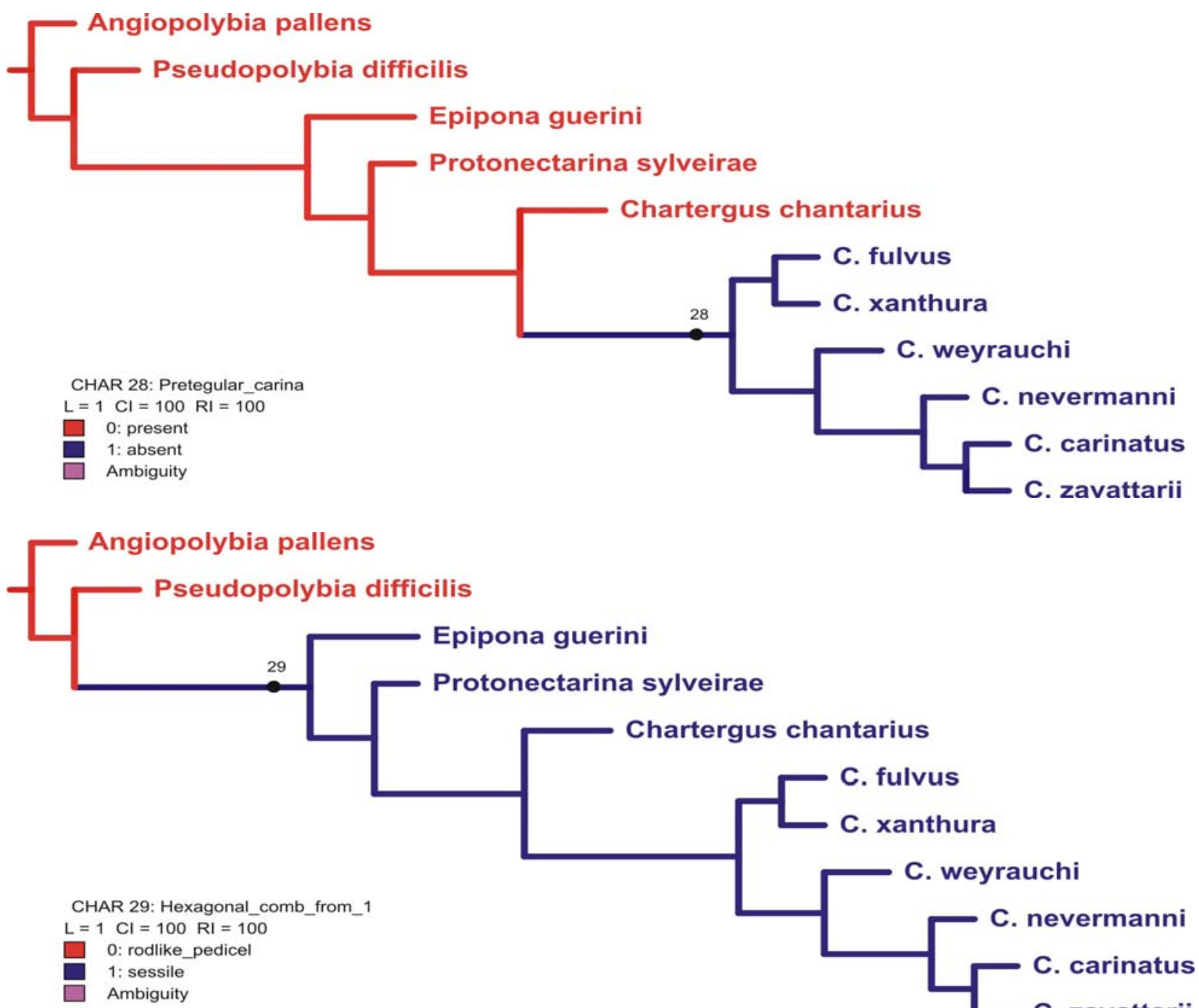

fficilis

Epipona guerini

Protonectarina sylveirae

Chartergus chantarius

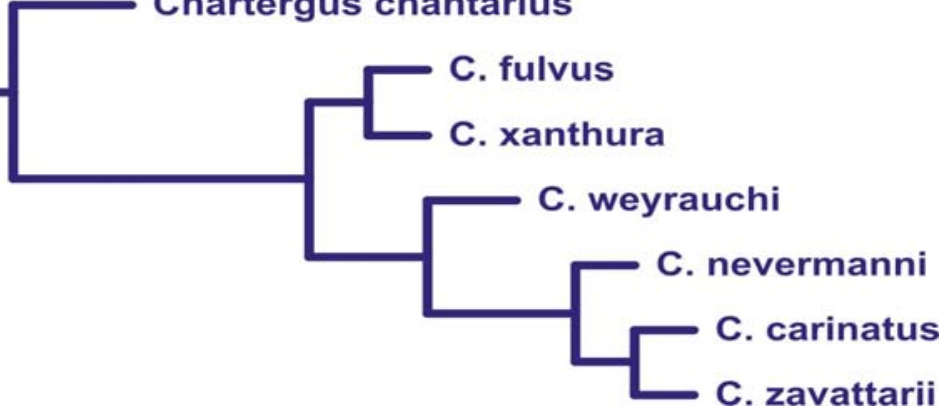

Angiopolybia pallens

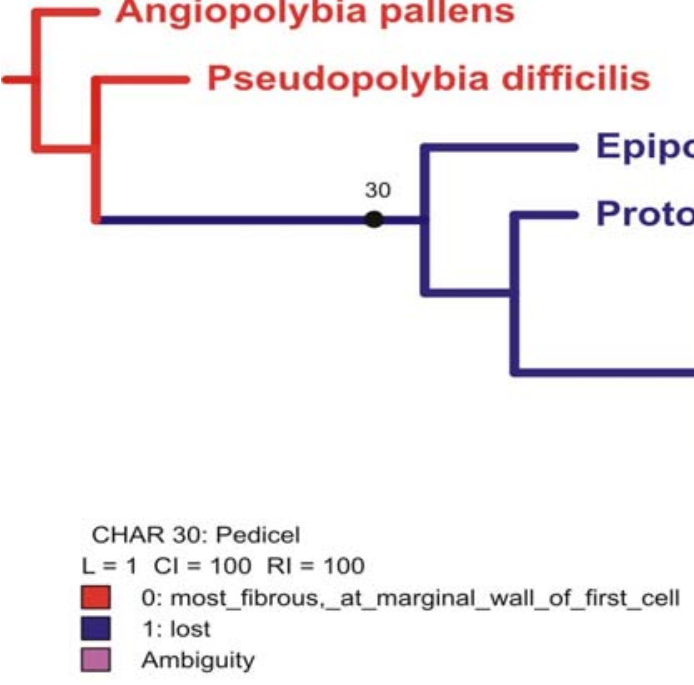

Epipona guerini

Protonectarina sylveirae

Chartergus chantarius

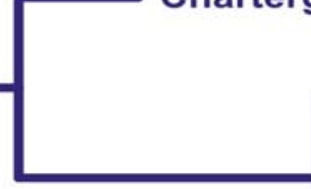

C. fulvus
C. xanthura

C. weyrauchi

C. nevermanni

C. carinatus

C. zavattarii

Figura 15 - Otimização dos caracteres 28, 29 e 30. 

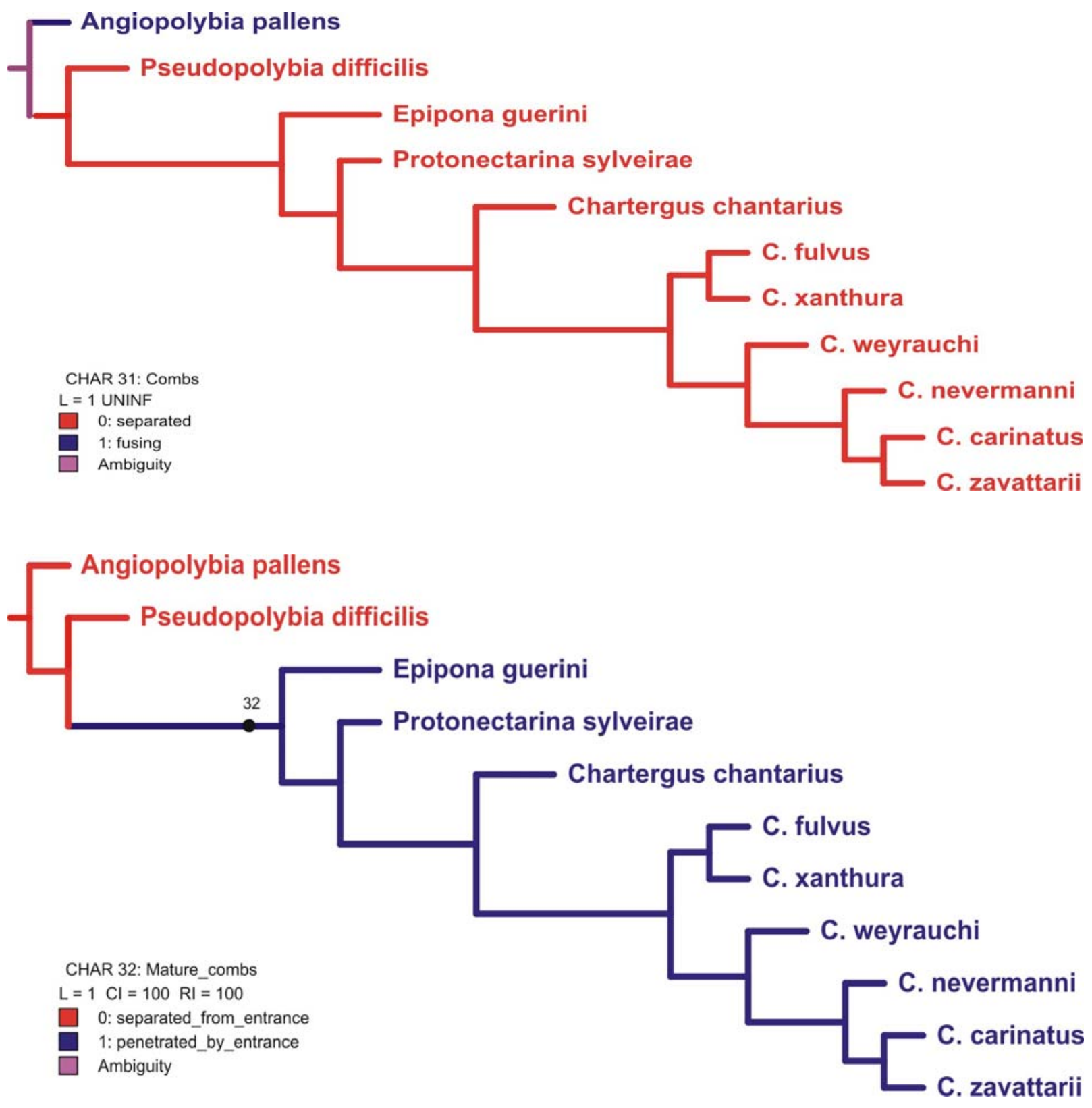

Figura 16 - Otimização dos caracteres 31 e 32. 


\section{6- REFERÊNCIAS}

Bequaert, J.C. 1918. A revision of the Vespidae of the Belgian Congo based on teh collection of the American Museum Congo Expedition, with a list of Ethiopian diplopterous wasps. Bulletin of the American Museum of Natural History, (39): 1384.

Carpenter, J.M. 1991. Phylogenetic relationships and the origin of social behavior in the Vespidae. In: Ross, K.G. \&. Matthews, R.W (eds), The social biology of wasps. Cornell University Press, Ithaca, New York,pp. 7-32.

Carpenter, J.M. \& Marques, O.M. 2001. Contribuição ao estudo dos vespídeos do Brasil (Insecta, Hymenoptera, Vespoidea, Vespidae). Série Publicações Digitais - Volume 2. Universidade Federal da Bahia.

Griboldo, G. 1982. Contribuzioni Imenoterologische. Sopra alcune specie nuove o poco conosciute di Imenotteri diplotteri. Nota iv. Bolletino della Societa entomologica italiana, 23: 242-300.

Kojima, J. \& Carpenter, J.M. 1998. The type of Icaria xanthura de Saussure, 1854, a species of the neotropical Polistinae genus Charterginus Fox, with a note on development of the "Parategula" in Charterginus (Hymenoptera: Vespidae). Entomological Science, 1(3): 417-421.

Magretti, P. 1884. Risultati di raccolte imenotterologiche nell'Africa orientale. I. Annali des Museo Cívico di Storia Naturale, Genova, 2 (1): 523-636.

Nixon, K.C. \& Carpenter, J.M. 1993. On outgroups. Cladistics, 9, 413-426.

Noll. F.B. 2000. Uma análise da evolução das castas nos Epiponini (Hymenoptera: Vespidade). Tese de Doutorado. Ribeirão Preto. 217 pp.

Richards O.W. 1978. The social wasps of the Americas excluding the Vespinae. London British Museum (Natural History), 580 pp.

Saussure, H. De. 1853-1858. Études sur la Famille des Véspides. Vol 2. Monographie des Guêpes Sociales, ou de la Tribe de Véspiens. Masson, Paris, and Dessmann, Genève.

Vecht, J. Van der \& Carpenter, J.M. 1990. A catalogue of the genera of the Vespidade (Hymenoptera). Zoologische Verhandelingern, 260: 1-62.

Wenzel, J.W. 1993 Application of the biogenetic law to behavioral ontogeny: a test using nest architecture in paper wasps. Journal of Evolutionary Biology, 6: 229247.

Wenzel, J.W. 1998. A generic key to the nests of hornets, yellowjackets, ande paper wasps worldwide (Vespidae: Vespinae, Polistinae). American Museum Novitates, 3224: 39 pp. 
Wenzel, J.W. \& Carpenter, J. M. 1994. Comparing methods: adaptative traits and tests of adaptation In: Eggleton, P. \& Vane-Wright, R. (eds.), Phylogenetics and Ecology. Academis Press, London, pp 79-101. 
Apêndice 1 - Localidade dos exemplares de Charterginus examinados.

C. carinatus - Colômbia (Sucir Coloso).

C. fulvus - Colômbia (Metavilla- Vicencio); Peru (Tingo Maria).

C. nevermanni - Costa Rica (Suretka Prov. - Hamburg), Panamá (Canal Zone).

C. weyrauchi- Peru; Colômbia (Narino, Barbacoas).

C. xanthura - British Guiana (Rio Essequibo; Waratuk); Suriname.

C. zavattarii - Localidade não especificada. 